Universidad Nacional de La Plata

Facultad de Humanidades y Ciencias de la Educación

Secretaría de Posgrado

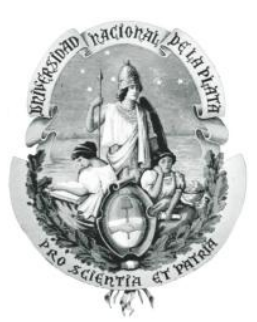

\title{
La cuestión cautelar
}

El uso de la prisión preventiva en la provincia de Buenos Aires a partir de la ley 11.922 (1998-2013)

\author{
Ezequiel Kostenwein
}

Tesis para optar por el grado de Doctor en Ciencias Sociales

\author{
Director: Gabriel Kessler, UNLP \\ Co-Director: Máximo Sozzo, UNL
}

La Plata, 4 de febrero de 2015 


\section{RESUMEN}

El objetivo general de esta tesis es contribuir a la comprensión del uso de la prisión preventiva en la provincia de Buenos Aires llevando adelante un estudio normativo de la misma, junto con el análisis de las prácticas y los discursos que ofrecen los actores judiciales al respecto. Con la intención de que pueda ser leída por quienes no estén necesariamente familiarizados con cuestiones legales o formen parte del ámbito jurídico, pero también con el propósito de que aporte elementos de reflexión para quienes sí pertenezcan a este ámbito, nuestra investigación se organizará en cinco partes. La primera presenta los distintos abordajes que se han realizado sobre la prisión preventiva. Segundo, un plano extrajudicial en el cual señalamos los actores que por fuera de los tribunales tienen injerencia en el problema de la prisión preventiva, o que son percibidos como relevantes por los operadores jurídicos. Un tercer plano jurídico, en el que abordamos la regulación legal de esta medida cautelar en la provincia de Buenos Aires junto a las transformaciones más importantes que dicha regulación ha experimentado. En cuarto lugar, el plano judicial o institucional a partir del cual describimos los modos de argumentación de los actores judiciales en la práctica, examinando las justificaciones y las críticas que ellos ofrecen en los expedientes y las audiencias. Por último, un análisis sobre el uso de la prisión preventiva que va desde las disposiciones que los actores han adquirido en el Poder Judicial hasta las competencias que despliegan en las situaciones concretas, recuperando sus testimonios y prácticas.

Palabras claves: prisión preventiva, justificación, competencia, expediente, audiencia 


\section{ÍNDICE}

ÍNDICE DE ABREVIATURAS..............................................................................9

INTRODUCCIÓN............................................................................................10

\section{PRIMERA PARTE}

CAPITULO I. PENSAR LA PRISIÓN PREVENTIVA...................................26

1- La dogmática del encierro preventivo....................................................26

1.1 ¿Cómo se llega a ser inocente?................................................................................27

1.2 La ilustración, el positivismo criminológico y el principio de inocencia

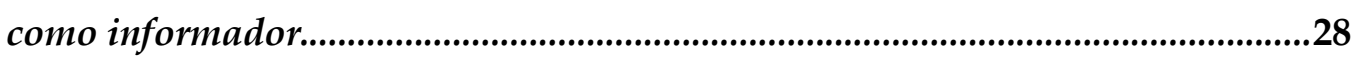

1.3 Enfoque constitucional.........................................................................................31

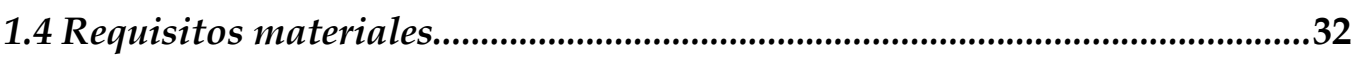

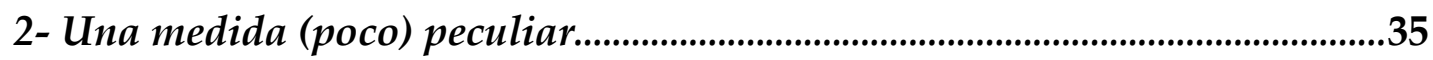

3- La prisión preventiva como instrumento..........................................................43

4- Nuestra hipótesis sobre la prisión preventiva.......................................................48

4.1 El límite de la dogmática y las ONGs......................................................................48

4.2 El límite dentro de las ciencias sociales..........................................................50

4.3 La prisión preventiva como consecuencia..............................................................54

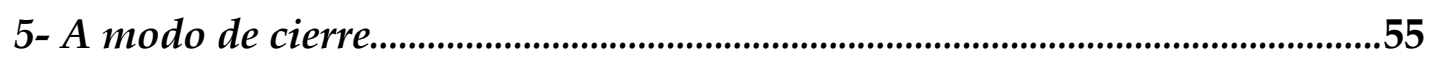

\section{SEGUNDA PARTE}

CAPITULO II. LA PRISIÓN PREVENTIVA FUERA DE LOS MÁRGENES

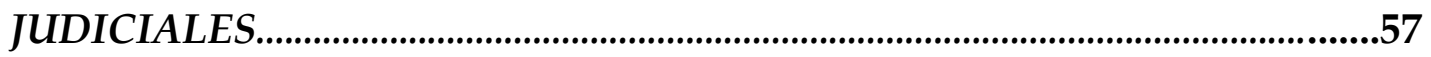

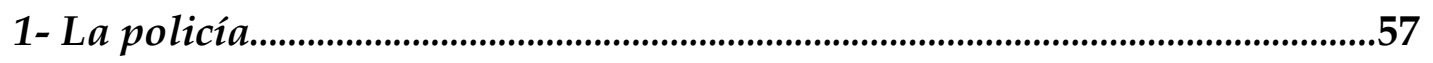

2- Los medios de comunicación.........................................................................62

3- Las autoridades politicas..................................................................................67

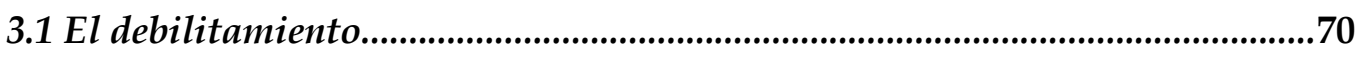

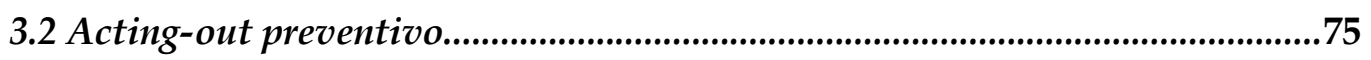




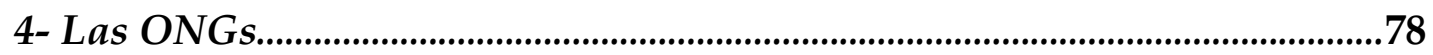

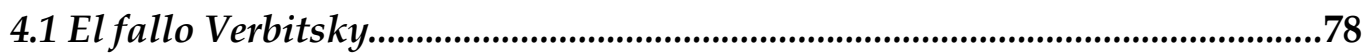

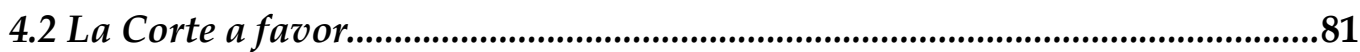

4.3 La prisión preventiva como problema público....................................................83

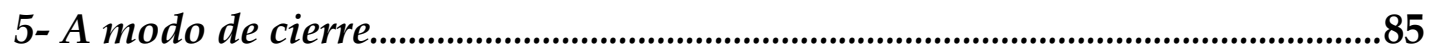

\section{TERCERA PARTE}

CAPITULO III. PODER PARA PREVER............................................................87

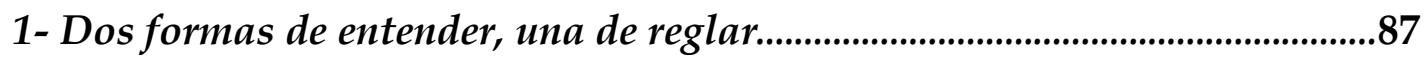

1.1 Sustancialismo y procesalismo en la provincia de Buenos Aires....................88

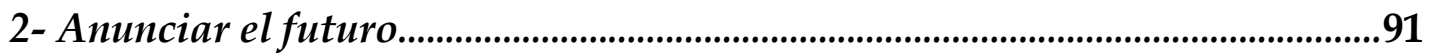

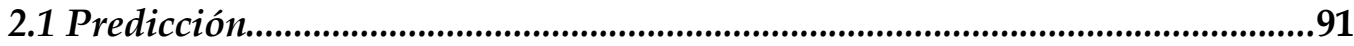

2.2 Ideal rehabilitador y prisión preventiva .............................................................92

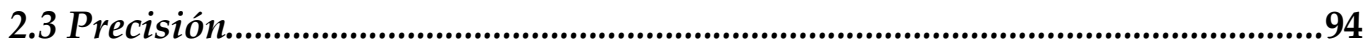

3- Legislar el problema, ¿es la solución?..............................................................98

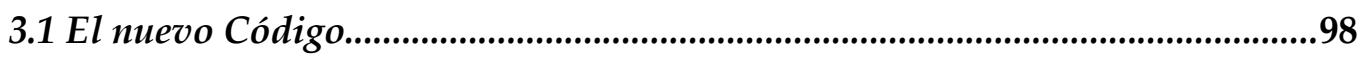

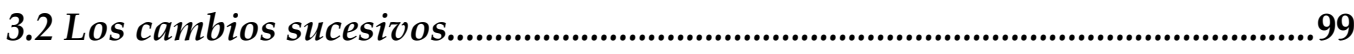

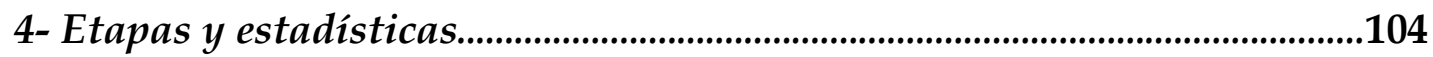

5- Percepciones, encarcelamiento y prisión preventiva......................................108

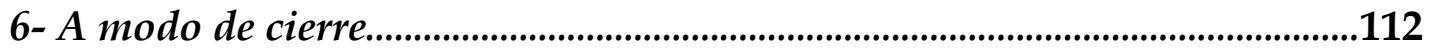

\section{CUARTA PARTE}

CAPITULO IV. POR ESCRITO: EL USO DE LA PRISIÓN PREVENTIVA

EN LOS EXPEDIENTES..........................................................................................114

1- Cuerpos que constituyen causas......................................................................114

1.1 Los buenos y los malos motivos...........................................................................115

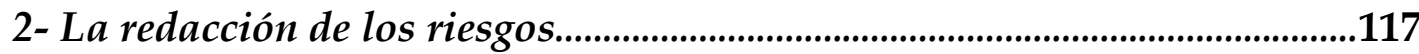

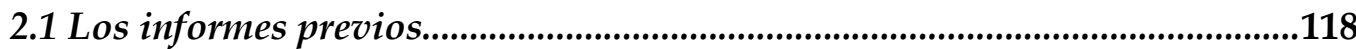

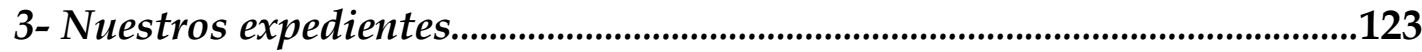

3.1. Hechos y rasgos.......................................................................................................124

3.2. ¿Cómo estudiar la prisión preventiva al estudiar los expedientes?............126

3.2.1 Argumentos en base a la ley................................................................128

3.2.2 Argumentos en base a un acuerdo tácito..........................................133 
CAPITULO V. EL ESPACIO DE LAS AUDIENCIAS: PRISIÓN PREVENTIVA EN TIEMPOS DE FLAGRANCIA.

1- La flagrancia en el código. .149

1.1 La profundización del modelo acusatorio......................................................152

1.2 La evaluación del proceso de flagrancia..............................................................154

2- Audiencias: oralidad, celeridad, inmediación...............................................160

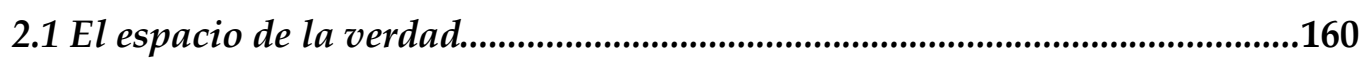

2.2 Audiencias y prisión preventiva....................................................................163

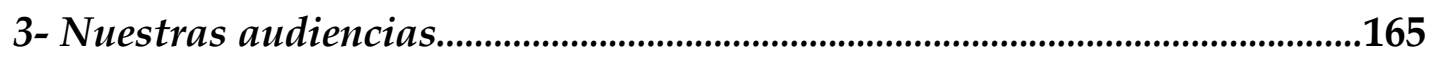

3.1 Argumentos en base a la velocidad.............................................................166

3.2 Argumentos en base a las personas...............................................................172

3.3 Argumentos en base a los delitos...................................................................176

3.4 Argumentos en base a la policía sospechada.....................................................181

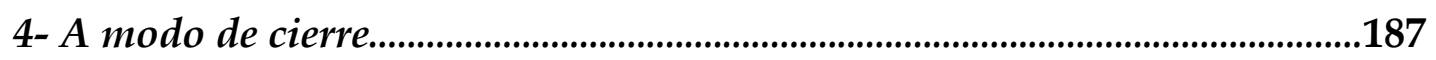

\section{QUINTA PARTE}

CAPITULO VI. UNA PRÁCTICA JUDICIAL COMPLEJA..............................190

1- La prisión preventiva como práctica................................................................190

1.1 Práctica, motivación y control...........................................................................190

1.2 Desencantamiento y delegación....................................................................194

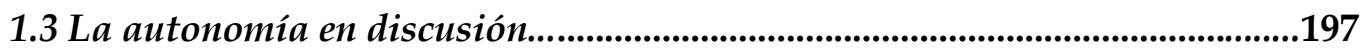

1.4 Elementos para entender la prisión preventiva como una práctica..............201

2- De las disposiciones a las competencias.............................................................204

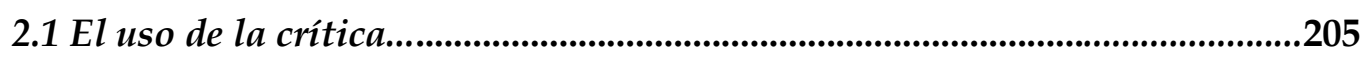

2.2 Los principios superiores comunes..........................................................................208

3- A modo de cierre..............................................................................................211

CAPITULO VII. PRISIÓN PREVENTIVA, ENTRE LA JUSTICIA Y EL AMOR. 
1- Equivalencias y pruebas justificables.........................................................213

1.1 Los modelos y el sentido de la normalidad en los expedientes......................217

1.2 Los modelos y el sentido de la normalidad en las audiencias........................218

2- Delito, violencia y justicia...........................................................................220

2.1 La prisión preventiva como consecuencia............................................................222

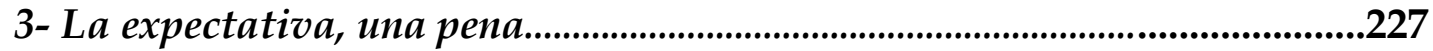

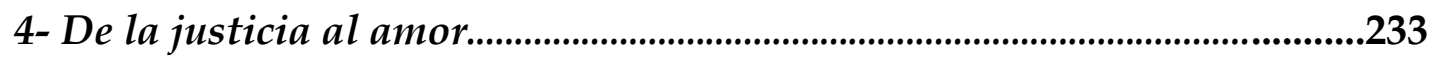

4.1 El amor en las audiencias..................................................................................234

4.2 El amor por escrito....................................................................................................239

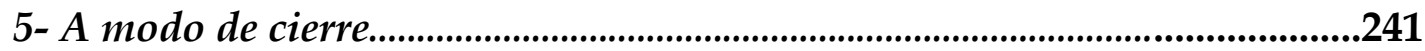

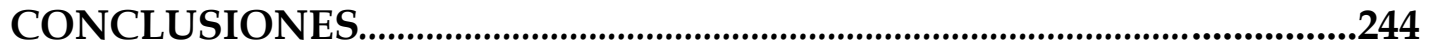

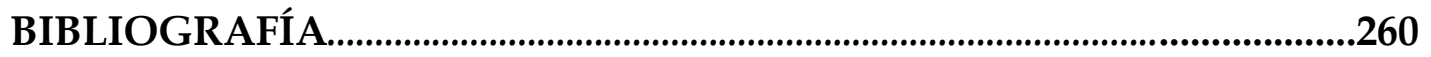


El antropólogo Lloyd Warner solía contar que había investigado la sociedad aborigen australiana, cuyos miembros -según afirmaban los primeros trabajos antropológicos- no comprendían la base fisiológica del embarazo. Cuando les preguntó de dónde venían los bebés, le dijeron lo mismo que les habían dicho a los anteriores investigadores: que los bebés esperaban en el espíritu del clan hasta que una mujer tenía un sueño especial, y que sólo entonces el espíritu del bebé abandonaba la fuente de los espíritus y entraba en su vientre. Warner insistió: ¿Y qué pasa cuando los hombres y las mujeres, ya saben, tienen relaciones sexuales? ¿Eso no tiene nada que ver con el embarazo? Los aborígenes lo miraron con lástima, como si fuera un niño tonto, y le dijeron que por supuesto que sí, que así se hacían los bebés. Pero le recordaron que los hombres y las mujeres hacían aquello todo el tiempo, y que las mujeres sólo quedaban embarazadas de vez en cuando: solamente, adujeron triunfales, cuando la madre soñaba con la fuente de los espíritus.

Howard Becker 


\section{ABREVIATURAS}

ADC: Asociación por los Derechos Civiles

ART.: Artículo

CEJA: Centro de Estudios de Justicia de las Américas

CEJIL: Center for Justice and International Law

CELS: Centro de Estudios Legales y Sociales

CIPPEC: Centro de Implementación de Políticas Públicas para la Equidad y el Crecimiento

CN: Constitución Nacional

CORREPI: Coordinadora Contra la Represión Policial e Institucional

CP: Código Penal

CPBA: Constitución de la Provincia de Buenos Aires

CPP: Código Procesal Penal

CSJN: Corte Suprema de Justicia de la Nación

DJ: Departamento Judicial

INECIP: Instituto de Estudios Comparados en Ciencias Penales y Sociales

IPP: Investigación Penal Preparatoria

JG: Juez de Garantías

MPF: Ministerio Público Fiscal

ONG: Organización No Gubernamental

PBA: Provincia de Buenos Aires

PCF: Procedimiento en caso de flagrancia

PEE: Pena en expectativa

PJ: Poder Judicial

PP: Prisión preventiva

SCBA: Suprema Corte de la Provincia de Buenos Aires

SNEEP: Sistema Nacional de Estadísticas sobre Ejecución de la Pena

SPB: Servicio Penitenciario Bonaerense 


\section{INTRODUCCIÓN}

La prisión preventiva (en adelante, PP), es decir, el encarcelamiento de aquellas personas que siendo investigadas por la comisión de algún delito aún no tienen una sentencia condenatoria firme, se ha vuelto un tema significativo para juristas, activistas, ONGs, gobiernos, políticos y medios de comunicación. Desde la última década y media, en diferentes países alrededor del mundo, en América Latina y en Argentina -esto con especial anclaje en la provincia de Buenos Aires (en adelante, PBA)-, el encierro de quienes aún mantienen su condición jurídica de inocentes ha originado numerosos informes, documentos, artículos y libros.

Teniendo en cuenta dicha situación, esta tesis se propone contribuir a la descripción de las relaciones que en el ámbito de la PBA instaura el pedido de la prisión preventiva entre actores judiciales y extrajudiciales. $\mathrm{Y}$ junto a esto, puntualizar las exigencias que este pedido impone para los actores judiciales, a partir de los argumentos que utilizan para justificarlo.

Con la intención de que pueda ser leída por quienes no estén necesariamente familiarizados con cuestiones legales o formen parte del ámbito jurídico, pero también con el propósito de que aporte nuevas herramientas de reflexión para quienes sí pertenezcan a este ámbito, nuestra investigación fue organizada en cinco partes. La primera presenta los distintos abordajes que se han realizado sobre la PP. Segundo, un plano extrajudicial en el cual señalamos los actores que por fuera de los tribunales tienen injerencia en el problema de la PP, o que son percibidos como relevantes por los operadores jurídicos. Un tercer plano jurídico, en el que abordamos la regulación legal de esta medida cautelar en la PBA junto a las transformaciones más importantes que dicha regulación ha experimentado. En cuarto lugar, el plano judicial o institucional a partir del cual describimos los modos de argumentación de los actores judiciales en la práctica, examinando las justificaciones y las críticas que ellos ofrecen en los expedientes y las audiencias. Por último, un análisis sobre el uso de la PP que va desde las disposiciones que los actores han adquirido en el Poder Judicial (en adelante, PJ) hasta las competencias que despliegan en las situaciones concretas, recuperando sus testimonios y prácticas. 


\section{La prisión preventiva en la Investigación Penal Preparatoria}

\section{Las dos etapas}

El proceso penal bonaerense está compuesto por dos etapas: la investigación penal preparatoria (en adelante, IPP) y la de juicio. Durante la IPP los Fiscales están a cargo de la dirección de la investigación del supuesto delito ocurrido y tienen la potestad de acusar a quienes identifiquen como autores probables del mismo. Por su parte, el Juez de Garantías (en adelante, JG) tiene a su cargo la tarea de controlar la legalidad de las diligencias que se llevan adelante durante el proceso. Para el caso de la PP, es facultad del Fiscal solicitarla, del Defensor del imputado impugnarla si lo considera procedente, y del JG concederla o denegarla. A su vez, en esta etapa de la IPP las decisiones del JG pueden ser recurridas ante la Cámara de Apelación y Garantías, conformada por cuerpos colegiados compuestos por tres jueces.

La etapa de juicio continúa en un Juzgado Correccional o en un Tribunal Criminal Oral, dependiendo de la gravedad del delito a juzgar. Los Juzgados Correccionales son unipersonales y deciden las causas en las cuales se investigan delitos cuya pena no exceda los seis años de prisión. Los Tribunales Orales Criminales son órganos colegiados compuestos por tres Jueces e intervienen en los casos cuya pena este por encima de los seis años ${ }^{1}$. Las sentencias emitidas por los Juzgados Correccionales son apelables ante las Cámaras de Apelación y Garantías, y las de los Tribunales Orales Criminales ante el Tribunal de Casación Penal.

\section{La etapa elegida}

Nuestro trabajo sobre el uso de la PP lo delimitamos a la IPP, que puede definirse como el conjunto de diligencias, trámites o averiguaciones que se llevan adelante antes de la realización del juicio. Según el Código Procesal Penal (en adelante, CPP) de la PBA en su Art. 266, la finalidad de la IPP es

La de comprobar, mediante las diligencias conducentes al descubrimiento de la verdad, si existe un hecho delictuoso. Establecer las circunstancias que lo califiquen, agraven, atenúen, justifiquen o incidan en su punibilidad. Individualizar a los autores y partícipes del hecho investigado. Verificar la edad, educación, costumbres, condiciones de vida, medios de subsistencia y antecedentes del imputado; el estado y desarrollo de sus facultades mentales, las condiciones en que actuó, los motivos que han podido

\footnotetext{
${ }^{1}$ Sin embargo, con las últimas reformas los Tribunales Orales Criminales pueden constituirse por un solo miembro para juzgar los casos menos graves.
} 
determinarlo a delinquir y las demás circunstancias que revelen su mayor o menor peligrosidad. Comprobar a los efectos penales, la extensión del daño causado por el delito.

Por lo tanto, durante la IPP se debe investigar si se ha cometido un delito, si ese delito amerita ser calificado de una forma especial, definir quien o quienes pueden haber cometido el hecho, aportar datos relevantes sobre los imputados, y determinar las consecuencias del ilícito.

La decisión de ceñirnos a la IPP implica que no hemos tenido en cuenta lo que sucedía con la PP a partir de la etapa de juicio en los casos en que la sentencia de primera instancia se hubiese recurrido ${ }^{2}$. Esta determinación la tomamos por tres motivos fundamentales:

- Por nuestra intención de especificar los modelos de argumentación que surgían al analizar los criterios utilizados por los actores judiciales para conceder o rechazar la medida cautelar cuando ingresaban al PJ, lo que no hubiese sido posible de haber tenido en cuenta otras instancias judiciales $^{3}$. En otras palabras, nos interesaba indagar cómo surgía la PP dentro del PJ y a partir de qué tipo de argumentos ocurría dicha emergencia.

- Por motivos de orden cuantitativo, basados en que la mayoría de las personas que estaban presas preventivamente lo estaban mientras se tramitaba la IPP, y no luego de la etapa de juicio. Si observamos las cifras que da la Procuración de la PBA al respecto para el año $2013^{4}$, alrededor del 44\% del total de las personas encarceladas (13.913) son imputados con PP cuyos procesos se encontraban en la etapa de la IPP, mientras que el 16\% (5.059) estaban condenados sin una sentencia firme.

\footnotetext{
${ }^{2}$ Sería importante en el futuro producir información y desarrollar trabajos sobre la PP que tomen en cuenta el periplo de ésta medida cautelar a través de las distintas etapas procesales.

${ }^{3}$ Tanto para las Cámaras de Apelación y Garantías, como para los tribunales superiores, las decisiones no se toman individualmente como lo hacen los JG, sino de manera colegiada. En estos fallos, los jueces pueden simplemente remitir a los argumentos de otro de los integrantes del tribunal, sin especificar sus justificaciones o motivaciones.

${ }^{4}$ Según los Datos de la Procuración de la PBA, en el 2012 el porcentaje de detenidos con PP en pleno trámite de la IPP fue del $45 \%$. Véase Informe Anual de la Procuración de la PBA. No contamos con esta información para años anteriores, ya que no se desagregan los datos sobre las personas bajo PP entre quienes están en la IPP y quines están con sentencia no definitiva.
} 
- Porque para conocer los argumentos sobre la PP resultaron más accesibles los expedientes y a las audiencias durante la IPP.

Limitar nuestra investigación sobre el encierro preventivo a los procesos que transcurriesen sólo durante la IPP supuso dejar de lado casos que, aún luego del desarrollo de ésta última, seguían siendo técnicamente PP. Sin embargo, consideramos que esta delimitación ofrecería la ventaja de conocer con mayor exactitud las razones desplegadas individualmente por los actores judiciales a la hora de justificar la reclusión de un conjunto de personas jurídicamente inocentes, que según las estadísticas disponibles eran casi la mitad de la población carcelaria de la PBA.

\section{Marco teórico}

Las investigaciones y los estudios previos sobre la PP se han dirigido principalmente a las limitaciones que esta medida cautelar provoca y a ciertas utilidades políticas que la misma ofrece. Como veremos con más detalle en el capítulo inaugural de la tesis, son tres las orientaciones que trabajan dichas limitaciones y utilidades. En primer lugar, el enfoque dogmático que se concentra en el agravio que ocasiona la PP a Principios Constitucionales como los de Inocencia y Legalidad. En segundo lugar, la perspectiva de diferentes ONGs que prioriza la denuncia acerca de las pésimas condiciones de vida que el uso de la PP genera para las personas que están encarceladas. Por último, los planteos de las ciencias sociales que hacen hincapié en considerar al encarcelamiento preventivo como producto de las transformaciones del mercado de trabajo, de la llegada del actuarialismo al seno de la justicia penal o del advenimiento de criterios populistas para enfrentar el problema del delito.

En nuestro país no se han llevado a cabo investigaciones empíricas que aborden el problema de la PP desde la sociología en general o desde la sociología jurídica en particular. Existen trabajos de dogmáticos del derecho y afirmaciones sociológicas genéricas que no se sustentan en demostraciones empíricas. Y existen informes en los que se presentan datos, en algunos de los cuales se recupera la voz de los actores judiciales, pero nada de eso se articula con algún abordaje teórico que permita orientar el análisis del tema. A raíz de la situación que acabamos de presentar, lo que intentamos evitar en nuestra investigación es aquello que Lemieux (2012) considera como la arriesgada actitud que oscila entre una teoría sin hechos y la presentación de hechos sin 
ninguna teoría. Y lo hicimos a partir de tres enfoques principales que nos ayudaron a describir y plantear qué ocurre con la PP, qué papel tiene para los operadores jurídicos, cómo se legitima o invalida su uso, qué relaciones promueve con actores extrajudiciales. Se trata de la sociología crítica de Bourdieu, la sociología de la crítica de Boltanski, y la sociología de las asociaciones desarrollada por Latour.

De Bourdieu utilizamos la categoría de práctica, aplicada al análisis de la PP. En este sentido, partimos de su mirada problematizadora sobre la relación entre el derecho y las prácticas sociales, sobre qué lugar tiene el primero en el nacimiento de éstas últimas, incluso sobre qué se puede decir del derecho en tanto práctica social. Y para abordar estos interrogantes es necesario, afirma este autor, liberarse de dos criterios reduccionistas sobre el tema. Uno "formalista" para el cual existe completa independencia entre las reglas jurídicas y el ámbito social. El otro "instrumentalista", que considera al fenómeno del derecho como reflejo de las aspiraciones de la clase dominante. Según las propias palabras de Bourdieu,

La ciencia jurídica, tal como la conciben los juristas, y sobre todo los historiadores del derecho, que identifican la historia del derecho con la historia del desarrollo interno de sus conceptos y de sus métodos, entiende el derecho como un sistema cerrado y autónomo, cuyo desarrollo sólo puede ser comprendido según su dinámica interna [...]. Cuando se defiende lo contrario de esta especie de ideología profesional del cuerpo de doctores [...], es para ver en el derecho y la jurisprudencia un reflejo directo de las relaciones de fuerza existentes, donde se expresan las determinaciones económicas, y en particular los intereses de los dominantes (2001: 165-6).

Siguiendo este planteo, las prácticas de los actores dentro de la institución judicial deben ser consideradas producto de sus respectivas posiciones y disposiciones en el campo jurídico. $\mathrm{Y}$ en este sentido, sugerimos que la $\mathrm{PP}$ es una práctica que se despliega dentro del PJ como resultado de la existencia y la importancia de relaciones entre elementos jurídicos, judiciales y extrajudiciales.

Junto a Boltanski buscamos enfatizar en las competencias manifestadas y en las críticas expresadas por los actores judiciales. No hablamos aquí de actores "críticos" en el sentido tradicional del término cuyas denuncias están centradas en el capitalismo, el patriarcado o las relaciones asimétricas de poder. Si bien estos factores pueden 
presentarse, lo que nos interesa es el estudio del papel que presenta la crítica en la vida social. Tomando en cuenta este aspecto, todos los actores tienen a su disposición posibilidades de impugnar, y cuentan -aunque en niveles diferentes- con recursos críticos que utilizan de forma permanente en su vida cotidiana. La sociología pragmática de Boltanski (2000, 2005) concibe estos procesos de crítica como un momento interno del orden social. De allí que se esfuerce en poner de relieve las condiciones de posibilidad de la crítica: en lugar de postular ilusiones, analiza acusaciones (Demirović, 2008). Esto nos permitió, en primer lugar, tomar distancia de la idea de que la sociología emancipa del autoengaño a las personas, o que circunscribe el contexto de ilusiones que se producen y reproducen colectivamente (Wuggenig, 2008). En segundo lugar, y como resultado de lo anterior, pudimos analizar novedosamente las dos instancias donde la PP se materializa: expedientes y audiencias. Para concretar esto último, partimos del estudio de unos y otras, prestándole atención a la manera como los actores judiciales despliegan sus capacidades interpretativas respecto de lo que sucede cuando alguien formula una demanda de encarcelamiento preventivo. Y sobre estas capacidades interpretativas analizamos el grado de validez que los actores mismos le otorgan a las distintas consideraciones que entran en juego y que se enfrentan cuando surge un caso en el que la PP está en disputa.

Resumiendo, la propuesta de Boltanski (2000) nos ha permitido, en primer lugar, examinar a la PP como una problemática relacionada con la justicia, la crítica y la justificación desde un enfoque propio. Y en segundo lugar, especificar las competencias que los actores judiciales desarrollan para hacer uso de la PP y crear modelos argumentativos a partir de los cuales esclarecer cómo justifican dicho uso.

Por último, trabajamos con Latour para posicionarnos respecto de los enfoques que consideran a la PP como una herramienta con rentabilidad política que sirve, bien para neutralizar grupos excedentes, bien para consolidar una administración actuarial de la justicia penal, bien para implementar estilos demagógicos a la hora de combatir el delito. Si bien estas perspectivas no son opuestas a la nuestra, sí tienen otras prioridades ya que proponen una lectura amplia del fenómeno tomando en cuenta, principalmente, información secundaria y eventos notables. La diferencia entre estos enfoques y lo que nosotros tomamos del planteo de Latour puede entenderse, en concreto, a partir de la distinción que este autor realiza entre intermediarios y mediadores. En sus palabras, 
[...] implica una inmensa diferencia que se considere a los medios para producir lo social como intermediarios o como mediadores [...]. Un intermediario, en mi vocabulario, es lo que transporta significado o fuerza sin transformación: definir sus datos de entrada basta para definir sus datos de salida. Para todo propósito práctico un intermediario puede considerarse no solo una caja negra sino también una caja negra que funciona como una unidad, aunque internamente este compuesta de muchas partes. Los mediadores, en cambio, no pueden considerarse solo uno; pueden funcionar como uno, nada, varios o infinito. Sus datos de entrada nunca predicen bien los de salida; su especificidad debe tomarse en cuenta cada vez. Los mediadores transforman, traducen, distorsionan y modifican el significado o los elementos que se supone que deben transportar (2008: 62-3).

Desde los enfoques mencionados, la PP puede entenderse como un intermediario a partir del cual se canalizan y efectúan determinadas exigencias, por lo que en definitiva esta medida cautelar no es lo más importante. Esto supone, además, que otro instrumento podría cumplir las mismas funciones que la PP, es decir, ser el medio por el que dichas exigencias se conduzcan. De ésta manera, sostiene Latour,

$\mathrm{Si}$ un "factor social" es transportado a través de intermediarios, entonces todo lo importante esta en el factor, no en los intermediarios. Para todo fin práctico estos pueden ser sustituidos por aquel sin pérdida de matices. Si la sociedad explica la religión, entonces la sociedad basta. Si la sociedad explica el derecho, entonces la sociedad basta (Ibíd.: 154; 1992).

El factor, en nuestro caso, sería neutralizar grupos excedentes, consolidar una administración actuarial de justicia penal o apuntalar criterios populistas para afrontar la criminalidad. Entonces, la PP se explicaría a partir de un factor u otro, según la literatura y los enfoques que sigamos. Pero tal como estudiamos nosotros a la PP, esta no puede explicarse como efecto mecánico de otros factores sino como un mediador que teniendo su propia especificidad, transforma y modifica el significado con el que los actores judiciales trabajan cotidianamente, generando asociaciones y argumentos que les permitan vincularse. En definitiva, es crucial no definir por adelantado y en lugar de los actores judiciales cómo se produce y para qué sirve la PP, ya que el destino de esta medida cautelar está, al menos en parte, en sus manos. O lo que es igual, que las características de la PP son una consecuencia, y no una causa, de lo que hacen estos actores con ella. 


\section{El recorte espacial y temporal}

\section{La provincia de Buenos Aires}

El trabajo de campo lo llevamos a cabo dentro de la jurisdicción de la PBA en los Departamentos Judiciales (en adelante, DJ) de La Plata, Quilmes y Mar del Plata. Cabe aclarar que el ámbito de la justicia penal bonaerense es sumamente heterogéneo, lo que puede entenderse a partir de las diferentes configuraciones locales vinculadas a la densidad poblacional, al acceso al trabajo o a la vivienda, entre otras cosas ${ }^{5}$. Respecto a cuestiones ligadas con esta tesis, podemos constatarlo exhibiendo algunos indicadores de 2013 provistos por la Procuración General de la PBA, como por ejemplo la tasa de encarcelamiento de la PBA en general y de cada uno de sus DJ en particular. Estas cifras, a su vez, pueden analizarse respecto al porcentaje de detenidos que estos Departamentos tienen cada 100.000 habitantes.

\begin{tabular}{|l|c|c|c|c|}
\hline $\begin{array}{c}\text { Departamento } \\
\text { Judicial }\end{array}$ & $\begin{array}{c}\text { Personas } \\
\text { Detenidas }\end{array}$ & $\begin{array}{c}\text { Porcentaje } \\
\text { sobre el total } \\
\text { de la Pcia. }\end{array}$ & $\begin{array}{c}\text { Población } \\
\text { del Depto. }\end{array}$ & $\begin{array}{c}\text { Tasa cada } \\
\mathbf{1 0 0 . 0 0 0} \\
\text { habitantes }\end{array}$ \\
\hline Azul & 626 & $2 \%$ & 435.636 & 144 \\
\hline Bahía Blanca & 765 & $2 \%$ & 626.894 & 122 \\
\hline Dolores & 452 & $1 \%$ & 284.172 & 159 \\
\hline Junín & 321 & $1 \%$ & 274.158 & 117 \\
\hline La Matanza & 3.004 & $10 \%$ & 1.775 .816 & 169 \\
\hline La Plata & 2.852 & $9 \%$ & 1.160 .614 & 246 \\
\hline Lomas De Zamora & 5.118 & $16 \%$ & 2.435 .802 & 210 \\
\hline Mar Del Plata & 1.330 & $4 \%$ & 723.685 & 184 \\
\hline Mercedes & 2.804 & $9 \%$ & 1.098 .701 & 255 \\
\hline Morón & 2.521 & $8 \%$ & 1.198 .668 & 210 \\
\hline Necochea & 168 & $1 \%$ & 118.855 & 141 \\
\hline Pergamino & 244 & $1 \%$ & 129.480 & 188 \\
\hline Quilmes & 2.521 & $8 \%$ & 1.333 .192 & 189 \\
\hline San Isidro & 2.789 & $9 \%$ & 1.400 .996 & 199 \\
\hline San Martín & 4.141 & $13 \%$ & 1.618 .813 & 256 \\
\hline San Nicolás & 756 & $2 \%$ & 314.234 & 241 \\
\hline Trenque Lauquen & 364 & $1 \%$ & 243.214 & 150 \\
\hline Zárate-Campana & 845 & $3 \%$ & 452.154 & 187 \\
\hline Total Provincial & 31.621 & $100 \%$ & 15.625 .084 & 202 \\
\hline
\end{tabular}

\footnotetext{
5 Véase Censo 2010. Resultados finales por partido. Disponible en http://www.ec.gba.gov.ar/estadistica/librocenso2010.pdf.

${ }^{6}$ Según el Censo 2010.
} 
Como puede observarse, hay disparidades entre Departamentos que aportan el 1\% del total de encarcelados (Dolores, Junín, Necochea, Pergamino, Trenque Lauquen) y otros que proporcionan el 13\% (San Martín) o el 16\% (Lomas De Zamora). Además, vemos que la media total de la PBA es de 202 detenidos cada 100.000 habitantes, media que es superada en 6 de los 18 DJ (La Plata, Lomas De Zamora, Mercedes, Morón, San Martín, San Nicolás).

Si analizamos las estadísticas ofrecidas por el Sistema Nacional de Estadísticas sobre Ejecución de la Pena (en adelante, SNEEP) acerca de la evolución de la población encarcelada en los últimos 18 años $^{7}$, es posible decir además que en la PBA se dio el porcentaje de crecimiento más significativo de dicha población en comparación con el resto de las jurisdicciones de Argentina.

Evolución de la población encarcelada en la PBA

\begin{tabular}{|c|c|c|c|c|c|c|c|c|c|}
\hline AÑO & $\mathbf{1 9 9 6}$ & $\mathbf{1 9 9 7}$ & $\mathbf{1 9 9 8}$ & $\mathbf{1 9 9 9}$ & $\mathbf{2 0 0 0}$ & $\mathbf{2 0 0 1}$ & $\mathbf{2 0 0 2}$ & $\mathbf{2 0 0 3}$ & $\mathbf{2 0 0 4}$ \\
\hline $\mathbf{N}^{\circ}$ presos & 10.043 & 11.527 & 12.460 & 13.190 & 15.012 & 16.990 & 18.931 & 22.983 & 23.449 \\
\hline AÑO & $\mathbf{2 0 0 5}$ & $\mathbf{2 0 0 6}$ & $\mathbf{2 0 0 7}$ & $\mathbf{2 0 0 8}$ & $\mathbf{2 0 0 9}$ & $\mathbf{2 0 1 0}$ & $\mathbf{2 0 1 1}$ & $\mathbf{2 0 1 2}$ & $\mathbf{2 0 1 3}$ \\
\hline $\mathbf{N}^{\circ}$ presos & 24.721 & 23.878 & 23.336 & 24.139 & 25.660 & 26.903 & 27.749 & 27.959 & 28.273 \\
\hline
\end{tabular}

Según el SNEEP, en la PBA entre 1996 y 2013 el número de presos ascendió de 10.043 a $28.273^{8}$, lo que arroja un incremento del $182 \%$ en la jurisdicción con más presos del país. Por ejemplo, el Servicio Penitenciario Federal -segundo en cantidad de encarcelados- aumentó en ese mismo período un 60\%, registrando 6.112 en 1996 y 9.807 en 2013. El tercer Servicio Penitenciario en cantidad de reclusos, que es el de la Provincia de Córdoba, tenía 3.112 encarcelados en 1996 y 6.997 en 2013, o sea un aumento del $125 \%$. Y siempre según los datos del SNEEP, en la PBA se va de una tasa de encarcelamiento cada 100.000 habitantes de 75 en 1996 a 174 en 2013. Esta última tasa de encarcelamiento en la jurisdicción bonaerense está por encima de las que existen en el escenario nacional (152), y son considerablemente más altas que las que se observan a nivel mundial $(125)^{9}$.

\footnotetext{
${ }^{7}$ Tomamos 1996 como punto de partida porque no existen estadísticas al respecto entre 1984 y 1995.

${ }^{8} \mathrm{Si}$ bien no podemos ser categóricos al respecto, la diferencia entre las cifras de la Procuración General de la PBA y el SNEEP puede relacionarse con la cantidad de presos alojados en comisarías que el SNEEP no releva y la Procuración sí.

${ }^{9}$ Datos para nivel nacional e internacional suministrados por el SNEEP en su informe para los años 2012 y 2013. Véase http://www.jus.gob.ar/areas-tematicas/estadisticas-de-politica-criminal/mapa.aspx
} 
Otro indicador disponible para acercarnos a las particularidades de la PBA es el del número de aprehensiones y detenciones ${ }^{10}$. Al respecto, se considera "aprehensión" a los supuestos en que la privación de libertad se inicia por actuación policial en flagrancia, y "detención” a los casos en que la privación de libertad comienza por la ejecución de una orden judicial de detención. Durante el año 2013, la Procuración muestra los siguientes datos según los DJ respectivos ${ }^{11}$.

\begin{tabular}{|l|c|c|c|c|}
\hline \multirow{2}{*}{$\begin{array}{l}\text { Departamento } \\
\text { Judicial }\end{array}$} & \multicolumn{2}{|c|}{ Aprehensión } & \multicolumn{2}{c|}{ Detención (Orden Judicial Previa) } \\
& Cantidad & Porcentaje & Cantidad & Porcentaje \\
\hline Azul & 629 & $85 \%$ & 111 & $15 \%$ \\
\hline Bahía Blanca & 1211 & $96 \%$ & 53 & $4 \%$ \\
\hline Dolores & 907 & $90 \%$ & 96 & $10 \%$ \\
\hline Junín & 542 & $89 \%$ & 70 & $11 \%$ \\
\hline La Matanza & 1.995 & $89 \%$ & 259 & $11 \%$ \\
\hline La Plata & 2.343 & $83 \%$ & 477 & $17 \%$ \\
\hline Lomas De Zamora & 5.299 & $94 \%$ & 341 & $6 \%$ \\
\hline Mar Del Plata & 2.453 & $96 \%$ & 103 & $4 \%$ \\
\hline Mercedes & 2.238 & $84 \%$ & 414 & $16 \%$ \\
\hline Morón & 1.599 & $91 \%$ & 164 & $9 \%$ \\
\hline Necochea & 351 & $94 \%$ & 23 & $6 \%$ \\
\hline Pergamino & 370 & $84 \%$ & 73 & $16 \%$ \\
\hline Quilmes & 2.487 & $92 \%$ & 227 & $8 \%$ \\
\hline San Isidro & 2.094 & $92 \%$ & 188 & $8 \%$ \\
\hline San Martín & 2.446 & $93 \%$ & 186 & $7 \%$ \\
\hline San Nicolás & 1.015 & $84 \%$ & 200 & $16 \%$ \\
\hline Trenque Lauquen & 453 & $95 \%$ & 25 & $5 \%$ \\
\hline Zarate-Campana & 769 & $86 \%$ & 124 & $14 \%$ \\
\hline Total & 29.201 & $90 \%$ & 3.134 & $10 \%$ \\
\hline
\end{tabular}

Este cuadro nos permite señalar que los porcentajes de aprehensiones en los distintos Departamentos oscilan entre el $83 \%$ y el $96 \%$ sobre el total de las personas privadas de su libertad, lo que evidencia al respecto el predominio del trabajo policial por sobre el judicial. Encontramos que el número de detenidos con orden judicial supera los 400 sólo en los casos de La Plata (477) y Mercedes (414), teniendo ambos, junto a San Nicolás, los porcentajes más bajos de aprehendidos. Vale recordar que se trata de tres de los seis DJ con mayor nivel de encarcelamiento de la PBA -La Plata (246),

\footnotetext{
${ }^{10}$ Según el informe de la Procuración de la PBA, se trata de los "datos correspondientes a la totalidad de las personas que resultaron aprehendidas y/o detenidas durante el período, sin perjuicio de que luego hayan recuperado (o no) su libertad personal. Por razones de registración, se computaron aquí sólo las aprehensiones y/o detenciones en las que se haya celebrado la audiencia prevista en el Art. 308 primer párrafo del Código Procesal Penal de la Provincia de Buenos Aires. Los datos comprenden el período del año 2013 hasta el 17/12/2013, fecha de corte estadístico".

${ }^{11}$ En el Informe el desglose es mes por mes, lo que no resulta necesario para esta exposición.
} 
Mercedes (255), San Nicolás (241)- en el sentido de que todos ellos superan la tasa de personas encarceladas cada 100.000 habitantes en territorio bonaerense (202).

Por último, las estadísticas que más se vinculan con nuestro tema son las que muestran en cada DJ los porcentajes de aquellos que están bajo PP -tanto para quienes se encuentran procesados como para los que tienen una sentencia que aún no es definitiva- y aquellos que están condenados por medio de una sentencia firme.

\begin{tabular}{|l|c|c|c|c|}
\hline $\begin{array}{c}\text { Departamento } \\
\text { Judicial }\end{array}$ & Detenidos & $\begin{array}{c}\text { Condenados sin } \\
\text { sentencia firme }\end{array}$ & $\begin{array}{c}\text { Condenados con } \\
\text { sentencia firme }\end{array}$ & $\begin{array}{c}\text { Total } \\
\text { personas }\end{array}$ \\
\hline Azul & $38 \%$ & $26 \%$ & $36 \%$ & 626 \\
\hline Bahía Blanca & $23 \%$ & $26 \%$ & $51 \%$ & 765 \\
\hline Dolores & $56 \%$ & $23 \%$ & $21 \%$ & 452 \\
\hline Junín & $34 \%$ & $21 \%$ & $45 \%$ & 321 \\
\hline La Matanza & $37 \%$ & $13 \%$ & $50 \%$ & 3.004 \\
\hline La Plata & $60 \%$ & $11 \%$ & $29 \%$ & 2.852 \\
\hline Lomas De Zamora & $41 \%$ & $17 \%$ & $42 \%$ & 5.118 \\
\hline Mar Del Plata & $41 \%$ & $17 \%$ & $42 \%$ & 1.330 \\
\hline Mercedes & $50 \%$ & $7 \%$ & $44 \%$ & 2.804 \\
\hline Morón & $30 \%$ & $22 \%$ & $48 \%$ & 2.521 \\
\hline Necochea & $51 \%$ & $22 \%$ & $27 \%$ & 168 \\
\hline Pergamino & $51 \%$ & $23 \%$ & $27 \%$ & 244 \\
\hline Quilmes & $57 \%$ & $14 \%$ & $29 \%$ & 2.521 \\
\hline San Isidro & $36 \%$ & $19 \%$ & $45 \%$ & 2.789 \\
\hline San Martín & $43 \%$ & $14 \%$ & $43 \%$ & 4.141 \\
\hline San Nicolás & $47 \%$ & $28 \%$ & $24 \%$ & 756 \\
\hline Trenque Lauquen & $38 \%$ & $19 \%$ & $43 \%$ & 364 \\
\hline Zarate Campana & $60 \%$ & $10 \%$ & $31 \%$ & 845 \\
\hline Total Provincial & $44 \%$ & $16 \%$ & $40 \%$ & 31.621 \\
\hline
\end{tabular}

Al analizar estas cifras que surgen del informe de la Procuración, vemos que en la PBA el promedio de presos con condena firme es del 40\%. Los Departamentos con mayor porcentaje de presos preventivos son Dolores (79\%), San Nicolás (76\%), Pergamino y Necochea (ambos, 73\%), con la particularidad de que los cuatro DJ suman poco más del $5 \%$ del total de las personas detenidas en la provincia. De los DJ con mayor nivel de encarcelamiento, San Nicolás (76\%) y La Plata (71\%) son en los que se ha utilizado la PP preferentemente. Acerca de los tres Departamentos con mayor número de encarcelados, todos están por debajo del promedio que tiene la provincia 
respecto a los presos bajo PP: Lomas de Zamora (58\%), San Martín (57\%) y La Matanza $(50 \%)^{12}$.

En síntesis, teniendo en cuenta la información que acabamos de presentar es posible constatar que la PBA es una jurisdicción en la cual la administración de justicia penal no es un fenómeno homogéneo que se pueda interpretar y explicar en forma simple ${ }^{13}$.

\section{Período y Departamentos Judiciales considerados}

Para esta investigación llevamos adelante dos recortes temporales. El primero es el que va del año 1998 hasta el 2013, en el cual detallamos la evolución del número y porcentaje de los presos preventivos junto a los distintos cambios legislativos que han tenido incidencia sobre la PP. Este período fue seleccionado a raíz de que en 1998 se sancionó, por medio de la ley 11.922, el nuevo CPP de la PBA, el cual trajo aparejado cambios estructurales en la administración de la justicia penal y con el que se pretendió revertir una tendencia histórica acerca de la utilización excesiva de la PP. Y sobre esta idea fue que se organizó el título del CPP que reglamenta las medidas de coerción, sosteniendo que durante el proceso la libertad del imputado debía ser la regla.

El segundo recorte temporal corresponde al trabajo de campo que se desarrolló entre comienzos de 2009 y marzo de 2014. Durante esta etapa realizamos las entrevistas, obtuvimos y analizamos los expedientes, y presenciamos las audiencias tempranas que se realizan en la IPP. Por lo tanto, las fuentes primarias que obtuvimos sobre la PP pertenecen a estos años. El lugar de trabajo ${ }^{14}$ y residencia en el que se desarrolló nuestra investigación fue el DJ de La Plata, desplegándose las tareas mencionadas a lo largo de los años que duró la investigación (2009-2014). En el caso

\footnotetext{
${ }^{12}$ No detallamos variables como el género y la edad de las personas en situación de encierro porque muestran porcentajes análogos en los distintos DJ de la PBA. Respecto al sexo, hay una fuerte correspondencia: el género femenino oscila entre el 3\% (Mercedes, Necochea y Zárate-Campana) y el 7\% (Quilmes), siendo la media provincial el 5\%. Acerca del rango etario, excepto en Dolores en todos los Departamentos Judiciales el $40 \%$ o más de los detenidos tiene menos de 30 años de edad. El promedio total en la PBA es del 49\%. A su vez, los mayores de 40 años no superan el $30 \%$ en ningún Departamento, siendo el $19 \%$ el promedio de la provincia.

${ }^{13}$ La complejidad de la administración de justicia penal bonaerense es una de las razones por la que la Procuración divide geográficamente a los DJ en los del conurbano (La Matanza, Lomas de Zamora, Morón, Quilmes, San Isidro y San Martín), y los del interior (Azul, Bahía Blanca, Dolores, Junín, La Plata, Mar del plata, Mercedes, Necochea, Pergamino, San Nicolás, Trenque Lauquen, Zárate Campana) dentro de la PBA.

${ }^{14}$ El lugar de trabajo es el Instituto de Cultura Jurídica, que pertenece a la Facultad de Ciencias Jurídicas y Sociales, Universidad Nacional de La Plata.
} 
del Departamento de Mar del Plata, las actividades las llevamos a cabo durante el mes de septiembre de 2010, y en el DJ de Quilmes, a lo largo del mes de marzo de 2013.

La elección de los tres DJ mencionados para nuestro trabajo, dos del interior y uno del conurbano, obedece a varias razones. La primera, que es común a todos, se debe a la posibilidad de contar con acceso al campo, esto es, de tener informantes clave, conseguir entrevistas con los actores judiciales, reunir expedientes y presenciar audiencias.

La opción por el Departamento de La Plata se sustentó, como ya lo dijimos, en que allí desarrollamos nuestros primeros acercamientos sobre el uso de la PP y fue en el cual hemos tenido más facilidades para obtener información. Además, presenta características propias que lo hacen un DJ importante. Posee un alto porcentaje de los detenidos en la PBA (9\%), sólo superado por Lomas de Zamora (16\%), San Martín (13\%) y La Matanza (10\%). Y es el segundo Departamento con mayor tasa de personas en situación de encierro cada 100.000 habitantes (246), sólo detrás de San Martín (256). Asimismo, tiene el número más alto de detenidos con orden judicial previa de la provincia (477). Por último, se trata del quinto DJ con mayor porcentaje de personas bajo PP (71\%) detrás de Dolores (79\%), San Nicolás (76\%), Necochea (73\%) y Pergamino (73\%).

La decisión por el DJ de Mar del Plata estuvo justificada porque allí se llevó adelante el Plan Piloto del proceso de flagrancia por medio del cual se comenzaron a implementar las audiencias tempranas durante la IPP a partir de julio de $2005^{15}$. Consideramos importante recuperar las experiencias de este Plan puesto que rápidamente se extendió a toda la PBA. Además, presenta el porcentaje de aprehendidos más alto de todos los Departamentos bonaerenses (96\%). Finalmente, es uno de los DJ que más se acerca a la media provincial respecto de los procesados sin condena $(41 \%$; en PBA es $44 \%$ ) o con condena no definitiva (17\%; en PBA es $16 \%$ ) y condenados (42\%; en PBA es 40\%).

El DJ de Quilmes lo escogimos con la intención de tener acercamiento e información sobre uno de los Departamentos del conurbano de la PBA. Junto con esto vale mencionar que aporta el $8 \%$ del total de las personas encarceladas en el territorio bonaerense. Por último, tiene un índice de condenados con sentencia firme que llega al

\footnotetext{
${ }^{15}$ El contexto y las particularidades del Plan Piloto desarrollado en el DJ de Mar del Plata se analizarán en el capítulo V de esta tesis, en el que trabajaremos el uso de la PP en las audiencias.
} 
29\% y es, junto con el de La Plata, el quinto más bajo de la PBA -cuyo promedio general es del 40\%-.

\section{Metodología}

El objetivo general de esta tesis es contribuir a la comprensión del uso de la PP en la PBA para lo cual llevamos adelante un estudio normativo de la misma junto con el análisis de las prácticas y los discursos que ofrecen los actores judiciales al respecto. Como lo acabamos de decir, nuestra tarea de campo se llevó a cabo en tres DJ bonaerenses. En cada uno de ellos concretamos las tres actividades más importantes para esta tesis: observar expedientes, presenciar audiencias y entrevistar a los funcionarios que dentro del PJ desempeñen actividades para la aplicación o denegación de la PP durante la IPP, que son los Defensores, JG y Fiscales.

Los objetivos específicos de esta tesis son los siguientes:

- En primer lugar, identificar los actores judiciales y extrajudiciales que hayan participado en la configuración de la PP como un problema público desde la sanción del nuevo CPP-PBA en el año 1998 (plano extrajudicial).

- Segundo, caracterizar jurídicamente la medida cautelar para luego enumerar y explorar los cambios legislativos que desde la ley 11.922 en 1998 y hasta el año 2013 se dieron respecto de la PP, junto a los efectos que esto provocó en las cifras de presos preventivos (plano jurídico).

- En tercer lugar, indagar en los expedientes y en las audiencias las manifestaciones que los actores judiciales realizan para justificar su posición acerca de la PP, agrupándolos en modelos de argumentación que permitan analizar cómo dichos actores estructuran sus solicitudes respecto al uso de la medida cautelar (plano judicial).

- Cuarto y último, tomando en cuenta el plano jurídico y el judicial, recuperar los testimonios que los actores judiciales ofrecen sobre la PP y evaluarlos a partir del marco teórico elegido para nuestra investigación (plano socio jurídico). 
En función de los cuatro objetivos específicos propuestos, la investigación la hemos llevado adelante en base a las siguientes actividades. En primer lugar, caracterizamos las perspectivas que vienen trabajando la PP. Luego, relevamos qué actores intervienen en el problema del encarcelamiento preventivo por fuera del ámbito judicial a partir de dos criterios. Por un lado, identificando a quienes se hayan pronunciado públicamente sobre la $\mathrm{PP}$, es decir, aquellos que hayan definido a éste último como un problema de tipo moral que está causando algún tipo de daño, y que ese daño tiene un carácter extendido respecto del cual surge la necesidad de que alguien haga algo. Por el otro, mencionamos los actores extrajudiciales que consideraron relevantes los actores judiciales a la hora de brindar sus testimonios.

Para desarrollar el segundo objetivo específico rastreamos los cambios legislativos que ha tenido la PP desde la reforma estructural del CPP de la PBA en 1998, complementándolo con las justificaciones y las críticas que desde distintos sectores se le han hecho a esos cambios, en particular las justificaciones y las críticas que realizaron los actores judiciales. Por último, y a partir de las estadísticas disponibles, señalamos de qué manera influyeron estas sucesivas reformas en las cifras de presos preventivos.

El tercer objetivo específico lo llevamos a cabo analizando los expedientes a los que hemos podido acceder para identificar los argumentos que los actores judiciales utilizaron para validar su posición respecto a la PP. A su vez, tomando nota de lo que ocurrió en las audiencias, reconstruimos cómo los actores judiciales estructuraron sus solicitudes en torno al uso de la medida cautelar. Ambos, expedientes y audiencias, son fuentes primarias a partir de las cuales elaboramos modelos de argumentación o "gramáticas argumentativas", lo que implica considerar a la PP como resultado de un acuerdo activo a realizar, y no como producto de fuerzas judiciales -o extrajudicialesinscriptas de manera irreversible en los hábitos de los operadores jurídicos, predispuestas a funcionar en cualquier circunstancia (Boltanski, 2000; Latour, 2008). Por lo tanto, para este objetivo manejamos técnicas que pertenecen a la investigación cualitativa, a saber: la observación e interpretación de expedientes y audiencias por medio de criterios que nos han permitido obtener datos relevantes para nuestra tesis.

En el último de los cuatro objetivos específicos, analizamos y evaluamos los testimonios que los actores judiciales ofrecieron sobre la PP a partir del marco teórico elegido para nuestra investigación. Por tal motivo hemos entrevistado a un total de 46 personas entre expertos en seguridad, referentes de ONGs que trabajan el tema de la PP 
y actores judiciales con cargos de distintas jerarquías. Debido a que nuestro objetivo es la comprensión del uso de la PP durante la IPP, nos concentramos dentro de los DJ elegidos en los tres actores que hacia el interior del PJ tienen mayor protagonismo en esa etapa, a saber, Defensores (13), Fiscales (14) y JG (13) ${ }^{16}$. Las entrevistas fueron gestionadas previamente por informantes clave y realizadas personalmente. Todas se efectuaron en el lugar de trabajo, excepto la de un Defensor y la de un experto en seguridad, que fueron llevadas a cabo en sus respectivas casas.

La técnica que empleamos para explorar el plano discursivo de la PP es la entrevista semiestructurada (Sautu, 2003; Marradi, Archenti, y Piovani, 2007; Kunz y Cardinaux, 2004) o antropológica (Guber, 2005). Partimos de una guía de preguntas y temas que nos facilitó dialogar sin tener que apegarnos a ningún orden inflexible preestablecido, permitiéndonos incorporar elementos no previstos que surgieron de conformidad a los vaivenes del diálogo con nuestros entrevistados.

Como regla general, los actores judiciales mostraron una actitud reticente frente a la posibilidad de ser consultados, de hecho algunas entrevistas fueron canceladas de facto luego de la postergación de las mismas en varias oportunidades. Los Fiscales y JG han sido quienes durante el desarrollo de las entrevistas mantuvieron la mayor distancia mediante el uso de una formalidad en algunos casos excesiva. El caso de los Defensores fue distinto puesto que con el correr de las preguntas asumieron una actitud más llana cuya característica más frecuente fue la crítica hacia el funcionamiento de la justicia penal, a su selectividad, incluso a su indolencia en algunos casos.

A continuación, empezaremos por hacer referencia a tres perspectivas que han estudiado la utilización de la PP: la dogmática jurídica, los informes y documentos de las ONGs, y los trabajos provenientes de las ciencias sociales. Por último, introduciremos nuestro punto de vista sobre el problema del encierro preventivo.

\footnotetext{
${ }^{16}$ Como nuestro interés principal era el de analizar la dinámica judicial de la PP, decidimos no entrevistar a abogados u abogadas particulares porque, en términos generales, su relación con las prácticas, lugares y tradiciones propios del PJ no es la misma.
} 


\section{PRIMERA PARTE}

\section{CAPITULO I \\ Pensar la prisión preventiva}

Este capítulo presentará una serie de trabajos en los que se estudia la prisión preventiva (en adelante, PP), y que agruparemos en tres perspectivas diferentes. La primera de ellas es la que proviene de la dogmática jurídica, para la cual la PP es fundamentalmente un agravio a las garantías constitucionales y procesales de los ciudadanos. En segundo lugar, desarrollaremos el enfoque que ofrecen distintas organizaciones en sus documentos e informes acerca de la expansión del encierro preventivo junto a las consecuencias que esto acarrea. Luego, mencionaremos los abordajes que desde las ciencias sociales se han propuesto para explicar las funcionalidades de la PP como instrumento político, bien para imponer un estilo actuarial de justicia, bien para controlar grupos definidos como peligrosos, bien para consolidar el avance de cierto populismo punitivo. Por último, indicaremos nuestra postura al respecto.

\section{1- La dogmática del encierro preventivo}

La perspectiva que más tiempo lleva trabajando la problemática de la PP es aquella que proviene de una mirada internalista del fenómeno en cuestión, mirada característica de la ciencia o dogmática jurídica. En este sentido, entendemos por ciencia o dogmática jurídica a la disciplina que toma al derecho como norma escrita positiva, prescindiendo de los contextos y las relaciones sociales en las que esta norma escrita se promulga o aplica ${ }^{17}$. Por lo tanto, con la dogmática jurídica estamos frente a un enfoque normativo sobre el encarcelamiento preventivo, es decir, un enfoque que presupone una coherencia interna y una lógica autorreferencial del derecho según las cuales la presunción de inocencia del imputado es el sostén del edificio jurídico y la PP aquello que inevitablemente lo debilita.

\footnotetext{
${ }^{17}$ Se suele diferenciar a la ciencia jurídica de las ciencias jurídicas en general, pudiéndose ubicar dentro de estas últimas, por ejemplo, a la sociología jurídica o a la historia del derecho (Díaz, 1965).
} 
Este interés inaugural de la ciencia jurídica en el tema resulta comprensible debido a las impugnaciones que implica el encierro preventivo en relación a cánones jurídicos fundamentales como el Principio de Inocencia o el Principio de Legalidad. Estas impugnaciones, que desarrollaremos a continuación, son las que estructuran el planteo de la dogmática de la PP.

\section{1 ¿Cómo se llega a ser inocente?}

Comenzaremos por dar una definición de la PP amplia, para circunscribirla en los próximos dos capítulos a la jurisdicción y período estudiados en esta tesis. Y proponemos ahora una definición de este tipo por un motivo fundamental: es factible hacerlo. Si bien es verdad que las generalizaciones se vuelven insuficientes llegada cierta instancia en el desarrollo del análisis, esta medida cautelar tiene una serie de elementos comunes que podemos señalar más allá de los lugares y las coyunturas en los que se aplica. Entonces, podemos decir que la PP consiste en la privación de la libertad llevada a cabo antes de la existencia de una sentencia firme -efectuada por un Juez o Tribunal competente- contra una o más personas imputadas por la comisión de un delito. Según la doctrina jurídica ${ }^{18}$ mejor considerada, una vez que se comprueba la existencia de un ilícito y hay indicios vehementes de la participación de quien está siendo investigado, el encierro preventivo puede fundarse en el peligro de fuga del imputado, en el peligro de que este último pueda obstaculizar la averiguación de la verdad durante el proceso, o en ambos peligros a la vez. Dicho confinamiento se vuelve problemático, en primer lugar, por la contradicción que existe entre el mismo y el Principio de Inocencia, cuya formulación más célebre la hallamos en el noveno artículo de la Declaración de Derechos del Hombre y del Ciudadano francesa de 1789. Allí se afirma que

Todo hombre se presume inocente mientras no sea declarado culpable, si se juzga indispensable detenerlo, todo rigor que no sea necesario para apoderarse de su persona debe ser severamente reprimido por la ley.

Considerado "principio de principios" a la luz del abordaje que hace la ciencia o dogmática jurídica, el Principio de Inocencia es aquel que garantiza que cualquier persona sea estimada inocente mientras no exista un pronunciamiento firme que

\footnotetext{
${ }^{18}$ Se entiende por doctrina jurídica al conjunto de producciones teóricas e investigativas llevadas adelante por los dogmáticos del derecho.
} 
destruya ese estado jurídico. En definitiva, que todo individuo que no ha sido declarado culpable, aún siendo investigado por la comisión de un delito, aún habiendo sido condenado por medio de una sentencia no definitiva, goce de un trato diferente de aquel que ya ha recibido una condena firme (Bovino, 1998).

\subsection{La ilustración, el positivismo criminológico y el principio de} inocencia como informador

El rudimento del apartado anterior da lugar a la reflexión siempre intrincada sobre el estatuto legal de los individuos. Y no se trata de un debate reciente. Por el contrario, hace varios siglos que vienen reelaborándose los argumentos que reivindican o minimizan el Principio de Inocencia. Incluso antes de la Declaración de Derechos del Hombre y del Ciudadano ya mencionada se pueden encontrar proposiciones al respecto, como por ejemplo la de Hobbes cuando afirma no entender "cómo puede haber un delito para el que no hay sentencia, ni cómo puede infligirse una pena sin una sentencia previa” (1994 [1651]: 238). Este filósofo, precursor del pensamiento ilustrado, calificó a las sanciones sin sus respectivas condenas como un acto hostil contra todo ciudadano, alegando que

[...] todo castigo de súbditos inocentes, ya se trate de un castigo grande o pequeño, va contra la ley de la naturaleza porque el castigo es sólo debido a una trasgresión de la ley, y, por tanto, no puede castigarse al inocente (Ibíd.).

Por su parte Beccaria, en su célebre Del delito y de las penas escribe:

A un hombre no se le puede llamar reo antes de la sentencia del juez, ni la sociedad puede negarle su protección pública, sino cuando se haya decidido que ha violado los pactos con que se la otorgó. ¿Cuál es, pues, el derecho, si no es el de la fuerza, que dé potestad a un juez para aplicar una pena a un ciudadano mientras se duda todavía si es reo o es inocente? [Si el delito] es incierto, no se debe atormentar a un inocente, ya que tal es, según las leyes, un hombre cuyos delitos no están probados (1993 [1764]: 13).

Sin embargo, estas citas no deberían llevar a confusión puesto que dichos pensadores, como otros del siglo XVII o XVIII, no se manifestaron inequívocamente respecto al tratamiento que debían recibir quienes estaban siendo investigados por algún 
delito. De hecho fueron los mismos ilustrados ${ }^{19}$, entre quienes se puede ubicar en primera hilera al mismo Beccaria, quienes justificaron la llamada prisión provisional, al no considerarla reñida con el Principio de Inocencia:

La ley, pues, determinará los indicios de un delito que merezcan la custodia del reo, que lo sometan a un examen o a una pena. La fama pública, la fuga, la confesión extrajudicial, la de un compañero del delito, las amenazas y la constante enemistad del ofendido, el cuerpo del delito y otros indicios similares, son pruebas suficientes para capturar a un ciudadano (Ibíd..: 20).

Por lo tanto, es necesario bifurcar -situándolos- estos argumentos. Por un lado, se debe tener en cuenta que la cuestión que aquellos pensadores encontraban problemática no era tanto la PP en sí, a la cual respaldaron por diversos motivos, sino principalmente la dureza o el rigor en su ejecución. Por otro, se debe remarcar que aún sin proponérselo de forma explícita, fue este mismo pensamiento ilustrado el que en nombre de las más variadas necesidades, acabó apoyando la PP (Llobet Rodríguez, 1997: 25).

A partir de mediados del siglo XIX, la eficacia del Principio de Inocencia para limitar el uso del encierro preventivo declinó aún más, fundamentalmente como consecuencia de la hegemonía que alcanzó el positivismo criminológico italiano respecto al tratamiento del delincuente. Su pensador más refinado, Enrico Ferri, si bien admitió esta presunción de inocencia, consideró que debía suspenderse respecto de ciertas personas. Era el caso, según él, de los reincidentes y más en general de aquellos individuos cuyos indicios orgánicos y psíquicos ofrecidos por la antropología y la estadística criminal los hicieran aparecer como culpables. Son estos últimos, decía, quienes

Reconocen la racionalidad de la presunción contraria: me han condenado sin pruebas, sólo por mi capacidad de delinquir -me decía un ladrón habitual- y han hecho bien; jamás condenan al que no ha robado nunca; y si en alguna ocasión no se es culpable, vaya por las otras veces en que siéndolo no nos descubren (Ferri, 1907b: 194).

\footnotetext{
${ }^{19}$ Más allá de la dificultad de definir el período histórico de la Ilustración, en el ámbito penal y criminológico suele caracterizárselo como aquel movimiento que pretendió racionalizar el castigo con el fin de usarlo como una herramienta de control estatal para los ciudadanos y como un límite al propio Estado en resguardo de las garantías de los ciudadanos (Anitua, 2006: 96).
} 
Más drástico se mostraba su colega Raffaele Garófalo, quien aseveraba que a las personas que

Repiten la consabida, vacía y absurda frase de la presunción de inocencia hasta la sentencia definitiva, respondo que muchas veces el juicio se anticipa y la condena se pronuncia por el Tribunal de la opinión pública (1912: 361).

Por el frágil estatuto que Garófalo le otorgaba a la sentencia judicial, suele considerarse que apoyaba la subversión del Principio de Inocencia, dando lugar a la presunción de culpabilidad. Esta última supone que sea el imputado quien deba demostrar su inocencia y no el Estado quien deba comprobar su culpabilidad.

Esto que acabamos de presentar no tuvo como propósito ofrecer un minucioso catálogo sobre las perspectivas acerca del Principio de Inocencia y la limitación que éste sufre por el uso de la PP. Buscamos sí, aclarar que el encierro preventivo resulta un tema añoso cuya discusión no es para nada pacífica, y que llega desde regiones europeas a Latinoamérica y Argentina. En este sentido, es importante subrayar dos cuestiones acerca del Principio de Inocencia analizado. Por un lado, que no atestigua si el imputado ha participado o no en la comisión de una conducta punible. Su significado consiste, fundamentalmente, en atribuir a toda persona un estatus jurídico que exige que se la considere inocente durante la investigación de un ilícito sin importar, en esa etapa del proceso, que sea culpable de un ilícito o ajeno al mismo. En segundo lugar, que así como afirma una parte importante de la doctrina argentina, lo más significativo de la presunción de inocencia es su valor ideológico en tanto mandato político tendiente a garantizar la posición de libertad del imputado frente al interés estatal en la represión penal. De este modo, el Principio de Inocencia

Debe servir de presupuesto y parámetro de todas las actividades estatales concernientes a la represión criminal [y de] modelo de tratamiento del sospechoso, inculpado o acusado, que antes de la condena no puede sufrir ninguna equiparación con el culpable (Magalhaes Gomes, 1995: 42).

En síntesis, para la doctrina especializada el Principio de Inocencia debe interpretarse como un tópico informador del estatus jurídico de los individuos a lo largo de todo el procedimiento penal. 


\subsection{Enfoque constitucional}

Considerado como uno de los más distinguidos representantes del garantismo penal, el jurista italiano Luigi Ferrajoli afirma que

Si no se quiere reducir la presunción de inocencia a puro oropel inútil, debe aceptarse [...] que no sólo el abuso, sino ya antes el uso de este instituto [la PP] es radicalmente ilegítimo y además idóneo para provocar [...] el desvanecimiento de todas las demás garantías penales y procesales (1989: 555).

A partir de esta aseveración surge en la dogmática jurídica el interrogante por el sentido de un principio como el Principio de Inocencia, si el Estado está en condiciones de encarcelar a quien todavía no ha sido condenado. Si bien no es nuestro objetivo dar respuesta a este interrogante, sí parece oportuno vincular el principio mencionado con otro complementario que se encuentra en la Constitución Nacional (en adelante, $\mathrm{CN}$ ). En su Art. 18, se observa la formulación de otra garantía fundamental para un Estado de Derecho vinculada al ya trabajado Principio de Inocencia, y es la garantía que encarna el Principio de Legalidad. En concreto, la CN afirma: "Ningún habitante de la Nación puede ser penado sin juicio previo fundado en ley anterior al hecho del proceso [...]"20.

Desde un sector de la doctrina jurídica se afirma que existe entre ambos preceptos una reciprocidad funcional a raíz de la cual no se puede castigar a nadie, aunque sea por una ley anterior al hecho juzgado, sin un juicio previo (Principio de Inocencia). Y a su vez, que tampoco se puede infligir una pena, aunque exista juicio previo, sin que la ley que estipula la sanción sea anterior a la conducta perseguida (Principio de Legalidad). En otras palabras:

[...] tanto las garantías penales como las procesales valen no por sí mismas, sino también unas y otras como garantía recíproca de su efectividad. Gracias a este doble nexo, todo modelo de legitimación interna de los presupuestos de la pena remite a un correlativo modelo de legitimación de sus modos de determinación en el proceso penal. $\mathrm{Y}$, a la inversa, todo modelo de proceso penal, tanto si se le considera desde el punto de vista normativo, como del de la efectividad, indica siempre a su vez un correlativo sistema, normativo o efectivo, de derecho penal sustancial (Ferrajoli 1989: 537-8).

\footnotetext{
${ }^{20}$ Vale tener en cuenta que según Maier, el concepto de juicio (expuesto en la manda constitucional) y el de sentencia son fungibles ya que "la sentencia de condena es el juicio del tribunal que, declarando la culpabilidad del imputado, determina la aplicación de la pena" (Maier, 1989b: 240); por consiguiente, existe un proceso en primer término que resulta ser el antecedente necesario de este juicio o sentencia.
} 
Para este conjunto de teóricos del derecho, los Principios de Inocencia y Legalidad se encuentran entrelazados de forma tal que violentar uno implica en efecto minar al otro. A su vez, la cuestión de los dos Principios que acabamos de nombrar suscitan otro dilema y otras dos posturas disidentes: por un lado, están aquellos doctrinarios que afirman que tales Principios no son absolutos por lo que podrían, bajo ciertas condiciones, ser limitados. Por el otro, están quienes manifiestan su desacuerdo al respecto. En primer lugar, estos últimos afirman que si es posible restringir los Principios de Inocencia y Legalidad que acabamos de mencionar del Art. 18 de la CN, también sería dable en caso que las circunstancias lo ameriten, someter a alguien a la esclavitud, acotando de la misma manera las garantías del Art.15 de la Carta Magna. O si la coyuntura lo exigiese, podrían restablecerse las prerrogativas de sangre abolidas por el Art.16. Además, este grupo de juristas agrega que aún siendo verdad que algunas intrusiones puedan consentirse respecto de derechos fundamentales, sucede que la $\mathrm{CN}$ las autoriza expresamente ${ }^{21}$. Sostienen dichos doctrinarios que es el caso del Art. 18 en el cual se afirma que "El domicilio es inviolable [...] y una ley determinará en qué casos y con qué justificativos podrá procederse a su allanamiento y ocupación”. En definitiva, plantean estos juristas, en el mismo Art. 18 están estipulados los mecanismos para suspender la garantía de inviolabilidad del domicilio, pero nada dice para el Principio de Legalidad y el Principio de Inocencia ${ }^{22}$.

\subsection{Requisitos materiales}

A pesar del disenso mencionado sobre la entidad de los derechos constitucionales, en lo que sí existe acuerdo para la doctrina jurídica es respecto a un cúmulo de formalidades que deberían acompañar la aplicación de la PP, a las cuales han denominado requisitos materiales.

(a) PRINCIPIO DE EXCEPCIONALIDAD: según este precepto, el derecho a la libertad ambulatoria combinado con la presunción de inocencia impide que la PP se

\footnotetext{
${ }^{21}$ No tan radical se muestra Maier, doctrinario destacado en la materia: "Nuestra ley fundamental sigue esos pasos: pese a impedir la aplicación de una medida de coerción del Derecho material (la pena) hasta la sentencia firme de condena, tolera el arresto por orden escrita de autoridad competente, durante el procedimiento de persecución penal (CN, 18)" (1989b: 275).

${ }^{22}$ Acerca de esto, Bovino sostiene lo siguiente: "Si admitiéramos el razonamiento que permite injerencias de cualquier magnitud en todos los derechos fundamentales, no sólo deberíamos tolerar la prisión preventiva sino, también, que luego de un juicio se imponga una pena por un hecho no previsto en la ley penal, si existieran razones suficientes para fundar la necesidad de que tal hecho fuera castigado" (2005: $10)$.
} 
tome como la regla de uso habitual. La consecuencia principal de este precepto es la necesidad de agotar todas las formas de asegurar los fines procesales con herramientas distintas al encierro. En consecuencia, afirma Bovino,

El encarcelamiento preventivo sólo se justifica cuando resulta imposible neutralizar el peligro procesal con medidas de coerción alternativas al encarcelamiento preventivo (1998: 151).

\section{(b) VERIFICACIÓN DEL MÉRITO SUSTANTIVO O SOSPECHA SUSTANTIVA} DE RESPONSABILIDAD: de aquí surgen dos exigencias correlativas que son, en primer lugar, la comprobación de que se ha cometido una conducta tipificada penalmente. Y en segundo lugar, que el procesado ha intervenido en su realización puesto que

Si no se determina la probabilidad de que el imputado haya participado en la comisión de un hecho punible, la medida de coerción procesal pierde todo su sustento (Ibíd.: 157).

(c) FIN PROCESAL: evitar el peligro de fuga o el entorpecimiento en la averiguación de la verdad por parte del imputado son los únicos fundamentos para la PP. Esto significa que la detención cautelar sólo puede tener fines procesales como por ejemplo que la investigación se desarrolle normalmente, pero de ninguna manera los de evitar la comisión de otro delito, porque esto último le corresponde a la pena sustantiva. Por ello, señala Cafferata Nores,

La característica principal de la coerción procesal es la de no tener un fin en sí misma. Es siempre un medio para asegurar el logro de otros fines: los del proceso. Las medidas que la integran no tienen naturaleza sancionatoria (no son penas) sino instrumental y cautelar; sólo se conciben en cuanto sean necesarias para neutralizar los peligros que puedan cernirse sobre el descubrimiento de la verdad o la actuación de la ley sustantiva (1992: 3).

Como consecuencia, durante el desarrollo del proceso el estado de inocencia del imputado persiste, razón por la cual la PP no puede tener fines materiales propios de la sanción penal, sea como prevención general o como prevención especial ${ }^{23}$, sino aquellos

\footnotetext{
${ }^{23}$ En la filosofía del castigo se analizan las justificaciones o fundamentos por los cuales la sanción estatal amerita ser aplicada. Las preventivas generales consideran legitimada la pena cuando ésta busca integrar a la sociedad respetuosa de las leyes en torno a los valores predominantes (positiva) o cuando busca isuadir a los potenciales ofensores (negativa). Las preventivas especiales buscan su sostén en la rehabilitación del infractor (positiva) o por su mera neutralización (negativa) (Marí et al, 1983).
} 
propósitos que contribuyan a la búsqueda de la verdad y a la aplicación del derecho penal sustantivo.

(d) PRINCIPIO DE PROPORCIONALIDAD: aquí surge la exigencia de que quien se encuentra encarcelado preventivamente no reciba el mismo trato, ni mucho menos uno peor, que aquel que ya ha sido condenado. Según Bovino,

Se trata de impedir que la situación del individuo aún inocente sea peor que la de la persona ya condenada, es decir, de prohibir que la coerción meramente procesal resulte más gravosa que la propia pena (1998: 153).

Se observan, por lo tanto, dos usos de la proporcionalidad. Uno se vincula con el tiempo y otro con las condiciones. El primero de ellos se refiere a que la restricción propia de la PP resulte correspondiente a la pena que se espera, si el imputado llegara a ser condenado. Por otro lado, tampoco puede ejercerse una severidad mayor con la PP que aquella impuesta en la ejecución de la pena que es producto de una sentencia definitiva. De esta manera, y retomando el principio de proporcionalidad, nunca debería resultar "más elegible" ser un condenado por sentencia firme proveniente de un órgano de justicia penal, que un imputado que goza aún -y hasta que se declare lo contrario- de la presunción de inocencia.

(e) PRINCIPIO DE PROVISIONALIDAD: este principio supone la necesidad de que todas las condiciones que hicieron posible la PP se mantengan para que ésta continúe. O dicho de otra manera, que sólo es dable prolongar la detención si subsisten todas y cada una de las circunstancias que fundaron la necesidad original de ordenarla (Bovino, 1998: 160). Según el CPP-PBA, en su Art. 147, “en caso de advertirse la desaparición de una o más condiciones, en cualquier etapa del proceso, el órgano judicial podrá ${ }^{24}$ disponer a pedido de parte o de oficio, el cese inmediato de la cautela oportunamente dispuesta". Parte de los teóricos del derecho interpretan que si cesara alguna de las causas que motivaron el encierro preventivo, este último debe finalizar (Pastor, 1993).

Resumiendo lo que hemos expuesto sobre la primera perspectiva en los estudios sobre la PP, tenemos en la base al Principio de Inocencia según el cual toda persona

\footnotetext{
${ }^{24}$ La cursiva es nuestra.
} 
posee un estatus jurídico que obliga a considerarla inocente durante la investigación de un delito. Junto al Principio de Inocencia se encuentra el Principio de Legalidad que afirma que no se puede infligir un castigo, aún existiendo juicio previo, si la ley que estipula la sanción es posterior al hecho que se está investigando.

Además de estos parámetros constitucionales, expusimos los requisitos materiales que según la doctrina jurídica deberían orientar en la práctica la aplicación cuidadosa de la PP. Se trata cinco principios: excepcionalidad, sospecha sustantiva de responsabilidad, fin procesal, proporcionalidad y provisionalidad.

\section{2- Una medida (poco) peculiar}

Al comienzo de su último libro, Garland (2013) afirma que la pena de muerte en EE.UU. es una institución peculiar. Y según este autor, lo es por estar en desacuerdo con las finalidades de la justicia penal, porque parece tener alguna relación si bien no del todo clara con el legado de violencia racial del país, y porque EE.UU. es la única nación en occidente que mantiene vigente esta ejecución capital. Si reparamos en la última de estas tres características y la relacionamos con lo que sostienen diferentes estudios y documentos sobre el problema de la PP alrededor del mundo, podemos llegar al respecto a la conclusión contraria a la de Garland sobre la pena de muerte en EE.UU. Es decir, que la PP es una medida cautelar muy poco peculiar.

Según el trabajo Waiting for Trial realizado hace dos décadas en el Instituto Max Planck y editado por Frieder Dünkel y Jon Vagg (1994), en los hechos parecen confundirse los límites entre el encierro preventivo y la condena de prisión. Ambos autores afirman, en primer lugar, que a nivel internacional -se centran en Europa y EE.UU.- el abuso de esta medida cautelar se ha convertido en una estrategia utilizada sistemáticamente dentro de la justicia penal, lo que contribuye a que los periodos que muchos imputados pasan en PP se transformen en una condena que se cumple anticipadamente. En segundo lugar, según este estudio

La mayoría de los sistemas penitenciarios, en la práctica, niegan frecuentemente a los detenidos [preventivos] el acceso a muchas de sus instalaciones, a los derechos y privilegios de los que gozan los convictos recluidos [...] en ocasiones, esas privaciones configuran una instigación a que se declaren culpables para obtener mejores condiciones de confinamiento ( $\mathrm{p}$. XIV) 
Es decir, que la situación en la que se encuentran muchos presos preventivos es utilizada de modo extorsivo para lograr la aceptación de diversos cargos y el posterior dictado de sentencias condenatorias. Por último, dicen Dünkel y Vagg, surgen evidencias de que en ciertos casos las condenas impuestas luego del juicio se usan para validar retroactivamente las detenciones que se llevaron a cabo antes del juicio. Esto quiere decir que el lugar más relevante aquí no lo ocupan las pruebas obtenidas contra los imputados sino la necesidad de que la PP resulte administrativamente justificada.

En la publicación del año 2008 titulada Justice Initiatives de la organización Open Society, se presentó un informe sobre la magnitud y consecuencias de la PP alrededor del mundo. Dicho informe sostuvo que "más allá de un reducido grupo de reformadores penales, activistas en el sector de los derechos humanos y administradores penitenciarios, pocas personas se dedican a reflexionar sobre la detención previa al juicio y los problemas derivados de ella" (2008: 7). Esta escasa implicación en la problemática genera dificultades para alcanzar conclusiones rigurosas sobre la complejidad que implica el uso de la PP. A su vez, el informe sostiene que en el mundo angloparlante a las personas bajo encierro preventivo puede llamárselas de diversas maneras: "presos en detención", "detenidos", "detenidos en espera de juicio" o “prisioneros no sentenciados”. Pero que lo más importante, más allá de estas rotulaciones, es que todos los sistemas de justicia penal diferencian prisioneros sentenciados y no sentenciados, asignándoles al segundo grupo un estatus legal distinto.

La propuesta central de este documento es la de examinar y exponer el impacto que tiene la PP sobre los detenidos, sus familias, la comunidad en general, la gobernanza y la legalidad. Más allá de que estos objetivos se diluyan en el desarrollo del trabajo, éste último sí permite advertir la dimensión del problema:

A nivel mundial, al finalizar 2006 casi una de cada tres personas encarceladas lo estaba en el estatus de detención previa al juicio. Pero los porcentajes varían considerablemente de región en región. La zona con el mayor porcentaje de detenidos en espera de juicio es Asia (47.8 por ciento), seguida de África (35.2 por ciento). En Europa, cerca de uno de cada cinco prisioneros estuvo detenido con antelación al juicio en 2006 [...]. A finales de 2006, 44 de cada 100.000 personas se encontraban detenidas en espera de juicio en todo el mundo. La región con la mayor tasa (más del doble del promedio global general) es el Continente americano, seguido por Europa, Asia, África y Oceanía (Ibíd.: 9-10). 
Respecto a las consecuencias que acarrea en los detenidos el uso de la PP, se mencionan fundamentalmente los daños a la salud mental y el contagio de enfermedades infecciosas. A nivel familiar, se habla de la influencia negativa en los niños y del deterioro en la economía familiar, sobre todo en sectores pobres. Dentro de la comunidad, la extracción y el reingreso de personas que han estado presas preventivamente favorece el desajuste en las relaciones y debilita las normas sociales, las cuales se basan en la consolidación de vínculos a largo plazo. Por último, el informe sostiene que el uso excesivo de la PP puede horadar la gobernanza dado que su aplicación arbitraria y discriminatoria promueve la corrupción, lo que consecuentemente menoscaba el Estado de derecho que se sustenta en prácticas honestas y responsables del gobierno ${ }^{25}$.

En el año 2014, el documento Presumption of Guilt: The Global Overuse of Pretrial Detention editado por la misma Open Society sostuvo que si bien

El uso excesivo de la prisión preventiva a nivel mundial es enorme y forma parte de violaciones a los derechos humanos, en gran medida pasa desapercibido. Afecta directamente a por lo menos 15 millones de personas cada año, muchas de las cuales esperan meses o incluso años para que les llegue el día de su juicio en peores condiciones que las que tienen los presos condenados (2014: 174, traducción propia).

El señalamiento que acabamos de citar no es sólo por la supuesta aplicación indiscriminada de la PP, sino por las circunstancias en las que se encuentran los detenidos cautelares. En sintonía con el estudio previo que presentamos de Justice Initiatives, este informe plantea que hay otras personas que indirectamente son perjudicadas por el uso de la PP, como por ejemplo los familiares del procesado a raíz de la pérdida de los ingresos de dinero en los casos en que dicho procesado aportaba. Además, se suman las posibilidades reales de que contraigan enfermedades tanto el procesado como así también sus familiares en las visitas a la prisión o después de la liberación del detenido. La sociedad en general también se ve afectada por el uso

\footnotetext{
${ }^{25}$ Este informe agrega que la PP puede evaluarse a partir del número de días que las personas permanecen bajo esta medida cautelar. En este sentido, y de acuerdo con una investigación realizada en 2003 por la Comisión Europea, la duración promedio de la PP en 19 de los 25 estados miembros de la Unión Europea es de 167 días, es decir, 5 meses y medio.
} 
excesivo de la PP, a raíz de que se desperdicia el potencial humano de aquellos encarcelados preventivamente, favoreciendo esto un mal uso de los recursos del Estado.

El documento Presumption of Guilt concluye, por un lado, que los estándares y normas regionales e internacionales son claros respecto a las medidas de coerción previas a la condena: una persona de la que se presuma su inocencia, y mientras no se pruebe su culpabilidad, debe ser puesta en libertad a la espera del juicio, excepto si representa una amenaza. Pero por otro lado, afirma el documento, buena parte de los detenidos en PP no deberían estar encarcelados puesto que no constituyen un peligro efectivo para la sociedad. Esto demuestra que, tanto en el mundo desarrollado como en el que está en vías de desarrollo, la utilización de la PP sigue siendo por defecto la característica de la mayoría de los sistemas de justicia penal.

Los trabajos en torno a esta medida en América Latina mencionan una serie de dificultades para restringir su utilización que, más allá de adquirir sus respectivas particularidades, se observan en toda la región. En un conocido artículo, Elías Carranza sostiene que en nuestro continente existe lisa y llanamente una inversión de axiomas, puesto que "es evidente que, por sobre el Principio de Inocencia, prima lo que podríamos llamar principio de presunción de culpabilidad (ante la duda, marche preso)" (1999: 82; 2001; 1982). Para este autor, una de las explicaciones de las elevadas cifras de la PP en la región se encuentra en el sistema de justicia imperante

Un sistema de justicia penal escriturista y lento como el de América Latina, sin inmediación y en el que en muchísimos casos ni el juez de instrucción ni el juez de sentencia conocen personalmente al imputado [...], producen un altísimo número de presos sin condena (1999: 83).

Lo que plantea Carranza es una relación crucial entre un proceso penal primordialmente escrito, la demora judicial y la aplicación excesiva del encarcelamiento preventivo. Es decir, que el uso del expediente contribuye a la exigencia de trámites que no siempre resultan necesarios para avanzar en el desarrollo de una investigación. Además, un proceso penal escrito favorece que los pedidos y las concesiones de la PP sean prácticamente "automáticas", entre otras cosas, por el escaso conocimiento e interacción entre imputados y actores judiciales. En definitiva, según este autor el 
expediente encarna los más criticables elementos vinculados a una justicia penal abusivamente burocrática ${ }^{26}$.

En el año 2009, el Centro de Estudios de Justicia de las Américas (CEJA) publicó su primer documento sobre Prisión preventiva y reforma procesal en América Latina. Allí se afirma que la regulación de la PP ha sido uno de los temas más controvertidos en las reformas a la justicia criminal que tuvieron lugar en casi todos los países de la región. Estas reformas comenzaron a implementarse a partir de la última década del siglo XX y según este informe intentaron ir en contra del uso extendido del encarcelamiento cautelar que por aquel entonces se encontraba naturalizado. Se trataba de dejar de ver a la PP como una pena anticipada y empezar a considerarla como una medida excepcional que debía ser utilizada sólo para los casos donde fuese imprescindible para el desarrollo del proceso.

Esta búsqueda de transformación dentro de la región se vio interrumpida a comienzos de los años 2000 por un fenómeno que este trabajo del CEJA definió como "período de contrarreforma". Como consecuencia de este período, en buena parte de los países latinoamericanos la regulación de la PP se "endureció", estableciéndose delitos que necesariamente exigían dicha medida cautelar sin importar si existían riesgos procesales de quienes estuviesen acusados de haberlos cometido. En segundo lugar, la contrarreforma limitó la posibilidad de que se utilicen otras medidas cautelares que eviten el encierro, como por ejemplo el arresto domiciliario. Por último, se ampliaron las causales de procedencia de la PP por lo que había legalmente más posibilidades para aplicarla. Esta contrarreforma parece hoy haber retrocedido en algunos países si bien

En estos últimos años se ha ido consolidando un medio ambiente social en la mayoría de los países de la región de fuerte presión pública a los jueces al momento de decidir sobre la prisión preventiva [...] haciendo que factores externos a la ley cobren un rol de relevancia para la decisión en un caso particular (CEJA, 2009: 71-2; CIDH, 2013).

Por lo tanto, sostiene el documento, para que exista un verdadero programa con el cual moderar el uso de la PP, los sistemas procesales penales deben estar en condiciones de mostrar tanto eficacia en la persecución penal como eficiencia en el uso de las medidas cautelares personales.

\footnotetext{
${ }^{26}$ El nexo entre las características del proceso penal y la aplicación del encierro preventivo serán tratados en los capítulos IV y V de esta tesis, cuando analicemos el uso de la PP en los expedientes y las audiencias.
} 
En el informe Independencia judicial insuficiente, prisión preventiva deformada: los casos de Argentina, Colombia, Ecuador y Perú presentado en 2013 por la fundación Due Process of Law (DPLF) se articula el problema de la PP con una variada serie de fenómenos. El primero de ellos es el que pone frente a frente a la presunción de inocencia de los imputados con la inseguridad ciudadana, hasta volverlas prácticamente irreconciliables. Lo dicho significa que en buena parte de América Latina,

Para el caso de la persona que es sindicada por la policía como responsable de un delito, para quien el fiscal luego ha pedido la apertura de un proceso penal y el juez ha consentido en ello, en una importante medida la ciudadanía ha "naturalizado" la detención en cárcel como la consecuencia derivada (DPLF, 2013: 7)

Esto equivale a decir que el hecho de no encarcelar preventivamente a quien está siendo investigado por un caso delictivo grave o resonante, despierta en la comunidad un sentimiento de impunidad. Y según el informe, es lo que motoriza el gran respaldo popular a políticas "duras" en la represión del delito, en especial, por la necesidad de neutralizar a individuos que si bien son jurídicamente inocentes, resultan en apariencia amenazantes.

Otro fenómeno que gravita para la DPLF en la deformación de la PP es la intervención oportunista, tanto de la clase política como de los medios de comunicación.

En la constitución del clima social, mayor importancia que los hechos mismos cobra la lectura que de ellos proponen determinados actores. Según muestran los estudios nacionales, entre éstos destacan las autoridades y los medios de comunicación [...], muchos políticos en la región han abrazado, haciéndose eco de los reclamos de una "aplicación estricta" de la ley en la que parecería no haber lugar para otra medida cautelar que la imposición de la prisión preventiva (Ibíd.: 8-9).

Existiría una exaltación por parte de la prensa de aquellos discursos de las autoridades políticas que pugnan por una utilización amplia de la PP, junto al aprovechamiento "electoralista" de dichas autoridades para exhibirse como enérgicos opositores a cualquier actitud indulgente respecto de los presuntos autores de delitos. En este sentido, hay una retroalimentación entre ambos actores que tiene como corolario 
una mayor restricción a la libertad de los imputados en procesos penales, transformando al encierro preventivo en una "política pública no escrita".

Por último, este documento alude a la debilidad institucional de los actores judiciales, la cual se encuentra atravesada por una cultura judicial proclive a la aplicación de la PP. Esto además tiene relación con el endeble respaldo que operadores jurídicos perciben de la organización en la que trabajan, sumado al temor de ser indicados o denunciados públicamente como compasivos en determinadas causas por no haber echado mano del recurso del encierro preventivo. Y la situación descripta es más delicada en contextos como el latinoamericano, puesto que en sus tradiciones judiciales la presunción de inocencia parece tener un lugar considerablemente frágil.

La investigación del CEJA que se concentra en la Argentina señala que la incidencia de los presos preventivos es contundente en el problema más general de las severas condiciones carcelarias, incidencia que o bien pasa inadvertida o bien se la toma como un elemento irremediable de la realidad penitenciaria. Este informe del año 2011 reclama responsabilidad a las autoridades judiciales al momento de dictar la PP, las cuales deben tener en cuenta los cupos de alojamiento disponibles para que proceda la medida cautelar. Como complemento perjudicial, se observa el ascenso de una retórica más intransigente con el delito de la calle,

Un discurso montado sobre la variable de la "inseguridad pública" generó renovadas presiones sobre sectores judiciales, bastante proclives a la utilización del encierro cautelar como primera respuesta del sistema, presiones que incluso se tradujeron en recientes reformas legales que apelaron al endurecimiento del régimen "cautelar" en búsqueda de supuestos beneficios para la seguridad pública (CEJA, 2011: 66).

A lo anterior, la investigación agrega los inconvenientes que ocasiona el hecho de que durante el proceso penal determinados actores, en particular policías y Fiscales, puedan imponerse sobre otros, como es el caso de los Defensores, favoreciendo de ese modo el uso de la PP. Concretamente, las prácticas policiales tienen un gran impacto en la configuración del encarcelamiento preventivo porque los Fiscales han delegado la tarea investigativa en las fuerzas de seguridad, siendo estas últimas "quienes en base a criterios propios organizan y definen la actividad de investigación y persecución criminal o, en su caso, mensuran en base a criterios propios la necesidad y posibilidades concretas de avanzar en la investigación de delitos" (Ibíd.: 107). 
También afirma el trabajo que existe una tendencia en los actores judiciales a justificar la necesidad de esta medida cautelar sin tomar en cuenta lo que la legislación solicita al respecto, es decir, sin demostrar la existencia en los hechos de los peligros procesales. Esto último se vuelve más grave por el hecho de que las medidas alterativas a la PP, como por ejemplo la presentación ante autoridad judicial o el arresto domiciliario, se usan escasamente. En definitiva, sostiene este estudio, se trata de un perfil organizacional como el del PJ que requiere una transformación profunda para que se consolide un uso razonable del encarcelamiento preventivo.

Así como lo vimos antes en el trabajo Waiting for Trial, otros informes a nivel nacional enfatizan cómo el encierro preventivo se vuelve en algunos procesos un elemento de "chantaje" para las personas que lo están sufriendo, ya que las obliga a aceptar juicios abreviados con todas las limitaciones que estos juicios implican ${ }^{27}$ :

El encierro procesal genera una afectación directa en las personas que condicionan su libertad de elección y su posibilidad de armar una defensa eficaz. En ese contexto, opera como un factor de extorsión en aquellos sistemas en los que se prevé un acuerdo de juicio abreviado amplio, en donde en la mayoría de los casos se termina acordando una pena que muchas veces es similar al tiempo que estuvo detenido bajo esa modalidad (INECIP, 2012: 69).

Por lo tanto, con este tipo de juicio se resuelve la situación procesal del imputado, permitiéndole en muchos casos salir de prisión antes de lo que podrían hacerlo de esperar un juicio ordinario. Pero en muchos casos, esta resolución se consigue a costa de confesar delitos no cometidos.

Asimismo se indican como factores que benefician la utilización de la PP el manejo arbitrario de nombramientos y ascensos dentro del PJ, a raíz de que las designaciones pueden relacionarse con prebendas más que con méritos concretos del aspirante. Esto daría lugar a que los actores judiciales queden debilitados frente a los "padrinos" que los promovieron, perdiendo autonomía a la hora de tener que decidir en las causas judiciales en las que intervienen. A lo que se suma el hostigamiento sobre los

\footnotetext{
${ }^{27}$ El juicio -o proceso- abreviado elimina buena parte del debate oral que se debería realizar en el juicio. Este juicio abreviado se lleva adelante al terminar la etapa de investigación cuando el imputado reconoce o confiesa el delito que le atribuye el Fiscal aún no habiéndolo cometido. El Fiscal fija un máximo de pena inferior a la que podría corresponderle al imputado si el delito se probara en un juicio ordinario. El acuerdo es consensuado por el Fiscal, el imputado y la defensa, y elevado para que un Tribunal dicte una sentencia con la única limitación de no superar el máximo propuesto por el fiscal.
} 
actores judiciales que muestren un criterio favorable a la libertad del imputado durante el proceso, ya que "no hay persecuciones por dictar prisiones preventivas pero sí por excarcelar" (Gutiérrez, 2013: 58). Se trata de un hostigamiento que puede provenir separada o conjuntamente de las víctimas de algún delito, de las autoridades políticas y de los medios de comunicación, y eventualmente culminar en un juicio político.

En los informes que toman como referencia a la PBA se asegura que el elevado número de presos preventivos está atravesado por el "humor social", por la débil fundamentación que realizan los Fiscales al solicitarla, y por la persecución que sufren los JG que aplican la medida cautelar de manera restringida (CIPPEC, 2011). Además, se indican otros dos factores que facilitan la expansión del encierro preventivo en el ámbito bonaerense: por un lado, la formación profesional de los operadores jurídicos en la que existe gran tolerancia hacia su uso. Por el otro, la selectividad congénita en la represión del delito, que criminaliza a imputados vulnerables con escasas posibilidades de evitar la PP (ADC, 2012). Dicho esto, es necesario subrayar que respecto a los documentos pertenecientes a la PBA sólo mencionamos aquí algunas conclusiones generales dado que serán retomados con más detalle al analizar el uso de la PP dentro de los expedientes en el cuarto capítulo de la tesis.

\section{3- La prisión preventiva como instrumento}

Existe una tercera perspectiva que desde las ciencias sociales pretende describir y explicar el incremento de la PP en particular, junto con el aumento de la tasa de encarcelamiento en general, como resultado de procesos más amplios. Esta perspectiva está arraigada en un presupuesto que es el de considerar a la medida cautelar mencionada como un instrumento de dinámicas sociales que se originan en lugares distantes al PJ. Es decir, que desde esta perspectiva la PP no es tomada como objeto de estudio en sí mismo, sino como un elemento que emerge a partir de otras causas "reales" que son las que le adjudican su lugar como herramienta de control.

Un ejemplo de esto es el trabajo de Bernard Harcourt (2012), quien expuso algunas de sus ideas sobre el uso de la justicia punitiva de tipo preventiva en su artículo Punitive Preventive Justice: A Critique. Allí, este autor afirma que

La prevención puede ser, y a menudo es, parte de la pena, sobre todo para aquellos que defienden las teorías de castigo de la disuasión, la corrección o la incapacitación. Al 
mismo tiempo, la pena puede ser, y a menudo es, parte de la prevención [...] Es esto lo que hace que "las medidas cautelares penales" resulten tan peligrosas (2012: 8-9, traducción propia).

En términos generales, Harcourt considera que este enfoque punitivo preventivo que viene promoviéndose en EE.UU. se halla plagado de dificultades, principalmente por apoyarse en análisis utilitaristas de costo-beneficio, los cuales no tienen correlación con lo que ocurre en la vida social. En segundo lugar, si bien este enfoque se muestra simple y atractivo, dicho autor afirma que se basa en un conocimiento técnico y científico que privilegia la eficiencia, desplazando a la política como herramienta para abordar los problemas sociales. Este alejamiento de la política se vuelve relevante porque cambia por completo la relación entre las ciencias sociales y las normas legales, dado que los instrumentos de predicción con los que trabaja este enfoque punitivo preventivo han sido "creados e impulsados por la sociología y la criminología. Surgieron de las ciencias sociales y, en este sentido, son completamente exógenos al sistema legal" (2013: 128). Esta ajenidad, sin embargo, no ha impedido que la predicción resultara una de las nociones fundamentales para intentar administrar un ámbito tan crítico de la sociedad como lo es el del castigo.

Por lo tanto, para Harcourt la PP en tanto medida cautelar penal debe ubicarse dentro de un proceso más amplio que ha sido estructurado por el nacimiento y la implementación de métodos actuariales hacia el interior de la justicia criminal, con los cuales se busca predecir el comportamiento delictivo de una persona concreta para luego suministrar una medida punitiva determinada.

Para el caso de América Latina podemos mencionar el planteo de Eugenio Zaffaroni (2006), según el cual se viene propagando en la región lo que este autor define como "autoritarismo cool":

La característica más saliente del poder punitivo latinoamericano actual en su aspecto prisionizante es que la gran mayoría -aproximadamente tres cuartas partes- de los presos se hallan sometidos a medidas de contención porque son procesados no condenados [...]. Cárceles superpobladas de presos sin condena, donde el aumento de escalas penales no importa mayores penas sino más prisioneros preventivos (porque impide la excarcelación) (2006: 72). 
Zaffaroni sugiere que el sistema punitivo en América Latina se pone en práctica a partir de técnicas de neutralización para personas sospechosas y peligrosas, lo que en los hechos consolida un derecho penal de peligrosidad presunta. Sustentándose en esta supuesta peligrosidad, se aplican castigos para el número más alto de la población encarcelada sin que formalmente existan fallos condenatorios. Como consecuencia, las garantías tradicionales del derecho penal liberal vinculadas a los Principios de Inocencia y Legalidad son dejadas de lado, apareciendo en su lugar sentimientos de miedo y venganza frente a la figura del enemigo. En definitiva, así como Harcourt situaba a la PP en el interior de métodos actuariales en la justicia criminal, este jurista la ubica como una técnica de la que se echa mano en un contexto de autoritarismo cool en el que rige un derecho penal del enemigo para el cual aquellas personas consideradas riesgosas gozan de una presunción de culpabilidad y no de inocencia.

Otro autor que propone una línea de análisis similar a la de Zaffaroni, aunque analizando el caso de la Argentina, es Esteban Rodríguez (2012), quien describe un Estado de Malestar cuya prisión

No saca de circulación individuos peligrosos sino contingentes de personas referenciados como productores de riesgo, es un dispositivo de tratamiento de stock de categorías completas de individuos (2012: 86).

En este Estado de Malestar, el elevado porcentaje de personas encarceladas en PP permite advertir la pereza intelectual y el clasismo de los actores judiciales. En primer lugar, JG que no desempeñan correctamente sus funciones de contralor de las garantías procesales durante la investigación. Como complemento, Fiscales que están habituados a solicitar la PP de manera irreflexiva más allá de las pruebas que haya en contra de los imputados. En definitiva, el fenómeno del encierro preventivo "nos está informando de la demagogia punitiva y la ideología conservadora y autoritaria que prima entre los legisladores y funcionarios de turno" (Ibíd.: 88). Sin embargo, sostiene Rodríguez, este fenómeno no se explica sólo por la inobservancia de las obligaciones de los actores judiciales y las autoridades públicas. Hay que indagar al mismo tiempo sobre el uso estratégico de la PP y considerarlo como una práctica metódica que contribuye a componer el ámbito penitenciario. Práctica que no tiene tanto que ver con los riesgos procesales como con una necesidad concreta de defensa social. Para Argentina como para la PBA, 
El encarcelamiento masivo preventivo, entonces, es una forma de contener el excedente poblacional, pero también, al mismo tiempo, de insertar a los grupos de personas en las diversas clases de riesgo de las cuales formarán parte en el futuro [... lo] que contribuye a producir una identidad vulnerable que precipita a las personas en una especie de espiral, conforme al cual el sistema se reasegura un circuito marginal para estas personas que incluyen sucesivas "entradas” en la comisaría y las cárceles (Ibíd.: 88).

Lo dicho por este autor ubica a la PP en una posición instrumental, que se encuentra determinada por las características del Estado de Malestar, el cual tiene la capacidad de orientar mancomunadamente a un conjunto diverso de actores como es el caso de políticos, policías, jueces, penitenciarios. Y como corolario de esta orientación realizada por el Estado de Malestar, grupos o categorías "completas" de individuos son gestionados y estigmatizados a partir del uso de la PP, garantizándole un destino de marginalidad forzoso.

En un ensayo sobre la función política de la PP a nivel nacional, Sebastián Van den Dooren (2008) se propone tomar distancia del enfoque jurídico de esta medida cautelar para señalar qué tipo de consecuencias concretas posee en la sociedad. Según este autor, desde un punto de vista normativo la PP se contrapone a los parámetros constitucionales, es la excepción a dichos parámetros, o es incluso la negación de dichos parámetros. No obstante, si nos esforzamos en analizar para qué sirve en concreto el encierro preventivo, es posible advertir que se trata de

Una de las instituciones funcionales por excelencia del estado de excepción, puesto que hace efectiva la regulación de las emergencias totalmente libre de estorbos garantistas. Las llamadas medidas de prevención, de seguridad, cautelares, o de policía, [instauran] un sistema punitivo paralelo al ordinario: un derecho penal y procesal administrativo, inferior [...]. En razón de sus presupuestos, de sus modalidades y de las dimensiones que ha adquirido la prisión preventiva -fruto de transformaciones a nivel de leyes aprobadas en los años de la emergencia y dirigidas a hacer de la prisión preventiva una medida cada vez menos excepcional y cada vez más automática- se ha convertido en el signo más evidente de la crisis de la jurisdiccionalidad, [...] y sobre todo, de su degeneración en mecanismos directamente punitivos. Con rasgos inconfundiblemente policiales, su objetivo de control devela el carácter de defensa social de ésta medida de prevención (2008: 12) 
El planteo de Van den Dooren sugiere que la PP es una medida cautelar que en un contexto político de emergencia como el actual, sirve para llevar adelante el control de poblaciones inestables o peligrosas. Por lo tanto, no se trata de una medida excepcional como lo sostiene la retórica jurídica, sino de una regla práctica. Este instituto permite visualizar cómo se busca, desde lo institucional, no tanto una declaración de culpabilidad bajo el cumplimiento de las garantías procesales de los imputados, como sí la efectividad en la neutralización de ciertos individuos o grupos. Según este autor, existe una redefinición del derecho penal que supone un cambio de objetivo: ya no se trata del individuo culpable a reformar sino de grupos peligrosos a gestionar. Y en este sentido, la PP es uno de los instrumentos por excelencia que permiten la eficacia de dicha gestión.

Máximo Sozzo (2007), al analizar el cambio, o mejor dicho la combinación entre los ejes discursivos y las prácticas concretas respecto de la prisión en Argentina, ubica el aumento del uso de la PP como uno de los indicios del asenso del populismo punitivo en nuestro país. Hablamos de combinación debido al énfasis del autor por definir en términos de "economía mixta" el presente de la cárcel, puesto que oscila entre un descendente proyecto normalizador, disciplinario o correccional, y otro ascendente de tipo securitario ${ }^{28}$.

Según Sozzo, a lo largo de las dos últimas décadas tanto a nivel nacional como en algunas provincias en particular, han surgido una serie de transformaciones que dieron lugar a un fenómeno que puede considerarse como populismo penal ${ }^{29}$. Uno de los elementos más importantes en este fenómeno es el cambio en la retórica y la legislación sobre el control del delito y la función de la prisión. En especial, el de la

\footnotetext{
${ }^{28}$ Estos proyectos presentados como "tipos ideales" pueden resumirse afirmando que el primero de ellos, el normalizador o correccional, postula la finalidad de lograr un cambio positivo en los individuos bajo tratamiento penitenciario por medio de componentes como por ejemplo la educación, el trabajo, el contacto con la familia, la religión. El segundo proyecto, de tipo securitario, renuncia a la pretensión transformadora del recluso dado que la cárcel tiene el propósito de neutralizarlo fundamentalmente, de allí la imagen de prisión-depósito. Al sugerir Sozzo la expresión "economía mixta" intenta pensar no tanto en términos de una radical ruptura, sino que los componentes que definió como propios del tipoideal de la "prisión-depósito" han estado siempre presentes en la "prisión real" en la Argentina, junto con los componentes asociables al tipo ideal de la "prisión resocializadora".

${ }^{29}$ El concepto "populismo punitivo" fue propuesto originalmente por Anthony Bottoms en 1995 en su artículo The philosophy and politics of punishment and sentencing. Por medio de este concepto sugirió la existencia de un uso instrumental del derecho penal por parte de los gobernantes que se asienta en la asunción de que la ciudadanía exige sanciones más severas hacia la delincuencia. A partir de allí ha tenido diferentes definiciones. Aquí nos interesa destacar, fundamentalmente, dos características que suelen atribuírsele: por un lado, la escasa relevancia que tienen en la elaboración de la política criminal los expertos tradicionales. Por el otro, el lugar preponderante que ocupa el control del delito en las contiendas electorales (Garland, 2005).
} 
apropiación de ambos temas por parte de las autoridades políticas, quienes desde un abordaje simplista proponen eslóganes sobre estas cuestiones que están destinados a acumular capital electoral. Otro elemento significativo es el del crecimiento sostenido de la población encarcelada en general, crecimiento que presenta en Argentina altos índices de presos sin condena. Este gran incremento de los presos sin condena es explicado por el autor como una combinación de modificaciones legislativas de corte más represivo junto a una cultura penal que profundiza este tipo de recetas. En concreto, existe una legislación más dura con una organización judicial decidida a aplicarla más rígidamente. Según sus palabras, se advierte "una marcada tendencia de los operadores de la justicia penal a recurrir en forma acentuada a la denegación de la excarcelación durante el proceso penal" (Sozzo, 2007: 557). Esto significa que la PP, su uso en principio desmedido, incluso su legitimidad simbólica en la sociedad, es interpretada como uno de los indicios del advenimiento del populismo punitivo.

\section{4- Nuestra hipótesis sobre la prisión preventiva}

Las contribuciones que acabamos de presentar son las que han configurado el problema de la PP, y que a su vez ofrecen una serie de argumentos con los que entraremos en diálogo a lo largo de esta tesis. Sin embargo, plantean algunos inconvenientes que trataremos de explicitar a continuación, para luego señalar nuestra hipótesis respecto al encarcelamiento cautelar.

\subsection{El límite de la dogmática y las ONGs}

En suma, consideramos que tanto la dogmática jurídica como los informes y documentos de las ONGs junto a los trabajos ligados a las ciencias sociales, tienen la particularidad de evaluar los diferentes procesos y efectos que ocasiona la utilización de la PP desde un enfoque restrictivo. O lo que es lo mismo, si bien lo hacen con propósitos distintos, las tres perspectivas caracterizan a esta medida cautelar por los perjuicios que genera al ser aplicada. Tal como lo sugería Foucault (2002) acerca de los discursos sobre la sexualidad en la época moderna, también para el encarcelamiento preventivo parece existir una "hipótesis represiva"30 que sobrevuela los distintos estudios que se han hecho sobre el mismo. Con esto queremos decir que aquello en lo

\footnotetext{
${ }^{30}$ La expresión "hipótesis represiva" utilizada por Foucault en el primer volumen de La historia de la sexualidad nos parece provechosa para resumir en líneas generales los trabajos que se han hecho sobre la PP.
} 
que se enfatiza es en los efectos negativos que motiva este instituto del derecho procesal penal, desatendiendo buena parte de las relaciones que produce.

Respecto al enfoque dogmático del encierro preventivo se advierte que la preocupación está centrada en aquello que no se hace como se supone tendría que hacerse, dejando de lado la descripción y explicación de por qué se hace lo que se hace y no lo que debería hacerse. Una proposición que puede servir como sumario de esta perspectiva sostendría que

Si se lucha contra la criminalidad por medio de la prisión preventiva y antes de la sentencia pasada con autoridad de cosa juzgada, se irrespeta el principio de inocencia, se le quita valor al procedimiento principal y se lesiona a una persona sin fundamento jurídico (Cabrera, 2005: 5).

Más allá de que se trate de una postura opuesta a la utilización del encarcelamiento preventivo, resulta ser una teorización del fenómeno que deviene insuficiente para apreciar su complejidad. Tal como afirman Baratta y Silbernagl,

A la emergencia que, al interior del sistema penal, justifica la suspensión de principios fundamentales de la cultura jurídica, la crítica [dogmática] contrapone la normatividad de un sistema penal basado sobre principios irrenunciables de garantía para el imputado, así como de técnicas de comprobación de la verdad: a las excepciones se contrapone la normatividad de la normalidad (1985: 561-2).

Por lo tanto, la dogmática de la PP tiene el objetivo y el mérito de establecerse como un límite frente a las trasgresiones de los principios y las garantías que deben proteger a los ciudadanos frente al Estado en las investigaciones penales. Sin embargo, para comprender lo que ocurre en los hechos con esta medida cautelar, el mérito que posee la dogmática se vuelve un obstáculo porque la referencia que utiliza son las representaciones ideales y normativas de principios y garantías formales.

Acerca de los numerosos trabajos que expusimos de diversas ONGs, tanto provinciales, nacionales como internacionales, podemos sostener que sus conclusiones resultan prácticamente unánimes respecto a los efectos de la PP. Se trata de una medida cautelar que por utilizársela abusivamente agrava las ya deplorables condiciones de encierro, todo lo cual es producto de determinaciones políticas irresponsables y 
cortoplacistas con un objetivo electoral predominante (CEJA, 2009; CIDH, 2013; CIPPEC, 2011). A todo esto, se suma la influencia cada vez mayor de los medios de comunicación en las decisiones que toman los operadores jurídicos al respecto, lo que contribuye a debilitar la independencia del PJ (DPLF, 2013; ADC, 2012). Si bien no es nuestro objetivo pronunciarnos sobre la verdad o falsedad de dichos argumentos, los cuales además necesitan ser evaluados jurisdicción por jurisdicción, sí podemos afirmar que tal como se los plantea, estos argumentos terminan eclipsando el modo en que se estructuran las asociaciones a las que da lugar la PP. En otros términos, estamos insinuando que esta perspectiva relega cómo es que se producen la serie de relaciones que genera el uso del encierro preventivo entre actores judiciales y extrajudiciales. Relaciones que, sin ir más lejos, producen o generan los estudios e informes que dichas ONGs elaboran para denunciar a la PP.

\subsection{El limite dentro de las ciencias sociales}

Tanto o más que los planteos previos de las ONGs y del dogmatismo jurídico, es el tercer enfoque sobre la PP el que le quita la especificidad al problema en cuestión, al menos tal cual nos proponemos abordarlo en esta tesis. Esto último sucede porque dicho problema es reenviado a variables que lo muestran como un efecto o un reflejo de procesos externos al ámbito judicial.

Con matices, los trabajos que reunimos en la perspectiva que indaga a la PP desde las ciencias sociales muestran influencias de tres tipos de formulaciones. En la primera de estas formulaciones, cercana a propuestas como las de Feeley y Simon, se percibe a la medida cautelar en cuestión como producto del fortalecimiento de racionalidades actuariales aplicadas a la represión del delito. Las muy divulgadas tesis de Simon y Feeley, principalmente las que proceden de La nueva penología, sostienen que se han producido cambios en los discursos, los objetivos y las técnicas dentro del ámbito penal, generándose como consecuencia una serie de estrategias novedosas. En sus palabras, esta constelación

No tiene como referencia al castigo ni a la rehabilitación de individuos. Se refiere a la identificación y manejo de grupos difíciles de controlar [...]. Su meta no es eliminar el delincuente, sino hacerlo tolerable a través de una coordinación sistémica" (1995: 39).

Por lo tanto, el objetivo central ya no es el individuo sino la clase sistemáticamente expulsada e ignorada, sin educación ni posibilidades de jamás 
integrarse al mercado laboral, de allí que "las discusiones acerca de las estrategias políticas [...] enfatiza el manejo de grupos de alto riesgo y hace menos relevante las cualidades de los delincuentes como individuos y sus comunidades" (Ibíd.: 52). Conjuntamente, la administración de justicia para medir su labor ya no tiene como referencia factores sociales externos, como podría ser la disminución en la tasa de delito o la resocialización de los apresados, sino que lo hace prestando atención únicamente a su propio desempeño. Se trata de una nueva racionalización tecnocrática que tiende a aislar a las instituciones de las indefinidas exigencias del mundo social que resultan difíciles de gestionar. Como consecuencia de esta nueva racionalización, limitan la evaluación a indicadores que dichas instituciones puedan controlar ${ }^{31}$. Si bien todos los textos que presentamos en el apartado La prisión preventiva como instrumento remiten en cierta medida a esta formulación, en concreto los trabajo de Harcourt $(2012,2013)$ y de Van den Dooren (2008) son los que reflejan una mayor permeabilidad.

La segunda de las formulaciones contenida en la perspectiva proveniente de las ciencias sociales considera que la PP es una herramienta con la que se consuma la neutralización de grupos o poblaciones excedentes que proliferan debido a los cambios estructurales en el mercado laboral. En este sentido, se observa una afinidad con diagnósticos de autores como Wacqüant. Una de las características del trabajo de Wacqüant, que va desde Cárceles de la miseria hasta Castigar a los pobres, es la de haber desplazado el problema del delito y la criminalización, ubicando a las políticas neoliberales en el centro de la explicación sobre la excesiva tasa de encarcelamiento en EE.UU. Su propuesta empieza en el texto Las cárceles de la miseria, donde el sociólogo francés afirma que la caída de las protecciones sociales en los estratos inferiores de la sociedad encuentra su complemento en el despliegue de un circuito fundamentalmente represivo, "pues a la atrofia deliberada del Estado social corresponde la hipertrofia distópica del Estado penal: la miseria y la extinción de uno tienen como contrapartida directa y necesaria la grandeza y la prosperidad insolente del otro" (2004: 88). Diez años después, Wacqüant prosigue su investigación sobre la relación entre neoliberalismo y penalidad en Castigar a los pobres. En la segunda parte de este libro

\footnotetext{
31 Dentro de la explicación sobre acutarialismo de Feeley y Simon está presente junto con la administración de la justicia penal el mercado de trabajo y el control de la población excedente. De hecho utilizan el concepto de underclass para graficarlo. Sin embargo, consideramos que es un enfoque con el que se puede atender en concreto el cambio en la función de la administración de la justicia penal. Y los trabajos que nosotros mencionamos lo toman como una referencia en ese sentido. Véase Young (2003), Castel (2006), Christie (1993), O’Malley (2006, 2010).
} 
explora modalidades e identifica dispositivos del ensanchamiento del Estado penal norteamericano, el cual

Ha surgido súbitamente, ha crecido vorazmente y se ha autosituado en el centro del horizonte institucional que se ofrece a los pobres de Estados Unidos [... y esto] porque la pobreza del Estado social en el marco de la desregulación necesita y exige la grandeza del Estado penal y porque esa relación causal y funcional entre los dos sectores del campo burocrático se fortalece cuando el Estado se despoja de toda responsabilidad económica y tolera un alto nivel de pobreza y de desigualdad" (2010: 48-9).

Este Estado penal se expande a partir de dos procedimientos fundamentales: uno que radica en reajustar los servicios sociales a manera de herramienta de control para los grupos más revoltosos, como por ejemplo la obligación de aceptar cualquier tipo de trabajo que le sea ofrecido a una persona, bajo pena de perder el derecho a la asistencia que recibe (workfare). El otro procedimiento tiene que ver con la utilización masiva y sistemática del encierro con el cual se intenta contener -e incluso neutralizar- en el ámbito ciudadano los inconvenientes que provoca la falta de trabajo o su precarización (Harcourt, 2011; De Giorgi, 2006; Alexander, 2010). Tanto el trabajo de Rodríguez (2012) como el de Zaffaroni (2006) parecen abrevar principalmente en una propuesta como esta.

La última influencia de la que se sirven los trabajos que desde las ciencias sociales analizan el uso de la PP es la de abordajes como los de David Garland, en particular algunas hipótesis que este autor formuló en La cultura del control (2005 [2001]). En este trabajo, el autor busca dar cuenta de una serie de mutaciones en la penalidad, concebida ésta en sentido amplio, que va de la modernidad a la modernidad tardía. En este proceso se observan un mayor escepticismo frente al ideal rehabilitador; un resurgimiento de sanciones bajo el signo de una expresividad simbólica; las transformaciones en los principios rectores de la política criminal -menos reflexiva y más emocional-; un inusitado protagonismo de la víctima -principalmente en términos discursivos-; la aparición del público como aquél que debe ser resguardado; y, como correlato, la electoralización de la cuestión criminal y la justicia penal. En el análisis 
que hace el autor escocés del campo del control del delito ${ }^{32}$ en Gran Bretaña y EEUU, asevera que entre 1890 hasta 1960 existió una confianza plena en la justicia penal para lograr derrotar al delito, apuntalada por un programa correccionalista cuyo adagio fundamental era el de rehabilitar a quienes habían trasgredido la ley. Pero promediando la década de 1970, esto comienza a atomizarse dando lugar a una nueva configuración del campo: la policía experimenta varias reformas y un renovado protagonismo por esa época; la criminalidad es utilizada como eje de debate en las campañas electorales; las nuevas directrices acerca de la represión del delito dejan de estar en manos de los expertos únicamente; la proliferación de los medios de comunicación se transforma en una nueva usina acerca de lo que el delito es y de cómo habría que enfrentarlo; la aparición rutilante de la víctima como la figura que representa tanto el sufrimiento de la parte integrada de la comunidad como la reivindicación de los valores ultrajados por la trasgresión. Para Garland,

Los fundamentos políticos, económicos y culturales que en el pasado sostuvieron el moderno control del delito fueron crecientemente erosionados por las tendencias sociales de la modernidad tardía y los cambios intelectuales y políticos que las acompañaron. Estas tendencias, a su vez, plantearon nuevos problemas, dieron nacimiento a nuevas percepciones y moldearon diversas adaptaciones prácticas, de las que gradualmente surgieron las prácticas de control del delito y de la justicia penal del período actual (2005: 140).

Sintetizando el planteo de Garland, la policía, la politización de la política criminal, el papel de la experticia, los nuevos soportes comunicacionales y la víctima como figura simbólica, dejan de ser lo que eran, por lo que actores, relaciones y posiciones en el campo del control del delito necesitan ser reevaluadas (Pratt, 2007; Zimring, 1996; Haggerty, 2004). Para quienes utilizan este tipo de planteo al evaluar el uso de la PP en nuestro contexto, como es el caso de Sozzo (2007) primordialmente, dicha medida es un emergente de los cambios ocurridos entre los respectivos actores, relaciones y posiciones.

\footnotetext{
${ }^{32}$ Garland define el campo del control del delito y de la justicia penal como "un dominio relativamente diferenciado, con su propia dinámica y sus propias normas y expectativas hacia las que los agentes penales orientan sus conductas. Los determinantes sociales y económicos del «mundo exterior» afectan a la conducta de los agentes penales (funcionarios policiales, jueces, funcionarios penitenciarios, etcétera), pero lo hacen de modo indirecto, a través de la modificación gradual de las reglas de pensamiento y acción de un campo que tiene lo que los sociólogos llaman una «autonomía relativa»" (2005: 66).
} 


\subsection{La prisión preventiva como consecuencia}

Resumiendo las tres perspectivas que señalamos a lo largo de este capítulo, lo que se percibe es la intención de analizar al encierro preventivo, su incremento en especial, como un elemento que sólo cumple funciones negativas hacia el interior de un régimen jurídico penal, y no como una práctica concreta que genera relaciones entre actores judiciales y no judiciales. En términos de Bruno Latour (2008), las perspectivas que mencionamos proponen considerar a la PP como un intermediario, es decir, como un factor que traslada un impulso o una "fuerza social" sin modificarlos. Si estamos en condiciones de conocer la funcionalidad del encierro preventivo, se puede derivar de ello la explicación del fenómeno en su conjunto.

Nosotros asumiremos una posición distinta frente a la PP y es la de definirla en primer lugar por lo que produce, es decir, por lo que es capaz de articular. Y para desarrollar nuestra posición será necesario identificar los diferentes quehaceres y relaciones que origina, por un lado, entre los mismos actores judiciales, y por otro, entre dichos actores judiciales y determinados actores extrajudiciales. Esto significa que las prohibiciones, los rechazos, las censuras y las denegaciones que la hipótesis represiva sobre la $\mathrm{PP}^{33}$

reagrupa en un mecanismo central destinado a decir no, [serán consideradas] piezas que tienen un papel local y táctico que desempeñar en una puesta en discurso, pero que están lejos de reducirse sólo a un papel opresivo (Foucault, 2002: 20).

Más allá de no negar las secuelas perjudiciales que desencadena la utilización del encierro preventivo en concreto, nosotros analizaremos a la PP a partir de las asociaciones que hace posibles en los expedientes y en las audiencias. Esto último implica que la medida cautelar en cuestión no podría circular como circula si no fuese producida por medio de justificaciones, críticas, tomas de posición y decisión, a partir de los intercambios que se despliegan hacia adentro del PJ, y entre los actores del PJ y algunos actores extrajudiciales. La PP no es sólo un instituto que cumple un papel

\footnotetext{
${ }^{33}$ Sugerir la idea de una hipótesis represiva sobre la PP no significa soslayar algunos efectos que las perspectivas presentadas a lo largo de este capítulo mencionaron y que podrían considerarse "efectos positivos" de la PP. Ejemplo de lo dicho podría ser que la PP produce más juicios abreviados, produce más hacinamiento penitenciario, etc. Sin embargo, en la explicación de estos "efectos positivos" se prescinde de lo que estructura nuestra tesis: las relaciones que esto último genera entre actores judiciales entre sí, y entre estos y actores extrajudiciales.
} 
instrumental, ni es un instituto "fungible" cuyas competencias podrían ser desempeñadas por cualquier otra disposición judicial. Para que el encarcelamiento preventivo exista como existe resulta necesario que los actores hagan algo con él, que lo utilicen para validar sus demandas, sus objeciones, sus promesas, sus resoluciones. Parafraseando a Latour $(1992,2008)^{34}$, sugerimos que la PP no es tanto una sustancia como un movimiento, porque a diferencia de lo que parece proponer la hipótesis represiva que describimos previamente, las cualidades de la PP son una consecuencia, y no la causa, de la acción colectiva dentro y fuera del PJ.

\section{5- A modo de cierre}

En este capítulo hemos hablado de las tres perspectivas que han trabajado el problema de la PP a nivel internacional, nacional y provincial. En primer lugar vimos la relevancia que tiene para el enfoque dogmático del encarcelamiento preventivo el Principio de Inocencia y las disputas históricas que se han dado entre dicho encarcelamiento y dicho Principio. Consideramos que este enfoque dogmático se concentra fundamentalmente en informar que no pasa aquello que debería pasar según lo postulan las normas jurídicas, dejando de lado elementos que podrían contribuir a comprender por qué pasa lo que pasa respecto a la PP.

Luego señalamos cómo distintos documentos e informes provenientes de diferentes contextos revelan un cúmulo de regularidades al analizar el problema del encarcelamiento preventivo. Más allá de sus particularidades en Europa, EE.UU., América Latina, Argentina y en especial la PBA, se puede hablar de la PP como una medida cautelar poco peculiar. Si bien esta segunda perspectiva se encarga de llevar adelante un importante trabajo de denuncia y visibilización de las consecuencias del fenómeno, impide distinguir cómo se configuran las asociaciones a las que da lugar la PP. O lo que es lo mismo, prescinde de explicitar el modo en que se generan la serie de relaciones que el uso del encierro preventivo produce a diario entre actores judiciales y extrajudiciales.

\footnotetext{
${ }^{34}$ Así como lo propone Latour para lo social, nosotros creemos que se puede plantear para la PP: "El adjetivo "social" designa dos fenómenos por entero diferentes: es a la vez una sustancia, una especie de materia y también un movimiento entre elementos no sociales. En ambos casos, lo social desaparece. Cuando se lo toma como un sólido, pierde su capacidad de asociar; cuando se lo toma como fluido, lo social nuevamente desaparece porque destella sólo por un instante, justo en el momento fugaz en el que nuevas asociaciones están amalgamando lo colectivo [...]. Lo social solo es rastreable cuando está experimentando modificaciones" (2008: 227).
} 
En tercer lugar, presentamos la perspectiva que desde las ciencias sociales ubica a la PP como producto de procesos más vastos. Esto significa que la medida cautelar es considerada un instrumento de dinámicas sociales que se engendran en esferas lejanas a la institución judicial. En consecuencia, desde este enfoque la PP no es tenida en cuenta como objeto de estudio en sí mismo, sino como un fenómeno que emerge a partir de otros motivos "reales", que son los motivos que le confieren su papel en tanto herramienta de control.

Por último, ofrecimos nuestro punto de vista según el cual la PP debe definirse primeramente por lo que produce, por lo que está en condiciones de generar, para lo cual es imperioso rastrear las tareas y las relaciones que motiva, por un lado, entre los mismos actores judiciales, y por el otro, entre los actores judiciales y determinados actores extrajudiciales. 


\section{SEGUNDA PARTE}

\section{CAPITULO II \\ La prisión preventiva fuera de los márgenes judiciales}

En el presente capítulo describiremos y analizaremos a una serie de actores que por afuera del PJ intervienen en la estructuración del problema de la PP. En concreto, presentaremos algunas de las relaciones que el encarcelamiento preventivo guarda con la policía, los medios de comunicación, las autoridades políticas y determinadas ONGs. Existen actores que pueden influir en el uso cotidiano de esta medida cautelar, como es el caso de la policía, los medios de comunicación y las autoridades políticas. Otros actores lo hacen configurando a este instituto como un problema público, tal es lo que sucede con determinadas ONGs. El propósito de esta segunda parte es dejar en claro que si bien la PP se resuelve dentro del ámbito judicial, de ningún modo puede subsumírsela por entero a este ámbito.

Respecto a la policía y los medios de comunicación, no haremos un análisis pormenorizado de cada uno de ellos sino que señalaremos cómo perciben y evalúan su desempeño los operadores jurídicos, ponderando sus propias inquietudes al respecto ${ }^{35}$. Sobre las ONGs y los representantes políticos se incorporarán, además, declaraciones, propuestas y documentos que complementen los testimonios de dichos operadores.

\section{1- La policía}

La policía en la $\mathrm{PBA}^{36}$ es la que comienza la mayoría de las investigaciones penales que posteriormente pueden dar lugar a la aplicación de la PP. Tal como dijimos en la introducción de la tesis, según el Informe que presentó la Procuración General de la PBA sobre 2013 el $90 \%$ de los individuos encarcelados fueron aprehendidos sin una

\footnotetext{
${ }^{35}$ La decisión de no estudiar ni a la policía ni a los medios de comunicación en concreto obedece, además de al objetivo de nuestra tesis que es el de analizar el uso de la PP en la PBA, a que llevar adelante un trabajo de campo sobre estos actores hubiese sido de muy difícil concreción.

${ }^{36}$ La policía de la PBA es la fuerza de seguridad más grande del país. En la actualidad tiene un número de efectivos cercano a los 60.000. A su vez, según el gobernador D. Scioli, "Proyectamos a los 60 mil policías que tenemos, seis mil policías más por año. En cinco años podemos tener estimados esos índices". De esta manera, se incorporarían a la fuerza 30 mil nuevos efectivos. Diario La Nación (7-92013).
} 
orden judicial previa. Si bien no hay datos inequívocos, la mayoría de este $90 \%$ son producto de la actividad policial ${ }^{37}$. Un experto que se desempeñó como Subsecretario de Seguridad en el ámbito bonaerense nos manifestó lo siguiente:

"La puerta de entrada, el procesamiento del conflicto en concreto, es la bonaerense. Y tenés que tener en cuenta que trabaja como una burocracia, por lo que necesitan justificar su trabajo".

En esto coinciden también los actores judiciales que hemos entrevistado, es decir, en que la policía inicia con su accionar el número más elevado de las investigaciones penales preparatorias (en adelante, IPP). Sin embargo, estos actores mostraron diferencias al ser consultados por el desempeño de esta fuerza de seguridad, diferencias que en parte pueden interpretarse como consecuencia de la división judicial del trabajo. Esta división que por un lado estructura el fenómeno de la PP dentro del PJ, además contribuye para que el trato de los Fiscales, Defensores y JG con la policía no sea el mismo.

Los Fiscales son quienes tienen mayor acercamiento con esta fuerza de seguridad, puesto que en el desarrollo de la IPP la policía es su auxiliar ${ }^{38}$. La imagen que ofrecen los Fiscales de la policía es la de una institución vinculada a garantizar el cumplimiento o la aplicación de la ley, a la que se le debe exigir principalmente que actúe conforme a derecho, de modo previsible (Sozzo, 2005: 176-177, 229). Es el caso de los siguientes testimonios:

¿¿Policías?, hay buenos y malos. Son los funcionarios públicos que menores ingresos tienen en la administración. Y si vos pensás que a los jueces no se les descuenta ganancia [...]. Tiene que estar bien pago, no es que mal pago se justifica pero genera tres consecuencias: les falta educación y deben tenerla para comprender la ley, además deben no ser influidos por la miseria que los rodea, como en la serie policías en acción [...], que todo eso no les nuble el juicio. Y tienen pánico porque no quieren disparar; no se les cree lo que dicen o escriben. Como trabajadores no se sienten ni están respaldados, eso los hace trabajar mal. El 95\% de las causas que llegan a sentencia es

\footnotetext{
${ }^{37}$ El porcentaje de casos que comenzaron con la intervención policial según los 29 expedientes que leímos y las 47 audiencias que presenciamos es del $83 \%$.

${ }^{38}$ El Art. 56 del Código Procesal Penal de la Provincia afirma que los Fiscales son quienes promoverán y ejercerán la acción penal de carácter público dirigiendo a la policía en función judicial en la IPP. Véase también los Arts. 59 y 268 del mismo Código.
} 
por ellos y no por nosotros. Con las falencias que tienen, igual es muy importante su trabajo" (Fiscal de Instrucción, Departamento Judicial La Plata).

"Desde el Ministerio Público Fiscal estábamos con intención de mejorar la relación con la policía, lo que no significa llevarse mejor, sino optimizarla. Nunca me incliné por la cagada a pedos mal porque el policía es un negro, porque es un ignorante, pero tampoco pasar por boludo delante de ellos. Respecto a cómo trabaja la policía comparto los prejuicios [risas]. Con la reforma del ' 98 el problema es que muchos fiscales, imberbes, empiezan a ocupar el lugar que antes tenía la policía [...], consecuencias que no sé si estuvieron del todo previstas. Otra cosa son las purgas que si no se sabe administrarlas generan mano de obra desocupada [...], hay que tener en cuenta la exposición a la violencia del policía, sobre todo del de calle, no hay atención suficiente a ellos. No se los contiene: al día siguiente de un tiroteo, capaz tiene que ir a trabajar igual. Hay que distinguir si el accionar policial evita un delito de si eso luego da lugar al inicio de una causa judicial. Porque si tratamos al policía como un no-humano luego se comportará como una bestia" (Fiscal de Instrucción, Departamento Judicial de Mar del Plata).

Para estos operadores jurídicos, los problemas en cuestión son aquellos "problemas que debe enfrentar el policía", desde sus bajos recursos tanto económicos como intelectuales pasando por la gran exposición pública que padecen debido a su trabajo, hasta la escasa protección que tienen por parte del Estado. Según los testimonios citados, se trata de una contradicción en la que el policía, principalmente el de menor jerarquía, se encuentra envuelto a diario, que se expresa en el maltrato que éste recibe -de la sociedad y de la propia institución- y en el maltrato que reproduce, en el "disparo o no disparo" que lo desconcierta por miedo a sanciones. En definitiva, se observa en los Fiscales lo que Philippe Corcuff define como un régimen de compasión, o con sus palabras,

Lo que llamamos interpelación ética en el cara a cara, es decir, el hecho de tener un sentimiento de responsabilidad frente al otro [...] ese sentimiento de sentirse responsable de algo de lo cual no se es propiamente responsable (2010: 32; 2013: $125)^{39}$.

\footnotetext{
${ }^{39}$ Según Corcuff (2010), la noción de compasión fue utilizada porque era una palabra más conocida y entendida por todos, pero en su grupo de investigación apelaban a una expresión técnica que era la de "interpelación ética en el cara a cara".
} 
Más allá de que exista una fuerte dependencia de los Fiscales respecto del trabajo policial, en el trato cotidiano parece imponerse un vínculo cara a cara que se encuentra forjado más en la conmiseración que en la utilidad.

La postura más distante a la de los Fiscales es la de los Defensores, que son quienes expresan mayores críticas a la institución y para quienes la policía tiene una influencia perjudicial que en ciertos casos resulta decisiva. Esta fuerza de seguridad ejerce un tipo de control amplio e indeterminado que se asemeja, al menos en parte, a la antigua policía descripta por Foucault (2004: 374) que se encargaba del espacio de circulación y de las relaciones recíprocas entre los hombres. Además, la mayoría de estos actores judiciales concuerdan con las denuncias que realizan distintas ONGs sobre los métodos violentos que se encuentran arraigados en la labor policial (et al., CELS, 1998). Muchos de estos actores mencionaron la capacidad de los integrantes de esta fuerza para elaborar versiones falsas de los hechos que investiga, como también el ocultamiento, destrucción o fabricación de pruebas que contribuyan a desligar a agentes de policía comprometidos en alguna ilegalidad. Según los Defensores:

"El actor más importante es la policía, es la que convierte lo que la legislación y los medios definen como delito en una persona presa, y si vos querés, con prisión preventiva. Todos estamos en contra de los desarmaderos, pero si la policía no avanza, no pasa nada. No hay policías ingenuos, el ingenuo va como ordenanza al Poder Judicial [...]" (Defensor Oficial, Departamento Judicial de Quilmes).

"Yo recuerdo que la discusión seria sobre la cuestión de la seguridad en la provincia se da alrededor del año 1997. Hubo una serie de episodios graves que pusieron en crisis el gobierno de la provincia, elevado al grado de conmoción: la muerte de Cabezas y su esclarecimiento, y la vinculación de la AMIA con la bonaerense [...]. Esto obligó a que el gobierno dé alguna respuesta a la corrupción y el abuso policial, y esto se vincula con el protagonismo que históricamente tuvo la policía respecto del tema de la seguridad. El aparato penal: la policía, el Poder Judicial, la Legislatura, el SPB, se vio alterado, y se puso en riesgo la gobernabilidad, en primer lugar, por lo de Cabezas" (Defensor Oficial, Departamento Judicial de La Plata).

Alguno de los Defensores, como es el caso de éste último testimonio, señalan a la policía no sólo porque fomenta nichos de impunidad debido a la manipulación de pruebas o versiones falsas en determinados casos. También consideran que está en 
condiciones de promover crisis sensibles en el ejercicio del Poder Ejecutivo en general, y en el área de seguridad en particular.

Por último, los JG también plantean objeciones sobre la actuación policial como lo hacen los Defensores, pero las matizan con argumentos de tipo "estructuralistas". La policía es un componente de la seguridad pública relacionada y subordinada al gobierno estatal, el cual es responsable de fijar su doctrina, su organización y su funcionamiento (Saín, 2008: 85). En este sentido, los JG ven a la institución policial como producto del problema de la corrupción y los abusos, y no como su causa, apuntando al Estado y al poder político indistintamente como los máximos responsables:

"El desempeño de la policía deja mucho que desear en el contexto de la reforma procesal penal, ya que se trata de una agencia que no ha logrado renovarse en sus estructuras y sigue aportando a una concepción militarizada de la seguridad. [...] tiene mucha importancia en los procesos de selectividad del sistema penal porque en términos generales es quien define qué casos ingresarán al sistema. Igual, buena parte de esta responsabilidad es del poder político, que no ha sabido, no ha podido o no ha querido impulsar políticas de transformación a su respecto y, muy por el contrario, ha exhibido una línea zigzagueante en un tema de semejante trascendencia que va de Arslanián a Casal, pasando por Rico" (JG, Departamento Judicial de Mar del Plata).

"En la labor de la policía incide fuertemente la opinión pública junto a la agenda mediática y también la relación entre el comisariato y el poder político. Estos elementos sensibilizan a la policía, pero la condicionan de forma muy limitada, porque hay condiciones materiales fuertes: un policía de la bonaerense no está preparado para detectar un delito de cuello blanco [...]. Está comprobado que el patrullaje no previene el delito, pero sino patrullás estás muerto, porque es el elemento simbólico de que el Estado está presente. $\mathrm{Y}$ esto es un mito también, porque el Estado ya no es ni el más importante ni el mas eficiente proveedor de seguridad" (JG, Departamento Judicial de Quilmes).

Por lo tanto, para los JG la agencia policial debe analizarse en relación a otros actores y procesos que configuran su actividad, principalmente a las oscilaciones del poder político respecto al problema de la seguridad pública. 
Resumiendo, lo que surge de este apartado es una confirmación de aquello que señalamos en la introducción de esta tesis cuando hablamos de un predominio de la actividad policial por sobre la judicial durante la IPP. Esto significa que si bien la aplicación de la PP para los imputados por algún delito se resuelve en el PJ, esta resolución está precedida en la mayoría de los casos por el trabajo policial. Es este último el que generalmente da inicio a las causas en las cuales puede llegar a ser utilizado luego el encierro preventivo. Y según los testimonios que recogimos de los actores judiciales, este desempeño policial es evaluado, principalmente, a partir de las tareas que dichos actores realizan en el proceso. Por un lado, encontramos una crítica enérgica a esta fuerza de seguridad propia de los Defensores. Por otro lado, una mayor compasión ligada a los Fiscales. Por último, la subordinación de esta fuerza al espacio político que revelaron los JG, ofreciendo una mirada relacional.

\section{2- Los medios de comunicación}

En el desarrollo de las primeras entrevistas, un número elevado de operadores jurídicos mencionaron motu propio a los medios de comunicación como uno de los factores que condicionaba la administración de justicia en general, y el uso de la PP en particular. Con el objetivo de mantenernos cerca de las formulaciones e interpretaciones de los actores, subordinando nuestras inquietudes a la de los operadores jurídicos (Boltanski, 2000), nos propusimos recabar y organizar los argumentos que ofrecían acerca de este fenómeno ${ }^{40}$ sin considerar lo que los medios de comunicación presentan sobre la $\mathrm{PP}^{41}$.

En este sentido, las entrevistas han sido una técnica imprescindible para analizar la relación que, según los actores judiciales, se establece entre los medios de comunicación y la PP. Esto es así porque en los expedientes y en las audiencias ${ }^{42}$, que

\footnotetext{
${ }^{40}$ La literatura especializada afirma que en la actualidad, las personas tienen a los medios como una fuente primaria de información sobre la delincuencia, especialmente la televisión, que se expandió como objeto doméstico y contribuyó a que su auditorio esté en condiciones de registrar las noticias nacionales en detrimento de las locales, teniendo el delito un sitio cada vez más destacado y la figura de la víctima, un ascendente protagonismo (Pratt, 2007: 66; Garland, 2005: 263; Vilker, 2006: 96). Este fenómeno, que excede al ámbito de la PBA, ha permitido que se considere a los medios de comunicación como interlocutores eficaces respecto al fenómeno criminal, tanto para azuzar los pánicos morales (Young, 2011: 7-20) como para neutralizarlos (Kessler, 2009: 158). En palabras de Young, "la clave central para la valoración de las noticias es [...] lo atípico: aquello que sorprende, que está en contraste con lo que se concibe como normalidad cotidiana" (2012: 202).

${ }^{41}$ Un análisis del abordaje periodístico sobre la PP puede verse en INECIP (2012: 93). De cualquier modo consideramos que es una exploración que debería profundizarse en el futuro.

${ }^{42}$ En los capítulos IV y V de la tesis se analizarán los fundamentos que los operadores jurídicos ofrecen para la aplicación de la PP en los expedientes y en las audiencias, respectivamente.
} 
es donde en términos formales se decide sobre la medida cautelar, no existe la posibilidad de explicitar esa relación. Dicho más concretamente, cuando los Fiscales, Defensores y JG judiciales solicitan, objetan, aceptan o deniegan la medida cautelar, no pueden fundamentarlo en la "presión" que ejercen los medios sobre ellos mismos o sus colegas.

Como resultado de las entrevistas se puede indicar, en primer lugar, que no existe unanimidad entre los actores al señalar el nivel de influencia que los medios de comunicación tienen en el uso de la PP. Y en segundo lugar, que en esta falta de conformidad no juega un papel relevante la división del trabajo judicial entre Fiscales, Defensores y JG como vimos para el caso de la policía. A partir de los testimonios, elaboramos tres modelos generales en los que podrían agruparse los distintos argumentos. Uno de estos modelos, que podríamos definir como el de la "prensa hegemónica", es el que considera muy influyentes a los medios de comunicación sin la necesidad de agregar matices o especificaciones. La prensa ${ }^{43}$ es presentada como un factor determinante, en el sentido de fijar límites y ejercer presiones (Williams, 2009), para explicar la utilización de la PP. Dado que su incidencia es reconocida abiertamente, los medios de comunicación están lejos de poder ser considerados como un componente misterioso u oculto al que deba desentrañarse laboriosamente.

\begin{abstract}
"Mi percepción es que su influencia es absoluta. No tengo modo de probarlo, pero creo que sí. Por ejemplo, el caso de la Hiena Barrios, se seguía de acuerdo a lo que se decía afuera, tenías una Fiscal que le pidió una detención, y la Jueza de Garantías se la concedió. La Cámara la mató a la Jueza de Garantías que pensó que eso era lo correcto. La Cámara le pega porque dice que no se puede pedir prisión preventiva para un delito culposo que nunca habías dictado. Entonces, la Jueza de Garantías hizo la lectura del afuera, y la Cámara otra. Y la Fiscal lo hace por dolo eventual sabiendo que no lo es, pero lo hace para mostrarse más cerca de las victimas. Y la Fiscal armó una causa y va a perder el juicio" (Defensor Oficial, Departamento Judicial de Mar del Plata).
\end{abstract}

"Los medios influyen claramente sobre los Jueces. Es la mayor presión que hay actualmente en el PJ. Es por la forma grosera e ignorante que informan los hechos. Influyen en un $95 \%$ en las decisiones. Yo sé que en los Ministerios de Justicia y

\footnotetext{
${ }^{43}$ Si bien "prensa” y "medios de comunicación” no son sinónimos para la literatura especializada, aquí los utilizaremos como tales.
} 
Seguridad se gastan una millonada en los informes de prensa" (Fiscal de Instrucción, Departamento Judicial de La Plata).

"Sin duda que [la prensa] opera en quien tiene que decidir. Nadie quiere verse en los diarios después de haber resuelto sobre una prisión preventiva" (JG, Departamento Judicial de La Plata).

Por lo tanto, si bien los medios de comunicación informan de manera inexacta las cuestiones jurídicas, "fuerzan" a los actores judiciales a solicitar y conceder la PP principalmente debido al temor que estos tienen de ser identificados y señalados por aquellos.

En otro de los modelos, más cercano a lo que denominaríamos "voluntarismo judicial", los medios de comunicación son vistos como un factor a tener en cuenta pero que es posible contrarrestar, incluso neutralizar, si el operador jurídico enfrenta las embestidas de la prensa. Aquí, los testimonios no definen a ésta última como portadora de una influencia determinante, sino a los actores judiciales como virtualmente capaces de ponerles límites.

"[...] creo que los Jueces profesionales convencidos íntimamente de que el garantismo penal es la única opción posible en un Estado de derecho, en su gran mayoría no atienden a la presión mediática. Nuestro sistema judicial nos ha dado innumerables ejemplos de Jueces o Tribunales que no han sido presa de esta criminología mediática. Vayan como ejemplos los casos de las absoluciones en el juicio "Amia", las excarcelaciones en el caso "Cabezas" e innumerables casos más que cada uno de nosotros podría mencionar de su ámbito de incumbencia profesional. Si bien los medios están, lo que resulta necesario para que influyan es la debilidad del Juez" (Fiscal de Instrucción, Departamento Judicial de La Plata).

"Y, depende de la personalidad del Juez de Garantías o del Fiscal, no debería influenciarte para que hagas las cosas de manera distinta a la que pensás. Yo tuve presiones: la no detención de X acusado por la Fiscalía del triple crimen X. El día de las elecciones nacionales había un pedido expreso del Gobernador y del Ministro de Seguridad X que era el imputado el que había cometido el crimen. Me amenazaron con un juicio político, y yo no le di la detención porque no estaban los elementos necesarios en aquel momento. Y sabemos que no es simpático tener a los medios en contra, cuando sabemos cómo se manejan... el poder político es el manejo de la prensa, porque es muy 
difícil que los medios oficiales no estén contestes a los gobiernos de turno, algunos se la aguantan y otros no" (JG, Departamento Judicial de La Plata).

En este modelo la prensa aparece como un factor que entra en disputa por el control de las decisiones dentro de la institución judicial. La idea de que "Jueces profesionales convencidos íntimamente no atienden a la presión mediática" o de "que no es simpático tener a los medios en contra" permiten concluir que la prensa interviene. Sin embargo, termina siendo más decisivo "la debilidad del Juez, o lo que es lo mismo, "quién se la aguanta y quién no".

El tercer modelo, más crítico que los dos anteriores, considera a los medios de comunicación como una "astucia" que los mismos operadores jurídicos manipulan para evitar los compromisos y las responsabilidades que tendrían que tener en el trabajo dentro del PJ respecto de la PP. Se subraya la falta de oposición que existe al statu quo sobre el uso de esta medida cautelar, dándole un lugar subsidiario a la prensa en relación a las rutinas judiciales.

"Respecto de los medios, creo que es falso que influyan tanto, creo que es una especie de autojustificación ideológica. Influyen, pero no en los niveles que ellos mismos sostienen. Sin los medios, en lugar de $75 \%$ habría $70 \%$ de prisiones preventivas. No es un elemento decisivo, es ideológico. No son condiciones externas, sino internas: conozco jueces que son absolutamente reactivos a la prisión preventiva, que no quieren dictarla, pero son incapaces de enfrentarse a las variables que empujan dentro del sistema. Es por el habitus, no por pereza" (JG, Departamento Judicial de Mar del Plata).

"Respecto de los medios, llegaron corriendo al Poder Judicial por izquierda, como en el caso María Soledad, o Yabrán [...], por más que ahora lo corran por derecha. A Schiavo lo atacaron primero los políticos, no los medios. La influencia de los medios forma parte de su imaginario. La cuestión es que antes, al ser una familia cerrada, todo se podía resolver hacia adentro del Poder Judicial. Es por eso que son más vulnerables, no por los medios. Ahora no tiene menos independencia el Poder Judicial que antes, sino que son más, y se pelean más. Ya no pueden resolverse los conflictos hacia adentro sin hacer olas [...]" (Defensor Oficial, Departamento Judicial de Quilmes).

Los medios de comunicación no aparecen aquí como un componente autónomo en la conformación del problema de la PP, por el contrario, son utilizados para que 
componentes como la propia incapacidad o la mayor vulnerabilidad queden postergados o invisibilizados. En otras palabras, los medios aquí son un recurso argumentativo para que si los actores judiciales en determinada circunstancia no están dispuestos a tomar una decisión, no la tomen.

Con los modelos descriptos es posible comprobar que la influencia que los actores judiciales le adjudican a los medios de comunicación es diversa. Y la importancia de presentar dichas variantes estriba en que permite apreciar las particularidades del problema de la prensa y complejizarlo. Si bien puede afirmarse que existe una influencia creciente de los medios de comunicación en el PJ, dicho incremento se lo debe postular siempre que se ofrezcan comprobaciones al respecto. $\mathrm{Y}$ tal como lo señala Latour (2008), para brindar comprobaciones de esta naturaleza las escalas que presentan los actores resultan imprescindibles. Si descuidamos éstas escalas se puede caer en desconexiones interpretativas (Lahire, 2006) que nos concedan postular el influjo de los medios de comunicación sin la necesidad de demostrarlo. Un ejemplo significativo en el que puede observarse una desconexión interpretativa en la relación entre los medios de comunicación y los operadores jurídicos es el de la “criminología mediática”, propuesta por Eugenio Zaffaroni. El público, afirma este jurista,

Reclama cada vez mayor represión por efecto de una criminología mediática que no es fácil detener, porque responde a demasiados intereses generados por ella misma, como todas las industrias de seguridad [...]. Nadie con cierta experiencia judicial puede leer muchos expedientes sin reprimir la sensación de que, fuera del círculo de autores violentos -y aun entre éstos- cada condenado parece más tonto y torpe que otro [...]. En definitiva $-y$, por supuesto, sin subestimar el daño que causan-, creo que en la enorme mayoría de los casos estamos prisionizando a torpes desconcertados y no a quienes eligieron en plenitud. Por el peso de la criminología mediática se llenan las cárceles con un tercio de personas sin condena, o sea, con torpes cuyo delito no ha sido probado (2011: II-IV).

Frente a la sugerencia por parte de Zaffaroni de una "criminología mediática" omnipotente y anónima, cuya existencia se presupone sin demostrarse en concreto, los modelos que presentamos ofrecen una imagen variada de los medios de comunicación. Estos últimos no poseen una capacidad productora autónoma, no pueden intervenir en el 
vacio, erigiendo en problema algo que no es percibido como tal por parte de los actores judiciales, incluso por la sociedad en general. Lo que sí pueden hacer los medios de comunicación, y esto lo confirman algunos testimonios que presentamos, es redefinir ciertos problemas en caso de que existan elementos de interés compartidos. En definitiva, los testimonios de los actores judiciales debilitan la imagen de un PJ avasallado por los medios de comunicación, principalmente en torno al uso de la PP.

\section{3- Las autoridades politicas}

El ámbito político de la PBA ha tenido una gran capacidad para estructurar a la PP como un problema que va más allá de los márgenes judiciales, fundamentalmente vinculando al tema de la seguridad con el de las excarcelaciones. Esta capacidad se sustenta en la relación que mantiene dicho ámbito político con el PJ en sede penal junto a los dos actores previamente mencionados, es decir, la policía y los medios. Por lo tanto, buscaremos señalar algunos eventos donde estas relaciones se manifiestan complementándolo con los testimonios que ofrecen los actores judiciales al respecto.

A mediados de la década de 1990 el Poder Ejecutivo provincial emprendió una serie de reformas con las que intentó disciplinar a la policía bonaerense, fuerza de seguridad que se había transformado en un "riesgo político",44. Estas reformas comenzaron el 30 de diciembre de 1997 cuando se llevó adelante la creación de la Comisión y el Instituto de Política Criminal y Seguridad (IPCS), la cual debía encargarse de monitorear el proceso de reestructuración del sistema de seguridad en la PBA. Quien fuera su presidente, Carlos Arslanián, fue designado como Ministro de Justicia y Seguridad en marzo de 1998 como consecuencia de la creación de dicha cartera a través de la ley 12.090 (Dammert, 2005: 141). El 15 de julio de 1998 el Senado aprobó la Ley Provincial de Seguridad Pública (Ley 12.154) y la Ley de Organización de las Policías de La Provincia de Buenos Aires (Ley 12.155). Uno de los impulsores más destacados de aquellas modificaciones policiales nos expresó:

\footnotetext{
${ }^{44}$ En las elecciones desarrolladas durante el mes de octubre de 1997, se dio la caída electoral de Eduardo Duhalde, por aquel tiempo gobernador de la PBA, que dejó diezmadas sus aspiraciones presidenciales para 1999. Fue entonces cuando decidió avanzar hacia una política enérgica en torno a la seguridad: "Es en este contexto que finalmente maduró la decisión política de implementar la Reforma policial de la Bonaerense. El 19 de diciembre de 1997 [...] Luis Lugones, fue designado interventor" (Arzadún, 2005: 138).
} 
"Hay tres años en los que se reconfigura la justicia penal: 1997, 1998, 1999. Y en todas las reformas de esa época se observa la intención de quitarle hegemonía a la policía. La intención fue la de complicar el campo de la justicia penal introduciendo otros actores y quitándole centralidad a la policía. Y ahí se desordena todo [...] pero lo que no se ha podido es generar una nueva estructura [...] lo de la policía eclosiona y se rompe el pacto con el Ejecutivo con el caso Cabezas y la maldita policía [...]. Además hubo gente de la política que vio que la justicia como un tema de agenda política. [...] todos estos políticos tienen en común aprovechar momentos de crisis e ir para adelante. Nosotros llamábamos tener éxito a romper la estructura que ya había, removerla, para luego tratar de construir otra estrategia dentro de la justicia penal, donde avanzamos y retrocedimos con aliados como Arslanian. Y en este juego, la prisión preventiva es como la institución más sensible porque es una encrucijada [...]. La prisión preventiva es el termómetro de cómo se está jugando este juego. Cuando se da la crisis de la maldita policía, se abre una grieta, y a mí me criticaron mucho en ese entonces ¡Hace 15 años que estoy buscando esa grieta! ¡Yo ya sé quién es Duhalde!, pero no podemos dejar pasar esta oportunidad".

Esta crisis en el campo político provocada por las irregularidades de la agencia policial abrió la posibilidad para que la seguridad pública de la provincia sea discutida. Y en esa discusión política la justicia penal, que es el ámbito donde la PP se resuelve, también fue considerada una institución a transformar (Saín, 2002, 2008; González, 2005).

En efecto, en el mismo período en que la policía y la seguridad estaban siendo reconfiguradas se plasma el nuevo CPP de la PBA en el cual se regula novedosamente el encierro preventivo. Los cambios más importantes que generó esta reforma del mes de septiembre de 1998 fueron los siguientes: divide a la PBA en 18 departamentos judiciales, crea la Cámara de Casación como máximo tribunal penal bonaerense, se introduce en la órbita del PJ un nuevo actor: el Ministerio Público Fiscal que queda a cargo de la investigación penal frente a la comisión de un delito (Art. 6 del CPP de la PBA). Además se establecieron para el proceso:

a) Una etapa de investigación escrita conducida por el Ministerio Público que debía ser menos formalizada que la existente en el marco del código anterior.

b) Un control de la acusación ejercido por el JG y luego, a requerimiento de las partes, el acceso a la Cámara de Apelaciones y Garantías. 
c) Una posterior audiencia de preparación del juicio ya en la etapa de debate, efectuada por el mismo tribunal que entenderá en la causa.

d) Una etapa de debate oral en caso de llegar a juicio.

Según el Centro de Estudios Legales y Sociales (en adelante, CELS), esto fue posible por

La decisión política de implementar la reforma del procedimiento penal [la cual] se fundó sobre todo en el agotamiento del anterior modelo de enjuiciamiento penal y en la incapacidad del sistema procesal penal para lidiar con la compleja realidad y el creciente índice de criminalidad que presentaba por esos días la provincia de Buenos Aires (2004: 97).

A su vez, entre los argumentos legislativos que justificaban la reforma al CPP, la PP tuvo un lugar significativo ya que su uso excesivo era considerado como la causa más importante respecto del problema de la sobrepoblación carcelaria en la provincia.

De acuerdo a las manifestaciones que recogimos de los actores judiciales, este cambio en el CPP y en la estructura del PJ con el que se pretendía restringir el uso de la PP fue una decisión acertada por parte del poder político:

"La reforma de 1998 fue un paso necesario e imprescindible que dio la provincia de Buenos Aires para adecuar su procedimiento penal a los requerimientos constitucionales y convencionales. $\mathrm{Y}$ en este sentido hay que destacar que, no obstante las complejidades que presenta el territorio bonaerense, ha sido pionera en el proceso de reforma con relación al resto de las provincias. La reforma procesal penal es un proceso, con grandes implicancias políticas, y como todo proceso presenta sus avances y retrocesos, pero es un camino que debe ser transitado y profundizado. La renovación de los cuadros dirigenciales del Poder Judicial como Defensores, Fiscales y Jueces puede contribuir a remover los obstáculos para la reforma, en la medida que se abandonen prácticas y prejuicios que no contribuyen a su realización [...]. igual el objetivo de la reforma no se ha logrado y, muy por el contrario, en términos comparativos, se ha retrocedido con relación a lo que ocurría con la vigencia del Código Jofré, lo cual no deja de ser paradojal. Atribuyo este fenómeno a la falta de independencia de los jueces con respecto a los reclamos securitarios de ciertos sectores de la sociedad y la dirigencia política, a la falta de formación en principios esenciales de derechos humanos y, 
consecuentemente, a la ausencia de convencimiento sobre esos temas" (JG, Departamento Judicial de Mar del Plata).

"Yo estoy a favor de la 11.922, por pasar "al acusatorio". Un error en muchos compatriotas es pensar que los problemas se solucionan con las normas, que las leyes dan soluciones mágicas a los problemas: por eso dicen que hay que cambiar las leyes [...], las leyes primero hay que cumplirlas. Y después tener en cuenta que se trata de un sistema de normas y no una norma perdida que si uno la cambia, cambia la realidad, se emparcha permanentemente, y en este sentido la PP es la variable de ajuste, la excarcelación: salen todos, no sale nadie" (Defensor Oficial, Departamento Judicial de La Plata).

Si bien con distintas escalas, los actores judiciales se mostraron conformes con la reforma procesal. Esta valoración se observa en la idea de que esta reforma era necesaria para adecuar el procedimiento penal a los estándares constitucionales, en que debería contribuir a la renovación legítima de los funcionarios dentro del PJ, y en que al pasar al modelo acusatorio se separan las tareas de investigar de las de velar por las garantías del proceso.

En fin, el uso político que se le dio a la PP en esta etapa generó consensos entre las autoridades políticas y los actores judiciales. Este uso político quedó explicitado cuando los legisladores bonaerenses utilizaron al encierro preventivo para sustentar la aprobación de la Ley 11.922. En los Fundamentos de dicha Ley afirmaron que "[...] la superpoblación en las cárceles de la Provincia es [de] más del sesenta (60) por ciento de la población [y] está constituido por internos procesados que esperan la definición en sus causas". Posteriormente, esta conformidad de los operadores jurídicos con las decisiones tomadas por las autoridades políticas comenzó a debilitarse. Las razones principales que dan los operadores para justificar este desengaño del mundo judicial tienen que ver, por un lado, con el modo desestabilizador que decidieron utilizar las autoridades políticas en los medios de comunicación para condicionar su trabajo. Y por otro lado, con las direcciones "populistas" que fueron tomando los distintos gobiernos a la hora de concebir la política criminal.

\subsection{El debilitamiento}

Las declaraciones públicas de los políticos sobre el problema del delito y el modo en que se desempeña la justicia penal al respecto se han incrementado de manera 
sostenida desde la misma época en la que se dieron las reformas policiales y procesales mencionadas en los apartados anteriores. Específicamente en octubre de 1997, cuando se realizaron elecciones legislativas en el país, fue la primera vez que el fenómeno de la inseguridad $^{45}$ se utilizó como eje de una campaña electoral. En palabras de Lorenc Valcarce,

La seguridad era un tema secundario de los debates electorales hasta la decisiva campaña bonaerense de 1997 y sólo llega a consolidarse como eje central de las luchas políticas a partir de 1999. [...] las cuestiones relativas a la criminalidad y las preocupaciones que ella acarrea (amenaza real o imaginaria de ser victimizado, todavía no designada sistemáticamente como 'inseguridad') no ocupa un lugar privilegiado en los sondeos de opinión sino hasta 1997: entre 1986 y 1996, oscila entre el quinto y el sexto lugar de la lista de las 'principales preocupaciones de los argentinos', para acceder en 1997 a un segundo lugar del que no se moverá hasta nuestros días (2005: 8-9, 2012; Calzado, 2006).

Esta "politización" del delito llegó en un contexto en el cual dicho problema inquietaba a los votantes y en simultáneo aumentaba de manera desproporcionada en su cobertura mediática ${ }^{46}$. A su vez, dicha "politización" del delito se articuló con una "politización" de la institución judicial, lo que sucedió desde el momento en el que las autoridades gubernamentales lograron consolidar la metáfora de la "puerta giratoria" de las cárceles. Con esta metáfora los políticos consiguieron co-responsabilizar a la justicia penal del problema de la inseguridad, reclamándole por esto mismo un uso más intensivo de la PP. Al repetir que

La policía los detiene y los jueces los ponen en libertad ${ }^{47}$, lo que las autoridades gubernamentales [...] sugieren es negligencia o corrupción en el aparato judicial y

\footnotetext{
${ }^{45}$ Hablar de inseguridad no supone aludir necesariamente al problema del delito (Castel et al., 2006). En nuestro país, Kessler (2009) vincula la primera con la zozobra respecto a la integridad física, la cual no siempre exige la trasgresión de una norma jurídica. Sin embargo, consideramos útil tomarlos como sinónimos puesto que la aleatoriedad del peligro que caracterizaría el sentimiento de inseguridad se traduce la mayoría de las veces como un problema en torno al delito (Ibíd.: 96-7).

${ }^{46}$ Entre 1991 y 1994, la tasa de delitos registrados aumenta en un $23,2 \%$ mientras que la cobertura mediática de los hechos delictivos se incrementa en un 112,5\%; entre 1994 y 1997 los delitos se incrementan en un $25,2 \%$ aunque el tratamiento periodístico se eleva en un $72,7 \%$. (Lorenc Valcarce, 2005: 8; Kessler, 2009: 78)

${ }^{47}$ Existen variantes en este tipo de afirmaciones, como por ejemplo la de C. Ruckauf cuando afirmó siendo gobernador de la provincia-: "Les recuerdo que esos señores (Salvador Raineri y Diego Lucero) que estaban en libertad el otro día era por decisión de los jueces" (Página 12, 8-3-2000). Se trataba de dos imputados que habían sido excarcelados mientras se los investigaba por un delito y cometieron un nuevo delito. Una semana después el gobernador mandó un proyecto a la legislatura para ampliar el uso de la PP: "Espero que esta vez me la voten rápido, porque he escuchado a algún diputado frepasista que dice que esto atenta contra los derechos de los presos", dijo (Página 12, 16-3-2000).
} 
aumenta así tanto la presión sobre jueces y fiscales, para que generalicen la aplicación de la prisión preventiva, como la desconfianza ciudadana sobre el funcionamiento del aparato de justicia (DPLF, 2013: 13).

Se trata de afirmaciones que, según sostienen algunos actores judiciales, contribuyeron al debilitamiento de su independencia. En la PBA se puede encontrar por parte de las autoridades políticas referencias a una justicia penal proclive a liberar delincuentes, es decir, al uso indiscriminado de las excarcelaciones. Si bien este fenómeno comienza a mediados de la década de 1990, existieron casos resonantes en los cuales Jueces como Rafael Sal Lari y Nicolás Schiavo ${ }^{48}$ han resultado impugnados públicamente.

- "Scioli impulsa el jury del juez que dejó libre al asesino. Como reacción al cuádruple crimen de Campana, el gobernador bonaerense Daniel Scioli instruyó ayer a su jefe de Gabinete, Alberto Pérez en dos acciones concretas: que pida a los integrantes del Consejo de la Magistratura que evalúe el jury de enjuiciamiento para el juez Nicolás Schiavo, responsable de la excarcelación de Ángel Fernández uno de los acusados del brutal asesinato de una familia" (Diario Diagonales, 4-8-2008).

- "Comienza el juicio político al juez de San Isidro Rafael Sal Lari. El jury está integrado por los senadores Cristina Fioramonti (Frente para la Victoria) y Aníbal Asseff (Unión PRO Peronista); los diputados Gonzalo Atanasof (Unión Celeste y Blanco), Ramiro Gutiérrez (Proyecto Bonaerense) y Aldo Mensi (UCR) [...]. Sal Lari fue suspendido en su cargo en abril del año pasado, luego de que el jury decidió acusarlo sólo por una de las 11 causas por las que lo habían denunciado [...]. El intendente de San Isidro, Gustavo Posse, lo denunció también por haber excarcelado a un delincuente que poco después, en julio de 2008, mató al ingeniero Carlos Regis en su casa de Béccar, aunque esa causa no fue tomada en cuenta por el Jurado" (Télam, 5-7-2012).

\footnotetext{
${ }^{48} \mathrm{La}$ referencia hecha a estos jueces es recurrente en muchos de los entrevistados. En parte porque encarnan para los actores judiciales la antítesis de aquello que velada o explícitamente tanto se valora en el Poder Judicial: "pasar sin hacer olas". Schiavo, como JG del Departamento Judicial del San Martín, liberó a una persona que luego fue señalada como coautor de un cuádruple crimen en la ciudad de Campana, en 2008. Sal Lari, JG de San Isidro, fue llevado a juicio político por mal desempeño en su cargo. Se lo denunciaba, entre otros hechos, por excarcelar en 2008 a un individuo que tiempo después fue acusado de homicidio en intento de robo. Para la mayoría de las personas con quienes hablamos, ambos jueces han sido víctimas de una persecución, que a menudo alcanza el hostigamiento. Para el análisis de cada caso, véase Gutiérrez (2013).
} 
A estos casos se le deben sumar declaraciones y propuestas electorales de partidos políticos en las cuales, como se observará a continuación, aparece la necesidad expresa de generar leyes contra la "puerta giratoria" que amplíen el uso de la PP y como consecuencia limiten la aplicación de las excarcelaciones.

- El partido Frente Renovador -ganador en la jurisdicción bonaerense de las elecciones 2013- propuso un proyecto de ley de modificación del CPP para limitar las excarcelaciones denominado "Anti-Rueda Giratoria"49. Su principal candidato, Sergio Massa, expresó en declaraciones periodísticas: "Nosotros damos las peleas que valen la pena porque tenemos la decisión política para combatir la inseguridad. Por esto, hemos planteado penas de reclusión perpetua para narcotraficantes, un cambio al código de procedimiento que permita romper con lo que llamamos -la puerta giratoria- que hace que los delincuentes entren por una puerta y salgan por la otra" (Infobae, 28-7-2013).

- Natalia Gambaro, candidata a diputada nacional de Unión Celeste y Blanca -partido dirigido por F. De Narváez- sostuvo: "Dentro de los 153 proyectos que tenemos presentados también abarcamos la Justicia Penal y el sistema carcelario. Tenemos presentada una reforma que con una mínima modificación al Código Procesal se evita la puerta giratoria, no hay más liberaciones de comisaría y por teléfono, se decide la situación procesal de los detenidos en un Juzgado, frente a un juez, un fiscal, un defensor y la víctima" (Diario La Mañana, 8-10-2013).

- El gobernador de la PBA, Daniel Scioli, aseguró que se "está enfrentando a diario la mafia del crimen organizado, ante los delincuentes que parecen dispuestos a todo, y pidió a la justicia que aplique las penas que está pidiendo la sociedad. Es muy importante que el Poder Judicial aplique con la mayor rigurosidad y sus limitaciones las leyes vigentes. De esa manera tendremos una Provincia más justa" (Ámbito Financiero, 21-8-2013).

- El intendente de La Matanza, Fernando Espinoza, dijo: “debemos terminar con la puerta giratoria en los juzgados, porque se los detiene y al otro día salen por la otra puerta y esto se debe terminar. El que tiene que estar en la cárcel, debe estar en la cárcel [...]" (Télam, 13-9-2013).

\footnotetext{
${ }^{49}$ Disponible en http://www.frenterenovador.org.ar
} 
Para los operadores jurídicos, estas expresiones vinculadas al desempeño de la justicia buscan un "efecto disciplinador" en el PJ que conspira en contra de la autonomía de éste último respecto de los otros poderes del Estado. Si bien es cierto que este “efecto disciplinador" es difícil de medir (Gutiérrez, 2013), la idea de persecución a operadores renuentes a aplicar la PP está muy presente en sus testimonios.

\footnotetext{
"La advertencia estatal y situación sufrida por compañeros sometidos a juicio político como Sal Lari o Schiavo condicionan a aquellos que no quieren ocupar ese lugar y prefieren transitar una magistratura sin riesgos, sacrificando tal vez su independencia de criterio, si es que la tienen" (JG, Departamento Judicial de Mar del Plata).
}

"Te quieren hacer sentir como que tenés que reprimir el delito vos, y que te abstengas de liberar o excarcelar a imputados de delitos graves, lo que muchos políticos y medios todavía llaman sistema de la puerta giratoria" (Defensor Oficial, Departamento Judicial de La Plata).

"Los que aplican la ley en los términos en que está escrita se exponen al riesgo de que de existir algún hecho posterior que genere conmoción social en el que esté involucrado un imputado que liberaron anteriormente, pierdan su trabajo por la denuncia de dirigentes políticos [...]. Parece que del peligro procesal en los últimos años pasamos al peligro judicial que sería el peligro de que el Juez pierda su trabajo aún aplicando la norma tal cual está escrita" (Fiscal de Instrucción, Departamento Judicial de Quilmes).

"Los discursos punitivos de actores políticos pueden influir negativamente en operadores judiciales como la puerta giratoria, acompañados de acciones concretas por sectores políticos contra jueces identificados como garantistas como Schiavo y Sal Lari, por ejemplo. Digo "pueden" porque es una presunción que no puedo verificar, pero [...]" (JG, Departamento Judicial de La Plata).

Según estos testimonios, la justicia penal de la PBA se percibe dentro de un proceso de debilitamiento en el que pierde autonomía respecto de las imposiciones de los poderes Ejecutivo y Legislativo. Como señala Simon (2011: 344) para el contexto estadounidense, los dirigentes políticos presentan una imagen de los actores judiciales con gran poder y propensos a actuar en contra de los intereses de los ciudadanos comunes. En éste sentido, y siguiendo el diagnóstico realizado por John Lea, se advierte 
[Una] repolitización de la justicia penal, a través de la mezcla altamente volátil de afirmaciones de políticos populistas en torno a la eficacia del encarcelamiento, las posteriores restricciones sobre los derechos del acusado, y la necesidad y efectividad de nuevos poderes policiales (2006: 320).

Y como hemos podido ver hasta aquí, en esta repolitización dentro de la PBA la PP tiene un lugar privilegiado tanto para los actores judiciales como para los actores políticos.

Como primer comentario de éste apartado podemos señalar que el acuerdo entre las autoridades políticas y los actores judiciales sobre la reforma procesal de 1998 fue coyuntural, lo que permite sugerir que los consensos respecto a temas de seguridad en general y a excarcelaciones en particular son generalmente frágiles. Esta fragilidad parece estar atravesada por el vínculo que se ha ido desplegando entre los representantes políticos y los medios de comunicación, en el sentido de que la presión pública que ejercen dichos representantes la efectúan principalmente desde los medios de comunicación. De esto deriva una segunda cuestión que es la consolidación de la metáfora de la "puerta giratoria" por medio de la cual se dramatiza el problema de las excarcelaciones (Gusfield, 2014). Con esta dramatización los políticos representan el peligro de dejar en libertad a las personas investigadas por cometer un delito, y los medios de comunicación ponen en escena el riesgo latente de una justicia condescendiente con los infractores.

\subsection{Acting-out preventivo}

El paso que complementa las declaraciones y propuestas de las autoridades de gobierno es el de la ejecución de una política criminal, entendiendo por ésta al conjunto de presupuestos y objetivos -junto con las decisiones que se toman en función de estos presupuestos y objetivos- que tiene el Estado respecto del delincuente, la víctima y el delito (Larrauri, 2001) . $^{50}$ Y según los testimonios de los operadores jurídicos, la

\footnotetext{
${ }^{50}$ Elegimos esta definición más allá de la dificultad por consensuar un concepto de política criminal ya que ésta última responde, según las distintas épocas, a variables económicas, culturales, y políticosociales valoradas al calor de prioridades muy distintas: “...mientras su finalidad es unívoca, su instrumental resulta indeterminable porque es definible sólo en términos negativos, a través de instrumentos penales, de un lado, e instrumentos no penales, del otro. Para decir que la finalidad de la política criminal es unívoca debemos hacer una puntualización: hasta un pasado no muy lejano ésta se entendió constantemente como la finalidad de controlar la criminalidad, es decir, reducir el número de infracciones delictivas. A partir del desarrollo de estudios victimológicos, y en particular por la preocupación acerca de las necesidades de la víctima, de su ambiente social y de la sociedad, el campo de
} 
exposición y puesta en práctica de esta política criminal ha reforzado las diferencias entre el ámbito político y el ámbito judicial. Las manifestaciones de Fiscales, Defensores y JG reflejaron un consenso sobre lo que Gobernadores, Ministros de Seguridad y Legisladores hacen -y han hecho- respecto del control del delito y la regulación de la PP luego de la reforma de 1998. Con diferentes análisis y sugerencias, los entrevistados expresaron su impugnación a la "mirada oficial" que existe sobre este problema:

"En los últimos 25 años no hay una política criminal seria. Es decir que existe un movimiento pendular desde la mano dura o la tolerancia cero al abolicionismo. Es difícil encontrar un equilibrio. Cada vez que un hecho grave conmueve nuestras conciencias ciudadanas, la prensa se hace eco y las encuestas de opinión de los políticos empiezan a descender. Se propugnan cambios a la legislación penal, principalmente a la procesal. Es más, las normas sobre excarcelación, eximición de prisión y PP son las normas más modificadas en los últimos 25 años" (Fiscal de Instrucción, Departamento Judicial de La Plata).

"La política criminal de la provincia de Buenos Aires se encuentra claramente orientada a la neutralización de los sospechosos por la comisión de cierto tipo de delitos y, principalmente, de los delitos contra la propiedad, que representan el $50 \%$ de las personas privadas de la libertad en la provincia. Y en la mayoría de los casos, son presos preventivos" (Defensor Oficial, Departamento Judicial de Mar del Plata).

"Existe ausencia de una Política de Estado en materia de seguridad que comprometa a todas las dependencias [...]. La política criminal se basa exclusivamente en la creencia que las leyes "manoduristas" son la panacea para solucionar el problema de la inseguridad" (JG, Departamento Judicial de La Plata).

"[...] entiendo que las autoridades políticas pueden haber incidido en la mayor tasa de prisonización, porque la política criminal se dirige especialmente a las personas más vulnerables, quienes por hechos que quizás no ameritan la aplicación de prisión preventiva, resultan el mayor porcentaje de detenidos" (JG, Departamento Judicial de Quilmes).

acción de la política criminal se extiende (por lo menos potencialmente) también hacia el control de las consecuencias del crimen, además de su prevención" (Baratta, 2004b: 152). 
La percepción de los actores judiciales sobre lo que consideran política criminal en la PBA es la de que sus responsables ejecutivos y legislativos muestran movimientos pendulares que van de un extremo represivo a otro en extremo indulgente. Junto a esto aparecen críticas a la selectividad en la represión de los delitos que favorece la incapacitación de personas no tanto por el delito que se les imputa como por la clase social a la pertenecen. En conjunto, los testimonios de JG, Defensores y Fiscales van en la misma dirección que planteos como los de Garland, para quien los políticos actúa[n] en el marco del horizonte temporal de la competencia electoral, a la luz de la publicidad obsesiva de los medios masivos de comunicación y se basa fundamentalmente en un saber «político»-sobre la opinión pública, las preferencias de grupos focales, las tácticas de la oposición y los valores políticos- más que en la experiencia organizacional o los resultados de la investigación científica. Las iniciativas de políticas públicas son frecuentemente reactivas, desencadenadas por eventos particulares y deliberadamente partisanas. Como consecuencia, tienden a ser apasionadas e improvisadas, construidas en torno a casos impactantes pero atípicos y a estar más preocupadas de ajustarse a la ideología política y a la percepción popular que al conocimiento experto o a las capacidades comprobadas de las instituciones (2005: 192).

Estos criterios para enfrentar el problema de la inseguridad permiten a las autoridades políticas proclamar medidas altisonantes de dudosa efectividad que evitan -o se niegan a- reconocer las dificultades que entraña dicho problema. Es por esto que Garland lo define como un estilo acting out de abordar el control del delito, a raíz de mostrarse como una forma de actuar irreflexiva e impulsiva (Ibíd.: 224). De esta manera los dirigentes renuncian a las complejidades y a las estrategias a largo plazo que requiere el problema del control del delito realmente, dándole prioridad a las respuestas inmediatas. En este sentido, es importante destacar que para los operadores jurídicos entrevistados, la PP es una de las herramientas predilectas de las autoridades políticas provinciales para alcanzar ventajas rápidas en lugar de soluciones duraderas. 


\section{4- Las ONGs}

Así como lo han hecho las autoridades políticas, también las $\mathrm{ONGs}^{51}$ contribuyeron para que el encarcelamiento preventivo adquiera relevancia por fuera del ámbito judicial. Si bien algunas de estas agrupaciones comenzaron sus actividades antes, fue en la segunda mitad de la década de 1990 cuando consolidaron su lugar en las discusiones y definiciones en torno a la PP y al problema de la seguridad en general. Según los especialistas

Resultaría difícil explicar la evolución de las políticas e instituciones de seguridad durante estos años sin mencionar las acciones desarrolladas por organizaciones de derechos humanos o por alianzas sociales donde estas organizaciones ocuparon un lugar importante (Palmieri, Perelman y García Méndez, 2008: 196).

En este sentido, uno de los antecedentes más relevantes acerca de la intervención de ONGs en estas cuestiones fue la presentación conjunta que hicieron a comienzos de 1997 los abogados de la familia de Walter Bulacio ${ }^{52}$, la Coordinadora Contra la Represión Policial e Institucional (en adelante, CORREPI), el CELS y el Center for Justice and International Law (en adelante, CEJIL), denunciando al Estado argentino ante la Comisión Interamericana de Derechos Humanos ${ }^{53}$.

Respecto a la PP, para rastrear el modo en que las ONGs contribuyeron a transformarla en un problema extrajudicial, examinaremos dos episodios en los cuales el encierro cautelar permitió que las controversias y las denuncias entre distintos actores pudiesen configurarse concretamente.

\subsection{El fallo Verbitsky}

El fallo "Verbitsky" resulta de gran complejidad y extensión debido a los temas que aborda. Lo que aquí nos importa mencionar es cómo, en tanto actor extrajudicial,

\footnotetext{
${ }^{51} \mathrm{Si}$ bien existen agrupaciones y ONGs que no necesariamente están en contra del uso de la PP, como Madres del dolor o Familiares de víctimas del delito, por ejemplo (Cerruti, 2009), nosotros trabajaremos fundamentalmente con aquellas que critican su uso (INECIP, CEJA, CELS, etc.) por la capacidad que han mostrado para producir documentos e informes al respecto.

${ }^{52}$ Este joven fue víctima de la violencia policial mientras aguardaba para ingresar a un recital. Luego fue llevado a la comisaría de la seccional 35 de la ciudad de Buenos Aires. Murió el 26 de abril de 1991. Su caso, emblemático al respecto, llegó hasta la Corte Interamericana de Derechos Humanos la cual dicto sentencia en el año 2003.

${ }^{53}$ Según Sofía Tiscornia esta presentación mantuvo "buena parte del estilo vehemente y apasionado de los escritos de la causa local [...]. Se narra -en forma breve- que Walter fue detenido durante un operativo policial; que cuando ello sucedió gozaba de perfecto estado de salud y que no existía razón para su arresto; que pocos días después, muere" (Tiscornia, 2008: 179).
} 
una ONG generó consecuencias dentro del PJ de la PBA, en particular respecto al encarcelamiento preventivo.

El trámite judicial comenzó en noviembre de 2001 cuando el CELS interpuso ante el Tribunal de Casación Penal de la PBA (en adelante, TCBA) una acción de Hábeas Corpus en defensa de cerca de 6.000 personas privadas de su libertad bajo PP. La denuncia del CELS objetaba las condiciones en las que se encontraban los encarcelados y establecía que esas detenciones debían efectuarse, por prescripción legal, en centros de reclusión especializados. El TCBA se declaró incompetente para tratar la acción afirmando que no estaba autorizado a suplir a los jueces propios de las causas individuales, además de que no correspondía tomar una única decisión que englobase las diferentes situaciones procesales. Siguiendo los pasos jurídicos correspondientes, el CELS apeló a la Suprema Corte de la Provincia de Buenos Aires (en adelante, SCBA), la cual respaldó al TCBA. Luego de este rechazo de la SCBA, el CELS quedó habilitado para recurrir frente a la Corte Suprema de Justicia de la Nación (en adelante, CSJN).

En mayo de 2005 la CSJN pronunció el fallo "Verbitsky" que decidió sobre la situación de aquellas 6.000 personas que estaban detenidas preventivamente en comisarías bonaerenses. En esta resolución el máximo tribunal del país aseveró que:

- Las condiciones de encierro en la PBA representan una violación tanto de las normas constitucionales como de los instrumentos internacionales de Derechos Humanos.

- Al menos el 75\% de las personas encarceladas en jurisdicción bonaerense son procesadas sin condena definitiva, es decir, en PP.

- Los esfuerzos del Poder Ejecutivo bonaerense no alcanzan para resolver el problema ya que la curva ascendente del número de presos no cede, y este aumento responde básicamente a leyes provinciales en materia excarcelatoria y penitenciaria.

- El mismo Poder Ejecutivo de la PBA admite la existencia de un excesivo uso de la PP por parte de los jueces de dicha jurisdicción.

En pocas palabras, la CSJN dejó en claro que los tres poderes del Estado provincial estaban involucrados en la situación lesiva por la que atravesaban buena parte de las personas privadas de su libertad en terreno bonaerense. Y la aplicación 
indiscriminada de la PP fue utilizada como uno de los argumentos más recurrentes para explicar esa situación lesiva. De hecho el apartado XI de la sentencia se tituló "Excesivo uso de la prisión preventiva", apartado en el cual se sugirió a los Poderes Ejecutivo y Legislativo que ajustaran su reglamentación procesal penal en materia de PP y excarcelación a los estándares constitucionales e internacionales.

\section{Según un informe del CELS,}

"Luego de que la Corte Suprema de Justicia de la Nación dictara el fallo Verbitsky, se ha verificado una disminución de la cantidad de personas privadas de su libertad en la provincia de Buenos Aires. Si bien la variación no es muy pronunciada, lo significativo es que se logró quebrar la tendencia constante al incremento de presos de los últimos años. Así, la cifra total de personas detenidas en la provincia, que el día de la sentencia era de 30.721, descendió un mes después a menos de 30.000. Esta cantidad siguió reduciéndose, hasta llegar a 28.129 personas en noviembre de 2006, lo que representa casi un 9\% menos desde el día de la sentencia de la CSJN" (2007: 243).

En noviembre de 2006, y como resultado de la falta de aplicación del fallo "Verbitsky", el CELS junto a la Asociación por los Derechos Civiles (en adelante, ADC), el Instituto de Estudios Comparados en Ciencias Penales y Sociales (en adelante, INECIP) y Human Rights Watch, requirieron a la SCBA que designe una audiencia oral y pública, además de brindar una serie de propuestas con el objetivo de que el fallo se instrumente efectivamente ${ }^{54}$. Según estas agrupaciones, desde la llegada a la gobernación de Daniel Scioli en diciembre de 2007 ha sido cada vez más difícil la puesta en práctica de las resoluciones de la CSJN en el caso "Verbitsky" (CELS, 2009).

En síntesis, y aún cuando los cambios generados por el fallo "Verbitsky" hayan sido transitorios ${ }^{55}$, es importante destacar que este caso reveló de qué manera una ONG pudo movilizar recursos tomando a la PP como uno de sus principales argumentos, provocando desplazamientos en algunas relaciones que se desarrollan por fuera del PJ.

\footnotetext{
${ }^{54}$ Algunas de estas propuestas fueron: establecer parámetros claros que permitan una aplicación uniforme del fallo de la CSJN, desarrollar un control sostenido en el tiempo del cumplimiento de esas pautas, y garantizar la realización de las audiencias preliminares para el análisis de la procedencia de la PP.

55 Según el CELS, esta brevedad se debió "a la falta de compromiso de algunos funcionarios judiciales jueces, fiscales y defensores- con la aplicación efectiva del fallo de la CSJN, a la inexistencia de criterios claros, precisos y uniformes que guíen el accionar de los operadores del sistema, así como a la ausencia de control de aquellos que de hecho existen" (2007: 257).
} 


\subsection{La Corte a favor}

En diciembre de 2009 se firmó un “Acuerdo para una política de seguridad democrática" ${ }^{~} 56$ en el que intervinieron diferentes grupos y sectores que, en términos generales, se enfrentaron a los criterios que el gobierno bonaerense había adoptado en los últimos quince años para afrontar los problemas vinculados a la inseguridad y el delito. En este acuerdo se hacía especial hincapié en la necesidad de restringir el uso del encierro preventivo. La objeción más severa giraba en torno de las sucesivas reformas sobre el régimen de excarcelaciones, reformas que según el acuerdo ni siquiera habían sido evaluadas respecto a sus consecuencias en materia de seguridad. Al contrario, sólo eran exhibidas por parte de diferentes autoridades de gobierno como un instrumento redentor frente al delito callejero. Por último, se indicaba que tanto Fiscales como Jueces tenían la facultad para solicitar y aceptar la PP con muy pocas exigencias probatorias.

En la coyuntura de este acuerdo, el Ejecutivo provincial impulsó un nuevo proyecto sobre el uso de la PP por medio del cual intentaba ir en sentido contrario y profundizar las restricciones de la libertad durante el proceso. Este proyecto se transformó luego en la ley $14.434^{57}$, que añade al Art. 171 del CPP el siguiente párrafo:

Tampoco se concederá la excarcelación cuando, en los supuestos de tenencia o portación ilegítima de arma de fuego de cualquier calibre, el imputado hubiera intentado eludir el accionar policial, evadir un operativo público de control o, de cualquier otro modo, desobedecer, resistirse o impedir el procedimiento [...].

Este agregado determina la existencia de ciertos delitos que en sí mismos no son excarcelables, más allá de la evaluación que haga el JG de los riesgos procesales que el imputado pudiese representar.

Dicha reforma fue impugnada por un conjunto de ONGs que habían participado en el acuerdo del año 2009, ya que consideraban un hecho de "oportunismo punitivo" contestar a las demandas de seguridad con el agravamiento de la legislación procesal penal. En concreto, la Asociación Civil La Cantora, la Asociación Pensamiento Penal, el CELS, el Centro de Estudios en Política Criminal y Derechos Humanos, y la Comisión Provincial por la Memoria (en adelante, CPM), emitieron un documento con severas críticas a dicha reforma, rechazando

\footnotetext{
56 El "Acuerdo para una política de seguridad democrática” completo está disponible en http://www.cels.org.ar/common/documentos/ASD\%20PBA\%20completo.pdf

${ }^{57}$ Promulgada el 8 de enero de 2013.
} 
El proyecto de ley aprobado esta tarde por la Legislatura Bonaerense, a partir de la propuesta del gobernador Daniel Scioli, de limitar las excarcelaciones en caso de portación ilegítima de armas de fuego. La justificación de este nuevo proyecto es que permitirá controlar la circulación de armas $\mathrm{y}$, como consecuencia, reducir los delitos más violentos. Nuevamente, el poder político insiste en la demagogia punitiva que procura responder a las demandas sociales de seguridad con el endurecimiento del sistema penal. Bajo estos mismos argumentos, en los últimos años se impulsaron más de treinta reformas procesales y los resultados han sido un fracaso [...]. En términos de una política de seguridad seria, sustentada en diagnósticos empíricos, las armas circulan porque el mercado ilegal está protegido y controlado por las mismas autoridades policiales. El propio Senado provincial, en el informe sobre el "Caso Candela", advirtió sobre la degradación y la inserción de redes ilegales en la Policía Bonaerense [...]. Para dar respuesta a las graves fallas en materia de seguridad e investigación criminal, no se requiere más encarcelamiento preventivo, sino avanzar en reformas institucionales y voluntad política de atacar los verdaderos problemas ${ }^{58}$.

En febrero de 2013 surge una solicitud para que la SCBA declare la inconstitucionalidad de la ley, y que hasta el momento en que presente su dictamen sobre el tema disponga la interrupción inmediata de sus efectos. Este pedido de interrupción se fundamentaba en que los efectos de la ley 14.434 aparecían contradiciendo derechos y garantías reservados a la Constitución Nacional (en adelante, CN) y la Constitución de la provincia de Buenos Aires (en adelante, CPBA). Dicho pedido estuvo a cargo del CELS, la CPM, el Centro de Estudios en Política Criminal y Derechos Humanos, el Colectivo de Investigación y Acción Jurídica, entre otros. El 26 de febrero del mismo año la SCBA dictaminó a favor del reclamo de las ONGs, argumentando que la PP debe ser utilizada como una medida que neutralice los peligros procesales y no como una herramienta para combatir el delito. El máximo tribunal de la PBA sostuvo:

"[...] no puede dejar de recordarse que el derecho a la excarcelación constituye una garantía del imputado detenido o sometido a prisión preventiva, surgido del artículo 18 in fine de la Constitución Nacional [...] por ello que, como principio, no cabe limitar la posibilidad de excarcelación convirtiendo la prisión preventiva en una carga más gravosa para el imputado que la posible pena que le correspondería de ser condenado [...]. Por otra parte, la norma en examen (ley 14.434) podría conducir, en principio, en

\footnotetext{
${ }^{58}$ Las cursivas son nuestras.
} 
dirección contraria a la marcada por la Corte Suprema de Justicia de la Nación en el fallo Verbitsky, en tanto allí se alertó a todos los poderes públicos de la Provincia de Buenos Aires acerca del uso excesivo de la prisión preventiva, instando a revertirlo [...]. En efecto, la ley 14.434 emplea, prima facie, el recurso de la prisión preventiva - que es la consecuencia necesaria de la improcedencia de la excarcelación- como instrumento de disuasión de delitos, en contra de la jurisprudencia antes aludida, y no deja margen de apreciación al juez para que evalúe si cierta conducta del imputado frente a un control policial o de otra índole, permite inferir que obstaculizará la acción de la justicia. Por lo tanto, acarrearía en ciertos supuestos, obligatoriamente, la consecuencia del encierro cautelar para individuos que podrían acceder, si fueran condenados, a la ejecución condicional prevista por el art. 26 del CP [...]. En esos términos, y con el objeto de resguardar en un determinado contexto ciertos bienes jurídicos, la reforma procesal podría estar desnaturalizando el fin cautelar del instituto de la prisión preventiva al convertirlo en una suerte de punición anticipada $[. .$.$] con el consecuente$ agravamiento que de ello se seguiría para la libertad del imputado durante la sustanciación del proceso [...]" $]^{n 9}$.

En este fallo el máximo Tribunal de la PBA se postula a favor de las ONGs denunciantes, homologando dos de sus reclamos tradicionales más importantes. Por un lado, la SCBA afirma que la ley 14.434 emplea, prima facie, el recurso de la PP como instrumento de disuasión de delitos, es decir, como una política criminal ad-hoc. Por el otro, sostiene que de aplicarse la ley 14.434 el encierro preventivo podría convertirse en una suerte de punición anticipada, o en otras palabras, que la PP resulte un adelanto de pena.

\subsection{La prisión preventiva como problema público}

Tomando en cuenta estos ejemplos, si hay algo que las ONGs han logrado con respecto a la PP es presentarla como un fenómeno que no puede ser analizado únicamente desde la institución judicial. Al adjudicar responsabilidades en el momento en el que llevan adelante sus demandas, estas agrupaciones permiten que el encierro preventivo sea considerado un problema extrajudicial, incluso un problema público ${ }^{60}$.

\footnotetext{
${ }^{59}$ Fallo de la SCBA sobre "CENTRO DE ESTUDIOS LEGALES Y SOCIALES (CELS) Y OTROS C/ PROVINCIA DE BS. AS. S/ INCONST. LEY 14.434".

${ }^{60}$ Para el CELS, "se trata de un problema con una multiplicidad de actores: por empezar, los más de 6.000 detenidos en comisarías; el organismo de derechos humanos que los representa colectivamente ante la justicia; la administración penitenciaria provincial; la justicia provincial; la legislatura provincial.
} 
En este sentido, para que algo sea considerado un problema es necesario que ciertos actores reconozcan su existencia, que se movilicen para mostrar que es un problema, y que sus definiciones de la realidad social sean aceptadas por un público más amplio (Lorenc Valcarse, 2005; Spector y Kitsuse, 1977).

Asimismo, la naturaleza pública de un problema también reside en las tensiones por las que atraviesan las diversas maneras que existen de concebir su solución o resolución (Gusfield, 2014). Remitiendo a Cefai (2014), el proceso de emergencia, estabilización e institucionalización de un problema público puede entenderse, por un lado, como producto de intereses en conflicto que se desarrollan entre diferentes sectores: asambleas legislativas, agencias administrativas, ámbitos académicos, medios de comunicación. Por el otro, como aquello que las personas consideran que es un problema público en términos morales, generando debates acerca de conductas definidas como deseables o indeseables (Pereyra, 2013). Más específicamente, un problema de este tipo involucra

Una definición moral: decir que algo es un problema social es decir que algo está mal, es decir, son situaciones evaluadas como negativas porque causan algún daño. En segundo lugar, para que algo adquiera el estatus de problema social tiene que tener un carácter extendido. Se diferencia, en este sentido, de un problema personal, es decir que afecta a un "número significativo de personas". En tercer lugar, implica una cierta dosis de optimismo; esto implica que esa situación problemática puede ser modificada por la acción humana. Por último, son situaciones que consideramos que deberían ser cambiadas: algo debe hacerse al respecto (Pereyra 2010: 31).

Y estos cuatro elementos, atribuibles a un problema público, es posible encontrarlos en la manera en que las ONGs abordan la cuestión de la PP. El uso excesivo de esta última es el que provoca una situación de sobrepoblación y hacinamiento de una gran cantidad de presos en la $\mathrm{PBA}^{61}$. Este perjuicio lo padecen los internos de muchas de las cárceles y comisarías bonaerenses ya que sus condiciones de

Parece claro también que cada uno de estos actores tiene intereses diversos, con variedad de convergencias y divergencias" (CELS, 2005: 116). Las cursivas son nuestras.

${ }^{61}$ En un informe del CELS se afirma que "los calabozos se encuentran en un estado deplorable de conservación e higiene; carecen de ventilación y luz natural. La humedad y, en verano, el calor, son agobiantes. No cuentan con ningún tipo de mobiliario, por lo que toda la actividad (comer, dormir) que desarrollan los internos debe llevarse a cabo en el piso. Los sanitarios no son suficientes para todos y no se garantiza la alimentación adecuada de los reclusos" (CELS, 2005: 92). 
habitabilidad son lesivas ${ }^{62}$. Dicha situación puede ser alterada, como de hecho lo ha sido ocasionalmente $^{63}$, si los tres poderes del Estado provincial se comprometen y trabajan mancomunados para erradicar la aplicación innecesaria de la PP. En definitiva, a partir de sus denuncias, las ONGs mencionadas intentaron

Convencer a otras personas, asociarlas a su protesta, movilizarlas, y para eso asegurarles no solamente que están diciendo la verdad sino también que esa verdad merece ser dicha y que la acusación, que señala a distintos actores estatales como responsables, está a la altura de la injusticia denunciada (Boltanski, 2000: 238; Mathieu, 2011).

En consecuencia, más allá de que los cambios logrados por estas agrupaciones puedan tener una moderada duración, sirven para observar cómo las ONGs han asumido a partir del problema de la PP una centralidad que les ha permitido impugnar, incluso en forma simultánea, a los tres poderes del Estado provincial.

\section{5- A modo de cierre}

Hemos visto en las secciones anteriores que existen por fuera del ámbito judicial un conjunto de actores que influyen en el problema de la PP dentro de la PBA. Cada uno de ellos posee distintas competencias a partir de las cuales "ingresan" al PJ y condicionan las decisiones de los operadores jurídicos. La policía, por su capacidad cotidiana de activar la mayoría de las investigaciones penales a realizar que posteriormente pueden dar lugar al uso de la PP. A su vez, vimos que esta fuerza de seguridad genera distintas percepciones en los actores judiciales: mayor consideración en los Fiscales, más escepticismo en los Defensores, y en los JG la necesidad de relacionarla con el desempeño de las autoridades políticas y sus directrices sobre la seguridad ciudadana.

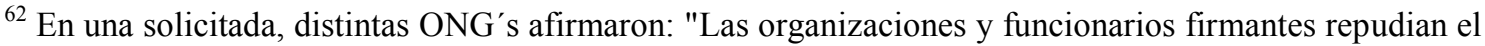
proyecto de ley aprobado esta tarde por la Legislatura Bonaerense, a partir de la propuesta del gobernador Daniel Scioli, de limitar las excarcelaciones en caso de portación ilegítima de armas de fuego. La Corte Suprema de Justicia de la Nación (CSJN) y la Corte Interamericana de Derechos Humanos han afirmado en reiteradas oportunidades que no pueden existir delitos no excarcelables y que la única posibilidad de privar de libertad a un individuo sin condena es por la acreditación de peligro procesal. Además de este vicio de inconstitucionalidad, la nueva ley no responde a una política de seguridad democrática y consistente y aumentará la cantidad de detenidos en condiciones absolutamente indignas. Alimentar la demagogia punitiva tiene altos costos sociales, aunque pueda verse como una táctica política beneficiosa en el presente". (Asociación Civil La Cantora, Asociación Pensamiento Penal, Centro de Estudios en Política Criminal y Derechos Humanos, Comisión Provincial por la Memoria, y otros).

${ }^{63}$ Esto ocurrió cuando se aplicaron transitoriamente las decisiones del fallo "Verbitsky". Véase nota 27.
} 
En segundo lugar, los medios de comunicación que al publicitar, y en ocasiones reprobar las decisiones judiciales generan cierta exposición para los actores judiciales. Sin embargo, estos actores valoran de diversas maneras a los medios, en particular respecto del uso de la PP: están quienes le adjudican un papel decisivo, quienes afirman que los operadores jurídicos pueden resistirse a su influencia, y quienes sostienen que los medios de comunicación se vuelven una excusa para que si los operadores jurídicos no están dispuestos a tomar una decisión, no la tomen.

Tercero, los representantes políticos, quienes por medio de acusaciones a los operadores jurídicos limitan sus posibles arbitrajes y debilitan su autonomía. Junto a esto, el estilo acting out que según dichos operadores tienen los dirigentes para abordar el control del delito y el papel de la justicia penal. En este aspecto, es para subrayar que según los testimonios de los operadores jurídicos, la PP se transformó en una de las medidas preferidas de las autoridades políticas en la PBA para conseguir ventajas rápidas en detrimento de soluciones estructurales.

Por último, vimos cómo las ONGs han logrado configurar a la PP como un problema en la agenda pública. Es decir, consiguieron que otros actores reconozcan su existencia, que se comprometan para exponer que es un problema, y que sus definiciones sobre la PP sean aceptadas por un público más amplio.

En definitiva, si bien no es el objetivo de esta tesis profundizar en estas relaciones, al traerlas a colación intentamos ofrecer un panorama amplio sobre la medida cautelar que estamos investigando. 


\section{TERCERA PARTE}

\section{CAPITULO III}

Poder para prever

En éste capítulo nos desplazaremos desde las trayectorias y los factores extrajudiciales vinculados a la PP hacia lo que ésta última debería ser según lo establecen las normas procesales. Hasta aquí mostramos qué actores por fuera del PJ bonaerense influyen en el uso del encierro preventivo, como es el caso de la policía, los medios de comunicación, el poder político y las ONGs, y de qué manera estos actores son percibidos por los operadores jurídicos. Ahora complementaremos la historia interna de la PP que presentamos en el primer capítulo de esta tesis al hablar de la dogmática del encierro preventivo. Para esto mencionaremos los requisitos legales que corresponde que se cumplan para que el encierro preventivo esté en condiciones de ser admitido, requisitos que a su vez han sido afectados por un número importante de reformas recientes. Por lo tanto, avanzaremos sobre dichos contenidos pormenorizando, en primer lugar, la regulación que ofrece el CPP de la PBA sobre la PP y las excarcelaciones. Luego, mencionaremos las modificaciones que dicha regulación ha experimentado. Y por último, introduciremos los testimonios que ofrecen al respecto los actores judiciales.

\section{1- Dos formas de entender, una de reglar}

A lo largo de este primer apartado profundizaremos en los presupuestos que según el CPP deben darse para que esta medida cautelar sea solicitada y concedida. O lo que es lo mismo, qué se necesita demostrar para considerar pertinente el uso de lo que los teóricos del derecho definen como la herramienta más violenta que tiene el Estado de Derecho durante el trámite investigativo (INECIP, 2011: 14) ${ }^{64}$. Para ello será útil hacer referencia a dos modelos, "sustancialista" y "procesalista", que también han sido desarrollados por la doctrina jurídica especializada. Si bien estas dos formas de entender

\footnotetext{
${ }^{64}$ También puede utilizarse la PP posteriormente a la investigación, aguardando la llegada del juicio o luego, mientras se confirma la sentencia.
} 
el encierro preventivo son construcciones de los doctrinarios del derecho, no dejan de tener cierta afinidad con lo que puede leerse en los distintos CPP, dentro de los cuales la PP se encuentra específicamente reglamentada.

\subsection{Sustancialismo y procesalismo en la provincia de Buenos Aires}

El primero de estos criterios, el "sustancialista", equipara a la PP con la ejecución por adelantado de una condena. Esto último menoscaba desde la garantía de juicio previo hasta Principios como el de Inocencia que referimos en el primer capítulo de la tesis. En este sentido, se sugiere que la medida cautelar adquiere

El carácter de sanción previa, infringiendo el bloque de constitucionalidad al tomar a la imputación como un hecho probado y la mera acusación como una sentencia previa [...], la prisión preventiva es utilizada [entonces] como instrumento de política de persecución penal eficaz; lo que evidencia una errónea interpretación de su finalidad, al buscar en las medidas cautelares la solución inmediata a la cuestión delictiva (INECIP, 2011: 15; DPLF, 2013: 34-40).

Esta interpretación tiene las siguientes consecuencias:

- Considerar como un evento alentador que el imputado esté bajo PP, ya que el encierro preventivo demostraría una persecución penal eficaz. Esto deja en un segundo plano a la investigación de los hechos denunciados, cuestión que debería ser la principal preocupación a lo largo del proceso judicial.

- En la legislación, se observa este modelo cuando son regulados, junto a los casos donde la PP puede aplicarse, los motivos que vuelven improcedente la excarcelación. Por ejemplo, mencionando un monto de pena en expectativa (en adelante, PEE) $)^{65}$, el tipo de delito imputado, la importancia del daño causado,

\footnotetext{
${ }^{65}$ Lo que se conoce como PEE es uno de los argumentos más frecuentes con los que se justifica la aplicación de la PP. Se trata de la condena que podría sufrir una persona en función del delito que se le imputa, por ejemplo si alguien está acusado de un homicidio simple su PEE es de 8 a 25 años. El primer Inc. del Art. 169 del CPP de la PBA afirma que podrá excarcelase a quien esté acusado de un delito cuya pena máxima prevista no supere los ocho (8) años de prisión o reclusión. Y el tercer Inc. sostiene que podrá excarcelarse si el delito tuviese una pena máxima prevista mayor a ocho (8) años, "pero de las circunstancias del o los hechos y de las características y antecedentes personales del procesado resultare probable que pueda aplicársele condena de ejecución condicional". La posibilidad de una condena de ejecución condicional, a su vez, está regulada en el CP. La primera parte del Art. 26 dice "en los casos de primera condena a pena de prisión que no exceda de tres años, será facultad de los tribunales disponer en el mismo pronunciamiento que se deje en suspenso el cumplimiento de la pena". Esto significa que la PEE es uno de los elementos que el JG podrá tomar para decidir sobre el uso de la PP, puesto que no es obligatorio. También supone que si alguien tiene antecedentes y llegara a recibir una sentencia
} 
los medios empleados para el delito, si éste último no prevé pena de ejecución condicional, así como las características personales del procesado o la resonancia social del hecho. También se observa con la posible declaración de reincidencia, o el otorgamiento de excarcelaciones previas.

- En términos concretos, el punto anterior describe los casos en que la regulación del CPP da a los operadores jurídicos más alternativas para poder aplicar la medida cautelar. Esto habilita un mayor uso de la PP, puesto que de demostrarse la existencia de alguno de los requisitos indicados la misma podría ser concedida.

En contraposición al criterio "sustancialista", los juristas dogmáticos proponen un enfoque "procesalista" que toma a la PP como un instituto excepcional, enfoque para el cual el objetivo de esta medida no es castigar al imputado sino desactivar cualquier tipo de riesgo que pueda obstaculizar la consecución del juicio y eventual ejecución de la condena. En este sentido:

- El encierro cautelar debe ser un medio que contribuya a garantizar los fines del proceso, por lo que se considera necesario restringir su utilización sólo para esos casos.

- La verosimilitud en el derecho ${ }^{66}$ y el peligro en la demora ${ }^{67}$ son dos indicadores que deben observarse simultáneamente.

- Sólo dos motivos permiten concluir la existencia del peligro en la demora: los ya mencionados entorpecimiento de la investigación y peligro de fuga. Únicamente cuando la libertad del imputado atente contra alguno de estos, la PP está justificada.

Como ya dijimos al comienzo de este apartado, el "sustancialismo" y el "procesalismo" son elaboraciones de doctrinarios del derecho con las que buscan definir y analizar el encierro preventivo. Sin embargo, no dejan de tener cierta afinidad con lo que puede leerse en los distintos CPP dentro de los cuales la PP se encuentra

condenatoria, la ejecución condicional no sería posible por lo que es más difícil que su excarcelación se formalice.

${ }^{66} \mathrm{Se}$ da cuando existe convicción suficientes para poder afirmar que el imputado es el autor -o participedel delito investigado.

${ }^{67}$ Este indicador exige que se demuestre la probabilidad concreta de que el imputado atentará contra los fines del proceso. 
específicamente reglamentada. En la PBA existen cuatro artículos que permiten introducirse en esta medida cautelar. El Art. 144 afirma que

El imputado permanecerá en libertad durante la sustanciación del proceso penal, siempre que no se den los supuestos previstos en la Ley para decidir lo contrario. La libertad personal y los demás derechos [...] sólo podrán ser restringidos cuando fuere absolutamente indispensable para asegurar la averiguación de la verdad, el desarrollo del procedimiento y la aplicación de la ley.

Esta norma pude ser ubicada dentro de un criterio "procesalista". Según el Art. 157, la detención se convertirá en PP cuando se den "conjuntamente" los siguientes requisitos: que esté justificada la existencia del delito, que el imputado haya declarado -o se haya negado a hacerlo-, que aparezcan elementos de convicción suficientes o indicios vehementes para sostener que el imputado sea probablemente autor o partícipe penalmente responsable del hecho, y que se den los presupuestos que impidan otorgar la excarcelación. Aquí ya empiezan a oscilar los parámetros, porque la redacción se inicia con un enfoque "procesalista" pero culmina con otro "sustancialista", limitando la libertad del imputado a que no se den los presupuestos que impidan la excarcelación.

A su vez, estos presupuestos se encuentran en el Art. 171, en el que se afirma que la excarcelación se rechazará siempre que haya indicios vehementes de que el imputado tratará de eludir la acción de la justicia o entorpecer la investigación. En realidad, esta norma debe interpretarse a partir de la lectura del Art. 148, donde se especifican las circunstancias de las que se podrán inferir los dos peligros procesales. En este artículo, el CPP ofrece criterios de merituación de la "peligrosidad procesal" que ciertamente se combinan con pautas afines a la "peligrosidad criminal":

Para merituar acerca de los peligros de fuga y entorpecimiento podrá tenerse en cuenta la objetiva y provisional valoración de las características del hecho, las condiciones personales del imputado, la posibilidad de la declaración de reincidencia por delitos dolosos, si hubiere gozado de excarcelaciones anteriores, que hicieren presumir fundadamente que el mismo intentará eludir la acción de la justicia o entorpecer las investigaciones $^{68}$.

Hasta aquí los criterios generales expuestos por el Art. 148 del CPP. Luego, en la misma norma, se enumeran circunstancias especiales que permiten suponer el peligro

\footnotetext{
${ }^{68}$ La cursiva es nuestra.
} 
de fuga, como es el caso de la falta arraigo, la magnitud de la pena en expectativa, la importancia del daño resarcible y el comportamiento procesal del imputado ${ }^{69}$. Con la enumeración de estos indicadores y presupuestos, dicho artículo se ubica en una posición "sustancialista".

En síntesis, la regulación que el CPP-PBA brinda para aplicar la PP es una, pero los criterios que esa regulación encierra son más. En algunos artículos se exalta la libertad del imputado, circunscribiendo la posibilidad del encarcelamiento a determinados presupuestos. En otras normas se facilita la denegación de la excarcelación ofreciendo numerosos indicadores para ello.

\section{2- Anunciar el futuro}

Como veremos a continuación, en la práctica el encierro preventivo se relaciona con la facultad que tienen los actores judiciales de predecir el comportamiento futuro de las personas procesadas. Se trata de un poder para prever el peligro de fuga o el entorpecimiento de la investigación. Estas predicciones, en primer lugar, parecen contribuir a la incapacitación y no a la rehabilitación del imputado ya que no se pretende con ellas ninguna respuesta activa, sino asegurar que el proceso se desarrolle con regularidad ${ }^{70}$. En segundo lugar, dichas predicciones se respaldan no en elementos probados, sino en especulaciones efectuadas en función de lo que regula el CPP bonaerense para los casos concretos.

\subsection{Predicción}

Con los peligros procesales de fuga y entorpecimiento en la investigación que ya mencionamos se pretende predecir algo que, de utilizarse la PP, nunca ocurriría. En este sentido, lo que el CPP ofrece a los operadores jurídicos es la posibilidad de anticiparse a los hechos. Tal como lo plantea Bovino, el encierro preventivo se inflige con la intención

\footnotetext{
${ }^{69}$ Respecto del peligro de entorpecimiento en la averiguación de la verdad, "se tendrá en cuenta la grave sospecha de que el imputado: 1. Destruirá, modificará, ocultará, suprimirá o falsificará elementos de prueba, 2. Influirá para que coimputados, testigos o peritos informen falsamente o se comporten de manera desleal o reticente, 3. Inducirá a otros a realizar tales comportamientos" (Art. 148 CPP-PBA).

${ }^{70} \mathrm{Si}$ bien el concepto de incapacitación dentro del campo de la criminología suele vinculárselo con la intención de asegurar que el detenido no vuelva a cometer delitos, nosotros encontramos afinidad en el hecho de que la PP busca impedir algo -la fuga o el entorpecimiento de la investigación por parte del imputado- por medio de la neutralización del imputado.
} 
De evitar hechos que podrían suceder en el futuro, esto es, aún no realizados, [por lo que] cabe preguntarse si es posible que, en el marco del procedimiento penal, se pueda verificar ese pronóstico (2005: 22).

Más en concreto, si se tuviese que pensar por ejemplo en el peligro de fuga, ¿de qué modo podríamos verificarlo fehacientemente? Dejando de lado extrañezas, como podría ser el caso de un imputado descubierto in fraganti comprando un pasaje para emigrar del país sin fecha de retorno, presagiar que alguien eludirá sus obligaciones con la justicia parece insostenible fácticamente. Con el peligro de entorpecimiento no sucede algo muy distinto: especular con que alguien destruirá pruebas que lo comprometen o amenazará a testigos para que no lo incriminen sigue siendo un pronóstico que carece de sustento empírico. Y aún en el supuesto de que el imputado tenga antecedentes por haber delinquido en oportunidades anteriores, por haberse fugado o por haber entorpecido una investigación judicial, tampoco estaríamos en condiciones de aseverar que repetirá comportamientos similares en el futuro.

A esto cabe agregar que según el CPP, el JG debe identificar la existencia concreta de los peligros procesales a través de pruebas objetivas que surjan de elementos y testimonios incorporados debidamente al proceso. Sin embargo,

Parece extremadamente difícil, al menos en la mayoría de los casos, probar la realización de un comportamiento del imputado que sucederá en el futuro (piénsese que si el Estado aún no ha podido probar un hecho que efectivamente ya fue cometido —el hecho punible objeto del proceso- cuánto más improbable es que "pruebe" —en verdad, se trata de una tarea imposible - que es muy probable que algo suceda en el futuro) (Bovino, 2005: 22-3).

Esta dificultad de comprobar la presencia efectiva de los peligros procesales durante la investigación de un ilícito es de mucha relevancia ya que plantea un grave problema para conciliar a la PP con el Principio de Inocencia, puesto que se encarcela a una persona jurídicamente inocente sin tener demostradas las razones que justificarían dicho encierro.

\subsection{Ideal rehabilitador y prisión preventiva}

El interrogante que hasta aquí ha atravesado el presente capítulo es el siguiente: ¿por qué las personas jurídicamente inocentes deberían estar encarceladas? Ahora 
bien, si a esta pregunta se le adiciona otra como ¿para qué lo están? el tema de la PP puede ser analizado a la luz de una nueva cuestión. Más concretamente, y sin olvidar las finalidades procesales antedichas, al examinar cuáles serían los propósitos penológicos ${ }^{71}$ por los que se considera legítimo mantener recluida a una persona jurídicamente inocente, la perplejidad respecto de la PP es aún mayor.

En la PBA la ley 12.256 es la que reglamenta la ejecución de la pena y lo hace poniendo de relieve su acuerdo con lo que se conoce como ideal rehabilitador (Garland, 2005, 2006), el cual ha gravitado en buena parte de la penología occidental desde el surgimiento de la cárcel moderna hasta la actualidad. En esta ley provincial se sostiene que el tratamiento a desarrollarse en la cárcel debe "[...]"mantener, fomentar y mejorar" la "educación e instrucción" del condenado y se establece que "La enseñanza será preponderantemente formativa, procurando que el interno comprenda sus deberes y las normas que regulan la convivencia en la sociedad" (Arts. 133 y 134). También se señala que el interno está autorizado "a satisfacer las exigencias de su vida religiosa, participando de ceremonias litúrgicas y a tener consigo objetos, libros de piedad, de moral e instrucción de su credo" (Art. 154) y se prevé que debe existir en cada establecimiento un "local adecuado" para las prácticas religiosas (Art. 155). Para cerrar esta breve descripción, la ley también establece que "las relaciones del interno con su familia, en tanto fueren convenientes para ambos y compatibles con su tratamiento, deberán ser facilitadas y estimuladas" (Art. 168) ${ }^{72}$.

Sin embargo, como refleja Sozzo (2007: 564), este ideal rehabilitador -o proyecto normalizador y correccional- poco tiene que ver con la PP. En primer lugar, un imputado que carece de una condena firme no puede ser pasible de ningún tratamiento en concreto porque no hay delito que se le haya comprobado. Por lo tanto, no tiene nada

\footnotetext{
${ }^{71}$ La penología es un ámbito de conocimiento orientado al análisis y evaluación sobre la ejecución de la pena, junto a los presupuestos que esa ejecución conlleva. (Rivera Beiras et al, 2008).

${ }^{72}$ Hay que tener presente que el ideal rehabilitador, en la práctica, se ha mostrado permanentemente frustrado. Tal como lo expuso Foucault, "[...] desde hace siglo y medio, se ha presentado siempre la prisión como su propio remedio; la reactivación de las técnicas penitenciarias como la única manera de reparar su perpetuo fracaso; la realización del proyecto correctivo como el único método para superar la imposibilidad de hacerlo pasar a los hechos" (1989, 273-4). Según Baratta, "[...] esto significa que la pena como instrumento principal de este sistema, falla en lo que respecta a la función de prevención de la criminalidad. Este estado de crisis se registra en todos los frentes: sea el de la prevención negativa general, es decir de la intimidación de los potenciales delincuentes, sea el de la prevención positiva especial, es decir, de la reinserción social de los actuales infractores de la ley penal. Estos fines preventivos son, a la luz de los hechos simplemente inalcanzables. Por otra parte otras funciones de prevención que parecen ser efectivamente realizables para el sistema penal, como la prevención negativa especial, es decir, la neutralización o la intimidación específica del criminal y la prevención general positiva, es decir, la afirmación simbólica de la validez de las normas que favorecen el proceso de integración social, son en realidad inadecuadas respecto de los criterios de valor que preceden a nuestras constituciones, a saber las constituciones del estado social y democrático de derecho" (2004b: 152-167).
} 
de qué rehabilitarse ya que es inocente para la ley. En segundo lugar, el ideal rehabilitador se encuentra, dentro de las teorías que justifican a la pena, en una perspectiva que considera al condenado capaz de mejorar si se realizan un diagnóstico y un tratamiento adecuados (prevención especial positiva). Por el contrario, la PP debería ser ubicada dentro de los enfoques que dan preferencia a la incapacitación o neutralización del imputado, puesto que busca impedir a partir de este encierro que entorpezca la investigación o se fugue (prevención especial negativa) ${ }^{73}$.

Vale recordar que la incapacitación como fundamento de la pena pretende la simple limitación o restricción de una persona condenada, con el objetivo fundamental de impedir que cometa nuevos delitos (Von Hirsch, 1992). Esta finalidad de la pena se la ha intentado alcanzar a través de predicciones sobre la probabilidad que tiene un condenado de reincidir. En palabras de Bovino,

Aquellos a quienes se considera más probable que reincidan tienen que ser neutralizados, por ejemplo, mediante una pena de prisión, o por una pena de prisión más larga de la que de todos modos recibirían (1998: 52).

Esto permite observar la afinidad que existe entre la incapacitación para quien está condenado y la PP para quien está procesado. Por un lado, esta última se justifica en base a un pronóstico predictivo sobre el comportamiento futuro del imputado, el cual se vincula con la existencia de riesgos procesales de fuga o entorpecimiento en la investigación. A su vez, de este imputado no se pretende ninguna respuesta activa -como sucede con el condenado al que se incapacita-, sólo garantizar por medio de su encierro que el proceso se desarrolle con normalidad.

\subsection{Precisión}

La importancia de los pronósticos sobre el comportamiento futuro de los imputados ha provocado una serie de objeciones. En primer lugar, se argumenta que estas predicciones para el caso de la PP no son un elemento complementario, sino el núcleo que respalda la decisión (INECIP, 2012). Por ejemplo, supongamos que dos personas son imputadas por el mismo tipo penal: robo agravado en grado de tentativa y

\footnotetext{
73 Para las teorías de la pena, véase nota 23 del capítulo I. Es importante volver a señalar que la incapacitación en tanto "prevención especial negativa" tiene el objetivo que la persona encarcelada no pueda volver a cometer delitos. La justificación legal de la PP no es esta última, sino conjurar riesgos procesales. Si bien no son las mismas finalidades, la analogía que nosotros advertimos tiene que ver con la necesidad de neutralizar al individuo en ambos casos para alcanzar sus finalidades respectivas.
} 
portación de arma de guerra ${ }^{74}$, y de una de ellas se predice que puede huir u obstaculizar el desarrollo del proceso y de la otra no. Los imputados en este supuesto tendrán destinos dispares debido a que la probabilidad de fugarse o entorpecer el proceso pondrá a uno en la cárcel y al otro no. En definitiva, se resuelve en forma diferente sobre la libertad de dos personas por la predicción de hechos que no sucedieron efectivamente.

En segundo lugar, se presenta lo que los especialistas en la materia han llamado el problema de la precisión en los pronósticos (Morris et al, 1992). Las investigaciones efectuadas en distintos contextos sobre predicciones de comportamientos para graduar futuras condenas ${ }^{75}$ han generado dos críticas significativas: la de los falsos negativos y la de los falsos positivos. Lo que se pone en el centro de la discusión es el grado de fidelidad que poseen estas predicciones sobre los individuos a los que se las realiza.

- En los falsos negativos se ha presagiado que determinadas personas no volverían a delinquir, y en efecto, lo hicieron. La predicción es negativa, dice Mathiesen, "en el sentido de que se declara que el delincuente no reincidirá, pero la predicción es falsa porque se produce la reincidencia" (2003: 147).

- La segunda crítica surge con los denominados falsos positivos en los que individuos a los que se hubiese encerrado por un largo período de tiempo, por sus altas posibilidades de delinquir nuevamente, no lo vuelven a hacer. La predicción es positiva, debido a que sostiene que el individuo reincidirá, pero falsa porque de hecho la reincidencia no acontece $^{76}$.

Ambas críticas sobre la precisión de los pronósticos respecto de la pena son aplicables respecto a la precisión de los pronósticos que se utilizan para solicitar,

\footnotetext{
${ }^{74}$ Hecho tipificado en el CP, Arts. 166 inc. 2 segundo párr., 42, 55 y 189 bis.

${ }^{75}$ Se trata de indicadores que sirven para predecir el comportamiento del infractor y de esa manera agravar o atenuar el tiempo en la condena. Estos indicadores suelen tener en cuenta condenas previas por un delito del mismo tipo, últimos años pasados en la cárcel, condena antes de los dieciséis años, presencia en una prisión juvenil estatal, consumo de drogas duras en los dos últimos años, consumo de drogas duras juvenil, y desempleo durante más de la mitad de los últimos dos años.

${ }^{76}$ Complementando la cuestión de la precisión con la de los principios, Mathiesen afirma: "El problema es el siguiente: ¿con qué base, en términos de principios, se condena a cárcel por actos que, de otra manera, sin la condena, pueden suceder o sucederán en el futuro? La prevención de actos futuros aquí no es un objetivo formulado más o menos vagamente, sino el fundamento o la razón explícita para la condena particular ¿Sobre qué base se sustenta una condena por actos futuros?” (2003: 148). Es difícil responder a eso, pero evidentemente la base o el sustento no se encuentra en los principios de legalidad e inocencia que poseen una gran importancia en el ámbito penal y procesal penal.
} 
conceder o denegar la PP. En una investigación empírica sobre 100.000 acusados realizada en EE.UU., se afirma que los predictores utilizados habitualmente por los jueces son mucho menos confiables de lo que se cree, pudiendo estar en libertad más del $25 \%$ de las personas que permanecen encerradas preventivamente (Baradaran y McIntyre, 2012).

Respecto a los pronósticos y precisiones sobre la PP en la PBA, el problema es mayor del que acabamos de describir. Aquello en lo que jurídicamente se sustenta esta medida cautelar es en la peligrosidad procesal, en la probabilidad de que el imputado huya u obstaculice la investigación. Pero a diferencia de lo que se mencionó para el caso de la graduación de la pena, el hecho de predecir el comportamiento de quien está imputado de un delito no surge de análisis probabilísticos ni de la distribución estadística, sino de la merituación que permite hacer el CPP como resultado de una operación formal combinada con saberes judiciales prácticos ${ }^{77}$.

Al entrevistar a los operadores jurídicos y consultarles en base a qué se pronostican los peligros procesales y a su vez, si tienen conocimiento acerca de investigaciones empíricas sobre fugas o entorpecimientos de personas imputadas que permanecían libres, expresaron lo siguiente:

\footnotetext{
"No está sustentado en estadísticas, es un presupuesto antropológico, o lógico, del CPP, no hay verificación estadística. Es una premisa objetiva a partir del delito cometido [...] por la imputación de un delito, lo cual puede cambiar luego. No deja de tener viso de razonabilidad, pero debe ser sólo un elemento, y no el único. La pena en expectativa tiene tanta relevancia si vos sólo te atenés al Art. 169, en una mirada literal u objetiva de la norma [...], pero se trata de un supuesto más, no es decisivo -de mayor o menor relevancia- de acuerdo al caso y al imputado, no es el único elemento" (Juez de Garantías, Departamento Judicial de La Plata).
}

\footnotetext{
${ }^{77}$ Feeley (2008), al hablar de los orígenes de la justicia actuarial, menciona cómo empezó a cobrar importancia el hecho de poder predecir quienes se iban a presentar y quienes no en las disputas tribunalicias en EEUU, lo que según este autor se encontraba en la antesala de pretender predecir la peligrosidad de los imputados. Pero estos pronósticos que menciona Feeley, aún con sus imprecisiones, se basaban en un "modelo de predicción por los lazos comunitarios": cuanto más fuertes eran esos lazos, menos probabilidades de que el imputado sea considerado un potencial evasor. En síntesis, la predicción aquí se realizaba en base al conocimiento que se tiene de las personas concretamente y no de operaciones formales como en el caso del CPP de la PBA. En América Latina existen algunas propuestas similares sobre evaluación de riesgos y supervisión de imputados en libertad (Carrasco Solís, 2009; Villadiego Burbano, 2010)
} 
"Se toma como referencia el Art. 169. En función del 148inc. 2. Es puramente normativo. La referencia es cuál va a ser el resultado del proceso [...]" (Fiscal de Instrucción, Departamento Judicial de Quilmes).

"[...] la prisión preventiva es solicitada en función de criterios sustancialistas, como la peligrosidad del imputado o la pena en expectativa. O la dogmática invocación del peligro procesal, sin acreditación de su existencia" (Juez de Garantías, Departamento Judicial de Mar del Plata).

"Debería pedirse [la PP] por los peligros procesales, y en la realidad nadie controla que haya algún peligro, y se lo hace por algún componente clasista y racista, o los pánicos mediáticos. En los hechos, la prisión preventiva es una pena adelantada, porque se basa en la pena en expectativa" (Defensor Oficial, Departamento Judicial de Mar del Plata).

Estos testimonios ofrecen la posibilidad de conocer dos elementos importantes. El primero, que los pronósticos en base a los cuales los actores judiciales solicitan y conceden la medida cautelar son el resultado de especulaciones que se apoyan en normas procesales y no en predicciones sustentables. Esto no quiere decir que a la hora de tomar una decisión sobre la PP estén ausentes por completo saberes prácticos configurados en el ámbito judicial. De hecho, la presencia en los relatos de la PEE del delito junto con la clase social o la peligrosidad del imputado, permite observar cómo esos principios formales del CPP entran en relación con aprendizajes locales que los actores judiciales han ido alcanzando. El segundo elemento se relaciona con que los argumentos de estos actores a la hora de sustentar sus definiciones sobre el uso cotidiano del encierro preventivo ofrecen una potencialidad crítica. Por lo general, los informes y documentos sobre el tema (ADC, 2012; INECIP, 2012) muestran a operadores jurídicos principalmente reproductores del orden existente en el PJ, impulsados a solicitar la PP por "fuerzas judiciales inconscientes". A diferencia de estas investigaciones sobre la PP, aquí se encontraron operadores jurídicos que, tal como lo señala Boltanski, "tienen acceso, aunque en grados desiguales, a recursos críticos, y los utilizan de un modo casi permanente en el curso ordinario de su [trabajo...] (2000: 53). Con esto queremos sugerir que los actores judiciales, en no pocos casos, llevan adelante operaciones críticas por medios de las cuales sostienen posturas disonantes con su propio entorno. 
Abreviando, en la práctica la PP está modelada por la posibilidad que tienen los actores judiciales de pronosticar el comportamiento de los imputados. Este poder para prever los riesgos procesales se sustenta, no tanto en datos empíricos o en estudios probabilísticos, sino en razonamientos efectuados en base a aprendizajes locales sobre cómo deben interpretarse los riesgos procesales mencionados. Dichos razonamientos parecen priorizar indicadores como la PEE, la clase social o la peligrosidad del imputado y no los Principios constitucionales de Inocencia o Legalidad. Por último, algunos operadores jurídicos expresan, además, una mirada crítica en la que describen las causas y las consecuencias de esa forma de razonar.

\section{3- Legislar el problema, ¿es la solución?}

El CPP actual fue aprobado por las dos cámaras legislativas el 10 de enero de 1997 y se publicó en el Boletín Oficial el 23 de enero de 1997. Fue promulgado por el entonces gobernador de la PBA Eduardo Duhalde, y el 28 de septiembre de 1998 entró en vigencia. Previo a esta reforma, la PP operaba bajo la regla de ser aplicada para todo imputado siempre que estuviera demostrada la existencia del delito, que se le haya tomado declaración indagatoria al imputado o que éste se hubiese negado a prestarla, y que existiese semiplena prueba o indicios vehementes para considerarlo responsable del hecho. Esto se mantuvo prácticamente inalterado desde 1935 hasta 1992 cuando se dicta la ley 10.484. Con ésta última se modificó el régimen de excarcelación que luego serviría como antecedente para los cambios implementados por la ley 11.922.

\subsection{El nuevo Código}

Como sugerimos en el capítulo anterior, con la reforma estructural al CPP de la PBA por medio de la ley 11.922 se pretendió revertir una tendencia histórica respecto al uso del encierro preventivo. Sobre esta cuestión se estructuró el título del Código que regula las medidas de coerción, considerando como regla la libertad del imputado mientras se desarrolle el proceso. Así pues, el Art. 144 original de la ley $11.922^{78}$ quedó redactado de la siguiente manera:

\footnotetext{
${ }^{78}$ En los fundamentos de esta ley, que datan del 30 de mayo de 1996, se observaba en torno a la PP: "Entre las instituciones arraigadas en la tradición jurídica de la Provincia, y que el proyecto ha receptado y mantenido, se destacan la figura del particular damnificado, el ya referido instrumento del hábeas corpus, y el sistema de excarcelación y eximición de prisión incorporado, esta vez, como integrante del cuerpo normativo, sobre la base de reconocer la situación de libertad del imputado como modo normal
} 
El imputado permanecerá en libertad durante la sustanciación del proceso penal. La libertad personal y los demás derechos y garantías reconocidos a toda persona por la Constitución de la provincia sólo podrán ser restringidos cuando fuere absolutamente indispensable para asegurar la averiguación de la verdad, el desarrollo del procedimiento y la aplicación de la ley.

Respecto al peligro de fuga y entorpecimiento en la investigación, el Art. 148 indicaba cuatro presunciones iuris tantum $^{79}$ para presumir su existencia. La PEE, la importancia del daño a resarcir, la ausencia de residencia fija y el comportamiento del imputado durante el procedimiento. Además, el Art. 169 señalaba que "debía" excarcelarse a todo aquel cuyo delito atribuido tuviera una pena máxima inferior a seis años. Asimismo, procedía la excarcelación en los casos en que a la persona, de ser condenada, no le correspondiese una pena de cumplimiento efectivo, o si el imputado hubiera cumplido el plazo máximo de dos años más uno de prórroga en PP.

Aún con estos cambios, la regulación en torno a la PP de la ley 11.922 no dejó de ser confusa. Pudiéndose sustentar la medida cautelar sólo en la necesidad de alcanzar los fines procesales, siguió habiendo referencias a cuestiones como el arraigo del imputado o la PEE, que poco tienen que ver con dicha necesidad.

\subsection{Los cambios sucesivos}

A partir de la sanción de la ley 11.922, la legislación procesal penal en la jurisdicción bonaerense mostró un gran número de cambios. Si bien no haremos hincapié en cada una de las modificaciones al CPP-PBA, sí es importante destacar que fueron más de treinta hasta principios del 2013. Se suma a esto que en más de una ocasión sus presupuestos, fundamentos y objetivos han sido discordantes, cuando no contradictorios $^{80}$. A continuación señalaremos los cambios más destacados respecto al encierro cautelar para luego brindar algunas conclusiones sobre lo que estos cambios trajeron aparejado:

\footnotetext{
de permanecer en el proceso, mientras no exista una sentencia condenatoria firme y siempre que no se verifiquen supuestos justificantes de la prisión preventiva" (Las cursivas son nuestras).

${ }^{79} \mathrm{Se}$ trata de una locución latina que significa que la ley presume la existencia de algún hecho, salvo que se pruebe lo contrario.

${ }^{80}$ Las leyes modificatorias de la Ley 11.922 hasta 2013 son las siguiente: $11.982,12.059,12.085,12.119$, $12.278,12.405,13.057,13.078,13.177,13.183,13.186,13.252,13.260,13.418,13.425,13.449,13.480$, $13.572,13.708,13.811,13.812,13.818,13.943,13.954,14.128,14.172,14.257,14.296,14.453,14.434 \mathrm{y}$ 14.442 .
} 
- El 8 de enero de 1998, la ley 12.059 que homologó la aplicación del nuevo CPP ya mostró cambios en lo atinente a la PP. Como indica un informe del CELS, "el tercer requisito de procedencia de la prisión preventiva quedó redactado de modo tal que desaparece la necesidad de que se verifiquen los fines procesales de la medida. Y para el caso de las excarcelaciones se modificó el deberá ser excarcelado [...] por un más moderado podrá [...]" (2004: 98). Esto dio lugar a una mayor discrecionalidad para que los JG puedan decidir el otorgamiento o no de la PP.

- En abril de 1999 se publica en el boletín oficial la ley 12.278 que elimina del CPP la necesidad de que las medidas de coerción, entre ellas la PP, se efectivicen únicamente en los casos en que resulten imprescindibles para el logro de los fines del proceso ${ }^{81}$. En otras palabras, se disminuyen las exigencias para la aplicación del encierro preventivo.

- Para el año 2000, en los albores de la gestión de Carlos Ruckauf como gobernador de la PBA, se sanciona la reforma bautizada con su mismo nombre. La ley $12.405^{82}$ agravó la legislación procesal en torno al uso de la $\mathrm{PP}^{83}$. Según los fundamentos de los legisladores, se necesitaba "equilibrar el interés del imputado de un delito por su libertad y el interés punitivo de la sociedad". Los cambios más significativos fueron: (A) En los casos en que la excarcelación al imputado fuera posible porque la PEE no estuviese por encima de los tres años, se exige además que "deba resultar probable que pueda corresponder condena de ejecución condicional". Esto quiere decir que además de una PEE baja, indirectamente se le exige al imputado carecer de antecedentes penales, porque si los tuviera podría corresponderle cumplir la condena efectivamente más allá del tiempo de duración de la pena. (B) Deja de ser obligatorio para el JG remplazar la PP por una medida cautelar menos grave ${ }^{84}$ en los casos en que estas

\footnotetext{
${ }^{81}$ ARTÍCULO 144.- (Texto Ley 12.278) Alcance: El imputado permanecerá en libertad durante la sustanciación del proceso penal, siempre que no se den los supuestos previstos en la Ley para decidir lo contrario.

${ }^{82}$ Se publica el 15 de marzo del año 2000, pero su aprobación había sido a fines de febrero. El diario La Nación lo reflejaba de la siguiente manera: "Tras cinco horas de maratónico debate, la Cámara de Diputados bonaerense sancionó ayer, a las 2.25 , la ley que endurece la legislación penal en la provincia. La nueva norma modifica y pone trabas al régimen de excarcelaciones y da mayores atribuciones a la policía. A partir de la promulgación de la norma PE 9/99/00, no quedarán en libertad los autores de robos con armas y los que ejercieran violencia sobre las personas para cometer un delito. Tampoco serán excarcelados los que abandonen a sus víctimas tras un homicidio culposo. La policía, en tanto, podrá requisar elementos y enseres, además de identificar sospechosos en operativos públicos.”.

${ }^{83}$ Diarios como La Nación (28-3.2000) y Clarín (13-2-2000) hablaban de "la mano dura de Ruckauf" y de su intención de restringir la salida de presos. Para Camou y Moreno, "esto no era sólo el abandono de las iniciativas reformistas, sino también un claro signo del inicio de un ciclo de contrareforma que apuntaría a desandar lo hecho desde fines de 1997 [...]" (2005: 164).

${ }^{84}$ En la PBA las medidas cautelares alternativas a la PP son: arresto domiciliario, presentación a la autoridad, arraigo, prohibición de concurrir a ciertos lugares, fianza, encarcelamiento con salidas laborales
} 
medidas aseguren los fines del proceso. La decisión pasa a ser discrecional del Magistrado. (C) Queda sometido a valoración del JG aquello que se considere "plazo razonable" cuando se presenten casos de mayor complejidad. Como consecuencia de esto se flexibiliza el tiempo estipulado por el CPP original de dos años -con uno más de prórroga- para los hechos investigados con personas encarceladas, quedando a merced de lo que el Magistrado considere "plazo razonable" (CELS, 2004: 99).

- En abril del mismo año 2000, el Procurador General, máxima autoridad del Ministerio Público de la $\mathrm{PBA}^{85}$, dictó la resolución 752 por la que instruye a los Fiscales para que apelen las decisiones judiciales que otorguen la excarcelación del imputado. Este pedido del Procurador se oponía a la ley 12.601 que organiza al Ministerio Público, en cuyo Art. 65 recomienda a los Fiscal evitar medidas de coerción personal, solicitando cuando fuere posible alternativas a la privación de libertad.

- Poco tiempo después del caso Blumberg, y en parte como respuesta política al mismo, se sancionó en abril de 2004 la ley 13.183. Respecto a la PP estrictamente, aumentó los supuestos en los que no es viable la excarcelación durante el desarrollo del proceso. Uno de esos supuestos fue el de portación de arma de fuego no declarada y sin la debida autorización.

- Dos años después, y en una dirección sensiblemente distinta a las reformas anteriores, se sanciona la ley $13.449^{86}$ que modifica siete artículos del CPP de la $\mathrm{PBA}^{87}$. Suele considerársela como corolario del "fallo Verbitsky" y de las exigencias que en dicha sentencia sostuvo la CSJN. Con esta ley dejaron de considerarse a determinados delitos per se no excarcelables. Según el Art. 144 del CPP reformado, la PP sólo procederá "cuando fuere absolutamente indispensable para asegurar la averiguación de la verdad, el desarrollo del procedimiento y la aplicación de la ley". Con la nueva redacción del Art. 159 los JG quedan obligados a aplicar medidas menos lesivas que el encierro cautelar si con ellas se puede garantizar los fines del proceso. Antes de esta reforma, el JG tenía la posibilidad de recurrir o no a esas medidas alternativas. Además, regula la posibilidad de evaluar cada ocho meses la conveniencia de la PP.

\footnotetext{
${ }^{85}$ El Ministerio Público bonaerense tiene una estructura jerárquica y está encabezado por el cargo de Procuradora General. A su vez, se encuentra divido en Ministerio Público Fiscal y Ministerio Público de la Defensa. Véase Ley 12.601 en sus Arts. 1 y 2.

${ }^{86}$ Fue publicada el 17 de marzo del 2006.

${ }^{87}$ Se trata de los Arts. $144 ; 148 ; 156 ; 157 ; 159 ; 169$ y 171.
} 
- En febrero de 2009 se publicó la Ley 13.943, con la que se volvió a limitar la posibilidad de aplicar medidas alternativas y morigeradoras de la PP sólo para casos excepcionales y por cuestiones humanitarias. Estos casos redactados en el Art. 159 habilitan sólo a personas mayores de 70 años, mujeres en estado de gravidez o con hijos menores de 5 años o quienes padecieran una enfermedad incurable a solicitar esos beneficios.

- El 4 de mayo de 2010 se dictó la Ley 14.128 que estableció nuevas restricciones a la excarcelación, pudiéndose otorgar en los casos que la PEE por el delito cometido no fuese superior a los ocho años de prisión. Esto último supone seguir el criterio que ubica el potencial castigo a sufrir como un indicador para evaluar si se otorga o no la excarcelación, dejando de lado los preceptos generales que -para restringir la libertad durante la investigación- exigen sustentarse en el peligro de fuga o entorpecimiento en la investigación.

- La ley 14.434 apareció en el Boletín Oficial el 8 de febrero del 2013 y modifica el artículo 171 del CPP que aborda los supuestos para denegar la excarcelación ${ }^{88}$. Esta reforma convalidó la inadmisibilidad de la excarcelación ante una imputación de una serie de delitos, impidiendo que el JG meritue el hecho y a quien se imputa por el mismo, forzándolo a negar la excarcelación automáticamente. En síntesis, la ley obliga a los JG a decretar la PP para los casos especificados.

- Como se expuso en el capítulo previo, las disposiciones de la ley 14.434 fueron suspendidas por la SCBA a partir de un Acuerdo homologado el 26 de febrero del 2013. Allí afirmaba el máximo tribunal bonaerense que "en el marco de una demanda originaria de inconstitucionalidad iniciada por el Centro de Estudios Legales (CELS) y otros, decidió, como medida cautelar, suspender los efectos de la ley 14.434, modificatoria del artículo 171 del Código Procesal Penal, hasta que se dicte sentencia definitiva por considerar que sus disposiciones, prima facie, resultan contrarias a derechos y garantías reconocidos por las constituciones de la Nación y la Provincia y

\footnotetext{
${ }^{88}$ Quedó redactado de la siguiente manera: "En ningún caso se concederá la excarcelación cuando hubiere indicios vehementes de que el imputado tratará de eludir la acción de la justicia o entorpecer la investigación. La eventual existencia de estos peligros procesales podrá inferirse de las circunstancias previstas en el artículo 148. Tampoco se concederá la excarcelación cuando, en los supuestos de tenencia o portación ilegítima de arma de fuego de cualquier calibre, el imputado hubiera intentado eludir el accionar policial, evadir un operativo público de control o, de cualquier otro modo, desobedecer, resistirse o impedir el procedimiento. A fin de garantizar la correcta aplicación de las disposiciones precedentes y de lo normado en el artículo 189 bis apartado $2^{\circ}$ párrafo octavo del Código Penal, a partir de la aprehensión la autoridad policial o judicial requerirá en forma inmediata los antecedentes del imputado". En cursiva, lo que agregó la reforma.
} 
diversos tratados internacionales de rango constitucional" ${ }^{19}$. De este modo la SCBA interrumpió la aplicación de la reforma.

- En julio de 2013, con la sanción de la ley 14.517, la redacción del Art. 171 volvió a modificarse eliminando los delitos no excarcelables ${ }^{90}$. Esto permitió que el JG pueda decidir cuando denegar u otorgar la PP.

Si se consideran globalmente estas reformas en la PBA, lo que parece orientar los vaivenes en la legislación procesal penal en general, y respecto de la PP en particular, es la coyuntura política y no las convicciones axiológicas. Por ello, tomando prestado lo que sugiere Garland (2005) para el contexto británico y estadounidense, si se considera el arco completo del discurso gubernamental bonaerense sobre la PP se hace evidente que está estructurado por un conjunto de conflictos y tensiones que descansan en presupuestos políticos y jurídicos que, tomados en su conjunto, son discordantes. Esto da por resultado criterios de regulación cada vez más dualistas y polarizados.

En este sentido, hay un primer intento entre los años 1996 y 1998 por limitar su uso, que va desde los debates legislativos sobre el nuevo CPP hasta su puesta en práctica $^{91}$. Ya a partir de 1999 esto parece trastocarse, con un momento crucial que es la sanción de la llamada "ley Ruckauf", y que se mantiene con parámetros similares hasta 2005, en particular con el paquete de "reformas Blumberg". Acompañando al "fallo Verbitsky" y la posterior sanción de la ley 13.449, desde comienzos del 2006 las excarcelaciones y medidas alternativas a la PP tuvieron un reverdecer en las normas procesales bonaerenses. Esta tendencia se interrumpe al limitarse las morigeraciones $\mathrm{u}$ opciones al encierro cautelar a principios de 2009 y llega hasta el intento frustrado de consagrar delitos no excarcelables a comienzos de 2013.

\footnotetext{
${ }^{89}$ Véase http://www.scba.gov.ar.

${ }^{90}$ Se sancionó el 8 de julio de 2013, y quedó de la siguiente manera "Denegatoria. El juez podrá considerar que concurren esos extremos cuando en los supuestos de tenencia o portación ilegítima de arma de fuego de cualquier calibre, el imputado hubiera intentado eludir el accionar policial, evadir un operativo público de control o, de cualquier otro modo, desobedecer, resistirse o impedir el procedimiento"

${ }_{91}$ En los Fundamentos de la ley 11.922 se afirma la necesidad "de reconocer la situación de libertad del imputado como modo normal de permanecer en el proceso, mientras no exista una sentencia condenatoria firme y siempre que no se verifiquen supuestos justificantes de la prisión preventiva".
} 


\section{4- Etapas y estadísticas}

Las oscilaciones en la legislación procesal sobre la PP que mencionamos en el apartado anterior tienen consecuencias difíciles de medir respecto al uso específico de la medida cautelar ${ }^{92}$. Uno de los indicadores concretos que existe para evaluar las derivaciones de estas reformas es la estadística sobre los porcentajes de presos preventivos.

Frente a la pregunta que planteamos anteriormente acerca de si legislar el problema de la PP es la solución, parece posible afirmar que en términos generales las reformas procesales han agravado dicho problema antes que remediarlo. Sucede, como ha quedado justificado en la enumeración de las modificaciones al CPP de la PBA, que éstas últimas no han tenido una orientación inequívoca. Más bien se trata de fluctuaciones que tienen un punto de partida, que es el de los debates previos a la ley 11.922, y que bajo retóricas muy diversas llegan hasta hoy.

Estas fluctuaciones legislativas las agruparemos en cuatro etapas. Cada una de estas etapas puede ser analizada ${ }^{93}$ como portadora de consignas y efectos sobre el uso de la PP. Dichas etapas se confrontarán ahora con las estadísticas disponibles de personas encarceladas y presos preventivos en cada una de ellas.

El primer período se sitúa, como ya dijimos, entre 1996 y 1998 y se caracteriza por las disputas parlamentarias y posterior sanción del nuevo CPP. Vale recordar también que en este flamante CPP la libertad del imputado durante el proceso fue considerada la regla. En esos años, el porcentaje de personas bajo PP en la PBA fue el siguiente.

\section{Personas privadas de libertad en la provincia de Buenos Aires, según situación procesal ${ }^{94}$}

\begin{tabular}{|c|c|c|c|}
\hline AÑO & $\begin{array}{c}\text { \% de procesados } \\
\text { con PP }\end{array}$ & $\%$ de condenados & Sin Datos \\
\hline 1996 & $81,8 \%$ & $18,2 \%$ & - \\
\hline
\end{tabular}

\footnotetext{
92 La difícil evaluación del modo en que estas reformas influyen se debe a la carencia de información e indicadores detallados que sobre la PP ofrece el PJ. Por ejemplo, sería necesario contar con la información acerca de cuantas PP se imponen a lo largo de un año en los Tribunales penales, por qué tipo de delitos, o cual es la duración media de la PP por categorías de delitos en un período determinado como una década o un lustro-.

${ }^{93}$ Los diferentes informes y documentos de las ONGs muestran consenso en delimitar los cambios en estos períodos (CEJA, 2011; CELS, 2005, 2010; INECIP, 2012).

94 Fuente para las estadísticas de todos los años respecto de la situación procesal de las personas encarceladas: CELS.
} 


\begin{tabular}{|c|c|c|c|}
\hline 1997 & $86,6 \%$ & $13,4 \%$ & - \\
\hline 1998 & $90,1 \%$ & $9,9 \%$ & - \\
\hline
\end{tabular}

Por lo tanto, se puede afirmar que en los años donde se instala un discurso progresista con el que se intenta limitar el uso de la PP, no obstante el porcentaje de la misma se incrementó.

A partir de 1999 y hasta 2005 se dan una serie de reformas de signo más represivo. Esta fue la evolución en el uso de la PP:

\begin{tabular}{|c|c|c|c|}
\hline AÑO & $\begin{array}{c}\% \text { de procesados } \\
\text { con PP }\end{array}$ & Sin Datos condenados & \\
\hline 1999 & $91,8 \%$ & $8,2 \%$ & - \\
\hline 2000 & $86 \%$ & $9 \%$ & $5 \%$ \\
\hline 2001 & $87 \%$ & $10 \%$ & $3 \%$ \\
\hline 2002 & $87 \%$ & $10 \%$ & $3 \%$ \\
\hline 2003 & $85 \%$ & $11 \%$ & $4 \%$ \\
\hline 2004 & $84 \%$ & $12 \%$ & $4 \%$ \\
\hline 2005 & $79 \%$ & $14 \%$ & $7 \%$ \\
\hline
\end{tabular}

La tendencia que se observa aquí es la de una baja en los porcentajes de presos preventivos a lo largo de un período distinguido por el endurecimiento en las normas procesales sobre el tema. Otro dato significativo que surge si se toman juntos estos dos períodos discursivamente antagónicos, es el del incremento sin precedentes en la tasa de presos cada 100.000 habitantes en la PBA, que va de 75 en 1996 a 169 en $2005^{95}$. Entre esos años se registró un

Nivel de crecimiento del $138 \%{ }^{96}$ de la tasa de encarcelamiento, que sería mas del doble de los considerados alarmantes en el contexto de la Unión Europea en el período 19922003 y del registrado en los Estados Unidos entre 1990 y 2000 (Sozzo, 2007: 531).

\footnotetext{
${ }^{95}$ Datos provistos por el SNEEP.

${ }^{96}$ Para las cifras que nosotros utilizamos, el incremento sería del 125\%. De cualquier modo sigue siendo, tal como lo plantea Sozzo, muy superior a los contextos europeos y norteamericanos.
} 
Por lo tanto, dos etapas que pueden considerarse enfrentadas, al menos desde sus retóricas y propuestas legislativas sobre encarcelamiento y el uso de la PP, implicaron un aumento progresivo en la cantidad de $\operatorname{presos}^{97}$.

Desde el 2006 al 2008, época del fallo "Verbitsky" y de cambios legislativos que buscaron limitar el uso de la PP, se dio un leve y simultáneo incremento tanto en el porcentaje de las personas procesadas como en el de las personas condenadas. Esta aparente paradoja tiene su explicación en que durante esos años se redujo el número de personas alojadas en comisarías, las cuales no eran contabilizadas hasta dicho momento, influyendo esa redistribución de internos en la construcción de las estadísticas al respecto.

\begin{tabular}{|c|c|c|c|}
\hline AÑO & $\begin{array}{c}\% \text { de procesados } \\
\text { con PP }\end{array}$ & S de condenados & Sin Datos \\
\hline 2006 & $73 \%$ & $15 \%$ & $12 \%$ \\
\hline 2007 & 73,1 & $16 \%$ & $10,9 \%$ \\
\hline 2008 & $75,2 \%$ & $19,7 \%$ & $5,1 \%$ \\
\hline
\end{tabular}

Cabe señalar que a diferencia de los dos anteriores, en este período si bien la tasa de encarcelados cada 100.000 habitantes disminuyó, lo hizo levemente: de 161 en 2006 a 160 en $2008^{98}$.

El último período que comienza en 2009 y continúa al día de hoy, muestra una retórica más severa acerca del control del delito, con una propensión a restringir el uso de las excarcelaciones. Sin embargo, los porcentajes de presos preventivos en la PBA descienden ${ }^{99}$.

\footnotetext{
${ }^{97}$ Es importante mencionar que en la PBA entre los años 1996 y 2005 existió, junto con el aumento en la tasa de encarcelamiento, un incremento en la tasa de hechos delictuosos cada 100.000 habitantes que va de 1.260 en 1996 a 1.633 en 2005, habiendo llegado a su pico máximo en el año 2002 con 2.523 (Informe SNIC, 2008).

${ }^{98}$ Datos provistos por el SNEEP.

${ }^{99}$ La caída en los porcentajes de presos preventivos a partir del año 2005 debe analizarse teniendo en cuenta la introducción del Proceso de Flagrancia en la PBA, que supone para ciertos delitos, juicios más expeditivos y condenas más rápidas. Esto se abordará en el capítulo V.
} 


\begin{tabular}{|c|c|c|c|}
\hline AÑO & $\begin{array}{c}\% \text { de procesados } \\
\text { con PP }\end{array}$ & de condenados & Sin Datos \\
\hline 2009 & $74 \%$ & $22,7 \%$ & $1,3 \%$ \\
\hline 2010 & $64,3 \%$ & $33,1 \%$ & $1,3 \%$ \\
\hline 2011 & $60,2 \%$ & $37,3 \%$ & $1,1 \%$ \\
\hline 2012 & $59,1 \%$ & $39,8 \%$ & $1,0 \%$ \\
\hline 2013 & $57,9 \%$ & $41,1 \%$ & $0,7 \%$ \\
\hline
\end{tabular}

Respecto de la tasa de personas encarceladas cada 100.000 habitantes desde el 2009 siguió incrementándose, con una estabilidad en los últimos tres años tal cual lo planteamos en la introducción de esta tesis: en 2009 fue de 169 cada 100.000, en 2010 de 171 , en 2011,2012 y 2013 de $174^{100}$.

Cabe aclarar que los indicadores disponibles que acabamos de presentar no son suficientes para revelar los factores que estructuran el problema entre los cambios legislativos, el encarcelamiento y el uso de la PP. Primero, porque no es posible determinar el tiempo en el cual los distintos cambios de regulación procesal logran traducirse en prácticas concretas - si es que lo consiguen- dentro de la institución judicial. Y fundamentalmente porque estas cifras anuales sobre la cantidad de presos preventivos no permiten saber cómo varían la cantidad de solicitudes de PP, y qué porcentaje de todas estas solicitudes son concedidas o no ${ }^{101}$. Por otro lado, sí permiten ver que acontecimientos considerados contra-reformistas como la "ley Ruckauf", punitivos como las reformas "Blumberg", o progresistas como el fallo "Verbitsky", tienen consecuencias menos evidentes de las que le suelen dar los informes y documentos de las ONGs. Un ejemplo al respecto es el documento del CEJA en el que se afirma que

A partir de la modificación, por el año 2000, de la legislación en materia de prisión preventiva por la conocida "ley Ruckauf", por entonces gobernador de la provincia, que endureció el régimen de encierro cautelar, se generó un exponencial aumento de los presos preventivos, lo que trasladó automáticamente innumerable cantidad de inconvenientes en los lugares de alojamiento (CEJA, 2011: 63-4).

\footnotetext{
${ }^{100}$ Datos provistos por el SNEEP.

${ }^{101}$ Esta información no existe, principalmente porque no hay obligación en el PJ de recolectarla. Esto dificulta la posibilidad de lograr diagnósticos más certeros sobre la circulación y uso de la PP en la PBA.
} 
Acerca del "caso Blumberg", el CELS sostuvo en su informe del año 2010 que la Ley 29.892 sancionada el 5 de mayo de 2004 en el marco del paquete de reformas impulsado por Juan Carlos Blumberg aumentó los requisitos para el acceso a la libertad condicional provocando mayores restricciones al respecto. Sobre el fallo "Verbitsky", tanto el CIPPEC (2011) como el CELS (2007) sugirieron que provocó una baja de la cantidad de personas privadas de la libertad en la PBA, tanto condenados como procesados. Por nuestra parte, y más allá de estas afirmaciones de las ONGs, lo que podemos concluir es que la relación entre los cambios legislativos, el encarcelamiento y el uso de la PP no es directa.

\section{5- Percepciones, encarcelamiento y prisión preventiva}

Ahora nos detendremos en la evaluación que hacen los actores judiciales sobre los cambios en la regulación procesal penal que acabamos de enumerar y su incidencia en la práctica judicial de la PP. Estos cambios al CPP de la PBA son percibidos de forma variada por los actores, pudiéndose agrupar las respuestas en cuatro modelos.

Uno de los modelos es el que le atribuye a las reformas procesales en materia de PP un lugar significativo. Esta perspectiva, que podríamos definir como "normativista", presupone que los cambios legislativos en la regulación de la medida cautelar son aceptados y puestos en práctica sin mediaciones ni resistencias específicas por parte de los operadores jurídicos.

\footnotetext{
"Una de las banderas de la reforma procesal penal en la provincia de Buenos Aires fue la de terminar con los presos sin condena. El texto original de la ley 11922 se orientaba claramente a evitar que los procesados estén con prisión preventiva, lo que quedaba claramente expuesto en el artículo 144. Sin embargo, no transcurrieron más de 18 meses de la puesta en vigencia del nuevo código para que se le introdujera una radical reforma (ley 12.405) que hacía girar en 180 grados la dirección del código en materia de situación ambulatoria del imputado frente al proceso. Lo que antes debía ser la excepción -la prisión preventiva-, pasó a ser la regla general, desembocando en un notorio incremento de la población carcelaria que desembocó en el fallo "Verbitsky". "Verbitsky" produjo una desaceleración de la tasa de encarcelamiento, y [...] lo cierto es
} 
que su filosofía impregnó el sistema y, fundamentalmente, las prácticas de los operadores [...]" (Defensor Oficial del Departamento Judicial de La Plata).

"Creo que con la sanción de una Ley como la 12.405 casi termina por transformarse a la excarcelación en la excepción y no la regla, lo que resultó decisivo para la duplicación de población carcelaria verificada en el primer lustro de la década pasada. Para contrarrestar esa duplicación años después tiene fundamental importancia la incidencia del fallo Verbitsky de la CSJN que provocó la modificación de aquellas reglas" (Fiscal de Instrucción del Departamento Judicial de Quilmes).

La reivindicación de las normas procesales como elemento central para comprender la práctica de la PP puede tener varias interpretaciones, porque estos testimonios describen situaciones en las que los actores judiciales deciden alinearse a los cambios legislativos, pero no nos permiten saber si este alineamiento sucede por convicción o por conveniencia. En definitiva, con este modelo podemos confirmar la importancia de las normas procesales, si bien no estamos en condiciones de precisar la motivación concreta de los actores detrás de esta importancia.

En otros casos, los operadores jurídicos argumentan acerca de la importancia de los cambios normativos complementándolo con factores externos al PJ, como es el caso del aumento del delito o la gestión y retórica políticas acerca del control del delito.

"Lo que yo vengo viendo es cómo las reformas legislativas tienen incidencia en la administración de justicia, que es muy permeable. Por ejemplo, con la reforma del '98 se restringió el uso de la PP. Con la reforma Ruckauf se extendió más allá de los pedidos de inconstitucionalidad. Me da la impresión que las reformas normativas tienen un impacto bastante importante luego. Con la reforma, que es pos Vertbisky, con seguimiento de la CSJN para que los jueces no mantengan a personas en comisarías, etc., se utilizaron todas las alternativas a la PP siempre que sea posible. Y también creo que las reformas normativas vienen acompañadas por los discursos políticos. La de Ruckauf viene con la idea de meter bala [...], la del '98 viene con un aire de progresismo [...], de esa manera, los jueces se acoplan a los discursos de la política. Con la reforma Vertbisky, hubo un presión importante de la CSJN, con notas fuertes, para que los jueces eviten el uso de la PP. Y eso tuvo un impacto importante [...]" (JG del Departamento Judicial de Mar del Plata). 
"Las modificaciones en materia de prisión preventiva y excarcelación son importantes. En mi opinión, la Ley 11.922 significó un avance en materia de prisión preventiva, dejando bien en claro cuál era su naturaleza y finalidad [...]. Pero lamentablemente, este siempre ha sido uno de los capítulos del código más afectados por las sucesivas reformas que pretendían vender, desde el discurso político, que se estaba trabando en materia de seguridad. Como consecuencia, el espíritu originario del Código fue sensiblemente trastocado, llegándose al punto de establecerse normativamente categorías de delitos "inexcarcelables", como lo que pretendía hacer la Ley 12.405" (Fiscal de Instrucción del Departamento Judicial de La Plata).

En estos relatos intervienen otros actores y otros elementos que se presentan como significativos para analizar los usos de la PP. Las normas jurídicas son importantes, pero no son producto de un proceso que esté fuera de las tensiones y pujas extrajudiciales. No son la recompensa de los espíritus libres, sino que están originadas gracias a múltiples imposiciones (Foucault, 1992: 198).

Otros actores judiciales apelaron a los mismos componentes, pero invirtiendo el orden en su escala. Por ejemplo, la importancia de las reformas legales es ubicada por detrás del aumento en la tasa del delito o la retórica política a la hora de aludir a los vaivenes del encarcelamiento y la aplicación de la PP.

"No son sólo cambios legislativos. Yo sigo la evolución del delito en estos pagos, y veo que los hechos son más graves que años atrás, más armas, mas droga, hechos de muchísima violencia, que si son esclarecidos colocan calificaciones muy severas. Obviamente también el tema de las sucesivas reformas de la excarcelación es otro que suma a la prisionización preventiva. Hay un tema que está relacionado con la presión política sobre los jueces, ya que la posible denuncia para el enjuiciamiento influyó en los jueces de primera instancia y también en los de segunda instancia" (Fiscal de Instrucción del Departamento Judicial de Mar del Plata).

"El aumento de la tasa de prisionalización obedece en primer lugar a la falta de una política de prevención del delito, en segundo lugar a las reformas procesales, en especial a aquellas que determinaron un aumento considerable de delitos no excarcelables como la 12.405 del 2000 o la 14.128 del 2010" (JG del Departamento Judicial de La Plata). 
En consecuencia, hay una alteración en la relación de los componentes señalados ya que sin un aumento en la tasas del delito o con una política seria en la prevención del mismo, las reformas legislativas difícilmente podrían materializarse.

En el cuarto modelo los operadores jurídicos agregan a los cambios legislativos y a la gestión gubernamental del control del delito, la figura de los medios de comunicación. Estos últimos -coincidiendo con uno de los criterios sugeridos en el capítulo anterior al trabajar dichos medios de comunicación- son descriptos como delimitadores del trabajo judicial:

"Para mí las causas van en el siguiente orden. Primero las reformas legislativas al código procesal penal, restringiendo el principio general que reconoce la libertad de toda persona imputada de un delito durante la substanciación del respectivo proceso. Dos, los discursos punitivos de actores políticos que podrían haber influido negativamente en operadores judiciales como la "puerta giratoria", acompañados de acciones concretas contra jueces identificados como "garantistas" por sectores políticos -casos Schiavo y Sal Lari, por ejemplo. Digo podrían porque es una presunción que no puedo verificar. Último, los reclamos sociales de mayor prisionización y castigo a través de medios masivos de comunicación, inmersos en un discurso de miedo y paranoia sobre la cuestión de la seguridad que han producido reformas en el código penal y podrían haber influido en actores judiciales" (Defensor Oficial del Departamento Judicial de Quilmes).

"El hostigamiento mediático y político a los jueces inexactamente catalogados como "garantistas". Las reformas legislativas que obedecieron a las políticas de seguridad de los gobiernos de turno con la falsa hipótesis que los problemas de seguridad son resueltos por el Poder Judicial [...]. Y también la incidencia de los discursos políticos y su efecto en la sociedad" (Fiscal de Instrucción del Departamento Judicial de La Plata).

La prensa es mencionada aquí como uno de los actores que gravitan junto a las reformas procesales y a las autoridades políticas. Por lo tanto, es el triángulo de relaciones que se da entre medios, normas jurídicas y representantes el que más influye en el desempeño de los actores judiciales.

A partir de estos cuatro modelos, es posible advertir que los cambios en la regulación procesal de la PP y las excarcelaciones tienen un lugar importante en la 
percepción de los operadores jurídicos. En algunos casos es considerado como un factor que posee autonomía para generar un mayor uso del encarcelamiento preventivo. En otros casos, las reformas procesales aparecen como un indicador del acting-out en la gestión y retórica políticas de los gobiernos respecto al control del delito. Como dijimos en el capítulo previo, este acting-out se manifiesta, según los actores judiciales, a partir de las formas contradictorias con las que las autoridades estatales y sus diversas agencias han respondido al dilema del delito y la PP. Estas respuestas, por lo general, han eludido la complejidad de este dilema buscando resultados a corto plazo.

Además, estos testimonios sirven para confirmar que los componentes extrajudiciales expuestos en el capítulo anterior son considerados promotores de vaivenes en el encarcelamiento y aplicación de la PP dentro de la $\mathrm{PBA}^{102}$. Y lo que resulta importante destacar sobre estos elementos no judiciales, es que aquí los operadores eligieron mencionar a la clase política, los medios de comunicación o el aumento en las tasas de delito sin que se les haya preguntado directamente por ellos. Las consultas realizadas en el capítulo precedente eran cerradas, y frente a ellas los actores judiciales expresaban su valoración. En este caso, los componentes son destacados por ellos sin nuestra intercesión.

En definitiva, a la hora de reconstruir la percepción de los operadores jurídicos sobre las causas del encarcelamiento y el uso de la PP en la PBA, se debe tener en cuenta las relaciones variadas que según ellos mismos se generan en la práctica entre diversos fenómenos (Williams: 2009; Hall, 2010). Están los vinculados a las reformas procesales y otros cuya influencia dentro del PJ es más difusa, como es el caso de la prensa, el de la política gubernamental sobre el control del delito o el del aumento de este último.

\section{6- A modo de cierre}

En este capítulo señalamos que el uso del encierro preventivo es considerado como anticipo de un castigo futuro desde una postura sustancialista. O por el contrario, como una medida excepcional reservada para los casos donde determinados peligros procesales puedan ser probados y no sólo declamados, lo que se denomina criterio procesalista. Dijimos, además, de qué manera estos peligros procesales son estipulados

\footnotetext{
${ }^{102}$ En rigor, las reformas procesales son un elemento externo al ámbito judicial como los anteriores, pero se diferencia de ellos porque reconfigura directamente la regulación jurídica de la PP. En otras palabras, si bien surge fuera del PJ ingresa formalmente a este último.
} 
a partir de pronósticos sobre hechos que no es posible corroborar en concreto, con la particularidad de que para la PP derivan de una combinación entre operaciones formales y saberes locales, y no de investigaciones e informaciones empíricas. Y sugerimos cierta analogía entre la incapacitación como finalidad de la pena y la PP como medida con la cual asegurar el proceso: amabas logran sus propósitos por medio de la neutralización del individuo.

Vimos también que desde 1998, año en el que se reformó estructuralmente el CPP-PBA, los cambios en su composición no han cesado, fundamentalmente en lo que tiene que ver con la PP y las excarcelaciones. Organizamos estos cambios en cuatro períodos: el primero entre los años 1996 y 1998 en el que buscó limitar el uso de la PP, el segundo entre 1999 y 2005 donde esto parece trastocarse, con dos eventos importantes: la sanción de la "ley Ruckauf" y el paquete de "reformas Blumberg". El tercero que va del 2006 al 2008 ligado al "fallo Verbitsky" y la posterior sanción de la ley 13.449 donde las excarcelaciones y medidas alternativas a la PP adquirieron aires renovados. Por último, el período que comienza en 2009 y se mantiene hasta hoy en el cual vuelven a limitarse las morigeraciones o alternativas al encierro cautelar junto con el intento frustrado de señalar delitos no excarcelables a principios de 2013. Sin embargo, estos períodos no nos permitieron concluir que la relación entre los cambios legislativos, el encarcelamiento y el uso de la PP sea directa.

Respecto de la percepción de los operadores jurídicos, las reformas procesales en la PBA son consideradas un elemento importante para evaluar el uso de la medida cautelar en particular, y el aumento del encarcelamiento en general. Y junto a este elemento también surgieron otros factores gravitantes como el aumento del delito, los medios de comunicación y la gestión y retórica políticas del control del delito. 


\section{CUARTA PARTE}

\section{CAPITULO IV \\ Por escrito: el uso de la prisión preventiva en los expedientes}

En el capítulo anterior presentamos, entre otras cuestiones, una perspectiva dogmática acerca de la PP en la que esta medida cautelar fue analizada por lo que es, o más exactamente, por lo que debería ser según lo que disponen las normas jurídicas. Teniendo en cuenta los testimonios que brindaron los actores judiciales, el tema del encarcelamiento y el uso de la PP puede interpretarse como resultado de la incongruencia entre la legislación y los tiempos en que ésta se aplica, como la errónea aplicación de las normas correctamente elaboradas, como producto del cada vez más notorio influjo de la prensa, o bien como respuesta al aumento de la tasa de criminalidad.

A continuación, pasaremos de un plano jurídico de la PP a otro judicial, es decir, de lo que afirman las normas legales sobre el encierro preventivo -y de lo que dicen los actores judiciales al respecto-, a lo que sucede con este último en la administración de justicia. Por tal motivo, introduciremos algunas características del objeto expediente para luego indicar qué hacen los actores judiciales en dicho instrumento con la PP. En segundo lugar, se mencionarán una serie de informes en los que se ha trabajado con métodos diferentes el uso del encierro preventivo a partir del expediente. Por último, tomando este instrumento como fuente primaria analizaremos aquello que se consigna para justificar la medida cautelar, agrupando los expedientes en cuatro modelos de argumentación.

\section{1- Cuerpos que constituyen causas}

Considerado en algunos trabajos y publicaciones como cuerpo fetiche dentro del PJ, el expediente ha tenido históricamente un lugar importante en la actividad judicial (Martínez, 2004; Sarrabayrouse, 2004; Barrera, 2007, 2008). Como rasgo preponderante de este instrumento puede mencionarse el de instituirse y circular a partir de la 
escritura $^{103}$, junto a los efectos de homologación que dicha escritura genera para los sucesos jurídicos allí designados. Respecto de los expedientes, la homologación facilita la comparación entre ellos y sus respectivos contenidos,

[...] la homologación hace posible una forma de racionalización entendida, con Max Weber, como previsibilidad y calculabilidad: a diferencia de dos jugadores que, a falta de haber discutido sobre la regla del juego, se dedican a acusarse de trampa cada vez que aparece una discordancia con la idea que cada uno de ellos se había hecho de las reglas, los agentes implicados en una acción codificada saben que pueden contar con una norma coherente y sin escapatoria [...]" (Bourdieu, 2001: 218).

Además, con la consolidación del objeto expediente surge la oportunidad para que un nuevo grupo de expertos esté en condiciones de producirlo e interpretarlo legítimamente. En este sentido, la escritura y las estandarizaciones normativas guardan una notoria afinidad con las características que Weber le adjudica a las burocracias modernas, con el agregado de que el expediente en estas últimas es tomado como un principio administrativo. Según sus propias palabras,

Los "expedientes", por un lado, y la disciplina burocrática, por otro, es decir, la sumisión de los funcionarios a la obediencia rigurosa dentro de su labor habitual, constituyen cada día más dentro de las esferas pública y privada el fundamento de toda organización (2002: 742).

Por lo tanto, las decisiones introducidas en los expedientes se ejecutan por medio de regulaciones y estándares normativos que se suponen neutrales, a partir de los cuales se favorecen las comparaciones entre estos instrumentos y limitar en ellos criterios arbitrarios.

\subsection{Los buenos y los malos motivos}

Durante todo el derrotero que transita el expediente, desde el inicio de su confección hasta el momento en que se archiva, ofrece algunas ventajas para los actores que intervienen a lo largo de un proceso. Un atributo importante es el de establecer continuidad a partir de la distribución y acoplamiento de distintos sucesos, relatos y

\footnotetext{
${ }^{103}$ La escritura, tal como lo plantea Godoy, "no afecta únicamente a las fuentes del derecho y al razonamiento legal, sino también a la organización del derecho. La relación del derecho con la sociedad se formaliza con el advenimiento de la escritura. [...] el derecho escrito alcanza autonomía propia, como lo hacen sus órganos. El tribunal se va separando gradualmente de la corte real o del jefe, adquiriendo sus propios especialistas, sumamente instruidos" (1990: 176; Souza Santos, 2009: 72).
} 
contribuciones que provienen de actores que, en los hechos, se encuentran dispersos (Renoldi, 2008; Barrera, 2011, 2012). Estas intervenciones son agilizadas, organizadas y pasibles de control a partir del expediente, prescribiéndose el modo y la forma en que los actores deben participar en él. En síntesis, brinda coherencia al conocimiento de un hecho, objetivándolo a partir de una serie de actividades que a priori son registradas adecuadamente, y no derivadas de procedimientos antojadizos.

En sintonía con la descripción que se acaba de realizar, Ciocchini (2013) le asigna a este instrumento la posibilidad de producir colectivamente un hecho que se transforma en judicial por seguir esos pasos y requisitos. Es la causa judicial -que necesita de la recolección y agrupamiento de diferentes eventos, de la articulación de las intervenciones de diversos actores- la que se materializa en el expediente. $\mathrm{O}$ en otras palabras, que es el expediente el que da lugar a este tipo de causa judicial penal, y no a la inversa. En definitiva, se trata del objeto en el que queda asentada la reconstrucción de un hecho delictivo,

Es decir, traduce testimonios de testigos, pericias de expertos, etc. al lenguaje jurídico técnico construyendo un relato jurídicamente significativo. El expediente es el soporte de ese relato judicial. Al contener las intervenciones precedentes de los diferentes actores judiciales permite recorrer, en cualquier momento, el proceso de construcción de dicho relato (Ciocchini, 2013: 147; Latour, 2010: 99) ${ }^{104}$.

Y es debido a estas características que se puede decir que el expediente es no sólo un instrumento, sino también un actor más dentro del proceso penal, ya que esta en condiciones de modificar con su incidencia las relaciones entre personas y eventos (Latour, 2008; Boltanski, 2000; Nardacchione, 2011).

Además de las utilidades que se acaban de mencionar del objeto expediente, éste instrumento ha sufrido un conjunto de críticas, de las cuales serán mencionadas dos muy relevantes. La primera, de tipo técnica, ha señalado al expediente como la encarnación del proceso inquisitivo y escriturario anterior a la reforma del CPP en la PBA durante $1998^{105}$. Según este tipo de detracciones, dicho instrumento facilita la

\footnotetext{
${ }^{104}$ Según Barrera, "la figura del expediente resume por antonomasia el funcionamiento del aparato judicial. De hecho, los expedientes son objetos cotidianos -y tal vez los más comunes- en la vida de un tribunal. Ellos son las formas que ponen en movimiento la dinámica de trabajo de un tribunal, organizando su actividad [...] a través de las cuales se desarrollan y realizan las capacidades personales" ( 2008: 224-39).

${ }^{105}$ Los reformadores y sus programas oponen a los componentes del proceso inquisitivo los del proceso acusatorio: oralidad e inmediación, sin papeleo excesivo, y con una mayor agilidad. Según autores como Levene, "el "inquisitivo" y el "acusatorio" son bastante más que modelos procesales. En verdad, representan manifestaciones abiertas o encubiertas de una cultura, pues expresan una determinada escala
} 
demora judicial, y la exigencia de una gran cantidad de trámites que no siempre son indispensables para el esclarecimiento de una causa.

Junto a estas objeciones existen otras de índole moral, que en términos generales sostienen, como lo hace Hazan, que la tramitación de los expedientes provoca en los funcionarios

Un distanciamiento de los casos concretos a resolver, y por lo tanto de las personas que protagonizan un conflicto, ya que no se le autoriza a los funcionarios a decretar normas especiales para cada caso particular, sino que le obliga a limitarse a una reglamentación abstracta" (2009: 173; Iud, 2009: 21).

El expediente, desde esta perspectiva, separa a quienes trabajan dentro del ámbito judicial de aquellas personas que deberían ser sus beneficiarias directas, contribuyendo a una mayor indolencia en la tarea de los operadores jurídicos.

Teniendo en cuenta lo que acabamos de introducir, una conclusión provisional sobre el instrumento expediente es que más allá de los argumentos expertos y los discursos reformadores que se mencionaron concisamente, y que en su mayoría son críticos, este instrumento se mantiene vigente (Barrera, 2012; Ciocchni, 2013). Y dicha permanencia no debe calificarse apresuradamente como producto de hábitos e intereses desprovistos de sensatez, de fuerzas institucionales arraigadas o de comportamientos desaprensivos por parte de los actores judiciales. Es importante conocer, antes que denunciar, de qué manera el expediente, con sus limitaciones y utilidades -históricas y actuales- contribuye a modelar el sentido de las prácticas que forman parte del trabajo cotidiano en el PJ en la PBA.

\section{2- La redacción de los riesgos}

Dentro del ámbito judicial bonaerense, la PP es una de esas prácticas que forman parte del trabajo cotidiano. Asimismo, afecta a la mayoría de las personas que se

\footnotetext{
de valores vigente en una sociedad en un momento o en un lapso histórico determinado" (Cafferata, 1992: 226). Debemos decir que difícilmente se pueda encontrar alguno de estos modelos en estado puro: con oscilaciones, existen mayoritariamente sistemas mixtos. Muy concisamente, "El proceso acusatorio, que tuvo principalmente en cuenta las garantías del acusado, se fue caracterizando por la separación de las tres funciones fundamentales, de acusar, defender y juzgar, la libertad de la defensa y libre apreciación de la prueba, pocas facultades del juez, inapelabilidad de la sentencia, que no se fundaba, y además como un proceso contradictorio, público y oral; el inquisitivo, que buscaba defender más los intereses de la defensa social, por el secreto, la no contradicción, la escritura, la concentración de las tres funciones en manos del juez, sistema de pruebas legales, la confesión como prueba esencial y, en consecuencia, el uso del tormento y la apelación de las sentencias" (1993: 105-6).
} 
encuentran encarceladas en esa jurisdicción. Y los expedientes están vinculados a dicha medida cautelar, a los riesgos procesales que deberían justificarla, porque es en estos instrumentos donde se despliegan argumentos para solicitarla, objetarla, aceptarla o denegarla (Vaughan, 1999, 2007). Estos instrumentos suelen estar compuestos por el acta de detención y notificación de derechos; las declaraciones de las víctimas, los policías actuantes y testigos; un croquis del lugar donde se dieron los hechos y los datos personales e información sobre antecedentes, condenas o procesos pendientes de los imputados; un informe médico legal $\mathrm{y}$, en los casos de robo, algún tipo de peritaje relacionado con el objeto de robo. Con este material elevado a sede judicial, el Juez decide la toma de declaración indagatoria de la persona imputada.

A continuación, presentaremos los resultados más destacados de algunos precedentes en los que se ha trabajado, con métodos y finalidades distintas, el lugar y las características que la PP exhibe en los expedientes, junto a los criterios que utilizan los operadores jurídicos para fundamentar el encierro preventivo.

\subsection{Los informes previos}

No son muchos los trabajos que evalúan el uso de la PP en los expedientes a los largo de la Investigación Penal Preparatoria (en adelante, IPP). En Francia, por ejemplo, el Comité para el monitoreo de la détention provisoire (2007) hace referencia a las decisiones que durante el procedimiento inciden en la detención provisoria. Al respecto, el informe de dicho Comité advierte que además de los requisitos legales y los relacionados con las necesidades de la investigación, tanto la carga de trabajo de los tribunales como los medios a su alcance vinculados al flujo de los expedientes, generan efectos sobre la duración de la PP. Sin embargo, no profundiza en el papel concreto que tiene esta medida cautelar en los expedientes.

En un estudio presentado en 2011 por el Centro de Implementación de Políticas Públicas para la Equidad y el Crecimiento (en adelante, CIPPEC) se indagaron los criterios que se ponen en juego a la hora de aplicar la PP en la PBA. Para ellos se analizaron diez expedientes buscando acercarse a una conclusión preliminar respecto de la actuación judicial a la hora de restringir la libertad durante el proceso (CIPPEC, 2011: 27). Allí se hizo hincapié en los parámetros utilizados para el pedido de la PP, si 
esos parámetros concuerdan con los cánones legales y constitucionales, y más en concreto, con los requisitos del proceso penal.

- Del total de las causas examinadas, 7 fueron iniciadas por delitos de robo o hurto en sus distintas calificaciones y variantes ${ }^{106}, 2$ por homicidio y 1 por abuso sexual.

- Sobre las 10 personas que fueron imputadas, 9 tenían entre 18 y 32 años, y 3 de esas 10 personas poseían antecedentes.

- A su vez, en 8 de las causas el Fiscal requirió la PP, concediéndosela los JG en todos los casos.

Si bien no se especifican los argumentos brindados en cada uno de los expedientes, el estudio asegura que los Fiscales nunca justificaron como lo requiere el CPP de la PBA el riesgo que provocaría, para los fines de la investigación penal, que el imputado conserve la libertad durante el proceso. A la hora de solicitar la aplicación de la $\mathrm{PP}$, los argumentos se fundaron

En la verosimilitud de los hechos y los indicios vehementes sobre la responsabilidad penal del imputado, según las pruebas obtenidas en escasos días, y no en el peligro real de fuga o entorpecimiento de la causa [agregando -con tono crítico- que] elementos tales como la pena en expectativa no bastan para decidir si existe peligro de entorpecimiento de la investigación o de fuga. Mencionar simplemente que se encuentran reunidos los extremos de los artículos 157 y 158 del Código Procesal Penal sin explicitarlo es insuficiente para tener por fundamentada la necesidad de aplicación de la prisión preventiva u otras medidas de coerción (Ibíd.: 29-31) ${ }^{107}$.

Lo que podemos destacar de este documento es que ofrece la ventaja de evaluar la aplicación de la PP a partir del objeto expediente, diferenciándose de otros estudios que, priorizando un abordaje dogmático jurídico, eluden la relación con los hechos concretos que hacen viable esta medida cautelar. Sin embargo, muestra dos grandes

\footnotetext{
${ }^{106}$ Las variantes pueden ser robo en grado de tentativa, robo simple o robo agravado. Este último puede configurarse si en mediante su realización se comete un homicidio, se lesiona a alguien, se utilice armas, etc. (Art. 164 a 167 bis del CP).

${ }^{107}$ Otra información que ofrece el documento refleja que de los diez procesos iniciados existió condena en siete de ellos, seis por juicio abreviado y la séptima en juicio ordinario. En dos casos hubo sobreseimiento para los imputados y en el restante desistimiento por parte del Fiscal para formular acción. Lo que destaca el documento es que de estos tres casos en los que no hubo condena, dos habían estado encarcelados bajo PP.
} 
limitaciones para nuestros objetivos. En primer lugar, y como consecuencia del número exiguo de causas que analiza, la poca variación entre los hechos investigados. La última, y más importante, es que no transcribe los argumentos que los operadores jurídicos ofrecen para discutir sobre la PP en particular.

En otra investigación sobre prácticas y discursos acerca de la PP, la Asociación por los Derechos Civiles (en adelante, ADC) hizo en 2012 un relevamiento de 26 expedientes, en el que la medida cautelar estuvo presente en 16 de ellos. Si bien no se trata de casos pertenecientes sólo al ámbito de la $\mathrm{PBA}^{108}$, resulta importante señalarlos puesto que aquí se hace mención a los argumentos expuestos por los JG a la hora de evaluar la utilización de la PP.

- Los hechos pertenecientes a la jurisdicción federal fueron $10 \operatorname{robos}^{109}, 6$ delitos relacionados con estupefacientes, sea tenencia o comercio, 3 ilícitos con agresión y armas, y 1 homicidio.

- Sobre los casos dentro de la PBA, 4 referían a homicidios en ocasión de robo, 1 a robo agravado y 1 a comercio de drogas.

- Tomando el universo total de los hechos, 15 contaban con imputados varones, mayormente detenidos por algún tipo de robo.

- En el caso de las mujeres, había 11 procesadas, 9 de ellas privadas de la libertad por la imputación de delitos vinculados a estupefacientes u homicidio en ocasión de robo, y 2 por robo en alguna de sus configuraciones.

- Del total de los imputados, había 2 en la PBA y 2 en el ámbito federal que registraban antecedentes.

- Por último, la mayoría de las personas investigadas se encontraban sin trabajo o con trabajos precarizados ${ }^{110}$.

Los procesos de los que habla el documento de la ADC (2012: 56-7) comenzaron, como sucede en la mayoría de los casos en la PBA, con detenciones policiales a partir de las cuales se obtuvieron las declaraciones o testimonios sobre los

\footnotetext{
${ }^{108}$ De las 26, 20 pertenecen al ámbito federal y 6 al de la PBA.

${ }^{109}$ Sin distinguir entre simples o agravados.

${ }^{110}$ En el informe se mencionan los casos de vendedor ambulante, cartoneros, amas de casa, de entre $20 \mathrm{y}$ 45 años
} 
hechos ${ }^{111}$. A su vez, en casi todos los casos revisados se consideró conveniente la aplicación de la PP por la PEE alta, de la que procedería una condena de efectivo cumplimiento. Más en concreto, según éste informe, si bien las razones a partir de las cuales se fundamentan las resoluciones sobre el encierro cautelar parten de los dos riegos procesales estipulados en el CPP-PBA, lo hacen de manera amplia e imprecisa, por lo que las argumentaciones resultan inconsistentes a la luz de las normas jurídicas. Esto significa que

Si bien se menciona que las únicas causales por las que se puede privar a una persona de su libertad de manera preventiva son el entorpecimiento en la investigación y la posibilidad de fuga, al momento de sopesar estas circunstancias hay un apego generalizado a los parámetros restrictivos establecidos por los códigos procesales, principalmente relacionados - directa o indirectamente- con la pena en expectativa $\mathrm{y}$, en segundo lugar, con la posibilidad de demostrar el arraigo (Ibíd.: 58-9).

Señalaremos a continuación los presupuestos, la jurisdicción y los argumentos de los JG de alguno de los casos que explora este informe ${ }^{112}$.

\begin{tabular}{|l|}
\hline $\begin{array}{l}\text { Presupuesto utilizado por el Juez de Garantías para conceder la PP: Pena en } \\
\text { expectativa }\end{array}$ \\
\hline Jurisdicción: Ciudad de Buenos Aires \\
\hline $\begin{array}{l}\text { Argumento del Juez de Garantías: "Analizada la situación bajo estas premisas } \\
\text { entiendo que la pena de efectivo cumplimiento que podría recaer resulta una pauta } \\
\text { para entender que de concedérsele la libertad, intentará eludir el accionar de la } \\
\text { justicia, ya que la certeza de que tendría que ir a prisión importa esa presunción". }\end{array}$ \\
\hline
\end{tabular}

Presupuesto utilizado por el Juez de Garantías para conceder la PP:

Reincidencia del imputado

Jurisdicción: Ciudad de Buenos Aires

\footnotetext{
${ }^{111}$ Los testimonios, según el informe, suelen ser imprecisos. Por ejemplo: “con la descripción de los autores, se logró dar alcance a quien resultó ser XXX [...] que había sido descripto de tez morena, alto y de contextura físicamente robusta" y, en el ámbito de la Provincia de Buenos Aires, "lo reconocí porque tenía puesto un jean y una remera de mangas cortas de color amarillo, tal cual lo había descripto la víctima" (ADC, 2012: 57). Por último, la persona sospechosa es detenida en base a descripciones amplias o ambiguas sobre las características físicas o de vestimenta.

${ }^{112}$ El CPP de la República Argentina tiene los mismos presupuestos que el CPP de la PBA respecto de la PP: "ART. 26. RESTRICCIONES A LA LIBERTAD. Las medidas restrictivas de la libertad tienen carácter excepcional y sólo podrán fundarse en la existencia de peligro de fuga u obstaculización de la investigación".
} 


Argumento del Juez de Garantías: "La objetiva valoración de la calidad de
reincidente en delitos contra la propiedad y lo que resulta de sus condiciones
personales se comportan como pautas obstativas que hacen presumir que en la
perspectiva de cumplir efectivamente pena privativa de libertad, resultara sustraerse
a las resueltas del proceso, con el riesgo procesal consecuente ya que considerada
globalmente su situación, la sanción que se le imponga deberá ser de considerable
duración. [...]. Las numerosas condenas anteriores que registra, cumplidas con
efectivo encierro ubican su situación en los presupuestos de los artículos 312 inc. 1 y
319 del Código Procesal de la Nación".

En estos argumentos se observa cómo la justificación esta sustentada en que los imputados "intentarán eludir" o "resultarán sustraerse" de la justicia, debido a que la eventual pena será alta o a que son reincidentes, motivos por los cuales deberían cumplir la condena efectivamente. Y frente a ese escenario hipotético, se presume que huirán si no se los encarcela preventivamente.

En otros casos, lo que se posiciona como elemento central para validar la concesión de la PP por parte del JG es la "falta de arraigo" del imputado, es decir, el hecho de que el imputado no cuente con un domicilio estable que la institución judicial pueda constatar.

\begin{tabular}{|l|}
\hline $\begin{array}{l}\text { Presupuesto utilizado por el Juez de Garantías para conceder la PP: Falta de } \\
\text { Arraigo }\end{array}$ \\
\hline Jurisdicción: Provincia de Buenos Aires \\
\hline Argumento del Juez de Garantías: “[...] teniendo en cuenta que la imputada no \\
cuenta con un trabajo estable y su lugar de residencia no es fijo, sino que alterna por \\
distintos establecimientos, no es posible determinar su ubicación cierta y eso atenta \\
con las posibilidades de su comparecencia al juicio $[\ldots]$ ”.
\end{tabular}

En estos argumentos se sugiere que quien no tiene un domicilio estable tampoco ofrece responsabilidad -o previsibilidad- en su comportamiento. Poseer vivienda y ocupación permanentes son elementos valorados como garantía de que el imputado cumplirá con sus obligaciones y se someterá al proceso. De lo contrario, se presume que intentará eludir la averiguación de la verdad. Lo que resulta paradójico de estos requisitos, afirma el documento de la $\mathrm{ADC}$, es que la mayoría de los casos en los que interviene la justicia penal pertenecen a grupos de personas que justamente carecen de 
recursos como trabajo u hogar, pudiendo considerarse esas carencias -al menos en partecomo uno de los motivos por los que esos delitos llegan a cometerse (ADC, 2012: 60).

Como conclusión de los dos documentos presentados, podemos señalar que así como el informe del CIPPEC tiene el mérito de ubicar a la PP dentro del expediente, relacionando las normas jurídicas con los hechos concretos, el estudio de la ADC brinda un nuevo avance: el de transcribir los argumentos que se redactan en los expedientes. Esto permite conocer las escalas que ofrecen los operadores jurídicos a la hora de legitimar su decisión sobre la PP. Estas escalas, que son producto de la actividad de los mismos operadores, muestran como un factor importante la necesidad de asegurar la realización del juicio, la cual puede verse frustrada, principalmente, en los casos en que el imputado se fugue. $\mathrm{Y}$ es a partir de dicha necesidad que deben evaluarse los argumentos que los actores revelan al justificar los pronósticos que realizan sobre el comportamiento futuro del imputado.

Se entiende que en los casos de una PEE futura muy alta, la sentencia, de ser condenatoria, deberá cumplirse efectivamente, razón suficiente para concluir que el imputado intentará evadirse.

También el pasado puede tener peso en estos argumentos, ya que el haber cometido un delito anterior al hecho que dio lugar al proceso actual -esto es, de ser reincidente-, es igualmente considerado un factor significativo para que a una persona se le otorgue la PP.

Por último, el presente suele mostrar importancia, ya que no poseer trabajo o casa, que es lo que configura la falta de arraigo según el CPP, contribuirían a que se presuma que un imputado no podrá ser localizado cuando la justicia lo requiera.

Es definitiva, no hay tiempo ajeno a la PP, ya que el comportamiento del procesado puede presagiarse por el futuro a partir de la PEE, por el pasado a partir de la reincidencia, y por el presente a partir del arraigo.

\section{3- Nuestros expedientes}

A diferencia de los documentos del CIPPEC y la ADC, en esta sección tomaremos como punto de partida la calificación legal propuesta en los expedientes, ya que permiten un acercamiento preliminar a la IPP. 
Posteriormente, se transcribirán los pedidos que llevan adelante los Fiscales una vez que la investigación ha comenzado a desarrollarse. Luego, se presentarán las respuestas de los JG. Esto se debe a que la serie de justificaciones en torno a la PP se inicia con la solicitud que hacen los Fiscales, justificaciones que para confeccionarse tienen -o al menos deberían tener- en cuenta las posibles objeciones que el JG les podría realizar. Como ya se ha dicho antes en esta tesis, el encierro preventivo no comienza ni termina en el PJ, sin embargo en este ámbito -y en esta etapa del proceso-, la relación que se despliega entre Fiscales y JG es crucial, al punto de reducir la incidencia que tienen los Defensores ${ }^{113}$. Estos últimos están facultados a plantear sus objeciones acerca del uso del encarcelamiento preventivo una vez que el JG ha decidido, positiva o negativamente, sobre el pedido del Fiscal respecto a la PP. Finalmente, ofreceremos un comentario sobre cada uno de los expedientes transcriptos que facilite su lectura.

\subsection{Hechos y rasgos}

En tanto fuente primaria, buscamos expedientes en los que la PP estuviese siempre presente, es decir, expedientes en los que al menos la Fiscalía haya solicitado la medida cautelar. Luego de esta solicitud, el JG puede otorgar o denegar dicha medida analizando, entre otras cosas, las características del hecho y los antecedentes de los imputados. Esto se justifica porque lo que nos interesa es explorar al encierro preventivo como una competencia que despliegan los actores judiciales al producir argumentos, desavenencias y acuerdos activos.

A partir de esta premisa, y por intermedio de nuestros informantes claves, hemos podido conseguir un total de 29 expedientes provenientes de los tres departamentos judiciales de la PBA en los que trabajamos para esta tesis. Si bien lo desarrollaremos luego, es necesario anticipar que en sólo 5 de los expedientes a los que accedimos la PP fue rechazada. Algunos detalles más que son importantes:

\footnotetext{
${ }^{113}$ Esta "marginalidad" de los Defensores ha sido confirmada por los testimonios de distintos operadores, y por los documentos ya mencionados. Por ejemplo, en el trabajo del CEJA sobre la PP en Argentina, se afirma como una de las críticas el bajo nivel de influencia de la Defensa Pública: "Este es un tema crucial en el buen funcionamiento del sistema penal. Sin una institución fuerte, con liderazgo, capacidad de organización y reacción ante las demandas de la comunidad, etc., no puede avanzarse hacia la consolidación de modelos racionales en el uso de la fuerza del Estado en general, y en particular de la prisión preventiva. Salvo contadas excepciones no hemos relevado sistemas de Defensa Pública que logren impactos considerables en la decisión sobre el encarcelamiento preventivo. Entre otras falencias, ello tiene directa incidencia en la poca utilización que se hace de las medidas alternativas (y morigeraciones) a la prisión preventiva, donde advertimos que ante la interpretación cerrada del régimen de prisión preventiva, y una vez que el caso encuadra en los límites objetivos que la ley dispone, los jueces disponen el encierro cautelar, en muchos casos sin siquiera contar con una petición de una afectación menos lesiva a los derechos de las personas" (2011: 124).
} 
- De los expedientes, hubo 9 que tuvieron que ver con homicidios o tentativas de homicidios, 16 con robos en sus diferentes tipificaciones, 2 con abuso sexual, 1 con lesiones graves y 1 con comercialización de estupefacientes.

- Se computaron un total de 89 imputados: (a) Una era mujer (b) 17 reincidentes (c) 5 fueron excarcelados de manera ordinaria por el JG (d) 48 no poseían empleo estable, y (e) 67 no superaban los 30 años.

- Vale mencionar que en una de las causas se investigó un robo calificado por su comisión en lugar poblado y en banda, y por el uso de arma. En dicho proceso se detuvieron a 52 personas, lo que supone un número poco frecuente de imputados para un solo hecho.

- Las características más frecuentes de estos expedientes fueron las de hallarse defectuosamente redactados, con faltas de ortografía, y una tendencia notoria a la repetición de fórmulas que se podría resumir bajo la expresión de copiar y pegar. Esto último se observa, por ejemplo, en la reproducción que los operadores jurídicos efectúan de los contenidos de los distintos apartados que conforman los expedientes. Las afirmaciones que realizan los Fiscales en cada uno de los títulos con los que se organizan dichos instrumentos ${ }^{114}$ resultan prácticamente las mismas a las que posteriormente llevan a cabo los JG.

Un Magistrado de la etapa de instrucción del proceso, dio un testimonio que puede servir para analizar esta tendencia a la reproducción de los argumentos en los expedientes:

"[...] pero acá estamos en la trinchera, acá no se hace fondo casi..., salen minutas, es milanesa con papa fritas, hay cientos y miles de causas, por lo que tenés que estar resolviendo permanentemente, y salís de un aborto, y vas a un homicidio, y vas a un hurto, habeas corpus, pungas, tenés una multiplicidad de funciones dentro de lo que es la primera instancia, con tiempos acotados, y en una instancia que es corregible, porque para eso está la alzada..., de última vos tenés la rectificatoria de tu superior jerárquico judicial. Que apele la Defensa o el Fiscal, en todo caso.

\footnotetext{
${ }^{114}$ Por lo general estos títulos son tres: Materialidad ilícita en el que se describen los hechos que dan inicio a la causa, Adecuación típica en el que se sustenta cómo esos hechos pueden ser considerados delitos, y Autoría responsable en el que se señala a los imputados como los supuestos causantes del delito investigado.
} 
ENTREVISTADOR: ¿Eso da más tranquilidad?

No es que da más tranquilidad pero lo pueden hacer con más tiempo, lo desmenuzan con más tranquilidad. Son tres personas, no una, porque yo también puedo leerte una causa muy bien en un mes, y no en 15 segundos, y antes y después tenés miles. Es un vértigo permanente. $\mathrm{Y}$ los superiores están para eso, para corregirnos si nos equivocamos. Lo que pasa es que en primera instancia estás más cerca de la realidad" (JG del Departamento Judicial del La Plata).

Este tipo de afirmaciones ha sido recurrente en los actores entrevistados. El hecho de estar expuestos a procesos penales variados, sobre los que hay que decidir en poco tiempo, beneficia el apego a fórmulas preestablecidas ya que reducen el tiempo empleado para cada una de las causas. Y en este sentido, el expediente facilita esa estandarización brindando la posibilidad de volver público el contenido de un proceso, una vez que los hechos han sido redactados en él. A esto último, conocido como el efecto de oficialización que genera la escritura, se le debe sumar el ya mencionado efecto de homologación, que ayuda a identificar determinados fenómenos cuando se utilizan determinadas palabras ${ }^{115}$. Ambos efectos restringen los resultados imprevistos, de allí que jueguen un papel importante en la producción del expediente, y en el modo en que la PP circula en este instrumento (García Inda, 1997: 265).

\section{2. ¿Cómo estudiar la prisión preventiva al estudiar los expedientes?}

Para analizar el uso de la PP, los expedientes se agruparán de acuerdo a cuatro modelos o "gramáticas argumentativas" (Chateauraynaud, 2005), que permitan localizar e documentar las justificaciones de los actores judiciales. Esto facilitará el estudio comparativo de los fundamentos con los cuales dichos actores despliegan la medida cautelar al solicitarla, aceptarla o denegarla ${ }^{116}$.

\footnotetext{
${ }^{115}$ Para García Inda, "la homologación de las formas jurídicas, por lo tanto, permite que los agentes que se encuentran en una situación codificada 'saben que pueden contar con una norma coherente y sin escapatoria, y por lo tanto calcular y prever tanto las consecuencias de la obediencia a la regla como los efectos de la trasgresión'; es decir, proporcionan esa previsibilidad y calculabilidad de la que hablábamos, por muchas zonas de oscuridad (lagunas, antinomias, etc.) que existan (y existen) en el discurso y el trabajo jurídico" (1997: 212). Respecto de la PP, los efectos de homologación se observan por ejemplo cuando se habla de PEE o reincidencia como requisitos que fundamentan la medida cautelar sin que los actores judiciales expliquen de qué se trata puntualmente.

${ }^{116}$ Las transcripciones de los expedientes serán hechas de forma literal, excepto el número de los artículos mencionados cuando no se vinculen con la medida cautelar que serán omitidos. Por lo tanto, se mantendrán expresiones técnicas, redacciones defectuosas y errores ortográficos.
} 
Siguiendo el enfoque propuesto por Boltanski (2000) para identificar principios válidos a los que recurren las personas a la hora de justificar sus posiciones en diferentes disputas, aquí la PP será considerada como resultado de un acuerdo activo a realizar, y no como producto de fuerzas judiciales -o extrajudiciales- inscriptas de manera irreversible en los hábitos de los operadores jurídicos, predispuestas a funcionar en cualquier circunstancia (Latour, 2008).

En segundo lugar, para la elaboración de dichos modelos de análisis, los argumentos que los actores judiciales desplieguen en los expedientes serán presentados sin ser traducidos, es decir, sin tratar de difamarlos o desautorizarlos para luego contraponerles una posición más sólida que sería la del investigador. Por tal motivo será necesario acumular la mayor cantidad de información que, tanto JG como Fiscales, produzcan respecto del uso de la PP, renunciando a introducir suposiciones ajenas a lo que puede leerse en los propios expedientes. Al igual que el juez, dice Boltanski,

El sociólogo [...] pone en escena el proceso recogiendo y registrando los informes de los actores, y su informe de investigación es ante todo un acta de esos registros, un informe de esos informes. En efecto, el sociólogo se obliga a seguir muy de cerca a los actores en su trabajo interpretativo, abriéndose camino a través de los informes que ellos han constituido. Toma en serio sus argumentos y las pruebas que proporcionan, sin tratar de reducirlos o de descalificarlos oponiéndoles una interpretación más fuerte (2000: 55).

Tercero, se mantendrá la diferencia planteada tradicionalmente en las ciencias sociales entre el actor y el investigador. Al analizar los argumentos sobre la PP que se encuentran en los expedientes, al confrontarlos en un mismo momento y lugar, realizaremos una tarea que los operadores jurídicos no llevan a cabo. Estos últimos, tienen la necesidad de decidir cuestiones concretas en una ocasión específica respecto a la medida cautelar. Sin embargo, y esto es lo más importante, la asimetría de la que hablamos no presupone una confrontación entre la supuesta interpretación "más fuerte" del investigador respecto de la del actor, poseedor de una menor jerarquía de credibilidad en términos de Becker (2005, 2009b).

En síntesis, los modelos que se expondrán en los próximos apartados son producto de haber tomado en cuenta los argumentos planteados por los actores, sin juzgar estos argumentos por lo que la PP debería ser en los expedientes según las normas jurídicas. Para ello, se responderán las siguientes preguntas: ¿qué redactan los 
Fiscales a la hora de solicitar y fundamentar el pedido de la PP?, ¿qué razones dan los JG al aceptar o denegar la requisitoria?, ¿cómo lo hacen?, ¿qué condiciones debe satisfacer el pedido de la PP para ser considerado viable o no? De esta manera, los expedientes serán introducidos en cuatro esquemas con los cuales acercarse a la serie de relaciones que el pedido de la PP instaura, junto a las exigencias que este pedido impone.

\subsubsection{Argumentos en base a la ley}

Uno de los modelos refleja el acuerdo entre Fiscal y JG, acuerdo que se puede considerar realizado en base a la ley. Luego de relatar los hechos e indicios que hacen posible suponer la autoría del imputado, las justificaciones sobre el pedido y aceptación de la PP se presentan en función de alguno de los dos riesgos procesales que requiere el CPP de la PBA para la concesión de la medida cautelar. Al solicitar esta última, la Fiscalía menciona el peligro de fuga, el entorpecimiento en la investigación, o ambos a la vez, y el JG -expresa o tácitamente- concede la PP apoyándose en ellos.

HECHO: Tentativa de homicidio agravado por el vínculo y por el uso de arma de fuego.

ARGUMENTO DE LA FISCALÍA: "Que teniendo en cuanta (SIC) la pena en expectativa del delito que se le imputa y/o la gravedad del hecho que se le imputa, existen razones para sospechar que el encausado procurará eludir la acción de la justicia, razón por la que solicito la conversión de detención a PP".

ARGUMENTO DEL JG: "[...] considero que en el caso en tratamiento concurren los presupuestos establecidos en el art. 171 en su remisión al artículo 148, la pena en espectativa (SIC), respecto del delito que se le imputa al causante, que hace presumir el peligro de fuga $[\ldots] "$.

OBSEVACIÓN: En este hecho se investiga una tentativa de homicidio agravado por el vínculo y por el uso de arma de fuego. Según el CP argentino, hay tentativa cuando alguien comienza la ejecución de un delito pero no puede consumarlo por circunstancias que son ajenas a su voluntad (Art. 42). El agravante propuesto por la Fiscalía respecto al vínculo tiene su fundamento en que el imputado de la tentativa de homicidio es el hijo de la víctima. Según queda expresado en el expediente, el imputado efectuó al menos un disparo en la cabeza de la víctima con claras intenciones de quitarle la vida, propósito que no logró por cuestiones que estuvieron fuera de su alcance.

HECHO: Homicidio simple. 
ARGUMENTO DE LA FISCALÍA: "[...] teniendo en cuenta la gravedad del hecho y consecuentemente la pena en expectativa lo cual torna cuanto menos dudosa la sujeción de los imputados al proceso y/o no elusión de accionar de justicia".

ARGUMENTO DEL JG: "[...] ello dado la pena en expectativa prevista para el delito endilgado, y la posible fuga, circunstancia que torna viable la medida de coerción peticionada". OBSEVACIÓN: La Fiscalía sustenta la atribución del delito y el pedido de la PP en los testimonios de la pareja del imputado y dos vecinos de éste último, a lo que agrega los relatos de los efectivos policiales. Se trata de un homicidio simple, producto de un cuchillazo efectuado por el imputado a la víctima durante una pelea entre ambos. El delito de homicidio simple está tipificado en el Art. 79 del CP, que dice: "Se aplicará reclusión o prisión de ocho a veinticinco años, al que matare a otro, siempre que en este Código no se estableciere otra pena".

HECHO: Tentativa de robo agravado por el empleo de arma de fuego en concurso real con portación de arma de guerra.

ARGUMENTO DE LA FISCALÍA: "[...] dada la pena en expectativa del hecho endilgado como asimismo la circunstancia de registrar el encartado antecedentes penales me llevan a concluir que resulta cuanto menos dudoso su sometimiento a proceso y/o no elusión de accionar de justicia".

ARGUMENTO DEL JG: "Me remito en honor a la brevedad a los argumentos expuestos por la Señora Agente Fiscal, los cuales comparto en su totalidad [...], resultando viable la medida de coerción peticionada debido a la existencia del peligro de fuga exigido por el CPP".

OBSEVACIÓN: En esta causa la policía impide que se concrete el robo a una verdulería sustrayéndole al imputado dos armas: una pistola calibre 22 y un revolver calibre 38 . La calificación del hecho realizada por la Fiscalía y homologada por el JG es la de una tentativa de robo agravado por el empleo de arma de fuego en concurso real con portación de arma de guerra. El concurso real se da cuando existe una pluralidad de conductas tipificadas penalmente que deben ser sancionadas en una misma sentencia. En este caso, el robo agravado por el empleo de arma es un delito, y la portación de arma de guerra es otro (Zaffaroni, 2001: 629). A su vez, la portación consiste en disponer, en un lugar público o de acceso público, de un arma de fuego cargada, en condiciones de uso inmediato. Ésta se distingue de la tenencia de un arma de fuego, que habilita al legítimo usuario a mantener el arma en su poder, transportarla descargada y separada de sus municiones y usarla con fines lícitos, por ejemplo tiro deportivo.

HECHO: Robo calificado por haberse cometido en un lugar poblado y en banda con el empleo de armas. 
ARGUMENTO DE LA FISCALÍA: "Motiva la solicitud de la presente medida cautelar la circunstancia de encontrarse reunidos conjuntamente los requisitos del art. 157 del CPP, [...] sumado a la gravedad del delito que se le imputa al detenido, situación que conlleva a presumir la existencia de peligros procesales ciertos que el encartado -de recuperar la libertad- tratará de eludir el procedimiento penal y/o entorpecer sus fines [...]".

ARGUMENTO DEL JG: "Habiéndose convocado al encartado a prestar declaración, [...] ello teniendo en cuenta la pena en expectativa que se espera como resultado del proceso, como así también la circunstancia de registrar una condena anterior, datos objetivos previstos en el art. 148 del CPP para merituar el peligro de fuga y que permite sostener la procedencia del encarcelamiento preventivo".

OBSEVACIÓN: Aquí hay un solo imputado más allá de que, según la Fiscalía, el delito fuera cometido por tres personas - dos de las cuales no pudieron ser detenidas-. El robo se llevó a cabo en una juguetería, y los testimonios que acreditaron el hecho fueron el del dueño del comercio, el de una empleada y el de un cliente. Además, estas tres personas señalaron al imputado como uno de los autores del robo en rueda de reconocimiento.

HECHO: Robo calificado por su comisión en lugar poblado y en banda, por el uso de arma en concurso real con daño.

ARGUMENTO DE LA FISCALÍA: "Se trata de un delito de índole no excarcelable, teniendo en cuenta la pena en espectativa (SIC), por lo que considero que en caso de recuperar la libertad los encartados procurarán eludir la acción de la justicia. Aduno a ello, que las víctimas, resultan ser a su vez testigos presenciales de los propios ataques, por lo que teniendo en cuenta la naturaleza del mismo, los móviles y los antecedentes en distintos territorios, debo cuidar que los mismos no corran riesgo alguno durante la tramitación de la presente investigación [...]. Ahora bien, respecto de los encartados XXX, los cuales poseen condenas firmes por delitos anteriores, considero que en caso de recaer sentencia la misma debe ser de efectivo cumplimiento".

ARGUMENTO DEL JG: "Que respecto de la existencia de peligros procesales conforme lo establecido por el artículo 171 del CPP, valoro en primer lugar la magnitud de la pena en expectativa, cuyo mínimo de pena es de cinco años de prisión e impediría una condena de ejecución condicional [...] lo que me permite presumir que los coimputados tengan la intención de eludir la acción de la justicia, dada la voluntad del hombre a permanecer en el medio libre. Que en tal sentido computo no sólo la escala penal en abstracto, sino también las características violenta de los hechos, como es el caso de haberse provocado incendios, emplear hierros y manoplas, el número de imputados que además usaron pasamontañas para no ser reconocidos, que junto a la multiplicidad de víctimas, me hacen concluir que existen peligros procesales de 
fuga y entorpecimiento en la investigación. Que asimismo cabe consignar que la Comisión Interamericana de Derechos Humanos ha resuelto que la gravedad del delito imputado y la severidad de la pena [...] es un parámetro razonable para sostener que los imputados podrían intentar eludir la acción de la justicia [...]. Considero pertinente evaluar la pertinencia si la coerción debe continuar respecto de todos los detenidos o si existen circunstancias especiales que permitan presumir que alguno de ellos no procurará eludir u obstaculizar la investigación ni burlar el accionar de la justicia. Para esto último tomo como pauta de interpretación el principio de libertad personal durante el proceso redactado en el $2^{\circ}$ Párr. del Art. 144 del CPP$\mathrm{PBA}^{117}$, libertad que sólo podrá ser restringida cuando fuera absolutamente indispensable para asegurar los fines del proceso. [...] siendo esto último doctrina de nuestra CSJN obtenida a través del fallo Verbitsky. Que por otra parte, tengo la obligación que la presente decisión judicial tenga las menores consecuencias en lo que se refiere a las restricciones de la libertad, por lo que considerando que la prisión preventiva involucra a 52 personas, habré de hacer uso de la excarcelación extraordinaria ${ }^{118}$ procediendo a [...] concederle la libertad a quienes aparecen con menores peligros procesales, tomando como basamento la falta de antecedentes".

OBSEVACIÓN: Se trata de una causa del todo inusual, principalmente por la cantidad de imputados. Según la Fiscalía, 52 personas mayores de edad se presentaron en la sede de una delegación gremial y prendieron fuego automóviles y causaron otros daños de diferente magnitud. Además, se apoderaron ilegítimamente de bienes que se encontraban en dicha sede gremial, como por ejemplo documentación, tarjetas de crédito y dinero. A raíz de esto, la Fiscalía solicita la PP para todos los imputados, haciendo especial hincapié en algunos de ellos que tenían condenas firmes por delitos anteriores. Si a estos últimos se los condenara, la pena sería de efectivo cumplimiento ya que no podrían gozar de una condena de ejecución condicional. La figura de condenación condicional se encuentra en el Art. 26 del CP: "En los casos de primera condena a pena de prisión que no exceda de tres años, será facultad de los tribunales disponer en el mismo pronunciamiento que se deje en suspenso el cumplimiento de

117 El segundo párrafo de este Art. expresa: "La libertad personal y los demás derechos y garantías reconocidos a toda persona por la Constitución de la Provincia sólo podrán ser restringidos cuando fuere absolutamente indispensable para asegurar la averiguación de la verdad, el desarrollo del procedimiento y la aplicación de la ley".

118 Este instituto está legislado en el Art. 170 del CPP, y dice: "Excarcelación extraordinaria.- En los casos que conforme a las previsiones de los incisos $1^{\circ}$ (El delito que se impute tenga prevista una pena cuyo máximo no supere los ocho (8) años de prisión o reclusión) y $2^{\circ}$ (En el caso de concurso real, la pena aplicable al mismo no supere los (8) ocho años de prisión o reclusión) del artículo anterior no correspondiere la excarcelación, podrá ser concedida de oficio o a pedido de parte cuando por la objetiva valoración de las características del o de los hechos atribuidos, de las condiciones personales del imputado y de otras circunstancias que se consideren relevantes, se pudiera presumir que el mismo no procurará eludir u obstaculizar la investigación ni burlar la acción de la justicia. En estos casos el órgano interviniente podrá, de acuerdo a las circunstancias y a la personalidad del detenido, someterlo al cumplimiento de reglas especiales de vigilancia y/o cuidado asistencial [...]. La excarcelación prevista por este artículo sólo podrá concederse mediante resolución fundada y se efectivizará cuando el auto que la conceda quede firme". 
la pena". Pero si quienes han sido beneficiados con este instituto vuelven a cometer un delito, deberán cumplir la pena efectivamente como lo expresa el Art. 27: "La condenación se tendrá como no pronunciada si dentro del término de cuatro años, contados a partir de la fecha de la sentencia firme, el condenado no cometiere un nuevo delito. Si cometiere un nuevo delito, sufrirá la pena impuesta en la primera condenación y la que le correspondiere por el segundo delito, conforme con lo dispuesto sobre acumulación de penas. El JG otorga la PP a 13 imputados basándose en el peligro de fuga que estos representan dado que por los antecedentes penales que tienen, su condena sería de efectivo cumplimiento "lo que me permite presumir escribió el JG en el expediente- que los coimputados tengan la intención de eludir la acción de la justicia". A los 39 imputados restantes les otorga la excarcelación extraordinaria. Esto significa que el JG habría concedido la PP si los imputados hubiesen sido menos numerosos, sin embargo optó por la excarcelación extraordinaria "teniendo en cuenta -según su propia redacción- las consecuencias inmediatas que acarrearía en las comisarías y el SPB semejante cantidad de presos preventivos".

Este primer modelo de argumentación lo observamos en 9 de los 29 expedientes a los que accedimos. Y permitieron apreciar, con variantes, de qué manera frente a diferentes delitos investigados la justificación respecto al pedido y aceptación de la PP se realiza en base a la ley, en el sentido de que se mencionan uno o ambos riesgos procesales estipulados en el CPP. Esto no significa que se haya comprobado fehacientemente el modo en que, tanto el peligro de fuga como el entorpecimiento en la investigación, podrían concretarse.

Los informes mencionados previamente, así como otros documentos que estudian la PP, coinciden en que la falta de verificación de la existencia de los riesgos procesales es una de las falencias más relevantes a la hora de evaluar el uso de esta medida cautelar ${ }^{119}$. La limitación que nosotros advertimos en estos trabajos es la de

\footnotetext{
${ }^{119}$ Para el INECIP, "si bien se mencionan causales -procesales o sustantivas- no explican la manera en que operan en el caso en concreto y por qué los lleva a sostener que el imputado entorpecerá la acción de la justicia.... (2012: 41-3). En el caso de la ADC, sugiere que "a la hora de fundamentar las decisiones, en casi todos los casos se mencionan las causales de riesgos procesales y la necesidad de determinar la decisión en base a elementos objetivos y probados en el caso concreto. Sin embargo, en la mayoría se hace de manera generalizada, ambigua y sin argumentación posterior que le de contenido y lo fundamente" (2012: 58). Según el CIPPEC, la falta de una "clara fundamentación sobre la existencia de peligros procesales que habiliten la aplicación de la prisión preventiva viola claramente los preceptos fundamentales que regulan el proceso penal... La verosimilitud de los hechos y de la culpabilidad del imputado que puedan llegar a surgir de las medidas de pruebas ordenadas en los primeros días de instrucción y elementos tales como la PEE no bastan para decidir si existe peligro de entorpecimiento de la investigación o de fuga. Mencionar simplemente que "se encuentran reunidos los extremos de los artículos 157 y 158 del Código Procesal Penal" sin explicitarlo es insuficiente para tener por fundamentada la necesidad de aplicación de la prisión preventiva u otras medidas de coerción" (2011: 31-
} 
formular una perspectiva sobre el encierro cautelar que, si bien no puede catalogarse de dogmática, conserva algo de ella, ya que su preocupación esta del lado de lo que la PP debería ser según parámetros legislativos, y no en el análisis de lo que es en concreto.

Y la PP, dentro de este modelo, es un acuerdo que se lleva a cabo entre el Fiscal y el JG al indicar explícitamente lo que el CPP exige. Esta coordinación es un tipo de compromiso a partir del cual la PP logra concretarse. Se trata, por lo tanto, de apoyos convencionales que organizan las justificaciones de los operadores jurídicos, que les permiten realizar ajustes y elaborar perspectivas comunes en torno a las razones que posibilitan el uso del encierro cautelar (Dodier, 1993).

\subsubsection{Argumentos en base a un acuerdo tácito}

En este segundo modelo de argumentación, presente en 8 de los expedientes revisados, se observa la descripción de los hechos que ocasionaron el inicio del proceso, junto a la presunta responsabilidad del imputado. Se alude con vaguedad a uno o más artículos que dentro del CPP remiten a la medida cautelar, sin que se formule concretamente, tanto para solicitarla como para concederla, alguno de los peligros procesales en las justificaciones. A continuación se expondrán los casos más destacados en los que se halla una falta explícita, tanto del peligro de fuga como del entorpecimiento en la investigación.

HECHO: Tentativa de homicidio.

ARGUMENTO DE LA FISCALÍA: "Solicito se dicte la PP respecto del imputado XXX por encontrarse reunidos los requisitos de procedencia exigidos por el art. 157 y concordantes del CPP".

ARGUMENTO DEL JG: "Encontrándose reunidos los requisitos para su procedencia, resuelvo convertir la detención en prisión preventiva".

OBSEVACIÓN: En esta causa la Fiscalía acusa al imputado de haber efectuado dos puñaladas a otra persona con la intención de matarla. Esto ocurrió en la puerta de un bar, habiendo tres testigos que confirmaron la versión del hecho. La policía llevó adelante la persecución y detención del procesado momentos después de que el hecho ocurrió. Según el JG, la PP debe ser otorgada porque las pruebas contra el imputado son suficientes al respecto.

50). En un documento del CELS se afirma: "Nuestra experiencia de trabajo nos muestra que existe una numerosa cantidad de causas en las que sin pruebas, y sin argumentación, se aplica la prisión preventiva. El argumento determinante es simplemente la pena en expectativa o que el imputado es reincidente" (2010: 13). 
HECHO: Robo agravado por el empleo de arma.

ARGUMENTO DE LA FISCALÍA: "Solicito dicte el auto de prisión preventiva de XXX por darse a su respecto los requisitos de procedencia exigidos por el artículo 157 y concordantes del Código de forma".

ARGUMENTO DEL JG: "Resuelvo convertir en prisión preventiva la detención que hasta el momento viene sufriendo XXX en orden al delito de robo agravado por el empleo de arma a tenor de lo normado por el Art. 166 Inc. 2 del CP, por darse los requisitos planteados por el Sr. Agente Fiscal".

OBSEVACIÓN: El hecho tipificado como robo agravado por el empleo de arma ocurrió en un supermercado. El imputado, según la denuncia, se apoderó del dinero de la caja del comercio amenazando a la empleada con una cuchilla. El JG consideró que estaban reunidos los elementos para la concesión de la medida cautelar.

HECHO: Robo agravado por el empleo de arma de fuego.

ARGUMENTO DEL FISCAL: "Que se encuentra acreditado en autos la responsabilidad de los ciudadanos XXX respecto del hecho que se les imputa. Que asimismo el suscripto entiende que la conducta observada por los encartados durante la comisión del hecho ilícito ha evidenciado un alto grado de violencia, existiendo además proporcionalidad entre la cautelar requerida y el objeto tutelado, junto a los requisitos de los Arts. 157, 171 y ccds.".

ARGUMENTO DEL JG: "Para justificar lo previsto en el inc. 4 del art. 157 del CPP, considero que en el caso en tratamiento concurren presupuestos establecidos en el art. 171 del CPP (Ley 13449) en su remisión al artículo 148, la pena en espectativa (SIC) respecto del delito que se les imputa a los causantes, circunstancia que torna viable la medida de coerción peticionada".

OBSEVACIÓN: La Fiscalía, en este proceso, acusa a dos personas de llevar adelante el robo de un kiosco por medio del uso de un arma de fuego. La policía los detiene con posterioridad a la comisión del hecho. Dos testigos presenciales y personal policial confirman esta versión de los hechos. El JG afirma que existen "prima facie" indicios vehementes para sostener la acusación de la Fiscalía, motivo por el cual hace lugar a la aplicación de la PP.

HECHO: Tentativa de robo calificado por el uso de arma de fuego.

ARGUMENTO DE LA FISCALÍA: "Que conforme surge de la ley 13.449 y Resolución 228/06 de la Procuración General de la Provincia de Buenos Aires este Ministerio viene por el presente a exponer los motivos que hacen procedente la imposición de la medida de coerción que se le solicita. Que se encuentra acreditada en autos la responsabilidad de los ciudadanos XXX respecto de los hechos que se le imputan en la presente, siendo que el primero posee 
antecedentes penales. Que asimismo quien suscribe entiende que dada la pena en expectativa, existe además proporcionalidad entre la cautelar requerida y el objeto tutelado".

ARGUMENTO DEL JG: "Visto la extensión de la escala penal prevista para este tipo de ilícito aunado a los antecedentes penales de XXX, no existiendo otra medida de coerción que la aquí dictada para asegurar la averiguación de la verdad, la realización del juicio y el cumplimiento de la ley, siendo que el primero de los imputados posee antecedentes penales [...], resuelvo convertir en prisión preventiva la detención que vienen sufriendo los imputados" ${ }^{120}$.

OBSEVACIÓN: Se les imputa a los dos detenidos el intento de robo de un automóvil utilizando para ello un arma de fuego con la cual amenazaron al dueño del vehículo. Para la Fiscalía se justifica el uso de la PP ya que "existe proporcionalidad entre la cautelar requerida y el objeto tutelado". El JG otorga la medida cautelar con un alegato ambiguo: por un lado, se basa en los antecedentes que posee uno de los imputados, por el otro, la PP se la impone a los dos.

En este modelo se observa una ausencia manifiesta de los peligros procesales requeridos por el CPP, o más específicamente, la innecesidad de mencionarlos en dichas justificaciones. Al consultar a dos informantes clave, una que se desempeña como ayudante en una Fiscalía, y otro en un Juzgado de Garantías, dijeron respectivamente:

¿¿Para qué te vas a gastar fundamentando si sabés que te la van a dar [a la PP]? Salvo que estés muy mal de pruebas, que no pueda decirse que el imputado haya tenido que ver con el hecho, en una tentativa de homicidio o en un robo con armas, te la dan" (Ayudante en Fiscalía).

"Mirá, acá por lo general se controla si el imputado tuvo que ver con el hecho, y si el hecho es grave. Si los peligros están escritos o no, eso viene después, si viene. No es lo más importante generalmente" (Ayudante en Juzgado de Garantías).

Estos testimonios sirven para vincular a este modelo con lo que Garfinkel definió como un "acuerdo compartido", en este caso respecto a los actores judiciales,

\footnotetext{
${ }^{120}$ Aquí es interesante ver cómo los antecedentes vuelven a jugar un papel importante, aunque no muy bien especificado, ya que sólo uno de los imputados los tiene, y sin embargo la PP es pedida para ambos. En síntesis, no queda claro cuál es en concreto el peso de los antecedentes porque las consecuencias son las mismas para quien los tiene y para quien no.
} 
debido a la capacidad que éste compromiso tiene para funcionar como una regla entre Fiscales y JG. Este acuerdo

[...] se refiere a los variados métodos sociales para lograr el reconocimiento por parte de los miembros de que algo fue dicho de-acuerdo-con-una-regla. [...] las características de la sociedad real son producidas por acuerdos motivados de personas con expectativas de trasfondo [...]. Ese trasfondo debe ser visto como el orden legítimo de creencias sobre la vida en sociedad vista «desde dentro» de esa sociedad. Vistos desde la perspectiva de la persona, sus compromisos con los acuerdos motivados consisten en un asimiento de y suscripción a los «hechos naturales de la vida en sociedad» (1996: 41-67).

Lo que parece surgir aquí entre los actores judiciales es un entendimiento común sobre asuntos concretos, permitiéndoles considerar que no siempre es necesario realizar especificaciones sobre el peligro de fuga o el entorpecimiento en la investigación. Al dar por sentado cuál será la interpretación que el JG realizará frente a la investigación de determinados delitos, existen cuestiones que no precisan ser manifestadas por parte del Fiscal. Si se acreditó la comisión del hecho y la posible participación del imputado, un JG que actúe de acuerdo con las "expectativas de trasfondo" que circulan dentro del ámbito judicial, podrá conceder la PP sin importar la referencia a los riesgos procesales en los argumentos.

Dos cosas para destacar del presente modelo. Por un lado, que sus casos evidencian, tal como lo plantearon algunos informes, que existen "resoluciones en las que ni siquiera se [hace] mención al peligro de fuga o entorpecimiento de la investigación [lo que] demuestra claramente que se sigue pensando al encarcelamiento como adelanto de pena" (INECIP, 2012: 69; CIPPEC, 2011). Por otro lado, y más importante si se quiere comprender el uso de la PP, que en este modelo se observan equivalencias sobre la medida cautelar que funcionan tácitamente, que están presentes como acuerdos compartidos para los operadores jurídicos. Es en función de estas equivalencias y estos acuerdos compartidos que ambos actores judiciales consideran adecuado utilizar la PP frente a determinados hechos sin la necesidad de explicitar al respecto los peligros procesales exigidos por el CPP.

\subsubsection{Argumentos en base a un acuerdo en disidencia}

Si en el modelo anterior existía un acuerdo tácito entre Fiscales y JG, en este no coinciden sus justificaciones. Lo dicho supone que los argumentos en los que el Fiscal 
sustenta el pedido de la PP no sean los mismos que aquellos en los que el JG apoya su otorgamiento. Sin embargo, la medida cautelar sigue siendo necesaria para ambos. En pocas palabras, a partir de los mismos hechos se llega a la misma resolución, que es la imposición del encierro preventivo, pero invocando distintos motivos.

HECHO: Tentativa de homicidio y homicidio.

ARGUMENTO DE LA FISCALÍA: "Que asimismo se cumple el extremo exigido por el inciso $4^{\circ}$ del artículo 157 del CPP de la PBA, ello así teniendo en cuenta la gravedad del hecho imputado, la circunstancia de encontrarse eventualmente vinculada una cuarta persona en los hechos, todo lo cual me lleva a sostener la necesidad del dictado de la prisión preventiva en orden asimismo al no entorpecimiento de la investigación".

ARGUMENTO DEL JG: "Encontrándose reunidos los requisitos para su procedencia (arts. 157 y 158 del CPP), y concurriendo los presupuestos establecidos en el art. 171 en relación al 148 del mismo cuerpo legal, ello teniendo en cuenta la pena en expectativa que se espera como resultado del proceso, dato objetivo previsto en el art. 148 inc. 2do. del CPP para merituar el peligro de fuga, y que permite sostener la procedencia del encarcelamiento preventivo".

OBSEVACIÓN: En esta causa hay tres imputados, uno de ellos por la comisión de un homicidio y la coautoría de una tentativa de homicidio. Los otros dos imputados, están acusados de ser coautores de dicha tentativa de homicidio. El hecho ocurre en la puerta de un club bailable, y es el primero de los imputados mencionados quien saca un arma de fuego y comienza a disparar matando a una persona. La Fiscalía sostiene su planteo en los testimonios de dos testigos presenciales, y de los efectivos policiales solicitando la PP para los tres detenidos. El JG confirma la medida cautelar basándose en el peligro de fuga, y no en el entorpecimiento de la investigación como lo había propuesto la Fiscalía.

HECHO: Homicidio agravado por el uso de arma de fuego en concurso real con el de amenazas calificadas por el uso de arma de fuego.

ARGUMENTO DE LA FISCALÍA: "Solicito se dicte auto de PP respecto del imputado XXX por encontrarse reunidos los requisitos de procedencia exigidos por el art. 157 y concordantes del CPP".

ARGUMENTO DEL JG: "Surgiendo de las constancias de autos la existencia de indicios vehementes de que el imputado tratará de eludir la acción de la justicia o entorpecer la investigación, ello en razón de la pena en expectativa del delito prenotado y valoración de los antecedentes penales que registra el imputado, considero que la medida de coerción intentada resulta procedente".

OBSEVACIÓN: La Fiscalía expresa que el imputado de la causa amenazó a un hombre con 
un arma de fuego en la vivienda de éste último, desistiendo de seguir adelante por la intervención de un vecino de la víctima. Ese día, unas horas más tarde y en el interior de otra vivienda, dicho imputado efectuó un disparo de arma de fuego contra el propietario de la misma causándole la muerte. Este planteo de la Fiscalía fue corroborado por tres testigos, dos de ellos presenciales. El JG otorga la PP solicitada, pero a diferencia de la Fiscalía que sólo menciona el art. 157 del CPP, aquel justifica la necesidad de la medida cautelar en "la existencia de indicios vehementes de que el imputado tratará de eludir la acción de la justicia o entorpecer la investigación".

HECHO: Robo agravado por el uso de arma de fuego en grado de tentativa y encubrimiento, todos en concurso.

ARGUMENTO DE LA FISCALÍA: "[...] dada la calificación del evento enrostrado, resulta imprescindible aplicar una medida de coerción personal, de conformidad con lo dispuesto por lo normado por los artículos 157, 158 y concordantes del CPP".

ARGUMENTO DEL JG: "[...] considero que se encuentran reunidos los presupuestos exigidos por el artículo 171 del CPP, toda vez que dada la magnitud de la pena en expectativa para el delito imputado, me permiten presumir que XXX intentará eludir la acción de la justicia, siendo éste uno de los fundamentos de la medida de carácter cautelar a adoptarse. [...]. Que conforme dichos argumentos es que convertiré en prisión preventiva la detención que viene sufriendo XXX, al entender que en caso de recaer condena, la misma no sería de ejecución condicional presumiendo en consecuencia, que intentará eludir el accionar de la justicia, existiendo por tanto peligros procesales que justifican la coerción".

OBSEVACIÓN: Según el relato de la Fiscalía este hecho es cometido por dos personas, una de las cuales se encuentra prófuga. Ambos intentan robar un automóvil por medio de la amenaza a su propietaria con un arma de fuego, lo que no logran concretar por la intervención del personal policial. Quien resultó detenido posteriormente intenta fugarse a bordo de una moto que tenía un pedido de secuestro activo, lo que constituye el delito de encubrimiento. La Fiscalía requiere la PP aludiendo a dos arts. del CPP y el JG concede la medida preventiva pero explicitando el peligro de fuga como fundamento.

HECHO: Lesiones graves agravadas por el uso de un arma de fuego en concurso real con homicidio con dolo eventual agravado por el uso de arma de fuego.

ARGUMENTO DE LA FISCALÍA: "Que en virtud de la gravedad de los hechos que se le imputan, teniendo en cuenta la pena en expectativa, existiendo apariencia de responsabilidad de XXX por el hecho y a los fines del desarrollo del procedimiento resulta indispensable la privación de la libertad del mismo". 
ARGUMENTO DEL JG: "Que las pruebas antes ponderadas resultan suficientes para adecuar el hecho en el delito de lesiones graves agravadas por el uso de arma de fuego [...]. Que como adelanté, me aparto de la calificación elegida por el agente fiscal interviniente, de homicidio con dolo eventual ${ }^{121}[\ldots]$. Por otra parte, se encuentran reunidos los presupuestos exigidos por el artículo 171 del CPP, toda vez que las características del hecho acusado, el modo en que sucedió y las condiciones personales del imputado, ante una eventual pena en expectativa, en caso de recaer condena, la pena sería de efectivo cumplimiento, sumado a que en caso de recuperar la libertad podría entorpecer la averiguación de la verdad, siendo éste el fundamento mismo de la medida cautelar $[\ldots]^{\prime 122}$.

OBSEVACIÓN: El hecho ocurrió en la puerta de un boliche bailable, afirmando la Fiscalía que el imputado realizó dos disparos contra una persona, la cual fue lesionada gravemente en una pierna, y dos disparos contra otra persona, ocasionándole la muerte. Según la Fiscalía, se trataba de un homicidio con dolo eventual, sin embargo el JG lo consideró un homicidio culposo agravado. Para este caso concreto, definirlo como un homicidio con dolo eventual o como un homicidio culposo agravado puede traer consecuencias directas respecto al uso de la PP. Teniendo en cuenta la PEE del primero que va de 8 a 25 años, esto podría transformarse en un elemento para solicitar y otorgar la medida cautelar (Art. 79 CP). En el caso de homicidio culposo la escala penal va de los 6 meses a los 5 años, pudiendo ser considerado como excarcelable (Art. $84 \mathrm{CP}$ ). Un informante clave nos dijo que este hecho fue controvertido a raíz de que el imputado era, además de Sargento de la policía de la PBA, hijo de un Comisario de la misma fuerza. Esto dio lugar a suspicacias, como por ejemplo que la recalificación hecha por el JG de homicidio doloso a culposo fue una prebenda por los rangos del imputado y su padre. Si bien la PP fue concedida por el JG, la recalificación que hizo permitió que la Defensa del imputado recurra la medida cautelar ante la Cámara de Apelación y Garantías y debido a que se trataba de un homicidio culposo agravado, el imputado fue excarcelado. Por otro lado, la Fiscalía fundamentó la solicitud de la PP en la PEE y el JG en el entorpecimiento de la investigación.

HECHO: Privación ilegal de la libertad y abuso sexual con acceso carnal, agravado por la

${ }^{121}$ Dejando de lado las discusiones que en doctrina penal se generan acerca de si es posible la existencia de "dolo eventual", para este caso concreto, definirlo como un homicidio con dolo eventual o como un homicidio culposo agravado puede traer consecuencias directas respecto al uso de la PP. Teniendo en cuenta la PEE del primero que va de 8 a 25 años, esto podría transformarse en un elemento para solicitar y otorgar la medida cautelar (Art. $79 \mathrm{CP}$ ). En el caso de homicidio culposo la escala penal va de los 6 meses a los 5 años, pudiendo ser considerado como excarcelable (Art. $84 \mathrm{CP}$ ). Véase en el Anexo Legislativo el Art. 169 del CPP de la PBA.

${ }^{122}$ Un informante clave nos dijo que este hecho fue controvertido a raíz de que la persona que había cometido el homicidio era, además de Sargento de la policía de la PBA, hijo de un Comisario de la misma fuerza. Esto dio lugar a que se considerara a la recalificación hecha por el JG de homicidio doloso a culposo como una prebenda por los rangos del imputado y su padre. 
participación de dos personas y el uso de arma blanca.

ARGUMENTO DE LA FISCALÍA: "[...] por encontrarse reunidos los extremos requeridos por el art. 157 del CPP, solicito se dicte el auto de prisión preventiva".

ARGUMENTO DEL JG: "La situación descripta no resulta captada por la previsión excarcelatoria del art. 169 del plexo de forma, atento a la penalidad prevista para el hecho imputado. Por otra parte, el análisis de la cuestión desde una mirada que complemente la verificación de peligros procesales derivados de la pena en expectativa, la objetiva y provisional valoración de las características del hecho, a mi juicio de suma gravedad, implica un obrar totalmente desamprensivo de la ley, que permite fundadamente presumir que el procesado en libertad intentará eludir la acción de la justicia o entorpecer la marcha del proceso y la investigación".

OBSEVACIÓN: Al imputado se le adjudica la privación ilegal de la libertad de una mujer y el abuso sexual con acceso carnal, agravado por la participación de otro hombre y el uso de arma blanca para intimidar a la víctima. Según esta última, el imputado la llevó a una maderera de la zona obligándola a tener relaciones sexuales con la participación de otro individuo, prófugo de la justicia. La Fiscalía solicita la PP en función de que se encuentran "reunidos los extremos requeridos por el art. 157 del CPP”. En cambio, para el JG dada la PEE y la gravedad del delito es necesario mencionar el peligro de fuga y el entorpecimiento de la investigación.

Como pudimos ver, en este modelo existe conformidad respecto al resultado al que los operadores jurídicos consideran necesario arribar, que es el uso de la PP, pero expresa diferencias en las justificaciones para llegar a ese resultado. Es esto lo que denominamos "acuerdo en disidencia", en el sentido que los actores judiciales proporcionan motivos dispares con la particularidad de que adhieren a un uso del lenguaje jurídico por medio del cual reconstituyen las equivalencias sobre la medida cautelar (Boltanski 2000: 106-8). Si bien no se trata de un enfrentamiento tradicional, con una oposición insalvable entre una postura y otra, existe un desajuste, una disputa, ya que el JG resuelve diferenciarse de los argumentos expuestos por el Fiscal. Es esto último lo que lo distingue, por un lado, del modelo de "acuerdo tácito" en el que prevalece un entendimiento común entre los actores judiciales por el cual no precisan realizar especificaciones respecto de sus decisiones. Y por otro lado, es lo que lo diferencia del "acuerdo en base a la ley" en el que el Fiscal y el JG coinciden en indicar explícitamente lo que el CPP exige. Formulado en 7 de los 29 expedientes, en este tercer modelo si bien las justificaciones sirven para restaurar equivalencias acerca de la obligatoriedad de la PP, lo hacen expresando disidencias en los motivos que las validan. 


\subsubsection{Argumentos en base a la confianza perdida}

A partir de la presentación de los tres modelos anteriores, y de la información que éstos han brindado, pudimos conocer los distintos tipos de justificaciones que formulan los operadores jurídicos para los casos en que la PP es homologada. Esto último obliga a preguntarnos ¿bajo qué argumentos solicitan los Fiscales la PP que luego no será concedida? Y a su vez, ¿cuáles son las justificaciones de los JG para denegarla? Con el cuarto modelo de argumentación se brindará una serie de casos que se distinguen de los presentados en los apartados previos, dado que se trata de negativas de los JG frente a los pedidos de PP efectuados por la Fiscalía. Analizarlos resulta sumamente importante ya que casos como estos han quedado relegados en los informes y documentos acerca de la medida cautelar ${ }^{123}$, sin que se expresen los motivos de dicho abandono. A su vez, debido a los inconvenientes que tuvimos para obtener expedientes donde la PP fuera denegada, expondremos las percepciones de los actores judiciales acerca de los porcentajes entre medidas cautelares admitidas y denegadas.

\section{HECHO: Lesiones graves calificadas por el vínculo.}

ARGUMENTO DE LA FISCALÍA: "Que atento a la gravedad del hecho aquí investigado, la pena en expectativa, la posibilidad de que el aquí encartado intente eludir el accionar de la justicia, aparece como cierto y probable. En virtud de ello, entiende este Fiscal, que la medida de coerción solicitada se encuentra así suficientemente fundada".

ARGUMENTO DEL JG: "Luego de una lectura concienzuda de la IPP no es posible encontrar justificada la existencia del ilícito. [...] la forma descripta por el Sr. Agente Fiscal de cómo se desarrollaran los hechos que causaran dicha lesión posee basamento principalmente sino únicamente- en el testimonio de su concubina $\mathrm{XXX}$, quien posteriormente, en sede judicial, brindó una versión de los hechos que ya no la ubican como testigo directo y presencial de la supuesta agresión. A ello debe sumarse, como circunstancia que, al menos, restan credibilidad a la testigo, que extrajudicialmente ensayó distintas explicaciones del acontecer de los hechos [...], de las cuales no es posible extraer justificadamente la intención de causar una lesión por parte del imputado XXX para con su hija menor de edad. Desde otra atalaya, y sin desmedro de lo antedicho, tampoco es posible colegir la existencia de peligros procesales ciertos. La actitud desarrollada por el aquí imputado en los momentos posteriores al acaecer ilícito permite inferir razonadamente que el mismo no intentará eludir el accionar de la justicia,

${ }^{123}$ Esta ausencia no sólo se observa en las investigaciones del CIPPEC (2011) y la ADC (2012), sino también en otras realizadas por el CELS (2010), CEJA (2009,2011), INECIP (2012) o DPLF (2013). 
ya que se había presentado con su DNI en la seccional policial en reiteradas ocasiones al tomar conocimiento de que era buscado [...]. Por lo tanto, no existiendo mérito alguno para que XXX permanezca privado de su libertad y de conformidad por lo dispuesto en el CPP, resuelvo no hacer lugar a la prisión preventiva solicitada por el Sr. Agente Fiscal, y decretar la libertad por falta de mérito de XXX".

OBSEVACIÓN: El imputado es un joven de 21 años acusado de lesionar a su hija de tres meses al haberla sacudido para que deje de llorar. El pedido de PP por parte de la Fiscalía se basa en la denuncia de la madre de la menor y concubina del detenido, junto con el reconocimiento médico que informa que la víctima sufrió una fractura de su fémur izquierdo. En un primer momento, la causa estuvo a cargo del JG subrogante ${ }^{124}$ quien otorgó la PP ya que la pena que recaería sobre el imputado no podría ser de carácter condicional, razón por la cual eso beneficiaría el peligro de fuga. Doce días después de esta resolución, el JG titular retornó a su trabajo. Éste último considera que el supuesto delito que investiga la Fiscalía se sustenta principalmente -sino únicamente- en el testimonio de su concubina, la cual ensayó distintas explicaciones del acontecer de los hechos. Junto a este escepticismo afirma que tampoco es posible colegir la existencia de peligros procesales ciertos. En resumidas cuentas, el JG no cree en la versión que la Fiscalía presenta para solicitar la aplicación de la PP.

\section{HECHO: Robo calificado.}

ARGUMENTO DE LA FISCALÍA: "Debido a la gravedad del hecho y la pena en expectativa, existe la posibilidad cierta de que el imputado pretenda eludir el accionar de la justicia. Y en virtud de que están reunidos los extremos del art. 157 del CPP, se encuentran acreditados los hechos y hay motivos suficientes para que el imputado resulte ser el autor penalmente responsable, solicito la medida cautelar".

ARGUMENTO DEL JG: "Que del contenido de los referenciados testimonios, no surge que haya directa imputación alguna hacia el imputado aquí detenido, por lo que si bien se encuentra justificada la existencia del cuerpo del delito, la sola valoración del acta referenciada no tiene la fuerza suficiente que requiere este estadio respecto de la participación en el hecho del imputado XXX, por lo que no alcanza a satisfacer los requisitos del inc 3 del art. 157 del CPP".

OBSEVACIÓN: La Fiscalía sostiene que el imputado junto a un individuo prófugo robaron una moto, desapoderando al dueño previo intimidarlo con un arma de fuego. Si bien el JG considera que el hecho delictivo efectivamente ocurrió, no se deriva de esto que el imputado haya sido uno de los autores. Por lo tanto, para el JG no hay elementos de convicción suficientes o indicios vehementes para sostener que el imputado sea probablemente autor o

${ }^{124}$ El Juez subrogante es quien designa la ley para ejercer momentáneamente el cargo del Juez titular frente a su ausencia. 
partícipe penalmente responsable del hecho (Art. 157 inc. 3 del CPP).

HECHO: Tenencia de estupefacientes con fines de comercialización.

ARGUMENTO DE LA FISCALÍA: "Que conforme surge de la ley 13.449 y res. 228/06 de la Procuración General de la Provincia de Buenos Aires este Ministerio viene por el presente a exponer los motivos que hacen procedente la imposición de la medida de coerción que se solicita. Que se encuentra acreditada la responsabilidad del ciudadano respecto del hecho que se le imputa en la calidad premencionada. Que asimismo el suscripto entiende que existe proporcionalidad entre la medida cautelar requerida y el objeto tutelado".

ARGUMENTO DEL JG: "Frente al requerimiento fiscal a despacho y partiendo de una concepción progresiva respecto de la comprobación de la hipótesis delictiva a medida que avanza el procedimiento, no aparece ahora suficientemente evidenciada aquella finalidad comercial evaluando también la manifestación del encartado [...]. Téngase en cuenta además que de la laxa e imprecisa maniobra de pasamanos referida en el acta xxx no es posible inferir que el imputado cumpliera el rol de vendedor. Tampoco a partir de la escasa suma de dinero que le fue secuestrada y las características del cambio de los billetes. En definitiva, no es posible sostener a esta altura probada la existencia de alguna conducta compatible con la finalidad de comerciar ni aparecen configurados los extremos que permitan fundar un reproche a partir de la simple tenencia de los estupefacientes. Bajo ese piso de marcha no existe mérito suficiente para continuar con la detención del mencionado XXX".

OBSEVACIÓN: Según el relato Fiscal, la policía advierte que una persona -el imputadorealiza una serie de maniobras con otra persona que podrían ser compatibles con la venta y adquisición de drogas. Los agentes policiales interceptan al primero encontrando en su campera 37 gramos de marihuana y $\$ 67$. Para la Fiscalía, este hecho constituye el delito de tenencia de estupefacientes con fines de comercialización. Por su parte, el JG no advierte con suficiente claridad el objetivo de comerciar atribuido al imputado por lo que no concede la PP.

HECHO: Robo con arma blanca.

ARGUMENTO DE LA FISCALÍA: "Se encuentran dados los requisitos de procedencia exigidos por el art. 157 y ccts del CPP, justificada la existencia del delito y la participación del imputado a partir de los testimonios de la víctima y los testigos. Que asimismo, considero que el imputado durante la comisión del delito ha evidenciado un alto grado de violencia y peligrosidad por lo que hay proporcionalidad entre la cautelar requerida y el objeto tutelado".

ARGUMENTO DEL JG: "Luego de analizar la prueba incorporada a la investigación, entiendo que la misma resulta insuficiente para mantener la medida de coerción mientras dura el proceso en tratamiento. Ello así, toda vez que no obstante haberse dispuesto la detención del 
causante, con posterioridad a ello no se ha incorporado a la investigación prueba alguna tendiente a corroborar los dichos de la víctima en sus testimonios. En tal sentido, el registro domiciliario del imputado con el objeto de secuestrar la ropa usada por el mismo para perpetrar el ilícito, como el arma blanca utilizada y el objeto sustraído a la víctima, dio negativo. Por lo expuesto, concluyo que no se dan los requisitos del art. 157, y dicto la falta de mérito del imputado".

OBSEVACIÓN: Para la Fiscalía, el imputado es el autor de un robo realizado con arma blanca a un comercio, robo que pudo concretar para luego huir con el dinero despojado. Esto es lo que moviliza el pedido de la PP. Por el contrario, para el JG las pruebas que existen contra el imputado no son suficientes para otorgar la medida cautelar, entre otras cosas, porque "el registro domiciliario del imputado con el objeto de secuestrar la ropa usada por el mismo para perpetrar el ilícito, como el arma blanca utilizada y el objeto sustraído a la víctima, dio negativo".

HECHO: Homicidio agravado criminis causa ${ }^{125}$, robo agravado con armas, y robo agravado con arma de fuego no apta para el disparo, todos concursados realmente entre sí $^{126}$.

ARGUMENTO DE LA FISCALÍA: "Que en virtud de las consideraciones sobre el hecho investigado, habiendo prestado declaración el imputado, dada la calificación del evento enrostrado, resulta imprescindible aplicar una medida de coerción personal, por lo que de conformidad con lo dispuesto por lo normado por los artículos 157, 158 y concordantes del CPP solicito se decrete la prisión preventiva de XXX".

ARGUMENTO DEL JG: "Que habré de hacer lugar a la libertad por falta de mérito, toda vez que de la prueba colectada hasta el presente, no puedo tener por acreditada la participación de XXX en los sucesos que se investigan. Para arribar a esa conclusión tengo presente que la posible participación de XXX se sostuvo con el cuerpo probatorio consistente en el resultado de la labor policial, que concluyó en sindicar a XXX como el autor de los ilícitos, junto a las declaraciones de las víctimas y testigos que aportaban características físicas similares a las del detenido. Ahora bien, no puedo dejar de valorar el resultado de los reconocimientos en rueda de personas ordenados por la fiscalía, de los que se desprende que los testigos no reconocen al imputado. Que haciendo un nuevo análisis de los elementos de prueba no generan la sincera convicción necesaria para sostener la hipótesis fiscal, todo lo contrario, no tengo más que duda respecto de la participación activa de XXX en los eventos, lo que no resulta suficiente para convertir en prisión preventiva la detención que viene sufriendo el imputado".

${ }^{125}$ Según el inc. $7^{\circ}$ del Art. 80 del CP, este delito se configura cuando el homicidio se realice "para preparar, facilitar, consumar u ocultar otro delito o para asegurar sus resultados o procurar la impunidad para si o para otro o por no haber logrado el fin propuesto al intentar otro delito".

${ }^{126}$ Véase nota 24. 
OBSEVACIÓN: El relato Fiscal describe en primer lugar el robo de una moto que realiza el imputado, mediante el uso de un arma blanca con la que apuñala al dueño del vehículo causándole la muerte. Dos días antes, según la Fiscalía, el imputado le había robado dinero a un transeúnte intimidándolo por medio de un arma blanca. En esa mismo jornada, siempre a partir del relato Fiscal, el individuo investigado robó una moto mediante el uso de una escopeta recortada y un cuchillo. Como consecuencia de este planteo, se solicita la medida cautelar. Por su parte, el JG asevera que las pruebas para incriminar al imputado provinieron de la actuación policial, y que a la hora de reconocer los testigos al acusado los resultados fueron negativos. En este sentido, deniega la PP porque no advierte méritos suficientes para otorgarla.

En este último modelo aparece una certeza debilitada, que se manifiesta en el escepticismo de los JG frente a los argumentos de los Fiscales. Las circunstancias en las que este escepticismo puede cristalizarse son dos: primero, a la hora de verificar la existencia de una conducta tipificada penalmente. Segundo, y en caso de que el delito haya podido comprobarse, que el imputado sea, prima facie, autor o partícipe en su comisión. Se trata de lo que en el capítulo anterior, al hablar de los requisitos materiales que corresponde que estén presentes al momento de utilizar la PP, definimos como la verificación del mérito sustantivo o sospecha sustantiva de responsabilidad.

De los casos analizados, en tres de ellos los JG consideraron que los Fiscales no habían podido demostrar la comisión de un delito, y en los otros dos, que si bien existían hechos ilícitos, no habían logrado "vincular incuestionablemente al imputado con ellos". Sin estas dos confirmaciones, los peligros procesales que requiere el CPP de la PBA pasan a un segundo plano en el acuerdo que debe existir entre Fiscales y JG para el dictado de la PP.

Por último, y tal como lo anticipamos al inicio de éste apartado, cabe mencionar la dificultad que tuvimos para conseguir expedientes en los que la PP se deniega. A raíz de este motivo consultamos a los actores judiciales por su percepción sobre las proporciones entre medidas cautelares aceptadas y rechazadas.

"En mi juzgado la estadística ha estado casi siempre 25 a 75 a favor, pero varia turno a turno.

ENTREVISTADOR: $¿ 25 \%$ concesiones, $75 \%$ denegaciones, o al revés?

Al revés, al revés. Si fuera como decís, estaría todos los días en la tapa de los diarios" (JG del Departamento Judicial de Mar del Plata). 
"Yo estimaría que el 90\% de las solicitadas, son concedidas. Y de las que son recurridas por los Defensores el porcentaje de confirmación es aproximadamente de un $85 \% "$ (Empleado de una Fiscalía del Departamento Judicial de Quilmes).

"Mirá, la verdad no sabría decirte exactamente [...], pero acá la mayoría de las preventivas que pedimos, nos las dan. Y por lo que tengo entendido, es en general así.

De hecho, hay un mito sobre un Juzgado de Garantías que dicen que nunca denegó una preventiva" (Empleada de una Fiscalía del Departamento Judicial de La Plata).

Estos testimonios sugieren que el principal obstáculo que tuvimos para encontrar expedientes con pedidos de PP denegados está en los porcentajes generales de aceptación, que son muy altos. Si bien esta información no podemos contrastarla con estadísticas $^{127}$, resulta un aporte valioso porque permite acercarse a un tema, el de las negativas frente a la solicitud de PP, que hasta el momento no ha sido estudiado ${ }^{128}$.

\section{4- A modo de cierre}

En el desarrollo de este capítulo se priorizaron los argumentos que utilizan JG y Fiscales en los expedientes durante la IPP. Estos instrumentos sirven para organizar el trabajo dentro del ámbito judicial: describen hechos, jerarquizan explicaciones, evidencian capacidades y delimitan responsabilidades. Es por esto que los trabajos del CIPPEC y la ADC pueden considerarse un avance a la hora de describir y analizar el uso de la PP en los expedientes. No obstante, estos documentos se mantienen más cerca de un enfoque jurídico que de un estudio socio-jurídico, en el sentido de que se proponen como uno de sus objetivos centrales intervenir en la práctica cotidiana de la medida cautelar por medio de diagnósticos y propuestas de cambio. Sin excepciones, postulan distintas recomendaciones acerca de lo que debería hacerse con este instituto, mostrándose más interesados en las soluciones que pretenden auspiciar que en el análisis del problema. Es decir, que priorizan transformar la realidad de la PP en la PBA, antes que comprenderla (Latour, 2008: 67).

\footnotetext{
${ }^{127}$ Como ya hemos dicho en el capítulo anterior, no existen cifras oficiales sobre la cantidad de medidas cautelares que se solicitan, aceptan o deniegan.

${ }^{128}$ Es necesario avanzar en el estudio de las denegaciones del encierro preventivo, sus porcentajes y particularidades. Intentamos conseguir la autorización de dos Juzgados de Garantías para cuantificar a lo largo de un año las PP que se solicitan, y de estas cuántas se aceptan y cuántas se deniegan, y no obtuvimos respuestas favorables.
} 
En la sección ulterior del capítulo buscamos esclarecer bajo qué manifestaciones la medida cautelar es solicitada, aceptada o rechazada, a raíz de que son estas manifestaciones las que permiten rastrear el movimiento de la PP dentro del PJ. Al examinar estas justificaciones comenzamos por el pedido de los Fiscales, ya que la sucesión de argumentos sobre la PP se inicia con su solicitud, y porque además estos fundamentos deberían tener en cuenta las eventuales críticas que puedan realizarle la Defensa del imputado y el JG. Para profundizar este análisis se construyeron cuatro modelos de argumentación, con los que se intentó evitar la "traducción" de las justificaciones, presentándolas tal cual fueron redactadas por los actores judiciales.

Los modelos permitieron evidenciar distintos grados de condicionamientos que los operadores jurídicos reflejaron en las situaciones en que se hallaban para conseguir que las solicitudes en el caso de los Fiscales, y las aceptaciones o denegaciones en el caso de los JG, resulten justificables.

El primero es un modelo de argumentación en base a la ley, dentro del cual la PP es solicitada y concedida respecto a uno -o dos- de los riesgos procesales que exige el CPP. El segundo se realiza en base a un acuerdo tácito, ya que la medida cautelar es pedida y otorgada, si bien no se mencionan en las justificaciones ni el peligro de fuga ni el entorpecimiento en la investigación. El tercero se compone de acuerdos en disidencia, a raíz de que los argumentos entre los Fiscales y los JG no concuerdan, pero la PP es igualmente aplicada.

Por último, y a partir de la serie de relaciones que el pedido de la PP instaura, estos tres modelos pueden concretarse siempre que las presentaciones de los Fiscales hayan satisfecho ciertos requisitos para ser consideradas viables. Según los expedientes consultados, estas condiciones son dos. Primero, que el Fiscal demuestre prima facie la existencia del delito, y segundo, que el imputado haya participado probablemente en este último. Sólo verificados ambos requisitos es posible que surja un acuerdo activo sobre la necesidad de hacer uso de la PP. De lo contrario, surgen argumentos en base a la confianza perdida.

En síntesis, pretendimos explorar al encierro preventivo como una competencia que desarrollan los operadores jurídicos al producir justificaciones y argumentos, escepticismos y acuerdos activos. Esto no significa minimizar los efectos nocivos que su utilización puede acarrear, como consecuencia del encarcelamiento de miles de personas jurídicamente inocentes en la PBA. Por el contrario, al ir más allá de las denuncias con las que se presenta a la PP cuando se intenta criticar su uso, buscamos 
revalorizarla como una práctica judicial que genera relaciones entre JG y Fiscales que intervienen en los expedientes. 


\section{CAPITULO V \\ El espacio de las audiencias: prisión preventiva en tiempos de flagrancia}

En el presente capítulo analizaremos los argumentos que expresan los actores judiciales para requerir, objetar, aceptar o denegar la utilización de la PP en las audiencias que se desarrollan dentro del proceso de flagrancia. Por este motivo, comenzaremos describiendo las características de dicho proceso junto a los presupuestos y objetivos a partir de los cuales se ha fundamentado su implementación. Estos contenidos serán complementados con la evaluación que los actores judiciales hacen de dicho proceso de flagrancia.

\section{1- La flagrancia en el código}

Como ya se ha mencionando en estas tesis, en el año 1998 comenzó a regir en la PBA la ley 11.922, que sustituyó el anterior CPP e introdujo el sistema acusatorio en reemplazo del inquisitivo. Vale recordar que para la mayor parte de la doctrina jurídica, el modelo inquisitivo del proceso penal se caracteriza por defender más los intereses de la defensa social, el uso del expediente, la no inmediación entre los actores que intervienen en un proceso, y la concentración en manos del Juez de las funciones de investigar y controlar la investigación. Por el contrario, al modelo acusatorio se lo define a partir de la trascendencia que le da a las garantías del imputado, de separar las tres funciones -acusar, defender y juzgar-, y de exigir un proceso contradictorio, público y oral. De cualquier modo, estos modelos difícilmente pueden encontrarse en estado puro, existiendo principalmente sistemas mixtos.

Al ser la reforma de 1998 de gran magnitud, sus impulsores admitieron que el cambio normativo no iba a ser suficiente para lograr el funcionamiento apropiado del incipiente sistema acusatorio. En otros términos, afirmaron que al ir implementándose dichas modificaciones, resultaría imperioso efectuar nuevos ajustes. Y uno de estos ajustes se dio en el año 2004 con la ley $13.183^{129}$ que, entre otras innovaciones, introdujo el "Procedimiento en caso de flagrancia". En los fundamentos de esta ley se hallan expuestos como propósitos: (a) optimizar las intervenciones estatales del sistema

\footnotetext{
${ }^{129}$ Publicada en el Boletín Oficial de la Provincia de Buenos Aires el 16 de abril de 2004.
} 
penal bonaerense, otorgándoles mayor eficacia, sin detrimento de las garantías individuales, y (b) simplificar el trámite y acelerar los procesos, mediante la mejor coordinación de la actividad de las partes, la concentración de peticiones y la simplificación de las formalidades. Concretamente, la ley 13.183 propició la utilización de criterios de oportunidad -como el archivo de actuaciones o la suspensión del juicio a prueba- y de procedimientos simplificados -como el juicio abreviado y el procedimiento en caso de flagrancia indicado ${ }^{130}$.

Según el CPP de la PBA, existe flagrancia cuando el autor de un hecho delictivo es sorprendido en el momento de cometerlo o inmediatamente después, o mientras es perseguido por la fuerza pública, el ofendido o el público, o mientras tiene objetos o presenta rastros que hagan presumir que acaba de participar en un delito (Art. 154) ${ }^{131}$. Y es para este tipo de casos que se previó el proceso de flagrancia, siempre que los delitos sean dolosos y su pena máxima no exceda los quince años de prisión o reclusión, o que tratándose de un concurso de delitos, ninguno de ellos supere esa cantidad de años (Art. 284 bis). El trámite que sigue este proceso puede esquematizarse del siguiente modo:

- Al conocer el Fiscal sobre la aprehensión de una persona, tiene 48 horas ${ }^{132}$ para declarar si el caso será investigado dentro del proceso de flagrancia, y si fuera pertinente, solicitar al JG que transforme la aprehensión en detención ${ }^{133}$. Esta declaración deberá notificarse a la Defensa inmediatamente, y en caso de que exista discrepancia sobre si se trata o no de un delito en flagrancia, se especificarán los motivos y fundamentos de tal desacuerdo. La decisión sobre

\footnotetext{
${ }^{130}$ Con estos criterios de oportunidad y procedimientos simplificados se buscó resolver los conflictos de poca relevancia y de prueba sencilla, para de esa manera destinar mayores recursos institucionales a las investigaciones más dificultosas, como por ejemplo el crimen organizado.

${ }^{131}$ Para un enfoque integral de la cuestión, remitimos a la lectura de los Arts. 153, 155 y 156 del CPP.

${ }^{132}$ El CPP de la PBA establece que este plazo puede extenderse por medio de una resolución fundada, si bien no especifica cuánto puede extenderse.

${ }^{133}$ Según el Art. 151 del CPP, "[...] el Juez librará orden de detención [...] siempre que existan elementos suficientes o indicios vehementes de la comisión de un delito y motivos bastantes para sospechar que ha participado en su comisión. La orden será escrita y fundada, contendrá los datos personales del imputado u otros que sirvan para identificarlo y el hecho que se le atribuye, Juez y Fiscal que intervienen y será notificada en el momento de ejecutarse inmediatamente después [...]. No procederá la detención cuando al hecho imputado le corresponda una pena que no supere, en su término medio, entre el mínimo y el máximo previstos, los tres (3) años de privación de la libertad o tratándose de un concurso de delitos, ninguno de ellos supere dicho monto y cuando de las circunstancias del hecho, y de las características y antecedentes personales del procesado, resulte probable que le pueda corresponder condena de ejecución condicional. Sin embargo, se dispondrá su detención cuando registre una condena anterior que impida una segunda condena condicional o hubiere motivos para presumir que no cumplirá la orden o intentará alterar los rastros del hecho, o se pondrá de acuerdo con terceros o inducirá a falsas declaraciones [...]".
} 
este desacuerdo sólo puede tomarla el JG, dentro de las 48 horas de realizada la notificación (Art. 284 ter).

- Si el caso queda comprendido dentro del proceso de flagrancia, el Fiscal deberá disponer la identificación inmediata del imputado y solicitar la certificación de sus antecedentes, la información ambiental y cumplir con las pericias que resulten necesarias para completar la investigación, todo, en un término no mayor de veinte (20) días desde la aprehensión, el que podrá ser prorrogado a requerimiento del Agente Fiscal por veinte (20) días más por resolución fundada del Juez de Garantías (Art. 284 quater) ${ }^{134}$.

- Dentro del plazo indicado -20 días, prorrogables por otros 20-, el Fiscal, el imputado y su Defensor, estarán en condiciones de solicitarle al JG la resolución del proceso sin llegar al juicio ordinario, como por ejemplo la suspensión de juicio a prueba, el juicio abreviado o el juicio directísimo, según corresponda.

- Transcurrido ese lapso de tiempo, sin que las partes requieran otro tipo de resolución del proceso, el Fiscal procederá en el término de cinco (5) días a formular por escrito la requisitoria de elevación a juicio, y al mismo tiempo, si el imputado se encontrare detenido, solicitar la prisión preventiva (Art. 284 sexies).

- Como consecuencia, la reducción de los tiempos en la etapa de investigación es considerable, ya que de un plazo de diez meses -en el proceso ordinario- se propone en el de flagrancia uno de cuarenta días. También existe una disminución en los plazos para llegar al juicio: en el proceso ordinario no existen límites específicos de tiempo, y en el de flagrancia, el tope es de sesenta días ${ }^{135}$. En palabras de Iud y Hazan, “[...] una persona acusada de un delito que fue sorprendida en flagrancia debe ser llevada a juicio en un plazo máximo de 100 días" (2009: 231) ${ }^{136}$.

\footnotetext{
${ }^{134}$ En la redacción de la ley 13.183 el plazo era de 15 días no prorrogables. La ley 13.260 de diciembre de 2004 estipuló los 20 días prorrogable por otros 20.

${ }^{135}$ Este plazo fue estipulado en el Art. 17 de la ley 13.811, posterior a la 13.183.

${ }^{136}$ Iud y Hazan consideran que hay relación entre el uso de la PP y la reducción de los plazos: "El principal factor de incidencia en la reducción de la prisión preventiva en el marco del plan de flagrancia ha sido la drástica disminución de los plazos [...]. En este sentido, las prisiones preventivas se suelen resolver en la audiencia de finalización, en el mismo acto en que la causa es elevada a juicio, por lo que duran aproximadamente los 100 días que en promedio debe llevar el proceso de flagrancia hasta la elevación a juicio. Por supuesto, ello no implica que las personas sean liberadas, ya que en los juicios pueden ser condenados y ése es el resultado casi ineluctable de los juicios abreviados" (2009: 250-1).
} 
$\mathrm{Si}$ bien este procedimiento establecido por la ley 13.183 propuso modificaciones, mantuvo sin variaciones la manera en que debía desarrollarse la tramitación para los casos de flagrancia, que era por escrito y haciendo uso del expediente. Por lo tanto, esta ley conservaba el procedimiento escriturario, paralizando el avance de la oralidad -que es uno de los pilares del sistema acusatorio- y de las audiencias -que es la instancia donde la oralidad se plasma- que la reforma al CPP de la PBA de 1998 había buscado impulsar.

\subsection{La profundización del modelo acusatorio}

Para intentar promover la oralidad y las audiencias, en diciembre de 2004 se diseñó un acuerdo firmado por la Procuración General de la PBA, el Ministerio de Justicia, el Centro de Estudios de Justicia de las Américas (en adelante, CEJA) y el Instituto de Estudios Comparados en Ciencias Penales y Sociales (en adelante, INECIP), al que posteriormente adhirió la SCBA. Este acuerdo se fundamentó en la necesidad de consolidar el sistema acusatorio implementado en la PBA seis años antes, y que se había visto obstaculizado por inconvenientes técnicos y operativos, entre los que CEJA e INECIP destacaron:

- La carencia o debilidad de los sistemas de información del PJ.

- Como consecuencia del punto anterior, la imposibilidad de tomar decisiones institucionales estratégicas para una política criminal sensata.

- La ausencia de una práctica de realización de audiencias orales y públicas en la IPP, especialmente para el control de las medidas de coerción.

- La falta de un sistema de gestión que organice dichas audiencias con la presencia de todos los operadores.

CEJA e INECIP, ambos encargados del apoyo técnico del convenio, afirmaron en un documento posterior que

[...] el objetivo general del proyecto fue el de profundizar el proceso de implementación del sistema acusatorio que había sido introducido en la reforma del año 1998. Con este propósito se pretendió incorporar la metodología de audiencias orales tempranas frente al juez de garantías como mecanismo destinado a fortalecer los valores originales de la reforma, [y desactivar] los incentivos opuestos que operaban en el marco del sistema 
escrito que tenían relación con la falta de contacto directo entre el imputado y el juez, [...] y que banalizaba la violencia que implica una prisión preventiva" (2006: 49-59).

Las audiencias tempranas, que son aquellas que anteceden a la etapa del juicio, fueron las que este convenio utilizó para materializar el avance de la oralidad. Estas audiencias comenzaron a implementarse por intermedio de un Plan Piloto para el Fortalecimiento del Sistema Acusatorio en el Departamento Judicial de Mar del Plata ${ }^{137}$. Como indican Gómez Urso y Paolini (2008), este Plan Piloto fue el primer resultado del convenio firmado por los organismos y las entidades mencionados antes. Y a partir del 4 de julio de 2005, se llevaron adelante las primeras audiencias del Plan piloto coordinadas por la Oficina de Gestión de Audiencias de Flagrancia (en adelante, OGA), creada para ese fin ${ }^{138}$.

Cuando entrevistamos a quien fue coordinador del Plan piloto, además de subdirector del INECIP en aquella época, justificó la elección del lugar de la siguiente manera:

"A fines de 2004 Mar del Plata fue pensado como un buen lugar para llevar adelante la profundización del sistema acusatorio por varias razones: no era un Departamento Judicial del Conurbano. Por la complejidad que tienen estos Departamentos no era bueno empezar por ahí. Además el sistema de justicia de Mar del Plata tiene un alto nivel profesional, buen nivel académico en general de los funcionarios. Había buenos interlocutores, había un buen contexto".

Debido a los auspiciosos resultados de la primera puesta en práctica de este Plan piloto en Mar del Plata, se firmó un nuevo convenio a través del cual se promovió la extensión progresiva de la experiencia para casos de flagrancia al resto de los Departamentos Judiciales bonaerenses hasta abarcar toda la PBA ${ }^{139}$.

\footnotetext{
${ }^{137}$ El Plan Piloto es resultado de la importación de la experiencia desarrollada en Chile previamente. En este país se encuentra la sede del CEJA, uno de los principales impulsores de la profundización cuyo financiamiento está a cargo de la Agencia de los Estados Unidos para el Desarrollo Internacional (USAID) (Langer, 2009; Duce y Riego, 2010).

${ }^{138}$ El objetivo más importante de ésta dependencia es programar y ejecutar las diligencias adecuadas para armonizar las agendas de los JG a un tiempo con la de los Defensores y Fiscales, persiguiendo que puedan llevarse a cabo las audiencias que son planificadas diariamente en esta oficina (Piñero, 2007). Con la ley 13.811, la actividad de la OGA quedó regulada en su Art. 4.

${ }^{139}$ En una primera etapa en Zárate - Campana y San Martín (fines de 2006), y en una segunda en Necochea y Pergamino (julio de 2007) y La Matanza y Mercedes (agosto de 2007). Los departamentos judiciales donde continuó la paulatina materialización del Plan han sido Junín, Trenque Lauquen
} 
En diciembre de 2007 se elaboró un Protocolo de actuación para los casos declarados en flagrancia ${ }^{140}$, que posteriormente fue sugerido como proyecto ante la Legislatura de la PBA, siendo promulgado por medio de la ley $13.811^{141}$. Esto último significa que, al contrario de lo que suele suceder en el PJ, la reforma legislativa que comenzó a regular el procedimiento para los casos de flagrancia fue producto de los cambios que habían promovido en la práctica los operadores jurídicos, a partir del Plan piloto llevado a cabo en Mar del Plata desde julio de 2005 y progresivamente extendido al territorio provincial.

De hecho, en los fundamentos de la ley 13.811 se afirma que el objetivo es "la normativización de aquellas prácticas que se han demostrado como más efectivas y que han gozado del mayor consenso de los operadores del sistema en los distintos lugares donde se lleva adelante la experiencia, de modo que su convalidación legislativa resultaría sumamente útil para la extensión y consolidación del Sistema Acusatorio de la Provincia de Buenos Aires”. Más concretamente, la reglamentación legal refrendó las prácticas que los actores judiciales del proceso de flagrancia habían desplegado previamente, transformándose en obligatoria su aplicación, tanto en los Departamentos judiciales de la PBA en los que ya se hubiese puesto en marcha el "Plan para el fortalecimiento del sistema acusatorio" como en los que gradualmente se incorporasen al mismo (Art. 1, ley 13.811).

\subsection{La evaluación del proceso de flagrancia}

Todos los operadores jurídicos que entrevistamos en los Departamentos Judiciales seleccionados habían comenzado a trabajar en el PJ antes de que se implementaran las audiencias tempranas en la etapa de investigación dentro del proceso de flagrancia. Esto significa que fueron testigos de los cambios suscitados por el Plan piloto desarrollado en Mar del Plata, y la posterior promulgación de la ley 13.811. Como consecuencia, nos pareció importante recabar sus valoraciones para luego avanzar en los argumentos que ofrecen en las audiencias respecto a la PP.

A partir de las entrevistas, pudimos constatar que el lugar que los actores tienen en la división judicial del trabajo condiciona, por encima de otros factores, su

\footnotetext{
(noviembre de 2007), Morón y Bahía Blanca (mayo de 2008); en La Plata se implementó en febrero de 2009 (Iud y Hazan, 2009: 196).

${ }^{140}$ Este protocolo fue elaborado por miembros del Ministerio de Justicia, de la Procuración General y Magistrados y Funcionarios Judiciales de diferentes Departamentos Judiciales.

${ }^{141}$ Publicada en el Boletín Oficial de la Provincia de Buenos Aires el 7 de abril de 2008
} 
percepción del proceso de flagrancia. Algo similar a lo que habíamos señalado en el segundo capítulo, en relación a las manifestaciones que estos actores realizaron sobre la policía.

Los Defensores son quienes han mostrado mayor escepticismo frente a las consecuencias del proceso de flagrancia, enfatizando primordialmente el sesgo clasista de los delitos que pueden encuadrarse dentro de este proceso.

"La cuestión de flagrancia no es un asunto procesal, es un asunto político. Los sistemas procesales no son ni buenos ni malos en sí mismos. El tema es a qué se aplica y cómo se aplica; para qué está creado. El problema de la flagrancia es ese. Ya la definición de flagrancia del Código te lo dice: al que fuere encontrado cometiendo un delito ¿A quién se va a encontrar? A los que trabajan en la city porteña no creo, lo va a cometer el pibe que no tiene operatividad. Después, ¿quién decide que eso es un delito flagrante? La policía. Entonces está direccionado para que caigan las personas más vulnerables al sistema penal. Desde su creación está planteado de esa manera, y si vos generás todo un proceso penal destinado a condenar ese tipo de gente, la selectividad la estás acentuando. Está tan claro eso [...]" (Defensor Oficial del Departamento Judicial de Mar del Plata).

"De flagrancia preguntate lo siguiente: ¿quién puede cometer esos delitos?, ¿quién puede probar esos delitos?, ¿cuál es el objetivo de esa criminalización? [...]. Nosotros condenamos pobres, y eso siempre fue así. Con la flagrancia se los condena en menos tiempo, con menos costo. Me pueden decir que la finalidad de flagrancia es altruista, pero la realidad es que condena más rápido y con menores costos. Igual es lo que dicen: vos lees la exposición de motivos, y están diciendo eso. Además, dicen que la oralidad garantiza mejores sentencias de los Jueces ¡¿Qué?! La oralidad es una forma de comunicarse, nada más que no garantiza que los Jueces dicten mejores sentencias" (Defensor Oficial del Departamento Judicial de Quilmes).

Algunos Defensores han señalado como rasgo positivo de las audiencias tempranas la inmediatez con el JG y con el Fiscal, junto con las ventajas de la oralidad. En particular, cierto número de Defensores valoraron positivamente que el JG deba decidir sobre la concesión o denegación de la PP teniendo en frente al imputado. Sin embargo, estas bondades fueron consideradas subsidiarias en torno a los perjuicios que acarrea el proceso de flagrancia. Este planteo encuentra correspondencia con la 
conclusión de Ciocchini (2013), quien en su trabajo sobre la demora en la justicia penal bonaerense afirma que de los actores judiciales consultados, aquellos que se mostraron más reticentes al proceso de flagrancia fueron los Defensores. Según este autor, dichos actores judiciales señalaron que los procedimientos de flagrancia "incrementan la eficacia de la picadora de carne al macdonalizar ${ }^{142}$ la justicia" (2013: 186-7), ubicando a la eficacia misma, en tanto capacidad de procesar más casos en menos tiempo, por sobre el respeto de la garantías procesales de los casos individuales. Como consecuencia, se focaliza en el tratamiento de los hechos delictivos de resolución más sencilla que permiten mostrar mayor eficiencia estadística. A esto se añade que por el tipo de delitos que se persiguen por medio de este proceso, se tiende a legitimar la actuación policial. En definitiva, y aún con los matices que mencionamos hace un instante $^{143}$, las objeciones más severas a dicho proceso provienen de estos actores judiciales.

Los JG, por su parte, son quienes destacan las virtudes y desventajas del proceso de flagrancia sin poner, categóricamente, a unas por encima de las otras. Elogian la oralidad en las audiencias, la posibilidad de dialogar con el imputado, junto a la conveniencia de resolver en poco tiempo delitos con pruebas irrebatibles. Critican el uso político que se ha hecho de este proceso, la profundización de la selectividad del sistema penal, el debilitamiento de las garantías procesales, y la gran cantidad de reincidencias que provoca, fundamentalmente de personas jóvenes.

"Lo que éste proceso buscó fue reforzar la inmediación, garantizar al imputado que tuviese al Juez en frente y que viera cómo lo defendía su Defensor. También se buscaba que el Juez resolviera en un lenguaje sencillo, y que supuestamente reduciría el tiempo

\footnotetext{
${ }^{142}$ Este argumento ha sido planteado por G. Ganon, quien en 2006 -cuando era Defensor General del Departamento Judicial de San Nicolás de la PBA- publicó un trabajo que tuvo repercusión hacia dentro del PJ: ¿La MacDonaldización del Sistema de Justicia Criminal? En éste último se afirma que los planes reformistas utilizan con demasiada insistencia las palabras sistemas, racionalización, capacitación, control de gestión y gerenciamiento de recursos materiales y humanos. Esto evidencia, según el autor, el surgimiento de nuevas estrategias destinadas a implementar modelos de eficiencia y estandarización, contrarios a las necesidades particulares que posee cada caso que llega a la justicia.

${ }^{143}$ Cabe agregar que en un informe del CEJA e INECIP se presentan a Defensores conformes con el proceso de flagrancia: "En línea con esta percepción, uno de los defensores entrevistados afirmó que con las audiencias se fortalece la igualdad de armas, gracias a la posibilidad de plantear directamente frente al juez las cosas; antes tenía que esperar al debate para poder discutir algo e introducir elementos de pruebas [...]. En particular, varios defensores señalaron que sienten que tienen mayor capacidad de incidir en la decisión del juez con una buena exposición en una audiencia antes que con un excelente escrito". (2009: 242-5). Para esta investigación, CEJA e INECIP entrevistaron un total de 7 Defensores provenientes de los DJ de Mar del Plata, San Martín, Zárate-Campana, Necochea, La Matanza, Pergamino y Mercedes.
} 
de prisión preventiva [...]. Estas eran las metas, y algunas se cumplen: el Juez ya no delega y decide él. El Fiscal tiene que argumentar en la audiencia de excarcelación por qué quiere la prisión preventiva. Pero también pasó que el titular del diario, después de la primera audiencia de flagrancia en Mar del Plata, no fue que El procesado había podido ver cómo su defensor trabajaba. Fue, y esto me lo acuerdo, Hace tres días robó, y ya lo condenaron a 5 años. Me parece que hubo una dualidad entre las buenas intenciones de las ONGs y los actores judiciales que participaron de esto. Pero, por otro lado, la utilización política, claramente vinculada a la cuestión de la seguridad. Es decir, la idea de que ya no entran y salen fácilmente, sino que logramos condenarlos inmediatamente. Me parece que hay dos lecturas posibles. Y más allá de estas finalidades programadas que sí se lograron, el resto no se logró nada. Me parece que la prisión preventiva no se redujo, y los recursos para los delitos complejos no aumentaron como ser preveía" (JG del Departamento Judicial de Mar del Plata).

"Por medio de la flagrancia tenemos la oralidad, gracias a Dios tenemos inmediación con los detenidos, inclusive con la familia. Y ver al detenido, y hablarle, y preguntarle si está entendiendo. En mi caso hago el gran esfuerzo por se didáctica, ser clara y llegar con el mensaje. Pero a veces los abogados tenemos ese defecto de hablar difícil. Yo le pregunto mucho ¿entiende que ésta libertad está condicionada a que cumpla con ciertas obligaciones? O le digo que vaya al colegio, es lo que les exijo a los más chicos, a que vayan al colegio, porque me parece que es la única manera de cambiarles el futuro y desafiar el destino que tienen muchos de ellos [...]. Lo que hay hoy, y que traerá grandes inconvenientes en el futuro no es tanto la prisión preventiva, sino las condenas que se dictan en los procesos de flagrancia. Yo soy bastante amiga de este proceso porque agiliza las causas que tienen pruebas evidentes en el momento de la detención. Pero lo que está trayendo como consecuencia negativa, es que al ser procesos tan rápidos, ellos pierden la posibilidad de seguir el proceso en libertad, habiendo que condenar con penas de efectivo cumplimiento. Se ven chicos muy jóvenes, con declaración de reincidencia. Habrá que reconsiderar muchas cosas por que hay muchos condenados que son muy jóvenes" (JG del Departamento Judicial de La Plata).

Los JG son quienes manifestaron mayor moderación en sus testimonios a la hora de evaluar las consecuencias de la agilización de las sentencias, alertando sobre la tergiversación oportunista que la clase política puede provocar sobre el mismo. Según estos actores, la trayectoria del proceso de flagrancia debe ser analizada en base a la tensión que existe entre la eficiencia de la administración de justicia penal y el respeto a 
las garantías constitucionales de los ciudadanos. En síntesis, que no es insignificante en la administración de justicia darle más importancia a la administración que dársela a la justicia.

A su vez, los Fiscales ofrecieron el mayor apoyo al proceso de flagrancia. Dichos actores se mostraron más permeables que los Defensores y los JG a los discursos de los programas reformadores que, desde fines del 2004, promovieron la implementación de las audiencias tempranas. En otras palabras, los Fiscales son quienes más han respaldado los planteos reformistas tal como lo muestran las siguientes expresiones.

"Oralidad y celeridad son las dos notas características del proceso. La celeridad porque es algo que siempre se le discute a la justicia. Por su lentitud en la resolución de los casos. La justicia lenta no es justicia, y eso hizo que la gente pierda la credibilidad en el sistema. Y con flagrancia te das cuenta que estás dando una respuesta es ágil, a la mayor brevedad posible. En cien días, a más tardar, tenés que tener el caso resuelto. Nosotros tuvimos algunos casos que a los tres días del hecho, llegamos a una sentencia condenatoria firme con declaración de reincidencia. Y así la gente vuelva a confiar en la justicia, porque llama la víctima para averiguar cómo sigue la causa, y le decimos que ya está la sentencia y se sorprende. En el otro sistema, el juicio llegaba a los tres o cuatro años del hecho, la gente se olvidaba, y lo mismo la policía que interviene en mil procedimientos, después no se acuerda de uno en particular. Y además en lo correccional $^{144}$ nadie terminaba condenado porque todo prescribía. Con el proceso de flagrancia todos terminan condenados. Y también te decía la oralidad, que exige que estén todos los protagonistas y que se vean cara a cara. El juez decide en la audiencia, no va a ir su secretario a decidir. Mirándole la cara al imputado. No es lo mismo denegar la excarcelación por escrito que mirando al imputado a la cara" (Fiscal de Instrucción del Departamento Judicial de La Plata).

"Para mí el proceso de flagrancia es un proceso ágil, eficiente, y desde el punto de vista de política criminal útil porque ya te digo al imputado se le está dando una solución en un plazo de cien días. Desde el punto de vista de lo que demanda la sociedad es altamente positivo" (Fiscal de Instrucción del Departamento Judicial de Quilmes). .

\footnotetext{
${ }^{144}$ Según el artículo 24 del CPP de la PBA, el Juez en lo Correccional conocerá en los delitos que tengan pena privativa de libertad cuyo máximo no exceda de seis años. Por encima de ese tiempo de condena, intervienen los Tribunales Criminales.
} 
Si bien existen algunos reparos sobre los beneficios del proceso de flagrancia ${ }^{145}$, los Fiscales han esgrimido una nomenclatura -celeridad, agilidad, eficiencia, brevedad, utilidad- análoga a la que ofrecieron, para su promoción, los discursos reformadores de la justicia penal -eficacia, acortamiento en la duración de los procesos, resolución en etapas muy tempranas, decisiones estratégicas rápidas-. Un caso concreto de estos programas reformadores es el del CEJA e INECIP, que plantearon en un informe sobre Plan piloto llevado a cabo en Mar del Plata, que

La eficacia en el funcionamiento del sistema se pretendía que esta aumentara por la vía del acortamiento sustancial de la duración de los procedimientos [...]. En el caso de que el resultado fuera un juicio oral se pretendió llegar a esta etapa rápidamente. Para los demás casos en que aparecían viables otras formas de solución del conflicto, se buscó que las audiencias las hicieran operativas en etapas muy tempranas del procedimiento. En todos los casos se pretendió que las audiencias orales obligaran a los fiscales y defensores a analizar en profundidad el caso y a tomar sus decisiones estratégicas prontamente, evitando así la prolongación innecesaria de casos sencillos de resolver (2006: 49).

Esto último permite apreciar la exitosa penetración que tuvieron dichos programas en este sector del campo judicial, logrando que tanto "las víctimas" como "la demanda de la sociedad" ocupen un lugar central en la validación de los cambios de prácticas. Aquí parece más clara la decantación por la administración que por la justicia.

Resumiendo este apartado podemos señalar de qué manera valoran los actores judiciales el proceso de flagrancia por medio del cual se implementaron las audiencias tempranas en las que se decide la conveniencia o no de utilizar la PP. En este sentido, la apreciación de dichos actores está organizada, fundamentalmente, por la posición que tienen en la división judicial del trabajo. Los Defensores son quienes expresaron las críticas más severas, los JG quienes exhibieron mayor moderación entre las virtudes y los inconvenientes, y los Fiscales quienes se manifestaron más conformes, empleando

\footnotetext{
${ }^{145}$ Podemos citar como ejemplo de la relativización de las ventajas de estar frente al imputado, las palabras de un Fiscal: "con el proceso de flagrancia, disminuyó el uso de la prisión preventiva. El hecho de la oralidad, de enfrentar al imputado con el Juez, tener contacto con los imputados, tener contacto con la familia. Eso hace que los Jueces, en algunos casos, lo mediten de otra manera, previo a decidir. Igual yo no estoy de acuerdo, porque en veinte minutos no podés establecer si una persona va o no a someterse a proceso, no son datos objetivos, por lo que en algunos casos va a beneficiar a alguien y en otros va a perjudicar".
} 
incluso una terminología similar a la que utilizaron los discursos reformadores para su promoción.

\section{2- Audiencias: oralidad, celeridad, inmediación}

Así como en el capítulo anterior sugerimos que el expediente es considerado un cuerpo fetiche, en el cual la PP circula a partir de los argumentos que los actores judiciales ofrecen para solicitarla, objetarla, aceptarla o denegarla, en esta sección veremos qué sucede con la medida cautelar en cuestión a partir de la implementación de las audiencias tempranas.

Como se podrá advertir, esto no sólo implica un cambio de escenario, sino también de estrategia respecto a la PP: al ser un marco de enunciación nuevo, las audiencias generan en los actores modificaciones a la hora de organizar y presentar sus argumentos. Tal como afirma Chateauraynaud,

Según los interlocutores, según el tipo de audiencia presente, según el grado de simetría de los intercambios entre los protagonistas, somos llevados a decir cosas diferentes teniendo por objetivo decir esencialmente lo mismo, o mejor dicho, defendiendo los mismos intereses y representaciones (2005: 9).

A partir de lo que hemos observado, en el próximo apartado describiremos las audiencias dentro del proceso de flagrancia en las que se decide la aplicación o rechazo de la PP.

\subsection{El espacio de la verdad}

La finalidad práctica del proceso penal en general, y del de flagrancia en particular, es la declaración de certeza de la verdad respecto a los hechos investigados, junto a la aplicación de sus consecuencias jurídicas ${ }^{146}$. Como consecuencia, las audiencias deben contribuir para que dicha certeza se alcance. En el caso de estas audiencias de flagrancia, las mismas se celebran en salas cuyas dimensiones varían según los distintos Departamentos Judiciales, si bien guardan semejanza en la ubicación

\footnotetext{
${ }^{146}$ En el derecho procesal penal, la verdad es la identidad o avenencia entre lo que pensamos y aquello sobre lo que pensamos, o bien, entre nuestra representación de un hecho determinado y su realidad ontológica. En estos términos, alcanzamos la verdad cuando la relación de conocimiento que existe entre un sujeto cognoscente y un objeto cognoscible concluye exitosamente. El proceso judicial en general, y el de flagrancia en especial, se hallan atravesados por esta problemática, ya que ambos son, "en gran medida, un método, regulado jurídicamente, de investigación histórica, precisamente porque uno de sus fines [...], consiste en el intento de averiguar la verdad acerca de una hipótesis histórica, positiva o negativa, que constituye el objeto de procedimiento" (Maier 1b, 1989: 565-6).
} 
espacial de los actores. Al ingresar a las mismas, se observa un estrado que se sitúa al fondo -y en el centro- del lugar. Allí se ubica el JG con su secretario, mirando hacia la entrada. A su izquierda están sentados, tras un escritorio, la Defensa y el imputado del proceso. Y a su derecha, tras otro escritorio, el representante del MPF. Defensa -e imputado- y MPF se encuentran enfrentados entre sí. Alejándose del estrado, y más próximas a la entrada de la sala, hay algunas hileras de sillas en las que se sientan los concurrentes, que por lo general son familiares de los imputados.

El registro de lo que se expone en las audiencias se realiza por medio de un sistema digital de audio que graba las declaraciones de los participantes, desde el inicio hasta su finalización. Según los partidarios del proceso de flagrancia, este tipo de registro supone

Un cambio de paradigma sobre la forma de los actos procesales, que pone en jaque mate a la cultura del expediente judicial [y] refuerza la práctica ligada a la necesidad de resolver en la propia audiencia y sin mediaciones escritas que suelen distorsionar lo acontecido o recortar la realidad" (Tapia, 2012: 10-12).

Otra de las innovaciones de estas audiencias es que son multipropósitos (Art. 7, ley 13.811). Esto significa que, si bien cada una de las tres audiencias posibles ${ }^{147}$ tiene asignado un objetivo particular, existe la posibilidad de proponer en cualquiera de ellas los institutos procesales admisibles (suspensión de juicio a prueba, juicio abreviado, cese de la PP u otra medida de coerción, etc.), por lo que en definitiva hay un mínimo de una audiencia, y un máximo de tres.

El inicio de las mismas está marcado por la introducción que lleva adelante el $\mathrm{JG}$, en la que deja constancia del día y la hora de realización de la misma, y el número de IPP. Luego se nombra a los sujetos presentes en la misma: Fiscal, Defensor, e imputado, a quien se le consulta por su nombre y apellido, DNI, domicilio, trabajo y conformación del grupo familiar. Esto último, como ya lo dijimos al hablar de los expedientes, es lo que configura su situación de arraigo, y que puede llegar a ser importante para decidir sobre el otorgamiento de la PP u otra medida de coerción.

En casi la totalidad de las audiencias que presenciamos, los JG informaron a los imputados, en un lenguaje sencillo, el motivo por el que se los estaba investigando. En algunos de estos casos, además, los JG les dijeron a los imputados que podían formular

\footnotetext{
${ }^{147}$ Las tres audiencias posibles son la de control de las condiciones de detención, la de excarcelación y posibles acuerdos y la de finalización.
} 
preguntas en caso de no entender las cuestiones que se estaban debatiendo. Según afirma Riquert, las audiencias son

Un entorno de mayor calidad en términos de garantías porque permite al imputado ver al Juez, escuchar al Fiscal, percibir la calidad de su Defensa y ser oído antes de resolver. También en su favor se cuenta que su situación es resuelta con rapidez y cesa su estado de incertidumbre. Finalmente, en caso de condena, el quantum de la pena responde al hecho y no a legitimar el tiempo pasado en prisión preventiva [...]. Dicho con brutalidad pero en forma realista: si el imputado lleva 10 meses detenido en prisión preventiva, ningún Fiscal va a consensuar una pena menor a ese lapso aún cuando el hecho lo mereciera. En cuanto a la víctima, la audiencia es un lugar donde recibe mejor calidad de información, donde sus intereses son atendidos con mayor celeridad y donde puede participar en tiempo oportuno de modos alternativos de resolución del conflicto que, probablemente, satisfagan mejor sus expectativas" (2008: 3).

Queda claro que una manifestación de este tipo procura resaltar los atributos positivos de las audiencias, y los del sistema acusatorio en general, en detrimento del expediente y el sistema inquisitivo. En consecuencia, no tiene el propósito de describir y analizar las audiencias como un espacio complejo en el cual existen acuerdos y disputas, entre otras cosas, por el uso de la PP.

A partir de nuestras observaciones, consideramos que la "mayor calidad" para las garantías del imputado en las audiencias no es algo que pueda declamarse de forma global, o algo que necesariamente se desprenda de la inmediación entre los actores judiciales y el imputado. Éste último, en general, tiene un nivel de participación efectiva muy baja, por lo que sus expresiones se limitan a locuciones monosilábicas como "sí" o "no". Tampoco la celeridad con la que se decide la situación procesal del imputado puede considerarse, en sí misma, un salto de calidad respecto al expediente. Si bien esto será profundizado en uno de los modelos de argumentación, podemos anticipar que en algunos casos, so pretexto de la mayor rapidez, los actores judiciales convalidan en las audiencias encierros preventivos muy débilmente fundamentados. En este sentido, Fiscales y JG suelen repetir argumentos del tipo "no será demasiado el tiempo en el que se realizarán las pericias" o "ello en atención al breve plazo procesal que tiene como fecha de culminación un proceso de flagrancia". Esto significa que la celeridad, en determinadas ocasiones, es empleada para validar -y no para restringir- el uso de la PP.

Respecto a la presión que podría generar en el Fiscal el tiempo transcurrido bajo encierro preventivo sobre el monto de la pena a solicitar, no es posible combatirlo a 
partir de la utilización o no de las audiencias. Hay que tener en cuenta que, si como sugiere Riquert, "ningún Fiscal consensúa una pena menor al lapso que el imputado estuvo detenido en prisión preventiva, aún cuando el hecho lo mereciera", dichos Fiscales lo hacen porque existe un entramado de relaciones y negociaciones en las cuales también están involucrados Defensores y JG -además de lo que opine al respecto el mismo imputado-. En definitiva, lo que el Fiscal pretenda consensuar sobre el monto de la pena no está únicamente restringido al tiempo en PP del imputado, sino a elementos institucionales que afectan a todos los actores judiciales.

Por último, acerca del lugar de las víctimas, lo que pudimos comprobar a partir de las audiencias que presenciamos es que su intervención fue prácticamente nula. Sólo en una de ellas, víctima e imputado compartieron la sala. Si bien no podemos ofrecer una conclusión inequívoca al respecto, es importante destacar que el absentismo en las instancias judiciales de los damnificados es un fenómeno que excede el ámbito de las audiencias de flagrancia.

\subsection{Audiencias y prisión preventiva}

Los trabajos publicados en los que se analiza a la PP en las audiencias suelen destacar sólo los beneficios que generan la inmediación y la oralización respecto a la utilización del encierro preventivo ${ }^{148}$. Si bien no existen mediciones inequívocas sobre la correlación entre inmediación, oralidad y encierro preventivo, en diversos artículos se argumenta que las audiencias facilitan una discusión caso por caso, impidiendo que la aplicación de la PP sea automática. Aún en investigaciones como Presumed innocent, behind bars $(2011)^{149}$ en la que se denuncia la falta de audiencias rápidas junto a la extensión de la PP, la crítica parece estar centrada en el modo en que la audiencia se utiliza y no en ella como espacio propio de la administración de justicia.

En este aspecto, se han presentado documentos sobre Costa Rica, Guatemala y Ecuador que afirman que el hecho de discutir sobre las medidas cautelares en una audiencia temprana ha producido, en corto plazo, un efecto racionalizador en el uso de

\footnotetext{
${ }^{148}$ Existen trabajos, como por ejemplo un informe del CELS, que plantean críticas e inconvenientes no tanto de las audiencias como del uso de la información estadística respecto de la PP en las audiencias, en el sentido de que existen "[...] problemas que tiene la información oficial, en tanto varía según la audiencia frente a la cual son expuestos. Además, los datos oficiales son presentados de un modo desprolijo e inconsistente, y por lo general sin hacer referencia a las fuentes de información, ni a las fechas de los datos" (2010: 18). Sin embargo, la mayoría de los documentos arriban a conclusiones elogiosas de las audiencias.

${ }^{149}$ Se trata de un estudio canadiense sobre el uso de la PP en Uganda.
} 
la PP (Zamalea, 2007; Duce, 2007). En el año 2008, el CEJA publicó un estudio sobre las Reformas Procesales Penales en América Latina, en el que se incluyó un Informe sobre el Plan de flagrancia en la PBA. En éste último, se afirmó que

Parece haber incidido en forma directa la contradicción propia de (las audiencias en las que se discuten las medidas cautelares son aquellas en las que la contradicción se presenta de manera más clara), marco en el que la discusión entre las partes lleva a la adopción de otras medidas cautelares distintas de la privación de la libertad que se pueden adaptar mejor al caso concreto, evitando de esa forma la utilización casi automática propia del sistema escrito (CEJA, 2008: 251).

Según los operadores jurídicos consultados para la realización del informe que acabamos de citar, las audiencias contribuyen para que haya un conocimiento más cercano de los imputados, pudiendo generar, según los casos, "buena impresión" en JG y Fiscales. Además, sigue el informe, en las audiencias se puede debatir directamente la medida cautelar, mientras que con el uso del expediente, la Defensa recién está en condiciones de apelar la PP cuando ésta ha sido dictada. En otras palabras, se promueve un mayor protagonismo de los Defensores.

Por su parte, Iud (2009) habla del impacto de la oralidad en la reducción del uso de la PP. Este autor indica, de forma algo idealizada, las ventajas de las audiencias respecto a las del expediente: mayor celeridad, fin de la delegación de las funciones del JG que es quien resuelve al finalizar el debate, consagración de las garantías de inmediación y publicidad. Según sus propias palabras,

La principal razón jurídica del generalizado uso del encarcelamiento preventivo es la escrituración del procedimiento penal. Es que, indudablemente, el expediente es el elemento estructurante del proceso penal, que permite que el tiempo pase sin que nada suceda, así como que los jueces tomen las resoluciones más absurdas y arbitrarias sin que nadie se entere, preparadas por funcionarios y empleados que nadie conoce (Ibíd.: $3)$.

Por lo tanto, desde la perspectiva de Iud, las audiencias permiten debilitar el instrumento expediente que contribuye, en tanto elemento arraigado en la cultura judicial, a que las homologaciones de las PP se lleven a cabo sin preocuparse demasiado por los efectos que generan concretamente en las personas. 
En la misma dirección, Tapia (2012) enfatiza sobre la innovación que ofrecen las audiencias a la hora de evaluar la concurrencia de los riesgos procesales. En este aspecto, el autor dice que

La concreción de la audiencia de prisión preventiva una vez culminada la investigación prevista en el Art. 284 sexies del CPPBA- permite descartar uno de los presupuestos de admisibilidad del instituto, usualmente mencionado sin mayor sustento que afirmaciones genéricas basadas en presunciones subjetivas: el riesgo de entorpecimiento de la investigación" (Ibíd.: 20).

Esto significa que una vez que la causa es elevada a juicio, ya no podría alegarse para el uso de la PP que el imputado pueda generar perjuicios para la investigación, justamente porque ésta última ya ha concluido. En síntesis, según Tapia, la existencia de una audiencia en la que se decide la finalización de la etapa de investigación, favorece un uso más restringido de la medida cautelar.

Por último, Hazan (2009) considera que la introducción de las audiencias tempranas puede ayudar a humanizar el proceso penal y, como consecuencia, la aplicación de la PP. Si bien ya mencionamos este planteo en el capítulo previo, vale la pena reiterar que para este autor, "la división del trabajo crea distancias entre la mayor parte de los que contribuyen al resultado final de la actividad colectiva (expediente) y el propio resultado (resolver la prisión preventiva de una persona, por ejemplo)" (Ibíd.: 175). Esto promovería que la PP sea vista como el producto de muchas intervenciones técnicas, debilitando la responsabilidad moral que supone encarcelar a personas que jurídicamente son inocentes. Por el contrario, las audiencias obligan a que los tres actores judiciales que intervienen en ellas, estén frente a frente: el Defensor patrocinando, el Fiscal acusando, y el JG resguardando los principios del proceso. Y lo más importante, que todo eso suceda en presencia del imputado.

\section{3- Nuestras audiencias}

La principal característica de los trabajos que acabamos de presentar es que no indagan acerca de la manera en que se justifica, dentro de las audiencias, el uso de la PP. Esto impide conocer específicamente qué tipo de argumentos ofrecen los actores judiciales para respaldar sus posturas acerca de dicha medida cautelar.

Tal cual lo hicimos con los expedientes, en este apartado expondremos la calificación legal propuesta durante la IPP. En segundo lugar, transcribiremos las 
solicitudes y planteos de Fiscales y Defensores, y luego las decisiones de los JG. Lo haremos así porque las justificaciones respecto a la PP en las audiencias se realizan en presencia de los tres actores judiciales mencionados, a diferencia de lo que sucede con los expedientes. Finalmente, agregaremos un comentario a cada uno de los hechos que contribuya a una comprensión más accesible de la causa, teniendo en cuenta la extensión y densidad de información que circula en dichas audiencias.

Nuestras observaciones se realizaron en 47 audiencias pertenecientes a los departamentos judiciales de Mar del Plata, Quilmes y La Plata, en las cuales hubo 64 imputados, 3 de los cuales fueron mujeres. Los imputados reincidentes fueron 19, y 49 eran menores de 30 años. Empleo estable poseían 17. Respecto a los ilícitos, se trataba de 32 casos de robo - 6 simples y 26 agravados-, 3 vinculados a tenencia y 6 a portación de armas, y 6 sobre lesiones. Vale recordar que en el proceso de flagrancia sólo pueden investigarse delitos dolosos cuya pena máxima no exceda los quince (15) años de prisión o reclusión, o tratándose de un concurso de delitos, que ninguno de ellos supere dicho monto.

Asimismo, volveremos a plantear modelos que, tal como lo hicimos en el capítulo precedente, faciliten el análisis y la comparación de los fundamentos que los actores judiciales brindan a la hora de trabajar con la $\mathrm{PP}^{150}$. En este sentido, las incógnitas a despejar serán las siguiente: ¿qué expresan los Fiscales en el momento de solicitar la PP?; ¿qué plantean los Defensores respecto a esa solicitud?; ¿qué indican los JG a la hora de aceptar o denegar la requisitoria?; ¿cómo lo hacen?; ¿qué requisitos deben satisfacer los pedidos del Fiscal y del Defensor sobre la PP para ser considerados viables por el JG? A partir de las audiencias se definirán una serie de esquemas con los que pueda describirse mejor la serie de relaciones que instaura el pedido de la PP, junto a las exigencias que este pedido impone.

\subsection{Argumentos en base a la velocidad}

El primer modelo de argumentación es el que ofrece un acuerdo ${ }^{151}$ entre el JG y el Fiscal para conceder la PP respaldado en la rapidez del proceso de flagrancia. Cabe decir que se trata de un fundamento que ambos actores judiciales complementan con otros indicios que permiten pronosticar los peligros procesales, como por ejemplo la

\footnotetext{
${ }^{150}$ Las transcripciones serán hechas de forma literal, manteniéndose expresiones técnicas.

${ }^{151} \mathrm{El}$ acuerdo entre el JG y el Fiscal se produce en detrimento del pedido excarcelatorio. del Defensor.
} 
PEE, la reincidencia, la gravedad del delito, y de ese modo denegar la excarcelación del imputado. Sin embargo, en estos casos la velocidad se muestra con un alcance inusitado. En otras palabras, es a partir del proceso de flagrancia y no antes, que a la hora de validar el uso de la PP empieza a consolidarse como argumento la velocidad.

HECHO: Tentativa de robo calificado por escalamiento y agravado por la participación de un menor de edad.

ARGUMENTO DE LA DEFENSA: "Esta Defensa va a ratificar el pedido de excarcelación, de mi asistido XXX, atento la calificación legal de los hechos que se le imputan, su situación procesal encuadra dentro del Art. 169 inc 1. Y además no teniendo condenas anteriores, más allá de que esté pendiente la resolución de una suspensión por juicio a prueba, entendemos que en ambos casos podría ser beneficiado con la no ejecución de la condena. Por lo tanto, no hay peligros procesales que hagan necesaria la medida cautelar. La que por otro lado aparece como desproporcionada, manteniendo encerrada a una persona cuando goza de una presunción de inocencia. Y que además, en la causa anterior, se ha presentado cuantas veces ha sido requerido y tiene arraigo en esta ciudad".

ARGUMENTO DE LA FISCALÍA: "Esta Fiscalía se va a oponer a la solicitud de beneficio excarcelatorio habida cuenta de que la PP tiene como único objetivo asegurar la comparecencia del imputado al proceso. Para ello la Fiscalía realiza un juicio de valor basado en pautas objetivas de acuerdo a lo establecido en el Art. 148 y 171 del CPP. El hecho de que el imputado haya sido excarcelado hace un año y ocho meses atrás, y estando en condiciones de recibir los beneficios de la suspensión de juicio a prueba, sea nuevamente detenido por la comisión de un delito en flagrancia, hace presumir que intentará eludir la justicia. A eso adunado la situación que cabe destacar que el proceso de flagrancia, en un término máximo de 100 días contará con una decisión final sobre la situación procesal del imputado. Por ello y con el fin de que no se obstaculice la posible realización del proceso ya que el Código Penal no permite la persecución penal en contumacia y a los fines de asegurar ese proceso cuya obligación cae en cabeza del Ministerio Público Fiscal es que a tenor de lo informado en sus antecedentes de lo previsto en el Art. 148, solicito se deniegue la excarcelación en función del Art. 171".

ARGUMENTO DEL JUZGADO DE GARANTÍAS: "Hago propio los argumentos, tanto de hecho como de derecho, que ha citado la señora Agente Fiscal denegando la excarcelación al imputado XXX, conforme lo dispone el art 148 del CPP, 169, 171. Es por el hecho descrito y tomando en consideración que este mismo juzgado fue el que otorgara el beneficio excarcelatorio en la causa anterior. Y fundamentalmente, valorando que se trata de un proceso dinámico como el de flagrancia. Creo que objetivamente en el hecho se tipifica el peligro de 
fuga, por ende rechazamos la excarcelación del mismo".

OBSEVACIÓN: En este hecho, en el que intervienen un mayor imputado y un menor de edad inimputable, el Defensor basa su pedido de excarcelación en la baja PEE del delito investigado, junto al cumplimiento por parte del imputado de las obligaciones de presentarse en tribunales cada vez que se lo solicitaron. La Fiscalía, por su lado, sostiene que la PP es necesaria a raíz de que el imputado venía gozando de un beneficio excarcelatorio y en ese contexto volvió a ser detenido y acusado de un nuevo delito. A partir de esto último, pronostica "objetivamente" el peligro de fuga, puesto que el CPP se lo permite. Luego, al evocar el proceso de flagrancia, sostiene que "en un término máximo de 100 días contará con una decisión final sobre la situación procesal del imputado". La celeridad es aquí, no tanto lo que justifica el encierro preventivo, como lo que lo vuelve más aceptable. En definitiva, y tal como lo señala luego el JG para convalidar la PP, "se trata de un proceso dinámico".

HECHO: Robo doblemente calificado por el uso de arma blanca y haberse hecho en poblado y en banda (4 imputados).

ARGUMENTO DE LA FISCALÍA: "No habiendo arribado en esta instancia a ningún acuerdo con los señores Defensores, y encontrándome en condiciones de ejercer la acción penal, voy a elevar a juicio a los presentes actuados, como así también he de requerir el dictado de la PP para los cuatro imputados de autos. Esto debido a que se encuentra debidamente acreditado que los cuatro imputados son penalmente responsables en la comisión del delito que se investiga [...]. Siendo que la pena en expectativa que se espera en caso de que sean condenados sería de cumplimiento efectivo, esto me hace presuponer los peligros de fuga que prevé el Art. 148 del CPP. Y siendo su señoría que este delito no es excarcelable, encontrándose reunidos los requisitos del Art. 157 del CPP, la consecuencia lógica es el dictado de la PP".

ARGUMENTO DE LA DEFENSA 1: "Voy a solicitar la morigeración de la PP. El joven que asisto ha trabajado desde muy joven, no ha hecho otra cosa que trabajar, hasta este episodio no ha tenido otra actividad que trabajar. La empresa en la que está actualmente le mantiene el trabajo si cesara la detención. No tiene antecedentes [...]. Tiene una familia que trabaja, cada uno de sus integrantes, los hermanos trabajan, por lo que no tengo dudas de que a pesar de la severidad de la pena por lo que hizo, va a comparecer a juicio. Y vuelvo a destacar la jurisprudencia nacional que ha sido condescendiente con las morigeraciones para quienes no van a entorpecer la investigación o van a fugarse. A pesar de la severidad de la pena en expectativa hay elementos para suponer que mi defendido va a comparecer en juicio".

ARGUMENTO DE LA DEFENSA 2: "Esta Defensa va a oponer dos cuestiones. Primero, a que la calificación del hecho sea robo calificado por el uso de arma blanca [...]. Y segundo va a 
recordar la vigencia del Art. 18 de la CN y el 19 de la CPBA, lo tipificado por el Art. 144 del CPP y 159 para que se aplique una medida morigeradora a la PP, atento a las condiciones personales de mi ahijado procesal, y disintiendo con la Fiscal que estarían dadas las condiciones del Art. 148. Esto porque no tiene procesos anteriores, carece totalmente de antecedentes penales, por eso presumir que va a evadir el accionar de la justicia sería algo prematura, sería prejuzgar, y no tendría ningún tipo de sustento, dado que al no haberse profugado nunca, por no haber estado nunca procesado, mal podemos presumir que eludirá el accionar de la justicia. En cuanto al entorpecimiento a la investigación, dado que la investigación ya ha terminado, mal podría mi defendido entorpecer la investigación. El padre del imputado, presente en la sala, sería el garante de que cumpla con las exigencias de la morigeración, en caso de que ésta se otorgue".

ARGUMENTO DE LA DEFENSA 3: "Su señoría, esta Defensa, va a solicitar que se evalúe en virtud de los Art. 1, 144, 148, 157 a contrario, y el 320, la ausencia de pruebas que existe sobre mi asistido [...]. Si bien tiene antecedentes, las pruebas lo mantienen fuera de la órbita delictiva. Él trabaja de remisero, es lo que está acreditado [...]. La calificación para mi defendido me parece excesiva".

ARGUMENTO DE LA DEFENSA 4: "Esta Defensa va a adherir al pedido de cambio de calificación solicitado por el Defensor [2]. Además, esta Defensa va a pedir una alternativa a la PP dado que mi defendido tiene domicilio fijo, tiene familia, tiene trabajo estable, no tiene antecedentes condenatorios, por lo que no sería necesario mantener la medida de coerción para poder esclarecer el hecho y eventualmente decidir sobre la condena. Por esto mi defendido debe ser beneficiado por una medida alternativa o morigeradora a la PP".

ARGUMENTO DE LA FISCALÍA: "No me voy a oponer al pedido de morigeración, sí me voy a oponer a que sea en esta instancia, en esta audiencia. Porque creo que previo a morigerar la PP se deben acreditar ciertos extremos como son el trabajo, el domicilio".

ARGUMENTO DE LA DEFENSA 1: "A la señora agente fiscal, con total honestidad intelectual, el domicilio de mi defendido es el que figura en su informe. Tengo un listado de todos los vecinos del barrio de mi defendido, que quiero que lo vea el JG y la Fiscal que confirma el arraigo. Tenemos un problema con las periciales oficiales que demoran mucho tiempo, por eso le pido señora Fiscal que con los elementos que tiene de mi asistido, sabiendo que además tiene trabajo, resuelva otorgarle la morigeración".

ARGUMENTO DE LA DEFENSA 3: "Sumándome a lo que dijo mi colega, agregando las nocivas consecuencias que trae el encierro, aún siendo preventivo, solicito la morigeración se decida en este momento".

ARGUMENTO DE LA FISCALÍA: "Yo entiendo que en los procesos de flagrancia, al ser tan acotados, la resolución es muy rápida. Incluyendo la morigeración. Así que cuando tenga 
un informe ambiental hecho por una asistente social que acredite los planteos de los Defensores, podría otorgarse la morigeración"

ARGUMENTO DEL JUZGADO DE GARANTÍAS: "Escuchadas que han sido las partes, entiendo no procedente, en esta instancia, en esta audiencia, la concesión del beneficio de morigeración de la PP solicitada por los señores Defensores. Ello en atención al breve plazo procesal que tiene como fecha de culminación un proceso de flagrancia y a la circunstancia de que para los supuestos de flagrancia se cumplen todas las etapas procesales, o sea, existen mecanismos correspondientes para poder cumplimentar los informes socio ambientales por parte de la asesoría pericial aún en el transcurso de la feria judicial. En consecuencia no corresponde hacer lugar al pedido de morigeración a la PP solicitado. Es procedente, sí, el cambio de calificación [...]. Como consecuencia, resuelvo convertir en PP la detención de los ciudadanos XXX, en orden al delito de robo calificado por el empleo de arma. Y no hacer lugar a la morigeración de la PP solicitada".

OBSEVACIÓN: La Fiscalía comienza alegando la PEE y su corolario, el peligro de fuga, para requerir la PP de los 4 imputados, ya que se trata de "un delito no excarcelable". El primer Defensor en intervenir solicita la morigeración del encierro preventivo, aduciendo la trayectoria laboral de su defendido, la cual permitiría avalar su comparecencia en el juicio. El segundo Defensor, por su parte, objeta la presencia de los dos peligros procesales: el peligro de fuga -"no tiene procesos anteriores, carece de antecedentes penales"- y el entorpecimiento en la investigación -"dado que la investigación ya ha terminado, mal podría mi defendido entorpecer la investigación"-. El tercero, sostiene que no hay elementos de peso para poder inculpar a su defendido. El último, invoca el arraigo y la contención de su asistido -"tiene domicilio fijo, tiene familia, tiene trabajo estable, no tiene antecedentes condenatorios". La Fiscalía asegura que en esa misma audiencia no va a decidir sobre la morigeración porque carece de la información necesaria. Posteriormente, dos de los Defensores, por medio de un buen concepto vecinal en un caso y por las nocivas consecuencias de la cárcel en otro, procuran conseguir la morigeración. En su réplica, la Fiscalía expresa que "en los procesos de flagrancia, al ser tan acotados, la resolución es muy rápida. Incluyendo la morigeración”. Es decir, una vez que se acopie la información exigida, la morigeración podrá otorgarse ágilmente. Éste planteo, es respaldado por el JG, quien considera "al breve plazo procesal que tiene como fecha de culminación un proceso de flagrancia" un elemento de relieve para justificar la aplicación de la PP.

Las manifestaciones que acabamos de transcribir de los actores judiciales, expuestas en 11 audiencias, permiten comprobar cómo los ejes de velocidad y brevedad, 
sobre los cuales se promocionó el proceso de flagrancia, han sido adoptados y adaptados junto a los peligros procesales para justificar el uso de la PP.

Como ejemplo de estos ejes están los fundamentos de las leyes 13.183, 13.260 y 13.811, en los que se habla de optimizar y dar mayor eficacia a las intervenciones estatales del sistema procesal penal, de allanar el trámite y acelerar los procesos, simplificando y agilizando las formalidades y las tomas de decisiones. En segundo lugar, están las publicaciones afines al procedimiento de flagrancia que manifiestan que si algún acusado exhibiese riesgos procesales, pasar bajo PP entre 20 y 40 días -que es lo que dura la etapa de investigación- no resultaría descabellado o excesivo. Según Gómez Urso y Paolini,

Si el imputado está por un delito grave, por ejemplo, con una pena mínima superior a los tres años de prisión, o si, aún con una pena menor, no es probable una condena de ejecución condicional, o si será declarado reincidente, etc., el encierro por veinte o hasta cuarenta días se muestra 'razonable' si hablamos de tiempo de detención en perspectiva de aquellos parámetros (2008: 90-1) $)^{152}$.

Por último, se pueden observar los informes de INECIP y CEJA, en los que se considera que la rapidez del proceso de flagrancia disminuye el uso de la PP, porque tanto JG como Fiscales tienen más confianza en localizar a los imputados cuando sea requerida su comparecencia ${ }^{153}$.

En síntesis, este modelo muestra cómo a la hora de justificar el encierro preventivo, los actores judiciales apelan al vocabulario con el que el proceso de flagrancia fue impulsado. Y lo hacen, justamente, porque a partir de la llegada de este proceso la velocidad con la que se desarrolla la investigación adquiere un protagonismo que antes no tenía. Pero que a diferencia de lo que sugieren las publicaciones y los informes que mencionamos hace un instante, la velocidad es utilizada para que la PP se solicite y se conceda.

\footnotetext{
${ }^{152}$ En esta cita se muestra cómo la velocidad y la PP se articulan. En la práctica, la solicitud de esta medida cautelar, por supuesto si no media otro arreglo alternativo -juicio abreviado, suspensión de juicio a prueba- se lleva adelante generalmente en la audiencia de finalización de la investigación, junto con la requisitoria de elevación a juicio, lo cual puede tardar unos 45 días desde la aprehensión del acusado (Gómez Urso y Paolini, 2008: 92). Esto último supone una paradoja: mientras que en el proceso ordinario, el plazo para solicitar la PP es de treinta días (Art. 158), en el sumarísimo proceso de flagrancia, el límite se extiende quince días más (Art. 284 sexies).

${ }^{153}$ Según uno de los informes de CEJA-INECIP, "pareciera que la duración del proceso está relacionada con el uso de la prisión preventiva, y cuanto más prolongado se sabe que será el proceso, menos confían los jueces en hallar a los imputados cuando deben comparecer, confiando exclusivamente en la eficiencia de la privación de la libertad para asegurar la realización del juicio, descartando otras opciones cautelares" (2006: 58-9).
} 


\subsection{Argumentos en base a las personas}

Un segundo modelo de argumentación es el que utiliza como justificación preferentemente a los imputados. En concreto, esto significa que los peligros procesales con los que se respalda la aplicación de la PP son invocados a partir del comportamiento, previo al hecho que se ventila, de las personas a quienes se está investigando.

Este planteo no es novedoso en el terreno de la justicia penal. Se pueden encontrar indicios en el positivismo criminológico italiano, de suma influencia en los discursos sobre la criminalidad a partir del último cuarto del siglo XIX. Sin los resabios biologicistas provenientes de esta tradición, la idea acerca de que el componente central es el delincuente -y no el delito ${ }^{154}$ - mantiene vigencia en la legislación bonaerense y en la interpretación que hacen de ésta los actores judiciales. Y el mismo CPP ofrece criterios para evaluar la peligrosidad ${ }^{155}$ procesal a partir de la cual se pueda presumir legítimamente que el imputado intentará eludir la acción de la justicia o entorpecer la investigación. Alguno de los ejemplos a partir de los cuales se puede valorar la peligrosidad son las condiciones personales del imputado, la posibilidad de que sea declarado reincidente por delitos dolosos, o de que hubiese gozado de excarcelaciones anteriores (Art. 148). Con innegables diferencias respecto a las primeras formulaciones deterministas del positivismo criminológico, sigue presente en la legislación -respecto al uso de la PP- la intención de presagiar y combatir la peligrosidad del delincuente.

HECHO: Robo simple en grado de tentativa.

ARGUMENTO DE LA DEFENSA: "Solicito la excarcelación por lo normado en el Art. 169 inc. 1, ya que se trata de una tentativa de robo simple, por lo que considero que es procedente tal beneficio. Se ha informado que mi defendido posee un pedido de captura por una causa que tramitaría en la ciudad de Olavarría, y se le ha revocado la excarcelación por ese hecho. Considero, a pesar de estas circunstancias, que en esta causa que tramita en el Departamento

\footnotetext{
${ }^{154}$ Ha sido la Escuela Penal Clásica, considerada germen del pensamiento criminológico por buena parte de la literatura especializada, quien dio preeminencia al tipo jurídico penal o delito (y no al delincuente) en sus análisis.

${ }^{155}$ El origen del concepto de "peligrosidad" surge con Garófalo (1912), representante del positivismo criminológico, quien la consideraba como el reflejo del grado de temibilitá de un delincuente. Esta temibilitá derivaba de la perversidad constante y activa de un individuo, y de la cantidad del mal previsto que hay que temer por parte de esa misma persona.
} 
Judicial de La Plata, sería desproporcionado el uso de la PP por la baja PEE que este delito tiene. El mínimo de la pena podría ser de 15 días de prisión, y el imputado no tiene condenas anteriores, por lo que sería factible que en caso de ser condenado, la pena no sería de efectivo cumplimiento. Por esto sería arbitrario y desproporcionado denegar la excarcelación".

ARGUMENTO DE LA FISCALÍA: "Esta Fiscalía se va a oponer al pedido de excarcelación. Como ya hemos sostenido antes, las medidas cautelares que se solicitan para asegurar la presencia del imputado son al solo efecto de poder garantizar el debido proceso. Y de esta manera, llegar a una solución definitiva en el proceso. El derecho penal argentino no permite la persecución en contumacia, y la actitud del imputado en una causa anterior ha hecho que no pudiese finalizar el proceso por su ausencia. Gozó de una excarcelación previamente, pero se le revocó por no presentarse a los estrados judiciales. Todo ello hace presumir a esta Fiscalía con total y absoluta objetividad, por los extremos del Art. 148, que existe un peligro cierto de fuga en la presente. Así mismo, la Jueza de Olavarría nos dijo que está interesada en que detengan al imputado, dado que tiene una audiencia de debate para dentro de pocos días. Por ende, esta Fiscalía va a solicitar se otorgue la PP, para que el imputado esté a disposición de este Juzgado y del de Olavarría".

ARGUMENTO DEL JUZGADO DE GARANTÍAS: "Creo que están dadas las condiciones del Art. 171 para denegar la excarcelación. Ud. no ha demostrado la sujeción a proceso que me permitiría excarcelarlo. Hay un pedido de captura que está activo. Hay una JG que está requiriéndolo en Olavarría. No me da confianza que Ud. se haya presentado en esta causa pero no lo haya hecho de la misma manera en Olavarría. Por estos motivos, y coincidiendo con la Agente Fiscal, voy a denegar la excarcelación y conceder la PP".

ARGUMENTO DE LA DEFENSA: "Voy a apelar, porque entiendo que la PP resulta arbitraria debido al delito que se le imputa en esta causa. Es desproporcionada esta medida cautelar para la baja PEE del delito".

ARGUMENTO DEL JUZGADO DE GARANTÍAS: "Defensora, los delitos podrían ser excarcelables si el comportamiento del imputado hubiese sido otro. Hoy por hoy, no me merece confianza, vuelvo a decirlo. Voy a negarle la excarcelación por los mismos motivos que lo hizo la Fiscalía".

ARGUMENTO DE LA FISCALÍA: "Para esta Fiscalía se encuentra justificado el pedido de PP, ya que se encuentra acreditado el delito. Y que existen motivos para considerar que el imputado es su autor penalmente responsable. La actitud demostrada por el imputado durante un procedimiento anterior, permiten sostener a esta Fiscalía que existen los peligros procesales necesarios para la solicitud de la medida cautelar, y que estos riesgos se mantendrán incólumes durante todo el proceso".

OBSEVACIÓN: En este caso, la Defensa solicita la excarcelación porque el delito que se 
investiga tiene una PEE baja, por lo que el imputado -aún siendo condenado- no tendría que cumplir efectivamente la pena. La Fiscalía sostiene la necesidad de la PP, no por el delito que se está investigando, sino por "la actitud del imputado en una causa anterior". El hecho que impulsó esta causa queda relegado al comportamiento del imputado en otra causa, lo que permite "presumir a esta Fiscalía con total y absoluta objetividad que existe un peligro cierto de fuga". En la misma dirección, el JG concede la PP porque no le da confianza que el imputado, si bien se presentó en esta causa, no lo haya hecho previamente en otra. Según sus palabras, "los delitos podrían ser excarcelables si el comportamiento del imputado hubiese sido otro". Tanto la Fiscalía como el JG desplazan el argumento del delito a la persona del imputado para justificar el encierro preventivo.

HECHO: Robo simple en grado de tentativa

ARGUMENTO DE LA DEFENSA: "En principio, solicito la excarcelación por la calificación de delito que encuadra perfectamente en el Art. 169 inc. 1 del CPP, ya que se trata de un robo en grado de tentativa cuya escala penal permite su excarcelación. No desconocemos lo normado por los Arts. 171 y 148 del CPP, y la eventual reincidencia que podría sobrevenir, en tanto obstáculo para la procedencia de este beneficio. Pero lo que sí quiero decir es que el imputado, en los dos procesos anteriores donde fue condenado, cumplió permanentemente con lo que se le exigió. Siempre estuvo a derecho, nunca ha faltado. Y aún en caso de que se lo condene y se tome en cuenta la reincidencia, la ejecución de la pena podría ser condicional. La declaración de reincidencia es una eventualidad, no es determinante, por lo que si se dicta la PP, se estaría violando el principio de inocencia".

ARGUMENTO DE LA FISCALÍA: "Este Ministerio se va a oponer al pedido excarcelatorio. Si bien el delito imputado estaría dentro de las previsiones del Art. 169 inc. 1 del CPP, no son los delitos excarcelabres, sino las personas. $\mathrm{Y}$ esta persona no es merecedora del beneficio. Esto último porque se dan las pautas objetivas del Art. 148 del CPP, ya que si bien cumplió permanentemente con lo que se le exigió, no cumplió con la más importante de las exigencias, que es la de no cometer delitos estando en libertad condicional. Y si llega a ser condenado en esta causa, será reincidente. Por lo dicho, se solicita la PP".

ARGUMENTO DEL JUZGADO DE GARANTÍAS: "Más allá de lo expresado por el Defensor, no resulta menos cierto lo expuesto por la Agente Fiscal, en cuanto a que el imputado habría cometido un delito gozando de libertad condicional. Esto resulta para este Juzgado un obstáculo insalvable para la concesión de cualquier beneficio excarcelatorio, para lo cual el Art. 171 del CPP es sumamente claro, sumado a lo normado por el Art. 148. Por esto habré de rechazar el beneficio excarcelatorio solicitado por la Defensa".

OBSEVACIÓN: Para este hecho la Defensa sostiene como argumento para solicitar la 
excarcelación, la baja PEE junto al comportamiento del imputado en los procesos anteriores. La Fiscalía rebate este pedido afirmando que "no son los delitos excarcelabres, sino las personas", por lo que la PP es necesaria por el imputado, y no por el hecho que se investiga. El JG deniega la excarcelación porque al momento de ser indicado como autor de un nuevo delito estaba en libertad condicional. Tal como sucedió en el caso anterior, aquí la persona imputada no merece confianza y es la señalada como argumento para el uso de la PP, por delante del hecho que dio lugar al proceso.

En este modelo, que apareció en 19 de las 47 audiencias, se puede ver que no se trata de casos de simple reincidencia del imputado, tal cual es definida la reincidencia por la ley ${ }^{156}$. La argumentación a favor de la aplicación de la PP se complementa aquí con elementos vinculados a la peligrosidad, tanto en términos procesales como en términos personales. Esto queda reflejado en afirmaciones como: "la actitud del imputado en una causa anterior ha hecho que no pudiese finalizar el proceso por su ausencia"; "los delitos podrían ser excarcelables si el comportamiento del imputado hubiese sido otro"; "la actitud demostrada por el imputado durante un procedimiento anterior, permiten sostener a esta Fiscalía que existen los peligros procesales necesarios para la solicitud de la medida cautelar, y que estos riesgos se mantendrán incólumes durante todo el proceso"; "si bien el delito imputado estaría dentro de las previsiones del Art. 169 inc. 1 del CPP, no son los delitos excarcelables, sino las personas"; "respecto al cambio de calificación, no es importante para incidir en la excarcelación porque lo que hace que la misma no les pueda ser otorgada son además de la PEE, las circunstancias personales de los imputados". En definitiva, tal como lo sostiene el estudio Predicting Violence de Baradaran y McIntyre (2012), para la determinación de la peligrosidad del imputado juega un papel fundamental su comportamiento previo al hecho investigado.

De lo formulado en este modelo, podemos subrayar dos cuestiones. En primer término, que la reincidencia que es esgrimida para justificar el encierro preventivo, lo es como una recaída deliberada e individual en la infracción. Sin embargo, no es interpretada como producto de la "ineficacia" de la institución carcelaria, que habiendo tenido a la persona recluida, no ha logrado sus objetivos resocializadores (Melossi,

156 Según el Art. 50 del CP, "habrá reincidencia siempre que quien hubiera cumplido, total o parcialmente, pena privativa de libertad impuesta por un tribunal del país cometiere un nuevo delito punible también con esa clase de pena". 
2012). En segundo lugar, que la misma reincidencia es asociada a una peligrosidad difusa, propia de un imputado refractario que no amerita confianza. Tanto la reincidencia como la peligrosidad funcionan como un tándem que legitima la aplicación de la PP. Y tal como afirma Pitch,

La idea renovada de peligrosidad ha perdido las connotaciones biológicas positivistas que acarreaba originalmente y ha adquirido connotaciones que facilitan la extensión de su uso [...]. Lo que deviene construido como peligrosidad es, precisamente, lo que se presenta como ingobernable e intratable" (2009: 55-61).

En el caso específico de la PP podemos decir que lo "ingobernable" tiene que ver con el comportamiento futuro e incierto del imputado a raíz del cual la neutralización se muestra como una respuesta eficaz. Y lo "intratable" con el hecho ya planteado en el tercer capítulo, de que una persona acusada de cometer un delito no puede ser pasible de tratamiento como a un delincuente porque aún no se sabe jurídicamente si es o no es culpable.

\subsection{Argumentos en base a los delitos}

En este modelo es la reciprocidad entre la PP y el delito -sus características y modalidades- la que asume mayor peso a la hora de solicitar y conceder la medida cautelar. Está claro que el delito es fundamental en todo proceso, puesto que motiva el inicio de cualquier IPP. Sin embargo, no siempre es igual de significativo en cuanto a las justificaciones del encierro preventivo.

Si en el modelo anterior sugerimos un resabio del positivismo criminológico, debido a la preeminencia que revelaba la trayectoria y características del imputado, aquí -desde luego con matices nuevamente- existe un paralelismo con la tradición ilustrada ${ }^{157}$. Esta última bregaba por la necesidad de que exista proporcionalidad entre la gravedad del delito cometido y la pena que se inflija a quien sea su autor. Uno de sus referentes, Bentham, sostuvo en Los principios de la moral y la legislación que "el valor del castigo no debe ser menor en ningún caso que lo que sea suficiente para superar el del provecho de la ofensa" (2008: 172).

La afinidad de la que estamos hablando entre el pensamiento ilustrado sobre el delito y la pena y este modelo, surge de la proporcionalidad entre la gravedad del delito

\footnotetext{
${ }^{157}$ Para un análisis general de la Escuela Clásica dentro del pensamiento criminológico, véase Anitua, 2006; Baratta, 2004a; Pavarini, 2003; Taylor, Walton \& Young, 2001.
} 
y las medidas que se toman como consecuencia, sea una pena, sea la PP. Y esta proporcionalidad es utilizada sin que sean decisivos factores personales utilizados en otras IPP, a saber: los antecedentes, el arraigo o la posibilidad de contar con un empleo (Larrauri y Cid Moliné, 2001).

Como veremos a continuación, los argumentos dentro de este tercer modelo tienen sustento en la correspondencia que los actores judiciales observan entre la gravedad de la conducta ilícita, realizada "de una u otra manera por las personas en ejercicio de su libre voluntad" ${ }^{158}$, y la aplicación del encierro preventivo.

HECHO: Tentativa de robo calificado por el uso de arma.

ARGUMENTO DE LA DEFENSA: "Esta Defensa va a sostener el pedido de excarcelación efectuado a tenor del Art. 169 inc. 3 del CPP. A tal fin voy a destacar que mi defendido vive hasta hoy en el mismo lugar donde vivió toda su vida. Vive con su señora madre que está presente aquí en la audiencia, su padre y su hermano. También voy a destacar que mi defendido se desempeña como ayudante de soldador en XXX, lugar en donde debe cumplir dichas tareas esta semana. Quiero señalar que tiene arraigo familiar, domicilio estable y trabajo. $\mathrm{Y}$ al carecer de antecedentes penales, no existe una PEE que indique algún tipo de peligro procesal, como para rechazar la excarcelación que estoy solicitando. Además, dado que la regla durante el proceso debe ser la libertad del imputado, no hay motivos para otorgar la PP”.

ARGUMENTO DE LA FISCALÍA: "El beneficio de excarcelación solicitado para el imputado tiene que ver con el inc. 3 del Art. 169, esto es, la magnitud de la PEE. Lo cual se vincula con la posibilidad de una ejecución condicional de una hipotética condena. Esta Fiscalía considera poco probable que haya una condena de ejecución condicional. Entendemos que la sola carencia de antecedentes no permite pensar en una condena de ejecución condicional. De hecho la regla es la pena de efectivo cumplimiento. Entendemos también que esta Fiscalía está en condiciones de realizar una estimación de pena a partir de un pronóstico, siempre objetivo, de la probabilidad de una condena de ejecución condicional. El hecho es un hecho violento, que se comete en la nocturnidad, además de la resistencia del imputado frente a

158 Esta cita, perteneciente a Enrico Ferri en su Sociología criminal, es utilizada para criticar el presupuesto del libre albedrío en el que abrevaba la Escuela Clásica: “[...] habiendo admitido como postulado implícito que de la libre voluntad de los hombres depende cometer o no los delitos, realizarlos de una o de otra manera y en más o en menos número, se ha atrofiado y detenido todo olio estudio sobre las causas naturales de este fenómeno social. En desquite, el criminalista clásico sabrá bien decir en qué caso un delito ha quedado en grado de tentativa o frustración y en cuál otro ha sido consumado, agravado o atenuado, y tales conocimientos nos serán también útiles a su tiempo; pero entretanto quedará perplejo y enmudecido ante estos otros problemas más urgentes, de los cuales reclama, sin embargo, la sociedad moderna una solución práctica y eficaz" (1907: 17). Para un análisis detallado de los postulados e implicancias del tópico del libre albedrío, en particular en Beccaria, véase Beirne (2002). 
la autoridad, lo que valoro como un indicio de fuga tan importante como los otros indicios que ofrece el Art. 148. En definitiva, al considerar poco probable una condena de ejecución condicional, es que solicito la PP".

ARGUMENTO DEL JUZGADO DE GARANTÍAS: "La pena prevista para este delito oscila entre los 2 años y 6 meses y los 10 años de prisión, con lo cual, debido a la carencia de antecedentes penales, cabe la posibilidad de pensar que podría ser en suspenso. Ahora bien, el legislador me obliga a hacer un presagio respecto de esa circunstancia, y el primer inconveniente que encuentro es que la pena en suspenso es la excepción a una regla, que es que las penas deben ser a cumplir. La pena es condicional si es que se dan una serie de requisitos, que el CPP redujo a tres: una, es la carencia de antecedentes penales, que en este caso el imputado no tiene. Otra sería las características personales, que no generan inconvenientes. No obstante, la tercera nos habla de las circunstancias del hecho. En este caso concreto, el uso de la violencia se da para apoderarse del objeto robado y para evitar la detención de la policía. Y este uso de la violencia me lleva a mí a denegar el beneficio que ha solicitado la Defensa. Por lo tanto, dicto la PP".

OBSEVACIÓN: En este hecho, la Defensa solicita que no se conceda la PP porque el delito tiene una baja PEE, y la condena, en caso de concretarse, podría ser de ejecución condicional. Además, el imputado no tiene antecedentes, posee trabajo y domicilio estable. La Fiscalía no pone en duda estos argumentos, excepto el hecho de que "considera poco probable que haya una condena de ejecución condicional". Esto último ocurre a raíz de la violencia y el momento en el que el ilícito se llevó adelante. El JG, por su parte, hace lugar a la PP porque las circunstancias del hecho lo llevan "a denegar el beneficio excarcelatorio que ha solicitado la Defensa".

HECHO: Robo agravado por el uso de arma y por ser cometido en poblado y en banda.

ARGUMENTO DE LA DEFENSA: "Vamos a solicitar la excarcelación del imputado XXX, en los términos del Art. 169 inc. 3 del CPP. Todo esto resulta de la calificación del hecho, que sería la de robo en poblado y en banda, y no como ha sido calificada por el JG como robo agravado por el uso de arma y por ser cometido en poblado y en banda. Es por esto que le correspondería una condena de ejecución condicional. Ello debido a la carencia de antecedentes del imputado [...]. Propicio entonces el cambio de calificación, y solicito en esos términos la excarcelación de mi defendido".

ARGUMENTO DE LA FISCALÍA: "La Fiscalía se va a oponer al pedido excarcelatorio por un planteo principal, y uno subsidiario. En relación al planteo principal, entendemos que el hecho investigado es constitutivo del delito de robo calificado por el uso de arma [...] que aumentó el poder del agresor, y disminuyó el poder de resistencia de la víctima. Esto hace 
aplicable la PP. Como subsidiario, y aún cuando el JG se incline por la calificación propuesta por la Defensa, nos encontraríamos en el inc. 3 del Art. 169. Entiendo que la hipotética ejecución condicional de la que habla la Defensa surge de la ausencia de antecedentes penales del imputado. La sola ausencia de antecedentes en una persona mayor de 18 años, no lo hace inmediatamente acreedor del beneficio de una modalidad de ejecución condicional. En este sentido, el JG debe analizar las circunstancias personales del autor, y la naturaleza del hecho. Y de la naturaleza del hecho, lo que obtenemos son agravantes: una víctima menor de edad, la mayor violencia desplegada. Estos agravantes nos hablan del hecho que lo ubicarían fuera de una ejecución condicional de la condena. Por lo menos, es lo que debe hacer la Fiscalía: evaluar la probabilidad basadas en circunstancias objetivas. Y estas son las circunstancias objetivas que encontramos: la utilización de un arma, la edad de una de las víctimas, y los golpes recibidos. Por estas cuestiones propicio el rechazo al cambio de calificación legal, y en este sentido no se haga lugar a la excarcelación solicitada [...]”.

ARGUMENTO DEL JUZGADO DE GARANTÍAS: "Llamado a resolver la cuestión, voy a decir que ya me he expedido anteriormente sobre la calificación legal aplicable, la que considero como robo doblemente agravado por el uso de arma y por ser realizado en poblado y en banda [...]. Esto es así porque la víctima fue intimidada con un objeto que le fue apoyado en su cuello, con lo cual se puede hablar de un arma impropia [...]. Y aún en el caso de seguir la hipótesis de la Defensa, tampoco sería admisible la excarcelación. Ello por cuanto, en primer lugar, el máximo de pena establecido para la concesión de un ejecución condicional debe compararse con el mínimo de la escala penal del delito investigado, que es de 3 años. Dado que la regla es que las condenas se cumplan, y la condicionalidad es la excepción, debemos evaluar las condiciones personales del imputado y la modalidad con la que se ha cometido el delito enrostrado. Respecto de condiciones personales, no hay nada que decir porque el imputado no tiene antecedentes. Ahora, respecto de la modalidad, es distinto: la pluralidad de intervinientes, el doble agravante, la violencia desplegada, tornan imposible, a mi criterio, la aplicación de una condena de ejecución condicional. Se trata de una agresión a un menor, efectuada de un modo artero, de un modo cobarde, y mediante la utilización de armas. Así las cosas, por el momento, no resulta posible la aplicación de una condena de ejecución condicional, por lo que deniego la excarcelación solicitada por la Defensa".

OBSEVACIÓN: En este caso, está en discusión la calificación legal del hecho investigado. Para la Defensa, se trata de un robo agravado por haberse cometido en poblado y en banda. Esto permitiría excarcelar al imputado dado que, de recibir una condena, podría ser de ejecución condicional. La Fiscalía sostiene que el robo es agravado por la utilización de un arma impropia, es decir, un arma que no ha sido creada como arma pero es utilizada como tal por el imputado. Y que además, por "la naturaleza del hecho en los que hay una víctima menor 
de edad y una mayor violencia desplegada, lo ubicarían fuera de una ejecución condicional de la condena". El JG mantiene la calificación legal que había formulado al inicio de la causa: robo agravado por el uso de arma y por ser cometido en poblado y en banda. Esto es complementado, para validar el otorgamiento de la PP, con "la modalidad con la que se ha cometido el delito enrostrado [...]: la pluralidad de intervinientes, el doble agravante, la violencia desplegada, tornan imposible, a mi criterio, la aplicación de una condena de ejecución condicional".

En su trabajo De los delitos y de las penas, Beccaria afirmaba que los motivos que disuadan a las personas para cometer delitos deben ser más fuertes en la medida que dichos delitos más atenten contra el bien público, y en la medida que existan más estímulos para cometerlos; "debe por esto haber una proporción entre los delitos y las penas" (1993: 86).

Por intermedio del equilibrio entre unos y otras, este pensador italiano creía posible contrarrestar las motivaciones de las personas para transgredir las normas jurídicas. En los casos indicados en este modelo, si bien no se pretende contrarrestar motivaciones a partir de la proporcionalidad entre el delito y la PP, sí se intenta justificar la necesidad de encerrar cautelarmente a un imputado. Incluso existen correspondencias con planteos posteriores conocidos como neo-clásicos. Von Hirsch, por ejemplo, evalúa la relación concreta entre censura, proporcionalidad y castigo. Este autor considera que la proporcionalidad entre delito y pena debe ser el elemento más importante a la hora de establecer esta última, por ofrecer una guía más o menos practicable de las penas a imponer por la comisión de determinados hechos, y fundamentalmente por ser "éticamente plausible". Según sus propias palabras, "un sistema penológico debería intentar ser justo -o como mínimo lo menos injusto posible[propósito éste] que subyace en el principio de proporcionalidad" (1998: 159). En Von Hirsch, así como en este modelo, el delito asume un lugar central porque es el elemento a partir del cual se evalúa el equilibrio entre la pena y la infracción que se ha cometido, o entre la PP y el hecho que se está investigando.

Además, lo que acabamos de exponer tiene una importancia especial porque, si bien la PP no es una condena en términos estrictos, en este modelo se la justifica de un modo análogo. De hecho, muchos de los informes sobre el encierro preventivo ${ }^{159}$, así

\footnotetext{
${ }^{159}$ En el trabajo del IINECIP sobre la PP se afirma: "Como ya adelantamos, la utilización de criterios sustantivos enmascarados bajo criterios procesales es moneda corriente en los distintos tribunales del
} 
como actores judiciales que hemos entrevistado, sostienen que la PP es un "adelanto de pena", es decir, que se la impone en función de la condena que en el futuro podría ser aplicada por el delito que se investiga. En este sentido, la CSJN sostuvo en un renombrado fallo que

La limitación de la libertad personal durante el proceso motivada en el reproche o la repulsa social de ciertas conductas -por más aberrantes que puedan ser, como remedio tendiente a combatir el auge de determinada delincuencia ante la necesidad de mayor protección de determinados bienes jurídicos, $[\ldots]$ desvirtúa la naturaleza cautelar de la prisión preventiva al convertirla en una verdadera pena anticipada ${ }^{160}$.

En definitiva, ocurre en los 15 casos pertenecientes a este modelo que la PP es validada a partir de delitos que, por sus características, permiten conjeturar alguno de los riesgos procesales. Y es también por las características de esos hechos investigados que la utilización del encierro preventivo se considera proporcionado.

\subsection{Argumentos en base a la policía sospechada}

En el último de los modelos no se hace lugar a la aplicación de la PP. Tal como lo llevamos adelante para el caso de los expedientes, analizaremos bajo qué argumentos solicitan los Fiscales la PP que luego no será otorgada por los JG, con la particularidad de que en las audiencias están presentes los Defensores, quienes incluso pueden intervenir antes que los Fiscales ${ }^{161}$.

HECHO: Portación ilegal de arma de uso civil y encubrimiento

ARGUMENTO DE LA FISCALíA: "Esta Fiscalía va a pedir la elevación a juicio y el dictado de la PP. Entendemos que se encuentra probado, en lo que se exige para esta etapa procesal para la persecución de éste trámite [...]. En este sentido, hemos podido acreditar que [...] el imputado portaba en su cintura un revolver con denominación suprimida a golpes, según la información de pericia balística, con 7 proyectiles en su interior, 5 de ellos de punta hueca [...]. Luego se acreditó que el imputado no es legítimo usuario de la misma, lo que motivó su aprehensión y el secuestro del arma objeto del ilícito [...]. Esto permite hablar del

país. El encarcelamiento preventivo sigue funcionando como una forma de castigar el tipo de delito en forma anticipada al medir el peligro procesal bajo el prisma de la pena en expectativa" (2012: 40).

${ }^{160}$ Fallo Nápoli, Erika E. y otros, del 22 de diciembre de 1998.

${ }^{161}$ La importancia de mencionar estos casos es análoga a la que señaláramos cuando hablamos de los expedientes, ya que las denegaciones de la PP han quedado relegadas en los informes y documentos acerca de la medida cautelar en las audiencias. 
delito de portación ilegal de arma de uso civil y encubrimiento por su denominación suprimida [...]. Por último, entendemos que $\mathrm{XXX}$ es el autor penalmente responsable del delito previamente descripto, la aprehensión que se hace del mismo en flagrancia con el arma en su poder [...]. Dicho esto, me permito dar por acreditado los inc. 1 y 3 del Art. 157. En relación al inc. 2, el imputado tuvo su declaración. $\mathrm{Y}$ en relación al inc. 4, por las características mencionadas del hecho, se encuentra latente el peligro de fuga, por sus antecedentes, ya que de ser condenado enfrentaría una pena de efectivo cumplimiento. Además, el imputado ha gozado de excarcelaciones previas. Todo esto nos hace sostener que se dan los peligros procesales del Art. 148, y por ende, que la PP es el único medio de asegurar los fines del proceso".

ARGUMENTO DE LA DEFENSA: "Esta Defensa se va a oponer a la elevación a juicio, va a plantear el sobreseimiento, por el planteo de una nulidad que ha surgido en esta IPP. La nulidad versa sobre el arma y los proyectiles que se han secuestrado en la causa. No tenemos la certeza de que el arma secuestrada y los proyectiles sean los que se han periciado. En el primer reconocimiento de visu se marca que hay un arma con 7 proyectiles. Cuando se abre el sobre termosellado frente a esta Defensa, donde debería estar el arma y los 7 proyectiles, sólo había 5. Es más, 1 de esos 5 proyectiles estaba percutido. La prueba que presentó la Fiscalía habla de 7 proyectiles, pero en la audiencia de la pericia que yo presencié había 5 ¿Qué garantías, Sr. Juez, podemos tener de que el arma no haya sido cambiada, o si no funcionaba, arreglada, o que las balas no hayan sido otras? Es evidente que la cadena de custodia se ha alterado para un elemento clave para los dos delitos que se le endilgan al imputado. Tanto el encubrimiento como la portación de arma, se sustentan en los proyectiles y el arma. Dejo planteada esta nulidad. Como segundo planteo, para el caso de que no se haga lugar a la nulidad, y consiguiente sobreseimiento de mi defendido, solicito la recalificación del hecho, y que se eleve a juicio por portación de arma, y no por encubrimiento. Esto porque, hasta el momento, la Fiscalía no ha logrado reunir los elementos necesarios para intentar probar el delito de encubrimiento. Por último, vuestra señoría, para el caso que no haga lugar a ninguno de los pedidos presentados, solicito que en caso de convertir en PP la detención de mi defendido, se le conceda un beneficio de morigeración de la PP, habida cuenta las particulares circunstancias de esta causa. Por medio de una prisión domiciliaria mi defendido podría esperar el debate. Él tiene trabajo conocido, la PEE para este delito es muy baja, no existe entorpecimiento probatorio, y como surge de la información de la causa, mi defendido nunca intentó eludir o entorpecer la justicia".

ARGUMENTO DE LA FISCALÍA: "No existe ningún motivo para declarar la nulidad. Los 5 proyectiles que se secuestraron, estuvieron siempre, y fueron los que se periciaron. Estos 5 proyectiles son los que configuran el delito de portación. Respecto de los otros 2 proyectiles, se podrá discutir en el debate qué ocurrió, a partir de las declaraciones de los efectivos policiales 
que intervinieron. No es cierto que se hayan termosellado 7 proyectiles, y al momento de la pericia había 5. Son estos 5 proyectiles los que fueron remitidos a policía científica. Esto significa que no hay ninguna situación que afecte las garantías constitucionales, ni que haya dudas como para sobreseer al imputado en ésta etapa. Recordemos que la duda en el juicio, exige la absolución, pero la duda durante la IPP amerita la discusión en el debate. Respecto a la morigeración, entiendo que no se dan los elementos para otorgar ese beneficio, porque faltan informes que acrediten la ausencia de los peligros procesales que se deben presumir iuris tantum según el legislador. Habría que hacer un amplio informe socio-ambiental para que se pueda otorgar el beneficio de la prisión domiciliaria. Todo lo que acabo de expresar me obliga a solicitar que no se haga lugar a la nulidad, eleve la causa a juicio, y dicte la PP”.

ARGUMENTO DE LA DEFENSA: "En el oficio que se remite desde la comisaría hacia la policía científica, se menciona el envío de un arma y 7 proyectiles. O sea, el envío, estuvo. Lo que no se sabe, es qué pasó en el camino. Y pasó que se violó la cadena de custodia, y con ello, las garantías constitucionales de mi defendido. Nada más, su señoría”.

ARGUMENTO DEL JUZGADO DE GARANTÍAS: “[...] Respecto de la nulidad de la pericia planteada por la Defensa, por la violación de la cadena de custodia, parece que esta cadena no ha sido efectivamente preservada. Respecto del arma, y a diferencia de lo que planteó la Fiscalía, habiéndose suprimido la numeración de la misma, se vuelve una cosa fungible, es decir, que podría cambiarse por otra. Pero además, algo más delicado es el caso de los proyectiles, que son elementos absolutamente fungibles porque no hay forma de reconocerlos. Por lo tanto, la pericia adolece de nulidad, y así lo declaro. Y como consecuencia de esto, resuelvo sobreseer al imputado por el delito de portación ilegal de arma de uso civil y encubrimiento que se le atribuye. Consecuentemente, procedo a excarcelar al imputado XXX".

OBSEVACIÓN: La Fiscalía considera probado el delito y la autoría del mismo. Se trata de un imputado con antecedentes, por lo que la pena sería de efectivo cumplimiento. En esto último se sustenta el peligro de fuga y la solicitud de la PP. La defensa solicita la nulidad de la investigación porque "la cadena de custodia se ha alterado para un elemento clave para los dos delitos que se le endilgan al imputado". Es decir, que no hay certeza de que el arma o los proyectiles sean los que efectivamente se le secuestraron al imputado. Para el caso de que no se considere nula la IPP, la Defensa requiere que el delito se "eleve a juicio por portación de arma y no por encubrimiento". Y en caso de que el hecho no se recalifique, la Defensa solicita que la detención sea domiciliaria, y no en la cárcel, ya que no existen peligros procesales que justifiquen el uso de la PP. La Fiscalía sostiene que no hay elementos suficientes para que se decrete la nulidad, porque "la duda en el juicio, exige la absolución, pero la duda durante la IPP amerita la discusión en el debate". Y que no hay información necesaria para conceder el beneficio de la morigeración de la PP ya que "los peligros procesales se deben presumir [...] 
según el legislador", hasta que se demuestre lo contrario. El JG afirma que la pericia realizada está viciada porque la "cadena [de custodia de los elementos secuestrados] no ha sido efectivamente preservada", por lo que declara la nulidad de la pericia y el sobreseimiento del imputado haciendo cesar la PP.

HECHO: Portación ilegal de arma de fuego por uso civil

ARGUMENTO DE LA DEFENSA: "Ha encontrado la Defensa una serie de inconsistencias o irregularidades en este procedimiento. Cuando uno toma el acta de procedimiento, nos encontramos con un relato policial en el cual [...] la persecución se inicia porque una moto circulaba a gran velocidad. La moto se cae, y se secuestra un arma de fuego con proyectiles. El que manejaba la moto era menor, el acompañante es el imputado. Los testigos son tres, dos de ellos policías. Los testimonios son idénticos, como suele pasar, dónde sólo se cambian los nombres de las personas. Según el relato, la policía da voz de alto, y una de las personas que iba en la moto, el imputado, apunta con un arma al patrullero sin disparar. Cuando la moto se cae, según el relato policial, al sujeto que llevaba el arma se le cayó. El problema es que no hay acta de secuestro que permita saber dónde estaba el arma de fuego, lo que tampoco se aclara en el acta de procedimiento. Supuestamente, todo hace indicar que el arma estaría en el piso. El testigo presencial, al declarar, dijo que el arma se la sacó la policía de adentro de la campera de uno de los imputados. Lo cual ya es distinto de lo expuesto por la policía, que es que durante la persecución uno de las dos personas les habían apuntado. El imputado, declaró que efectivamente se habían caído de la moto y que luego ve un arma. Y que no tenía problemas en hacer las pruebas necesarias para comprobar si el arma tenía sus huellas, ya que se lo acusaba de ser el portador. Por lo tanto, tenemos tres versiones de los hechos: la del testigo, la del imputado, y la de la policía. Parece evidente que el relato policial está pensado para poder justificar su actuación, dando a entender que era una situación sospechosa. Esta Defensa plantea, en primer lugar, la nulidad del procedimiento, porque no había una sospecha previa verdadera para habilitar la interceptación en la vía pública por parte de la policía. Lo que esta Defensa sostiene es que al imputado XXX, se lo paró no por lo que estaba haciendo, sino por ser XXX. Y como este accionar la policía lo debe justificar, genera toda esta fantasía de que iba en una moto, y apuntó con un arma de fuego, y por eso nosotros lo interceptamos. Y esto se contradice con lo que dijo el testigo, por lo que hay una falsedad en los relatos. Y respecto a la PP solicitada por la Fiscalía para que se mantenga, queda claro que no están presentes los peligros procesales para justificarla. Además, el imputado tiene un domicilio fijo, tiene un arraigo, tiene su familia. Por último, solicita esta Defensa que se dicte la falta de mérito".

ARGUMENTO DE LA FISCALÍA: "No es la primera vez que me pasa de tener que escuchar que la versión de la policía parece ser la versión de marcianos, y por lo tanto, carecen 
de valor convictivo por el solo hecho de que son policías. Pero aún en la versión del testigo, el motivo para que la policía interceptara a la moto, estaba. La zona y la alta velocidad son suficientes para que la policía intercepte a una moto. Lo que declaran los oficiales, es lo que vieron. Parece como improbable que la discordancia señalada por la Defensa se muestre como un obrar predeterminado. Es inconcebible que la policía monte todo ese operativo para imputarle al imputado XXX la comisión de un delito, y convoque a un testigo que no tiene nada que ver con la actividad policial, que es un tercero ajeno, que termina comprometiendo aún más la situación de XXX. La discordancia entre lo que narra la policía y lo que narra el testigo, es nada más que una diferencia de apreciación. La única diferencia entre los testimonios es de dónde sacan el arma, pero el arma siempre está, en las dos versiones. Según la declaración del imputado, en un primer momento no había habido ningún arma. Después dijo que sí, que creía que le habían puesto un arma. Esto se contradice con lo que dijo el testigo, sobre el cual no tengo motivos para dudar que haya dicho la verdad. Lo que dijo el testigo viene a corroborar lo que dijo la policía. Y las versiones antojadizas del imputado, que cambian de acuerdo a las nuevas pruebas que aparecen, aunque tiene derecho a decir lo que quiera, no tienen asidero. Además de los antecedentes que el imputado tenía respecto a la portación de arma. Por lo dicho es que solicito se eleve esta causa a juicio, en donde se discutirán los detalles de la causa. En cuanto a la PP, es necesario que se mantenga la misma, toda vez que la magnitud y modalidad de PEE, me hace descreer que el imputado se va a quedar sentado en su casa esperando que algún día se lo condene a una pena de efectivo cumplimiento. Cuenta con sentencias condenatorias previas, tiene otra causa abierta donde se le imputa el mismo delito. Por lo tanto, en libertad, buscará obstaculizar el avance de la investigación".

ARGUMENTO DE LA DEFENSA: "La discordancia, por más pequeña que sea, es sobre la que tenemos que dilucidar en este proceso, que es dónde estaba el arma, si la tenía alguno de ellos, y en todo caso, quién la tenía. Segundo, hablar de peligro de fuga cuando el imputado está aguardando el juicio en libertad por otro delito de portación de arma, como dijo la Fiscalía, parece excesivo, ya que no se ha escapado. En síntesis, no existe ningún riesgo de fuga probable".

ARGUMENTO DEL JUZGADO DE GARANTÍAS: "Entiendo que la cuestión, que la descripción inicial, efectuada en el acta inicial, no debe ser nulificada. Vale decir, en concreto, la imputación de la portación del arma al imputado XXX es fundada sobre la base de una atribución que hace el personal policial interviniente de que el acompañante ubicado en la moto esgrime amenazante un arma contra el mismo personal policial. Estas circunstancias no han podido ser, a esta altura, corroboradas en forma contundente. En primer lugar, no se han encontrado sobre el arma huellas dactilares. Y esto, a su vez, debe complementarse con el 
testimonio del testigo $\mathrm{X}$, que es crucial para dilucidar esta cuestión. Según él, el arma se la sacaron de adentro de la ropa de uno de los detenidos, y no estaba en el piso. Entiendo que todas las dudas que surgen de los diferentes dichos podrán aclararse en un juicio, frente a un tribunal. En esta instancia de control inicial de la investigación, no puede quedar detenida una persona con el estado dubitativo de las pruebas en su contra. Por esto declaro el cese de la PP. Estas circunstancias me llevan, por un lado, a rechazar el pedido de nulidad por no evidenciarse aún los vicios que alegó la Defensa. Y rechazar también el sobreseimiento. Como segundo punto, entiendo disponer la libertad por falta de mérito, y hacer cesar la PP del imputado. Como tercer punto, se va a disponer la elevación a juicio de la causa".

OBSEVACIÓN: La Defensa pone en duda el relato policial de los hechos por no haber registros confiables que permitan confirmarlo. A su vez, no coincide con lo que declara el único de los testigos de la causa que no es policía. Al ser el imputado una persona con antecedentes y conocida por la policía, la Defensa alega que se lo persiguió porque era él, y no porque haya sacado un arma y apuntado a un patrullero mientras iba como acompañante en una moto. Respecto a la PP, asegura que no existen los riesgos procesales exigidos para otorgarla. La Fiscalía sostiene que las versiones policiales son, por lo general, puestas en duda. Y que parece "improbable que la discordancia [entre lo que dice el testigo y lo que dicen los policías] señalada por la Defensa se muestre como un obrar predeterminado. Es inconcebible que la policía monte todo ese operativo para imputarle al imputado la comisión de un delito". La diferencia es menor, ya que se limita al lugar donde se encuentra el arma. Además, el imputado tiene antecedentes respecto de este mismo tipo de delitos. Por dichos motivos, requiere la elevación a juicio y el mantenimiento de la PP “toda vez que la magnitud y modalidad de PEE, me hace descreer que el imputado se va a quedar sentado en su casa esperando que algún día se lo condene a una pena de efectivo cumplimiento". La Defensa considera que esa diferencia menor de la que habla la Fiscalía es decisiva para la causa que se está investigando. Lo complementa con la afirmación de que del comportamiento del imputado no se pueden presumir los peligros procesales. El JG considera que hay elementos suficientes para no hacer lugar a la nulidad y elevar la causa a juicio. Pero las discrepancias entre los testimonios provoca que el JG no mantenga la PP.

Si tomamos las 47 audiencias que presenciamos, y dentro de ellas las 2 en las cuales no se concedió la PP, podemos decir que las denegaciones apenas superan el 4\%. Debido a que no existen estadísticas oficiales sobre la cantidad de pedidos, otorgamientos o rechazos de PP, le preguntamos a los actores judiciales sobre su percepción general al respecto. La respuesta más recurrente fue "la de un 10 a 1", o para ser más claros, que 10 PP se concedían y 1 no. Esto daría cerca de un 9\% de rechazos, 
lo cual si bien está por encima de lo que arrojó nuestra muestra, tampoco es categóricamente distinta, en el sentido de que en ambas son muy bajas las denegaciones respecto a las concesiones de la medida cautelar.

En los dos casos señalados, es la policía el actor que provoca suspicacia para la Defensa y el JG. En el primer hecho, las irregularidades respecto a la preservación de las pruebas hacen que se decrete no sólo la denegación de la PP sino el sobreseimiento del imputado. En el segundo, el JG no cree en el planteo que hace la Fiscalía sustentado en el relato policial, por lo que no encuentra motivos para que el encierro preventivo del imputado se mantenga.

Tal como lo planteamos en el segundo capítulo, la policía es una institución sumamente objetada por la Defensa, capaz de manipular el vasto control que ejerce y provocar versiones falaces de los hechos investigados. Como conclusión preliminar podemos decir que en la medida en que la Defensa logra persuadir al JG de que la policía ha empleado alguna modalidad fraudulenta en una causa determinada, más posibilidades existen para que la PP no se otorgue.

\section{4- A modo de cierre}

Este capítulo ha servido para mostrar cómo surge y se consolida el proceso de flagrancia a partir del cual se implementaron las audiencias tempranas. Y señalamos que la evaluación de los operadores jurídicos respecto de dicho proceso está guiada, fundamentalmente, por el lugar que tienen en la división judicial del trabajo. Los Defensores son quienes ofrecieron las críticas más severas, los JG quienes manifestaron mayor equilibrio entre las ventajas y los perjuicios, y los Fiscales quienes se mostraron más conformes, esgrimiendo incluso un vocabulario análogo al que utilizaron los discursos de los reformadores para su promoción

Se hizo mención, además, a las modificaciones que generó el empleo de las audiencias durante la IPP en el uso de la PP, ya que supuso un cambio de escenario en el cual los planteos se realizan oralmente y en presencia de los otros actores judiciales.

Presentamos los trabajos publicados en los que se analiza a la PP en las audiencias, los cuales suelen destacar fundamentalmente los beneficios que provocan la inmediación y la oralización. Al mismo tiempo, se trata de trabajos que no indagan en la manera en que se justifica el uso del encierro preventivo, lo que permite conocer qué tipo de argumentos ofrecen los actores judiciales para respaldar sus posturas. 
Posteriormente, se elaboraron cuatro modelos con los cuales describir mejor la serie de relaciones que instaura el pedido de la PP, junto a las exigencias que este pedido impone. El primero de los modelos muestra que a la hora de justificar el encierro preventivo, los Fiscales y JG apelan al vocabulario con el que el proceso de flagrancia se impulsó, utilizando a la velocidad para solicitar y conceder la PP. El segundo modelo, con cierta afinidad respecto del positivismo criminológico, pone como principal argumento a los imputados, invocando los peligros procesales a partir del comportamiento previo de quienes se está investigando. En el tercero, con resabios del pensamiento ilustrado sobre el delito y la pena, los argumentos en las audiencias se sustentan en la correspondencia que los actores judiciales observan entre la gravedad de la conducta ilícita realizada y la aplicación del encierro preventivo. En el último modelo no se hace lugar a la aplicación de la PP, dado que la policía incita desconfianza para la Defensa y el JG. Esto permite suponer que cuando la Defensa logra persuadir al JG que la policía ha empleado en una causa un modo fraudulento de investigar, más posibilidades existen para que la PP no se otorgue. 


\section{QUINTA PARTE}

A diferencia de las anteriores, esta quinta parte de la tesis requiere una breve introducción. Esto se entiende porque en los dos capítulos que siguen nos proponemos articular el plano judicial de la PP con los testimonios de los operadores jurídicos a partir de las perspectivas mencionadas en el marco teórico. Para ello relacionaremos lo que estos operadores hacen en la práctica con lo que expresan en las entrevistas respecto de la utilización de la medida cautelar, y de ese modo ofrecer un plano en conjunto que posibilite describir y analizar más exhaustivamente las relaciones que instaura el pedido de la PP, junto a las exigencias que este pedido impone. Asimismo, podremos ver con más precisión la manera en que los actores judiciales hablan acerca de lo que hacen con la PP, identificando y clasificando prácticas y saberes. Esto último se explica, al menos en parte, porque

Las prácticas y los saberes se hacen más visibles y declarables en la medida que son claramente sostenidos por instituciones. Cuanto más ligados están la práctica y el saber a tiempos y lugares específicos, relativamente autónomos, son más visibles y designables como tales (Lahire, 2006: 137-9).

Esta relación entre prácticas, saberes, tiempos y lugares específicos facilita que los actores judiciales relacionen al encarcelamiento preventivo no sólo con criterios sustancialistas y procesalistas procedentes de la dogmática del derecho, sino también con rasgos propios de la institución judicial y con la intervención dentro de esta última de actores extrajudiciales. En definitiva, estamos sugiriendo que los operadores jurídicos advierten correspondencias y divergencias entre parámetros legales nominados -como el principio de inocencia, o los peligros procesales de fuga y entorpecimiento en la investigación, etc.- y factores extralegales determinables -como los medios de comunicación, las autoridades políticas, entre otros-, los cuales resultan elementos importantes en el uso de la PP. 


\section{CAPITULO VI \\ Una práctica judicial compleja}

\section{1- La prisión preventiva como práctica}

En los dos capítulos anteriores analizamos la PP a partir de su utilización concreta en los expedientes y en las audiencias, buscando describir el plano judicial de esta medida cautelar. Tomando en cuenta las justificaciones esgrimidas por los operadores jurídicos señalamos distintos modelos de argumentación para conceder o denegar el encierro preventivo. Esto último hizo posible complejizar la explicación de la dogmática del derecho, según la cual todo lo atinente a esta medida cautelar se reduce a dos criterios antagónicos sobre dicho instituto: el sustancialista y el procesalista. En otras palabras, decir que la PP sólo sirve como una pena anticipada o, por el contrario, para neutralizar los peligros procesales, contribuye poco si lo que se intenta es comprender esta práctica judicial compleja. Por dicho motivo consideramos importante especificar qué alegan los actores judiciales cuando recurren a la PP en la práctica cotidiana. Hasta donde pudimos explorar, lo hacen generando acuerdos para concederla en base a la ley en los que tienen en cuenta el peligro de fuga o el entorpecimiento en la investigación, aunque también surgen otros: acuerdos tácitos o en disidencia entre los actores judiciales, vinculados a la velocidad característica del proceso de flagrancia, a los imputados y sus trayectorias o a los delitos que se investigan. Y para denegar la medida cautelar lo realizan en base a la confianza perdida en los Fiscales o a la policía sospechada.

\subsection{Práctica, motivación y control}

Somos concientes que al planteo que presentamos sobre la PP como acuerdo activo en los capítulos previos sobre expedientes y audiencias podría replicársele que los argumentos que ofrecen los actores judiciales no son, en particular, suficientemente decisivos para comprender el uso de la PP. Es decir, que dichos argumentos no son un elemento significativo. Según lo que hemos trabajado, esto podría inferirse de los expedientes -por el hecho de que en las justificaciones se repiten con frecuencia fórmulas similares- y de las audiencias -porque salvo una extralimitación policial, la PP 
suele concederse sin requisitos minuciosos-. Si seguimos esta línea de razonamiento, lo que corresponde buscar es aquello que el uso cotidiano de la PP oculta o disimula para luego explicitar los presupuestos tácitos que, bajo la apariencia de necesarios, gobiernan dicho uso en la institución judicial. Y un abordaje que desde las ciencias sociales puede contribuir a desentrañar esos presupuestos es el abordaje de Pierre Bourdieu. Concretamente nos referimos a su teoría de la práctica. Según sus propias palabras,

Es una sola y la misma cosa descubrir el error teórico que consiste en dar la visión teórica de la práctica para la relación práctica con la práctica y, más precisamente, en colocar en el principio de la práctica el modelo que se debe construir para explicarla y percibir que el principio de ese error es la antinomia entre el tiempo de la ciencia y el tiempo de la acción que conduce a destruir la práctica imponiéndole el tiempo intemporal de la ciencia (2007: 130).

De acuerdo con este argumento, la actitud que Bourdieu está criticando de la visión teórica de la práctica es similar a la que nosotros describimos al hablar del enfoque dogmático de la PP, en el que desarrollamos tanto la historia interna de la medida cautelar como las limitaciones que ésta provoca. Vale la pena recordar que esta historia interna toma como referencia lo que sostienen las normas jurídicas para luego denunciar que en la actividad cotidiana de los tribunales esas normas son quebrantadas, como es el caso de los principios constitucionales de inocencia y legalidad, o la insuficiente demostración de los riesgos procesales. Sin embargo, ésta perspectiva interna al considerar que la PP es en primer lugar una vulneración de principios constitucionales está desconociendo la relación práctica que con esta práctica judicial tienen los operadores jurídicos.

En concreto, lo que intentamos decir es que los diferentes postulados jurídicos deben analizarse en relación a factores extrajurídicos -sean judiciales o extrajudiciales-, puesto que aquellos postulados y estos factores tienen diferentes tiempos como los tienen, según Bourdieu, la ciencia y la práctica. El tiempo queda abolido para el dogmático del derecho, no solo porque "no puede tener incertidumbre sobre lo que puede sobrevenir, sino también porque tiene tiempo para totalizar, es decir para superar los efectos del tiempo" (Ibíd.: 131). En consecuencia, al centrarse el trabajo del dogmático en las normas jurídicas puede destemporalizar el tiempo de la práctica, al estar destemporalizada respecto de la práctica del actor judicial. 
Para acercarnos a la relación práctica que tienen los actores judiciales con la práctica de la PP, es importante recuperar uno de los temas que estos últimos esgrimen con mayor frecuencia para relativizar el peso de las normas jurídicas en la utilización cotidiana de la medida cautelar. Se trata de la carrera judicial, en la cual parece intervenir un proceso de aprendizaje local, es decir, un conjunto de saberes más ligados a la organización judicial del ámbito penal que a lo dogmático jurídico. Y en este proceso de aprendizaje que se alimenta de interpretaciones específicas del trabajo cotidiano,

Prácticas, rutinas y procedimientos que conforman el ámbito penal siempre se toman como el marco inmediato de significado [que] es la amalgama indefinida [...] de la experiencia acumulada, la sabiduría institucional y el sentido común profesional que enmarca las acciones de los agentes penales y confiere significado a su quehacer (Garland, 2006: 245-6).

En tanto amalgama indefinida, la carrera judicial es un cúmulo experiencias institucionales acumuladas y reconocidas con sus propias expresiones, categorías y escalas, que configuran el contexto inmediato y particular en el que la PP es aplicada (Fucito, 2001). Algunos trabajos destacan cómo en esta carrera son decisivos los favoritismos y las protecciones informales, los cuales contribuyen a estructurar el trabajo cotidiano en dicha institución. Tal como afirma Sarrabayrouse,

Existe una urdimbre de relaciones basadas en el parentesco, el status y las jerarquías que atraviesa la estructura, que da un sentido particular a la acción de los actores y a la que se hace imprescindible recurrir si se quiere comprender el funcionamiento institucional (2004: 203).

Pese a que en el PJ rigen un conjunto de pautas abstractas de tipo universales e impersonales propias de todo aparato burocrático, hay otro régimen coexistente que impera simultáneamente con él. Con otras palabras, existe una serie de reglas y de leyes generales y por el otro un conjunto de relaciones personales caracterizadas por el clientelismo, el status y la jerarquía.

"Una de las cosas que más rápido aprendés acá adentro es la importancia que tiene pasar sin hacer grandes olas. Para lo que sea, esto es importante: para tu tranquilidad, para pensar en un acenso [...]. La corporación [judicial] influye para que las 
complicidades y amiguismos graviten en las decisiones. Sirve para que todo esté tranquilo" (JG del Departamento Judicial de La Plata).

"Y en el PJ la falta de convicción se nota cuando antes de decidir se está pensando en qué van a decir los medios, qué los familiares de la víctima. Tenés que fijarte cómo te cuidás vos tu cargo, tu carrera, en desmedro de tus convicciones" (Fiscal del Departamento Judicial de Quilmes).

“QQué te dicen cuando un delito se viene repitiendo mucho? Hay que aumentar la pena. Esa es la respuesta fácil.

ENTREVISTADOR: ¿Esa respuesta la observás por fuera del PJ?

No, adentro, adentro ¿Cómo se comporta el JG? Ante la menor duda, el tipo queda en cana. No es cierto en la práctica que el principio es la libertad. Yo creo que hay muchas presiones, no directas, no te dicen "dejá a este tipo adentro", pero piensan, “ ¿y si yo dejo libre a éste y después hace tal cosa...?". Creo que hay mucha presión. Yo no creo que todos estén convencidos de usar la PP como lo hacen. Yo creo que hay más presión que convicción. Es miedo a que pase algo y salir en los diarios. Y paga más salir en el diario porque metiste en cana a alguien y no porque lo sacás.

ENTREVISTADOR: ¿Eso puede tener que ver con el poco respaldo que los actores judiciales tienen?

Es muy posible. Que hay poco respaldo no hay ninguna duda, te diría que ninguno. Te sueltan la mano. Mirá lo que ha pasado con jueces de ejecución que dieron la libertad condicional a un tipo, y volvió a cometer un delito, te hacen un juicio político (Defensora Oficial del Departamento Judicial de La Plata).

Si bien estos testimonios no son unívocos, podemos abreviar y decir que en ellos aparecen en tensión intereses utilitarios que la institución promueve y valores solidarios que la misma institución menoscaba, o al menos no fomenta. En este sentido, a la hora de evaluar la necesidad de la PP los actores judiciales deben tener presente, por un lado, aspiraciones de más largo alcance dentro del PJ, y por otro, compromisos y convicciones morales más cercanos, siempre según sus palabras, a la protección de los principios y las garantías jurídicos. Desde su percepción, existe una motivación institucional para especular con el uso de la PP, pidiéndola y concediéndola de acuerdo a la conveniencia personal -actitud calculadora-. Y a esta motivación se le suma un control débil de la misma institución para restringir o evitar su uso. De acuerdo con lo dicho, para analizar la trayectoria de la PP en el PJ bonaerense debe tenerse en cuenta la 
combinación que existe en la institución judicial entre un frágil control para limitarla y una persistente motivación para especular con su utilización (Young, 2003: 244). En definitiva, ambos lados de la ecuación de la PP, motivación y control, se vuelven elementos destacados para el entendimiento de los índices de ésta medida cautelar.

\subsection{Desencantamiento y delegación}

Las ideas de motivación y control no son las únicas que surgen de los testimonios de los operadores jurídicos. Para algunos de ellos la carrera judicial provoca cierto desencantamiento que favorece, en primer lugar, la delegación de responsabilidades. Esta delegación se aduce a partir de las jerarquías formales dentro de la institución judicial, lo que como veremos a continuación influye en las decisiones sobre la PP.

Si bien conocemos el peso que tiene la metáfora del desencantamiento del mundo en el ámbito de las ciencias sociales ${ }^{162}$, nosotros la utilizamos con un sentido muy específico. Tomando en cuenta lo que expresan los mismos operadores, hablamos de desencantamiento del mundo judicial para dar cuenta de un declive en el prestigio y una disminución de la autonomía de dicha institución.

\footnotetext{
"Tengo que reconocer que esos peligros [procesales que se deben tener en cuenta para aplicar o no la PP] se usan arbitrariamente; no es lo mismo un hecho que sale en la tapa de los diarios que otro que no sale, y eso influye en el ánimo de quienes formamos parte de la causa. Eso para mí tiene mucho que ver con la designación de los Jueces, con la baja de calidad de los Jueces en los últimos años. Casos graves hubo siempre, pero antes los Jueces leían el diario y no les importaba; ahora no es así" (Fiscal de Instrucción del Departamento Judicial de La Plata).
}

\footnotetext{
162 Como es sabido, Weber sostuvo que las carencias de mitos y valores imperativos propios de la modernidad contribuyeron a eliminar el enigma de la existencia, induciendo al hombre a considerarse capaz de dominarlo todo a través de la ciencia. El proceso de racionalización ocurrido en occidente se encuentra inseparablemente ligado al itinerario que culminó con el desencantamiento del mundo: la ciencia ha demolido hábitos y creencias religiosas, morales y cosmogónicas, orientándose hacia la contracción de nuestro universo espiritual, imponiendo elementos lógicamente explicables. En sus propias palabras, "la tensión entre religión y conocimiento intelectual se ha evidenciado de modo acusado cada vez que el conocimiento empírico-racional ha colaborado firmemente en el desencantamiento del mundo y su transformación en un mecanismo causal. La ciencia, entonces, contradice el postulado ético de que el mundo es un cosmos ordenado por Dios y que, por tanto, está significativa y éticamente dirigido en alguna dirección [... por ello] la ciencia carece de sentido puesto que no tiene respuesta para las únicas cuestiones que nos importan, las de qué debemos hacer y cómo debemos vivir" (1997: 55).
} 
Esta manifestación resulta interesante ya que articula el debilitamiento del prestigio y la falta de idoneidad de los integrantes del PJ con la injerencia que tienen en esto los medios de comunicación. Según este Fiscal, es la baja calidad de los Jueces que han sido nombrados en los últimos años lo que facilita que lo que sale en los diarios tenga tanta importancia.

En concreto, el debilitamiento del prestigio del mundo judicial es expresado por los operadores jurídicos como el agotamiento de componentes característicos de su historia y su tradición. El mérito, la trayectoria, el esfuerzo persistente, que según algunos testimonios recogidos supieron ser la base en la consolidación de antiguas y respetables carreras judiciales, hoy parecen haber cedido primacía.

"Hay Jueces de Cámara de Casación que no los pondría a trabajar ni de empleados [...]. Después tenés Fiscales que son macanudos [risas]. Y es serio. El respeto por lo que dice unJuez, ya no hay más ese respeto. $\mathrm{Y}$ otra cosa son las designaciones fundamentalmente políticas en cargos importantes que rompieron con estructuras antiguas: antes se hablaba despectivamente de la familia judicial. Un Juez le pedía a otro Juez que nombre a su hijo, pero al hijo del Juez se lo nombraba en el último cargo, no lo nombraban de Secretario con un año de recibido para que al año siguiente sea Fiscal. Se rompió la famosa carrera judicial. Antes llegar a Camarista era el premio a toda una vida en el Poder Judicial, ahora lo podés conseguir en cinco años" (Defensora Oficial del Departamento Judicial de La Plata).

Si bien se trata de reconstrucciones hechas en base a percepciones situadas de los operadores jurídicos, su importancia está dada no tanto por su exactitud -la cual no es posible determinar- como por el hecho de que mustran el desprestigio en el que ha caído el PJ para algunos de sus integrantes ${ }^{163}$. Agreguemos a esto las objeciones que provoca la utilización de criterios considerados indebidos en la elección del personal, criterios que auspician una actitud escéptica en quienes lo advierten de ese modo.

\footnotetext{
${ }^{163} \mathrm{Al}$ subrayar la faz discursiva de los actores judiciales, intentamos recuperar una imagen no homogénea del derecho y la PP, de lo que debe entenderse por ambos, lo cual incide en distintos ámbitos, desde las facultades, en etapas tempranas mientras el futuro jurista se forma, hasta en la manera de ejercer dominio político legal en una sociedad. Para Bergalli, "supone un conocimiento no sólo de las estructuras que componen el aparato judicial, sino también del comportamiento de los jueces, de la valoración que de éstos realizan los ciudadanos, de la ideologías e intereses sociales que alientan los magistrados, de la imagen que ellos forman de su función y profesión, de la comunicación recíproca que debe existir entre la sociedad y la justicia, etc." (Bergalli en Rusche y Kirchheimer, 2004: XXII). En definitiva, es importante no minimizar lo que se dice, o lo que puede ser dicho, independientemente de sus aplicaciones concretas.
} 
"Yo no puedo sentir espíritu de cuerpo con algunos personajes que llegaron como llegaron a sus cargos. Es angustiante. A mí más que bronca, me hace irme mal del trabajo. Te saca el incentivo, te saca las ganas de laburar" (Fiscal de Instrucción del Departamento Judicial de La Plata).

Sin que desaparezca el interés de los actores judiciales por integrar el PJ, sin que decidan renunciar a sus empleos por calificar ilegítimos varios de sus procedimientos, estos actores expresan su desencanto, en el sentido de que ya no creen en algo que antes creían, y en simultáneo, comienzan a reconocer mecanismos reprochables que antes desconocían. En palabras de Fucito, "en la última década del siglo XX [...] el nombramiento puramente político de jueces afines [...] se extendió hasta el punto de sobrepasar todos los límites tolerables, incluso en un sistema familista" como el sistema judicial (2001: 64). No es que la institución judicial haya dejado sin respuestas a los actores judiciales sobre cuestiones importantes como las relacionadas a qué deben hacer o cómo deben hacerlo (Weber, 1997), sino que dicha institución ha ofrecido nuevas respuestas que fomentan la desidia de estos actores a la hora de percibir qué pueden hacer concretamente.

En este aspecto, vale recordar los cambios que se dieron dentro del PJ de la PBA, tanto en su expansión como en su composición. En primer lugar, hubo un gran crecimiento en el número del personal, el cual se duplicó con creces ${ }^{164}$ : según las cifras de la Suprema Corte de Justicia de la PBA a las que accedimos, en diciembre de 1998 había un total de 11.385 empleados sumando la Administración de Justicia y el Ministerio Público. Para octubre de 2014, la cifra es de 24.630. En segundo lugar, este incremento se dio junto con la llegada de abogados jóvenes formados con programas de estudios en materia penal y procesal penal más actualizados que aquellos con los que se habían instruido los actores judiciales con más tiempo en la institución judicial bonaerense. Como ya lo mencionamos en esta tesis, la reforma al CPP bonaerense del año 1998 implicó una nueva división del PJ que exigía la ampliación del número de empleados,

Al girarse hacia un sistema de enjuiciamiento de espíritu más acusatorio se multiplicaron los cargos en la Procuración General (fiscalías y defensorías), se separaron a los jueces que intervendrían en la instrucción (de garantías) y los de juicio.

\footnotetext{
${ }^{164}$ Según las cifras oficiales de la Suprema Corte de Justicia de la PBA a las que accedimos, en diciembre de 1998 había un total de 11.385 empleados sumando la Administración de Justicia y el Ministerio Público. Para octubre de 2014, la cifra es de 24.630.
} 
Y para los casos de delitos graves, el juicio estaría a cargo de un tribunal compuesto por tres jueces. Esta súbita expansión de los cargos jerárquicos permitió que junto con los operadores políticos ingresaran al mundo judicial (y hasta como necesidad de sostener ideológicamente el nuevo proyecto) varios funcionarios del área académica de la Universidad de Buenos Aires y sus universidades satélite, que habían demostrado capacidad de análisis para poder crear jurisprudencia y una visión crítica del viejo poder judicial cerrado y endogámico, y del viejo sistema de enjuiciamiento inquisitivo (Gutiérrez y Álvarez, 2009) ${ }^{165}$.

Por lo tanto, el debilitamiento del prestigio dentro de la institución judicial en la PBA puede entenderse, al menos para determinados actores judiciales, a partir de la percepción de estos nuevos nombramientos y ascensos como arbitrarios. En términos generales, esta nueva configuración en el PJ es experimentada como una situación injusta que a su vez podría ser evitada. Situación que, además, no es vista por dichos actores judiciales como resultado de su propio comportamiento, sino que se la atribuyen a las autoridades institucionales y políticas que están por fuera de su ámbito de influencia $^{166}$. En definitiva, desde la perspectiva de estos actores parece existir una institución judicial en la cual se socializa a los recién llegados lejos de su tradicional cultura del esfuerzo. Y como consecuencia de esta nueva socialización, se desalienta a los empleados con más trayectoria allí dentro.

\subsection{La autonomía en discusión}

Junto con el debilitamiento del prestigio que acabamos de mencionar, indicamos un segundo elemento que hemos caracterizado como la disminución de la autonomía del PJ. En primer lugar, es importante aclarar que la pérdida de autonomía no se contradice con la motivación institucional mencionada anteriormente, sino que, por el contrario, parece existir reciprocidad entre ambos componentes. Las exigencias "utilitaristas" de la carrera judicial estimulan a los operadores a echar mano del recurso de la PP en tanto

\footnotetext{
${ }^{165}$ La reforma procesal en la PBA supuso cambios institucionales importantes: "Durante este período, y principalmente el primer año que va de 1998 a 1999 el Poder Judicial de la Provincia se pobló de jóvenes profesores, que sin atacar a la estructura judicial en sí misma ni sus dinámicas internas, con actitud militante se propusieron cambiar las formas de actuación, provocar un cambio en la formas de entender el enjuiciamiento y crear una nueva corriente jurisprudencial” (Gutiérrez y Álvarez, 2009).

${ }^{166}$ Esta experimentación de la situación como injusta por parte de los actores judiciales tiene cierta relación con lo que algunos autores definen como "privación relativa", concepto que se suele utilizar, por ejemplo, para analizar ciertos delitos y las motivaciones para cometerlos en determinado contextos donde no es la "privación absoluta" de bienes y recursos lo que permitiría explicar estos comportamientos (Lea y Young, 2008; Young, 2003).
} 
respuesta individual. En este sentido, la menor autonomía del PJ puede ser interpretada como una de las razones de la eficacia de la motivación institucional para recurrir al encarcelamiento cautelar.

Al respecto, merece renovada atención el influjo creciente de actores extrajudiciales en la pérdida de la autonomía. Los medios de comunicación y las diferentes autoridades políticas aparecen como cada vez más imperantes en la administración de justicia penal en general, y en el uso de la PP en particular. Sin embargo, esta mayor preponderancia es considerada en algunos casos como la causa de la disminución de la autonomía, y en otros testimonios como la consecuencia de dicha disminución. Este detalle es importante para comprender cómo los actores judiciales reconstruyen ese proceso, y de qué modo atribuyen responsabilidades al respecto.

Un primer grupo de operadores jurídicos hace hincapié en particularidades o cambios que son internos a la institución judicial para dar cuenta de su menor autonomía. Como consecuencia, la posibilidad de que los medios y los políticos puedan ejercer influencia se vuelve posible sólo si la independencia judicial se hubiese debilitado con anterioridad. En otras palabras, es la disminución de la autonomía la que permite explicar la injerencia de actores extrajudiciales, dado que estos últimos no estarían en condiciones de imponerse por sí solos. Tal es el caso de los siguientes testimonios:

"El cambio debería provenir de nuestros superiores, tanto de la Suprema Corte como de la Procuración General [...]. Si la Corte y la Procuración se pusieran firmes defendiendo la independencia, que es vital, las cosas cambiarían. Que no me diga ni el Poder Ejecutivo ni el Poder Legislativo qué tengo que hacer como Fiscal, que me lo digan mis superiores, no los diarios, porque ésta es una estructura jerárquica que se acepta" (Fiscal de Instrucción del Departamento Judicial de La Plata).

"Reforzar la independencia que se ha perdido, que a veces se la refuerza sólo desde el discurso. Y que permite que cualquiera juzgue nuestro trabajo. Que el Magistrado sepa que no está sólo en el mundo, porque no está sólo en el mundo. Que se lo contenga de las presiones de otros poderes para que no crea que sólo debe cubrirse" (JG del Departamento Judicial de Quilmes). 
Como surge de estos relatos, tanto la ausencia de los superiores a la hora de defender la independencia judicial como la falta de respaldo de los operadores jurídicos frente a los embates de actores extrajudiciales, son los elementos que abren el resquicio por el cual el PJ empieza a disipar su autonomía. Y junto a esto último, cabe agregar que según los actores mencionados la posibilidad de revertir esta tendencia depende también de la misma institución, es decir, de sus superiores.

El otro grupo de operadores jurídicos es el que considera que la pérdida o disminución de la autonomía del PJ sobreviene como consecuencia de la injerencia de actores extrajudiciales. En sintonía con lo que señalamos en el capítulo II cuando hablamos del debilitamiento en las relaciones entre políticos y operadores jurídicos, aquí el acento está puesto en las diferentes actividades y discursos con los que los actores extrajudiciales consiguieron atravesar el umbral de la institución judicial.

"En los último 5 años, debido a la injerencia de unos Poderes sobre otros reina lo que yo llamo la ley del rugby: pasar la pelota y no quedar en offside. Los Fiscales pedimos la detención, eventualmente que el Juez decida. El Juez la decreta, y que eventualmente resuelva la Cámara. La Cámara, dependiendo de la circunstancia, confirma. Todo el mundo pasa la pelota y no quiere quedar pegado, ¿por qué? Porque nadie quiere ser Schiavo, Sal Lari” (Fiscal de Instrucción del Departamento Judicial de Mar del Plata).

"[...] la presión política es una pauta, aunque sea inconsciente, que puede influir en decisiones de este tipo. Y con el mantenimiento de la PP, si ese imputado luego con el tiempo recupera la libertad por lo que dice la Cámara de Apelaciones y vuelve a cometer un delito, el juez que dictó la PP estará luego libre de imputación política o social por el hecho. Digamos que cada uno cumple con lo que le corresponde: el Fiscal pide la PP, el JG la otorga, y así que se vayan haciendo cargo los superiores que les corresponda". (JG del Departamento Judicial de La Plata)

"Los medios, y la opinión pública, influyen absolutamente y se refuerzan. Los jueces son los más débiles de todos los funcionarios judiciales, y eso se va profundizando. En términos generales, veo al PJ cada vez más permeable, porque la lógica es: yo como Fiscal pido la PP, y que el JG me diga que no. El JG dice "yo se la doy, y que la revoque la Cámara, y la Cámara dice, “¿la vamos a venir a revocar nosotros? Y sigue 
[...], si en algún momento explota [...], el lema es pasála y que no vuelva" (Defensora Oficial del Departamento Judicial de La Plata).

En estos testimonios la autonomía del PJ es debilitada, en primer lugar, por la intervención de actores extrajudiciales, intervención que contribuye a reconfigurar las relaciones entre los actores judiciales que deciden sobre la aplicación de la PP. Sólo después de la injerencia de los medios de comunicación y los discursos altisonantes de las autoridades políticas, la autonomía judicial parece comenzar a socavarse. Tal como lo plantea Garland para el ámbito británico y norteamericano,

La justicia penal es ahora menos autónoma que [antes]. Los actores y agencias de la justicia penal son ahora menos capaces de dirigir su propio destino y darle forma a sus propias políticas y decisiones. Esto es en parte el resultado de la necesidad de trabajar con otros «proveedores» y de la preocupación por dar mejores respuestas al público y a otros «clientes». Pero la razón primordial de esta pérdida de autonomía es que las relaciones del campo con el público y con el proceso político han cambiado. Ha surgido una nueva relación entre los políticos, el público y los expertos penales en la que los políticos dan más directivas, los expertos son menos influyentes y la opinión pública se torna un punto clave de referencia para evaluar las diversas opciones. La justicia penal es ahora más vulnerable a los cambios de estado de ánimo del público o a la reacción política (2005: 282).

Trasladando este análisis a nuestro contexto, para este segundo grupo de operadores jurídicos la institución judicial penal bonaerense parece en la actualidad más permeable que antes de la reforma procesal en 1998. El auge de los medios de comunicación y la clase política interpelando y siendo interpelada por la comunidad respecto al problema del delito, expone y desgasta a quienes trabajan en el PJ de la PBA. Esto último impide, entre otras cosas, que las discusiones públicas sobre el uso de la PP se instituyan alrededor de un lenguaje técnico-jurídico dominado por juristas con el que se pueda reivindicar el Principio de Inocencia y la libertad del imputado durante el proceso. Muy por el contrario, según algunas expresiones de los operadores jurídicos, lo que se consigue es asociar la excarcelación con la impunidad de aquellas personas que están siendo investigadas por la comisión de algún ilícito.

Consideramos importante señalar las diferencias entre aquellos actores judiciales que plantean la disminución de la autonomía del PJ como causa y aquellos que la 
plantean como consecuencia de la participación de los actores extrajudiciales a los fines de comprender mejor la PP como una práctica judicial compleja. Dado que los actores judiciales suelen vincular el uso de la medida cautelar con el debilitamiento de la autonomía judicial y con la intromisión cada vez mayor de actores extrajudiciales, nos pareció significativo describir en qué orden afirman que sucedieron esos hechos ya que se trata de hechos que dieron luego condición de posibilidad para un uso más amplio de la PP.

Resumiendo este apartado, podemos retomar lo que dijimos en el segundo capítulo de la tesis cuando sugerimos que los medios de comunicación y los políticos eran considerados relevantes por los actores judiciales para analizar el desempeño de la justicia penal en general y el uso de la PP en particular. Según los testimonios recogidos al respecto, ahora sabemos dos cosas más: primero, que esos actores extrajudiciales influyen en la disminución de la autonomía del PJ, y segundo, que esa pérdida de autonomía en algunos casos es vista por los actores judiciales como causa de esa mayor influencia, y en otros casos como consecuencia.

\subsection{Elementos para entender la prisión preventiva como una práctica}

Por lo que vimos hasta aquí, al analizar el encierro preventivo como práctica surge que tanto la carrera judicial como el desencantamiento del mundo judicial ${ }^{167}$ deben ser tenidos en cuenta como dos factores que influyen en el uso de la PP. Entre otras cosas porque dichos factores facilitan que las normas constitucionales, que son las de mayor jerarquía en la pirámide jurídica y las que más límites le imponen al encierro preventivo queden relegadas por indicadores de riesgos procesales dispuestos en el CPP cuyo rango es inferior ${ }^{168}$.

Sobre esta inversión de las prioridades de las normas procesales en detrimento de las constitucionales podemos añadir tres cuestiones. En primer lugar, que dicha inversión ha sido criticada por teóricos del derecho, especialistas procesales y ONGs, los cuales abogan por un uso más acotado del encarcelamiento preventivo. Segundo, que las críticas señaladas no han sido suficientes para comprender con mayor claridad las razones que impulsan a los actores judiciales a llevar adelante en los hechos tal

\footnotetext{
167 Al hablar de carrera judicial pensamos fundamentalmente en la motivación y en el control institucional. Al hablar del desencantamiento del mundo judicial, de la pérdida de confianza en el prestigio y el declive en la autonomía del PJ.

${ }_{168}$ Recordemos que los indicadores de riesgos procesales en el CPP son, por ejemplo, la PEE, la reincidencia, la falta de arraigo, entre otros.
} 
inversión normativa. En tercer lugar, que son los mismos actores judiciales quienes confirman la existencia de esta inversión, más allá de que la analizan y valoran de manera variada. Y esta confirmación se observa tanto en los modelos de argumentación presentados en los capítulos sobre expedientes y audiencias -en donde prácticamente no se mencionan normas constitucionales-, como en los testimonios que siguen ahora mismo.

"Las garantías constitucionales dan la libertad, pero lo que pasa es que en ciertas circunstancias cuando se dan los supuestos del CPP hay que mantener la medida cautelar, porque verdaderamente es un riesgo social. Los principios constitucionales deben ceder allí donde la sociedad entra en peligro. Una persona que ha cometido varios delitos, que la sanción del Estado no lo moviliza, no internaliza las consecuencias de sus comportamientos. Si alguien tiene una suspensión de juicio a prueba y en breve comete otro delito, para mí es más que suficiente [...], esto tiene que ver con el criterio de cada juez. Es una cuestión de valoración pero yo creo que una primera oportunidad hay que dársela a la mayoría, yo la doy, a la segunda no" (JG del Departamento Judicial de La Plata).

"Los límites para la libertad durante el proceso son claros. La PP la pedís cuando creés que la persona no se va a someter a proceso, cuando tiene motivos para escaparse o para no venir, porque sabe que si lo condenan va a quedar detenido. Porque ha demostrado en causas anteriores que no se somete voluntariamente a proceso, porque lo llamás y no viene, o porque te da mal el domicilio. Y esto tiene una consecuencia seria y es que vos no podés terminar el proceso y la causa prescribe. Entonces se valen de eso para eludir la justicia” (Fiscal de Instrucción del Departamento Judicial de Mar del Plata).

"Lo que me parece que sucede es que no se toman muy en serio principios constitucionales y hasta discusiones legales. Ni siquiera hay que ir a la $\mathrm{CN}$; el mismo CPP de la PBA establece como regla general la libertad durante el proceso, y la restricción como excepción. Lo que pasa es que se determinan dejando de lado estos criterios por medio de los supuestos de excarcelación ordinarios, con lo que en la práctica el operador desplaza el principio de libertad y se maneja de acuerdo con los principios de excarcelación. Si no encaja en algún inc., no se excarcela al imputado y punto" (Defensor Oficial del Departamento Judicial de La Plata). 
Tomando en cuenta las manifestaciones anteriores, vemos que con mayores o menores objeciones las reglas que priorizan la libertad durante el proceso quedan postergadas por normas inferiores que resultan funcionales a la aplicación de la PP. Esta funcionalidad es valorada negativamente por aquellos actores judiciales que consideran que el encarcelamiento preventivo no se fundamenta debidamente. Desde una perspectiva diferente, otros actores dan a esa funcionalidad un signo positivo, ya que permite conjurar ciertos "riesgos sociales" o asegurar que la persona se someta al proceso. Pero lo más relevante es advertir que esta inversión en el uso de las normas jurídicas forma parte de los preceptos incorporados por los operadores jurídicos en la carrera judicial, preceptos que, como hemos visto, auspician la aplicación de la PP como respuesta individual en un contexto de motivación institucional. El hecho de obedecer estas consignas es lo que les permite a los actores judiciales "no hacer olas" o "pasar desapercibido", recomendaciones estas que pueden ayudar a decidir en circunstancias concretas aplicar el encarcelamiento preventivo en lugar de denegarlo.

Como primera conclusión es posible afirmar entonces que la utilización de la PP, es decir, la PP como práctica, no tiene el tiempo lineal, homogéneo y continuo que le adjudican teóricos del derecho, especialistas procesales y ONGs. La PP, en tanto práctica judicial compleja, no es un movimiento virulento que empieza dentro del Principio constitucional de Inocencia y acaba por transformarse, debido a su mal uso, en un anticipo de pena. Para los actores judiciales existe un tiempo práctico, configurado entre otros elementos por la carrera judicial o el desencantamiento de su mundo laboral, elementos que dentro del PJ suscitan ritmos particulares, con tiempos que a veces apremian según lo que se haga de esos tiempos, según las funciones que se le confieran a la aplicación o denegación del encierro preventivo en dichos tiempos.

Es por lo expuesto hasta aquí que debemos reconocerle a la PP como práctica una lógica que no es la que sugiere la dogmática jurídica, ni tampoco es sólo el evento con consecuencias deletéreas que denuncian las ONGs. Si evitamos analizar a la PP únicamente desde estos criterios, evitaremos también pedirles a los actores judiciales más lógica de la que pueden tener, creyendo que es suficiente para nuestro trabajo con evidenciar incoherencias en el uso del encierro preventivo, o con imponerle a este uso coherencias forzadas. En este sentido, la PP en la práctica puede que tenga poco que ver con las garantías constitucionales, con los principios de inocencia y legalidad, de allí 
que no sea conveniente avanzar en su análisis tomando a dichos principios y garantías como cuestiones prioritarias. Tal como habían surgido en los testimonios de los actores judiciales en el segundo capítulo de esta tesis, aquí también existen intereses personales, como la propia carrera judicial, y las preocupaciones del afuera, como los medios y los discursos políticos, que deben tenerse en cuenta para indagar el uso de la PP y las relaciones que este uso genera.

Desde luego que los intereses personales de los actores judiciales y sus preocupaciones por los medios de comunicación y los discursos políticos no surgen espontáneamente sino que van forjándose dentro de un PJ que, como indicamos, en número de empleados se expande y en términos de autonomía se debilita. En consecuencia, la PP debe entenderse como una práctica judicial compleja en parte estructurada por los factores mencionados, los cuales no pueden cumplir sus funciones prácticas sino en la medida en que involucran principios coherentes, en el sentido de dominables y manejables con cierta comodidad en el trabajo cotidiano (Zino Torrazza, 2003). En definitiva, la PP existe como una respuesta individual disponible, sugerida y avalada por la institución judicial, y que por el hecho mismo de transformarse en una respuesta para los operadores jurídicos, no les impulsa a tener que recurrir a nuevas respuestas frente a sucesos similares.

\section{2- De las disposiciones a las competencias}

En lo que va del presente capítulo hemos trabajado con las disposiciones heterogéneas que provocan en los actores judiciales elementos como la carrera judicial, el desencantamiento que ésta genera, la injerencia de los medios de comunicación y las autoridades políticas. Tal como expresa Corcuff (2008), una disposición es una tendencia, ligada a la socialización, o en nuestro caso, a la institucionalización judicial de los operadores jurídicos. A continuación, complementaremos esto con las competencias que los operadores despliegan para lograr acuerdos en torno a la PP, competencias que nos permitirán evidenciar un sentido de lo que estos últimos consideran justo e injusto a la hora de solicitar, objetar, conceder o denegar la PP. A diferencia de las disposiciones, estas competencias remiten al aprendizaje de una capacidad que se desarrolla en el marco de distintas situaciones y que debemos precisar sin reducir el problema de la PP a una cuestión de estrategia o interés. 


\subsection{El uso de la crítica}

Para caracterizar mejor las competencias de los actores judiciales y su potencial crítico, retomemos parte del planteo de Boltanski. Según este autor, genera serios inconvenientes para las ciencias sociales afirmar de manera categórica la separación entre ilusión y realidad, entre fuerzas ocultas verdaderas y motivos visibles pero aparentes. Fundamentalmente, porque esta separación presupone la existencia de un espacio compuesto por dos niveles: uno, el del actor y sus creencias, y el otro, el de la realidad profunda a la que tendría acceso el sociólogo.

Si bien hemos mostrado que deben tenerse en cuenta factores institucionales o estructurales ${ }^{169}$ como los condicionamientos de la carrera judicial o el desencantamiento del mundo judicial, esto no significa que ambos configuren un espacio en el que se produzcan de manera subrepticia comportamientos guiados por un sistema de disposiciones estructuradas y estructurantes a la hora de decidir sobre la PP. O dicho más concretamente, carecemos de motivos para insinuar que exista un habitus jurídico $^{170}$ en tanto

Disposiciones comunes forjadas «sobre la base de experiencias familiares parecidas, a través de los estudios de derecho y de la práctica de las profesiones jurídicas», y que funcionan como categorías que estructuran la percepción y apreciación de los conflictos ordinarios, y que orientan el trabajo destinado a transformarlos en confrontaciones jurídicas» (García Inda, 1997: 157).

\footnotetext{
${ }^{169}$ Cuando hablamos de factores estructurales, remitimos a Anthony Giddens cuando afirma que "las estructuras sociales" tienen una doble dimensión: "lo estructural es siempre a la vez constriñente y habilitante" (1987: 226).

${ }^{170}$ La propuesta de habitus jurídico presentada por García Inda es dependiente de la noción de habitus de Bourdieu. Según Lahire, esta noción supone que las experiencias socializadoras comunes son homogéneas, y que es justamente esta homogeneidad lo que resulta difícil de demostrar. Si observamos el mundo social, insiste dicho autor, "uno se da cuenta de que existen un millón de experiencias socializadoras que son heterogéneas y que, incluso, pueden ser contradictorias entre sí” (2004: 72). Esto significa que no tenemos un sistema coherente y homogéneo de disposiciones incorporado, sino que somos producto de disposiciones múltiples y muchas veces contradictorias. Junto a esto, el habitus en Bourdieu tiene el problema de su aparente "transferibilidad" a los diferentes contextos. Para Lahire, estos esquemas de pensamiento y de sentimiento no son pasibles de transferirse automáticamente de una situación a otra, o sea, que no son siempre los mismos esquemas. Por consiguiente, "Si tenemos un sistema de disposiciones heterogéneas, no son las mismas disposiciones las que se transfieren de una situación a otra. Según la situación en la cual nos encontremos, ciertas disposiciones van a actuar, algunas se van a inhibir y otras se van a activar" (Ibíd.). El mismo Boltanski propone otra crítica a la categoría de habitus, o más exactamente al uso "fuerte" de esta categoría, puesto que este uso lleva a minimizar la importancia que tiene la situación concreta en el estudio de las interacciones. El investigador, afirma Boltanski, "considera entonces que ha cumplido su tarea cuando logra mostrar que, inmerso en situaciones diferentes, el actor procedió actualizando los esquemas inscritos en su habitus, es decir, en cierta medida, de manera previsible, lo cual tiende a hacer desaparecer el asunto de la acción propiamente dicha" (2005: 175).
} 
En este sentido, a los factores que limitan o condicionan el comportamiento de los actores judiciales los pensamos a partir de las situaciones en las que dichos actores se desempeñan, y no como determinaciones que estos actores han interiorizado de una vez y para siempre.

Por lo tanto, para analizar los distintos tipos de limitaciones que existen en relación a los actores judiciales según las diferentes circunstancias por las que atraviesan, es necesario aludir nuevamente a la importancia de no considerar al investigador como aquel que esta en condiciones de acceder a un conocimiento superior al de los actores, en nuestro caso actores judiciales. Conocimiento que se volvería incluso más valioso cuanto más se oponga a la interpretación de estos actores, ya que eso evidenciaría que el investigador ve lo que dichos actores ignoran por completo. En palabras de Boltanski, para este enfoque clásico de las ciencias sociales,

[...] los actores no podrían acceder a la verdad de sus acciones. Ligados al mundo social por intereses, tenderían pues ya sea a disimular la verdad cuando es contraria a sus intereses o, en los modelos más sofisticados empleados en la sociología moderna, a ocultarse la verdad de sus actos y de sus tomas de posición [...] (2000: 38-9).

Con esto queremos decir que el uso de la PP dentro del PJ no se despliega sobre una ilusión que el investigador debe desenmascarar al describir la verdad que se mantiene oculta para quienes la utilizan en ese ámbito. De ser así, no tendría sentido analizar, como lo estamos haciendo en esta tesis, las operaciones críticas y de justificación que por diferentes caminos realizan los actores judiciales sobre el PJ y la PP. Esto último no significa que neguemos que sus operaciones críticas cuentan con oportunidades muy desiguales de modificar el estado del mundo que los rodea, oportunidades que se basan en el grado de dominio que posean sobre el medio judicial al que pertenecen.

De acuerdo con lo que acabamos de decir, han sido muchos los casos en los que los actores judiciales remiten a autores, textos o formulaciones expertas para respaldar sus afirmaciones sobre las reformas procesales que afectan la regulación de la PP, o sobre el influjo creciente de los medios de comunicación. Como veremos ahora mismo, esto significa que esa experticia les confiere recursos para la realización de sus operaciones críticas. 
"ENTREVISTADOR: ¿Cómo explicás los claroscuros de la reforma procesal, en particular sobre la prisión preventiva?

Los claroscuros tienen que ver con los mensajes y acciones del Poder Ejecutivo Provincial, acompañado por la Legislatura, de acuerdo a la ideología de ley y orden que se han mantenido a través de los distintos gobiernos con pretensión de dar respuestas mágicas, de emergencia y claramente punitivista al conflicto penal. Algunos convencidos de ellos, con una clara cuota de ignorancia y falta de experiencia en la materia, y otros que volvieron sobre sus pasos por especulación electoralista" (JG del Departamento Judicial de Mar del Plata).

"Los medios, a título personal, te puedo asegurar que no influyen. Pero sí, sí, son importantísimos, porque genera movilización de las personas, porque sólo se escucha la voz de la víctima. Bueno, Zaffaroni ha escrito libros sobre esto, uno de ellos es este $L a$ cuestión criminal..., ahí habla de la propaganda comunicacional, yo siempre digo que no estamos acá para dictar sentencias que sean simpáticas para la gente, para la opinión pública, sino para hacer cumplir la ley. Hay decisiones antipáticas, que no nos gustan, pero hay que tomarlas. Si yo tengo duda sobre alguien, no puedo pensar si está condenado por la sociedad o no. Si no cumple con los requisitos que me exigen las leyes, debo dejarlo en libertad porque es lo que corresponde. Los periodistas no están especializados y critican sin rigor jurídico, desde lo que la sociedad quiere, y seguro que eso influye" (JG del Departamento Judicial de La Plata).

En estos testimonios se observa la utilización de una nomenclatura análoga a la de la literatura especializada, como es el caso de quienes manifiestan críticas a las campañas de "ley y orden" considerándolas de tinte conservadora, tendientes a simplificar el problema del delito y no a analizarlo en su complejidad tal como lo supo plantear el realismo de izquierda británico (Lea y Young, et al, 2008). Sobre el ya mencionado tema de los medios de comunicación, surge como referencia la explicación propuesta por Zaffaroni (2012). Este último, más allá de sus aportes concretos a la comprensión de esta problemática con su categoría "criminología mediática", es considerado dentro del mundo judicial como una figura de referencia. De manera que, así como habíamos mencionado en el tercer capítulo de la tesis, es posible encontrar actores judiciales que realizan críticas a su propio entorno y a otros actores que intervienen en dicho entorno. Al mismo tiempo, estas críticas son complementadas aquí 
con la utilización de formulaciones y autores que les sirven de respaldo para sus propios argumentos.

\subsection{Los principios superiores comunes}

En la medida en que nos mantenemos alejados de la idea de que la sociología debe emancipar a las personas del autoengaño para de ese modo limitar la expansión de las ilusiones que se crean y recrean colectivamente (Boltanski, 2000), seguimos percibiendo a las explicaciones y a los planteos de los actores judiciales como elementos centrales para analizar el uso de la PP. Y es con la intención de hallar estos elementos que observamos y analizamos los argumentos y las competencias críticas que los actores judiciales intercambian en el curso de sus acuerdos y disputas acerca de la medida cautelar (Wuggenig, 2008). De esta manera, los criterios que utilizan JG, Fiscales y Defensores para merituar la necesidad de la PP no surgen, primeramente, de un sistema de disposiciones incorporadas y transferibles, sino a partir de los distintos escenarios que a lo largo de una jornada, o de diferentes jornadas, pueden cambiar, cambiando las escalas que guían las decisiones sobre el uso de la PP.

Al hablar de escalas o magnitudes, hacemos referencia a un orden que los actores judiciales no consideran arbitrario o injusto dado que descansa en la presencia de principios de equivalencia, principios superiores comunes a partir de los cuales es factible lograr acuerdos sobre una escala de valores y la magnitud relativa que esos valores poseen en cada caso ${ }^{171}$. Esto no significa que frente a todas las solicitudes de PP los actores judiciales estén de acuerdo, es decir, que cada uno de ellos considere justa su solicitud, y posterior aceptación o denegación. Significa que frente a toda solicitud, existe un principio superior común que les posibilita dirimirla dentro de un régimen de justicia $^{172}$, régimen en el cual las soluciones se logran por medio de la argumentación,

\footnotetext{
${ }^{171}$ Boltanski afirma al respecto: "las magnitudes, en el sentido que utilizamos ese término, que descansan sobre principios de equivalencia generales y cuya validez, en consecuencia, trasciende la situación presente, son susceptibles de fundar acuerdos aceptables por todos y orientados por ello hacia una perspectiva universalista" (2000: 78)

${ }_{172}$ Para Boltanski, "la justicia no deja de ser una disputa, pero que sustituye la disputa en la violencia por una disputa en la justicia. En esta última, las personas ya no se miden solamente una con la otra [...]. Se apoyan, para fundar sus medidas, en una equivalencia general tratada como universal. Esta equivalencia general introduce en su relación la referencia a un segundo nivel que no es ocupado por personas, ya que el juez no puede arbitrar más que refiriéndose a él [...]. La disputa puede de ese modo pasar de la violencia a la justicia cuando cada uno reconoce la equivalencia general y reconoce que el otro la reconoce [...]. La justicia trata la disputa relacionándola con una equivalencia general y sometiendo a las partes a una prueba definida por referencia a esta equivalencia" (2000: 132-3). Desde este punto de vista, la justicia está orientada hacia la disputa, al igual que el régimen de la violencia: cuando las personas tienen un litigio por resolver, entonces evocan habitualmente a la justicia. En el régimen de la justicia, las
} 
aún sabiendo -como es el caso de los Defensores en particular- que pueden tener menos posibilidades de conseguir aquello que se proponen.

Por consiguiente, con el pedido de la PP se activan principios de equivalencias dentro de los cuales las magnitudes pueden variar, debiendo los actores desplegar distintas competencias según corresponda. Más concretamente, las magnitudes con las que operan los actores judiciales para decidir sobre la PP pueden resultar incompatibles con otras magnitudes que ellos mismos utilizaron en otra situación. Esto se explica porque cada una de las magnitudes se postula como universal en la situación en que su validez se está reclamando. Un ejemplo de esto, que hemos podido observar, es el de un JG que para denegar un pedido de PP se sustentó en el comportamiento posterior al hecho del imputado ${ }^{173}$. Este indicador procesal es postulado como universal en esa situación, es decir, de carácter general. Sin embargo, ese mismo JG en otro caso ${ }^{174}$ en el cual decidió conceder la medida cautelar necesitó dejar de lado dicho indicador respaldando su decisión actual en los antecedentes del imputado junto a la PEE del delito investigado, indicadores procesales que en esa circunstancia también adquirieron carácter universal.

Como consecuencia, los actores judiciales deben tener la capacidad de ignorar, según lo ameriten los acontecimientos, aquellos principios sobre los cuales apoyaron sus justificaciones en las otras situaciones por las que han atravesado (Boltanski, 2000: 79). Tal como podremos observar en las siguientes manifestaciones, los actores judiciales no actúan siempre de la misma forma sin importar las circunstancias en las que se encuentren. $\mathrm{O}$ lo que es lo mismo, no se comportan como si fueran portadores forzosos de un mismo tipo de valores internalizados.

"La realidad es que para la preventiva es determinante la expectativa de pena. Las normas dicen que esta es un indicador de riesgo procesal. Si la pena en expectativa es baja, se trata de evitar. En general son delitos de gente que está en la lona. Y siempre que sean delitos que no engendren violencia física. Cuando hay violencia, entran las

personas se aferran a los principios de equivalencia para criticar o justificar el orden de magnitudes existente entre los seres presentes en una situación dada. En otras palabras, los principios de equivalencia son activados para apoyar las pretensiones que tienen las personas para decidir sobre quién es grande y quién es pequeño, sobre qué tipo de orden debe prevalecer entre las personas.

${ }^{173}$ El comportamiento posterior del imputado se vincula con su predisposición a estar al servicio de la justicia, es decir, de presentarse inmediatamente después de que el hecho investigado haya sucedido.

${ }_{174}$ En este segundo caso del que hablamos, el imputado también se había presentado inmediatamente después de que el hecho investigado sucedió. 
víctimas a tenerse en cuenta. Si hay amenazas. Hay que buscar que la víctima esté tranquila” (Fiscal de Instrucción del Departamento Judicial de Mar del Plata).

"Cuando el delito lo admite, y siempre tratando de preveer el peligro de fuga, se pide la prisión preventiva. Pero es muy difícil no dar la excarcelación, o una morigeración, si el tipo es primario. Salvo que el delito sea muy grave, que venga muy complicado. La reincidencia es importante, forma como una presunción de que no le va a dar bolilla a la excarcelación, de no cometer nuevos delitos, de no presentarse a las citaciones, etc. Eso es lo que trata de pedir el Fiscal, y no hay oposición de la Defensa cuando la cuestión es grave" (JG del Departamento Judicial de Quilmes).

"La prisión preventiva siempre se pide por el Fiscal, porque es un sistema acusatorio. En general, cuando se pide, se da. Tiene que ver con los peligros procesales, que están en el código. Los peligros procesales son la falta de domicilio, el comportamiento anterior, la pena en expectativa. Son todos los motivos por los cuales uno pueda pensar que pueda profugarse, sino al imputado se lo excarcela. Lo real es que la mayoría ya tiene antecedentes, los delitos con armas se complica más la excarcelación, por eso quizá la cantidad de presos preventivos que hay. Y los Fiscales la piden por esos motivos, porque la prisión preventiva no se puede pedir porque si. Durante el proceso, la libertad es la regla. Tienen que darse los requisitos del código" (JG del Departamento Judicial de La Plata).

Según los testimonios de los actores judiciales, podemos señalar cuatro cuestiones importantes. En primer lugar, que los indicadores de riesgos procesales como la PEE, la violencia que represente el delito, la reincidencia, entre otros, son los que conforman el orden de magnitudes que está presente en las circunstancias o situaciones, y estos indicadores contribuyen, según el caso, a decidir sobre el uso o no de la PP. El hecho de tomar en cuenta la violencia que implica el delito supone contemplar tanto a la víctima como a la conducta ilícita en concreto. Cuando se menciona la reincidencia, lo que se prioriza es a la persona del imputado. Y con la PEE lo que se valora es tanto la gravedad del delito, de la cual deriva la posible pena de efectivo cumplimiento, como la condición legal de la persona que está siendo investigada, puesto que si se trata de alguien con antecedentes, no podría gozar de una condena de ejecución condicional.

La segunda cuestión que se puede advertir es que los acuerdos activos acerca de la PP suelen ser más frecuentes entre JG y Fiscales, más concretamente, entre quien 
investiga y quien controla la investigación, postergando la injerencia de la Defensa. Si bien esto puede tener alguna relación con el hecho de que antes de la reforma del CPP de 1998 era el Juez de Instrucción quien realizaba conjuntamente las tareas de investigación y control, hoy se sustenta no sólo en ese antecedente sino en la percepción de que "el Fiscal es el que la puede pedir" según el CPP, y que cuando la pide "no hay oposición" porque es lo que corresponde según el CPP. Si bien no podemos ser categóricos al respecto, esto puede considerarse como uno de los elementos que favorecen la concesión del encarcelamiento preventivo.

Tercero, se refuerza en los testimonios lo que vimos en uno de los modelos de argumentación sobre los expedientes en el que la PP se otorgaba con acuerdo entre Fiscal y JG en base a la ley. Las respuestas más frecuentes suelen mencionar que la PP se pide y se otorga cuando se dan los requisitos estipulados en el CPP, y que únicamente se justifica su uso cuando esos requisitos se cumplen. En definitiva, la PP no se puede pedir y conceder "por que sí".

Por último, algo que resulta llamativo en las respuestas de los operadores es que confundan a menudo los riesgos procesales, únicos que pueden justificar la aplicación de la PP, con los indicadores de esos riesgos. Lo que significa que equiparan el peligro de fuga o el entorpecimiento en la investigación con los elementos que podrían hacer prever alguno de esos riesgos, como la falta de arraigo, la PEE, la gravedad del delito, etc. Esto puede contribuir a entender por qué en muchos casos a la hora de justificar el pedido o la concesión de la PP, tanto en los expedientes como en las audiencias, ni siquiera se mencionen alguno de los riesgos procesales.

\section{3- A modo de cierre}

A lo largo de este capítulo definimos a la PP como una práctica judicial que, en tanto práctica, necesita ser estudiada como el resultado de elementos judiciales y extrajudiciales, elementos que la dogmática jurídica no contempla a raíz de que no se orienta hacia cuestiones empíricas. En primer lugar, afirmamos que debe tenerse en cuenta la relación que existe dentro del PJ entre un débil control para limitarla y una constante motivación institucional para aplicarla. Se trata de dos variables importantes para entender la ecuación de la PP.

Según algunos testimonios, aparece también un desencantamiento de los actores judiciales promovido por el declive del prestigio dentro del PJ y por la percepción de 
cambios considerados arbitrarios. Esta experimentación de una situación como injusta que podría ser evitada si autoridades institucionales y políticas hicieran otra cosa, genera menos compromisos respecto de la utilización de la PP. Se trata, en definitiva, de no quedar expuesto dentro de una institución judicial que parece mostrar cada vez menos independencia.

Tanto los medios de comunicación como los representantes políticos son presentados por los actores judiciales como relevantes para analizar el desempeño de la justicia penal en general, y el uso de la PP en particular. Estos actores extrajudiciales influyen en la pérdida de autonomía del PJ, si bien para algunos operadores jurídicos esta influencia es la causa y para otros operadores es la consecuencia del declive en dicha autonomía. Y en un escenario de esta naturaleza, la PP se brinda como una respuesta disponible, sugerida y avalada por la institución judicial, lo que termina por limitar la posibilidad de recurrir a nuevas respuestas frente a sucesos similares.

También sostuvimos que son los indicadores de riesgos procesales como la PEE, la violencia que entrañe el delito, la reincidencia, entre otros, los que conforman el orden de magnitudes que están presentes en las circunstancias o situaciones que contribuyen, según el caso, a decidir sobre el uso o no de la PP. En segundo lugar, señalamos que los acuerdos activos acerca de la PP suelen ser más frecuentes entre JG y Fiscales, es decir, entre quien investiga y quien controla la investigación, postergando el protagonismo de la Defensa. En tercer lugar, confirmamos con algunos testimonios lo que ya habíamos visto en uno de los modelos de argumentación sobre los expedientes: que la PP se pide y se otorga cuando, según los actores judiciales, se dan los requisitos estipulados en el CPP, y que únicamente se justifica su uso cuando esos requisitos se cumplen. Cuarto y último, resultó llamativo que los actores confundan frecuentemente riesgos procesales, únicos que pueden justificar la aplicación de la PP, con indicadores de esos riesgos, equiparando el peligro de fuga o el entorpecimiento en la investigación con los factores que podrían hacer prever alguno de esos riesgos. 


\section{CAPITULO VII}

\section{Prisión preventiva, entre la justicia y el amor}

\section{1- Equivalencias y pruebas justificables}

Para seguir especificando las competencias que los actores judiciales despliegan en sus justificaciones y críticas sobre la PP, en este capítulo analizaremos la medida cautelar a partir de dos de los regímenes de acción que postula Boltanski. Como ya lo señalamos antes, no se trata de mostrar a las manifestaciones de los actores judiciales como ilusiones que encubren condicionamientos de otra naturaleza, sino de tomar en serio sus propósitos. En este sentido, al hablar de la tarea del sociólogo de la crítica, Boltanski afirma que éste debe tener en cuenta los argumentos y las pruebas que los actores ofrecen en su trabajo. De ese modo,

El sociólogo renuncia a fundar su propia interpretación [...] construida mediante el aprovechamiento [...] de lo que los sociólogos clásicos corrientemente denominan estructura social, para dejarse llevar por las formas estables que aparecen en los informes de los actores [...]. Tomamos los argumentos de los actores tal como se dan, sin someterlos a nuestra crítica, confrontándolos con modelos que son en sí mismos el producto de un trabajo de explicitación y de sistematización de la competencia común (2000: 56-61).

Esta renuncia a considerar nuestra interpretación como superior, no significa que anulemos la asimetría clásica entre la posición del investigador y la del actor. En lo fundamental porque es el investigador quien está en condiciones de recolectar un cúmulo de información que los actores en particular no tienen la necesidad de recolectar. Por el contrario, en nuestro caso significa que no pretendemos tener la última palabra respecto de los actores judiciales basándonos en una comprensión cabal de las "fuerzas" que orientan su comportamiento, "fuerzas" que permanecerían ocultas para dichos actores. Tal como lo plantea Latour (2008: 263), no sirve de mucho reivindicar aquello que los actores hacen si luego le vedamos la posibilidad de definir sus propias escalas ${ }^{175}$.

\footnotetext{
${ }^{175}$ Tal como lo planteamos en el capítulo anterior, al hablar de escalas o magnitudes, hacemos referencia a un orden que los actores judiciales no consideran arbitrario o injusto dado que descansa en la presencia de principios de equivalencia, principios superiores comunes a partir de los cuales es factible lograr acuerdos sobre una escala de valores y la magnitud relativa que esos valores poseen en cada caso. Por
} 
Buena parte de la información para el estudio de la PP la recolectamos del análisis de los expedientes y las audiencias, prestándole atención a la manera en que los actores judiciales en la situación en que se encuentran ponen en juego competencias para justificar o criticar aquello que sucede en el momento en que se esta investigando la consumación de un delito y la Fiscalía formula una demanda de encarcelamiento preventivo. Para esto último tuvimos que analizar el grado de validez que los actores mismos le otorgan, según las circunstancias, a las distintas consideraciones que entran en juego y se enfrentan cuando surge un caso en el que la PP está en disputa bajo un régimen de justicia.

Entendemos por régimen de justicia una modalidad de acción a la que apelan los actores cuando tienen una controversia y la resuelven en el marco de principios de equivalencia compartidos. Recordemos que estos principios de equivalencia o principios superiores comunes forman parte de un orden considerado legítimo compuesto de acuerdos más generales en los que deben coincidir las personas y tenerlos presentes para que un evento pueda desarrollarse con normalidad. En concreto, esto significa que frente a la solicitud de la PP todos los que participan en la decisión aceptan dirimirla por medio de la argumentación.

Con el objetivo de comprender mejor las particularidades del régimen de justicia, es posible ofrecer una tipología de los cuatro regímenes de acción propuestos por Boltanski, ordenándolos según dos parámetros. Tal como lo ilustra la tabla 1, un primer parámetro es el que tiene en cuenta en qué medida cada uno de los regímenes está orientado hacia la paz o hacia la disputa, y el segundo parámetro, hasta qué punto en cada uno de ellos están activados o no los principios de equivalencia que fundan un orden válido entre las personas.

Tabla 1- Tipología de los cuatro regímenes de acción

\begin{tabular}{|c|c|c|}
\hline & $\begin{array}{c}\text { Activación de los } \\
\text { principios de } \\
\text { equivalencia }\end{array}$ & $\begin{array}{c}\text { Desactivación de los } \\
\text { principios de } \\
\text { equivalencia }\end{array}$ \\
\hline Orientado hacia la paz & $\begin{array}{c}\text { Régimen de la rutina } \\
\text { (justeza) }\end{array}$ & $\begin{array}{c}\text { Régimen del amor } \\
\text { (ágape) }\end{array}$ \\
\hline $\begin{array}{c}\text { Orientado hacia la } \\
\text { disputa }\end{array}$ & Régimen de la justicia & Régimen de la violencia \\
\hline
\end{tabular}

ejemplo, la liberad del imputado durante el proceso es una escala de valor. Pero la magnitud de esta escala permite que en algunos casos esa escala se relativice y la PP pueda ser considerada pertinente. 
Según esta tipología, el régimen de justicia y el de violencia están encaminados hacia la disputa. Como consecuencia, cuando las personas tienen una controversia que solucionar, por lo general recurren al régimen de justicia. De lo contrario, se orientan por el régimen de violencia en el cual los principios de equivalencia son contradichos o alterados para establecer o mantener por la fuerza nuevas o viejas equivalencias ${ }^{176}$. A diferencia de los dos regímenes anteriores, el régimen del amor (o del ágape) es un régimen de paz, en el cual las personas dejan de lado las equivalencias provocando la imposibilidad de realizar cálculos ${ }^{177}$. Por último, esta el régimen de la rutina (o de la justeza), en el cual tampoco hay disputas. Existe por parte de los individuos cooperación tácita, como si se dejaran conducir por las equivalencias en la medida en que ellas están activas sosteniendo un orden ${ }^{178}$ (Guerrero y Ramírez, 2011).

Retomando el régimen de justicia, podemos caracterizarlo como aquel en el que las personas se sirven de los mencionados principios de equivalencia a partir de los cuales critican o justifican el orden de magnitudes existente entre quienes se encuentren presentes en esa disputa específica. O lo que es lo mismo, los principios de equivalencia son activados por las personas para apoyar sus propósitos a la hora de intentar zanjar cuestiones sobre lo que es aceptable y lo que no lo es, sobre qué tipo de escala debe prevalecer en un momento determinado.

En síntesis, este régimen de justicia está orientado hacia la resolución de una disputa bajo criterios o principios de equivalencia que reglamentan dicha resolución. Para nuestro caso en concreto, vale preguntarse: ¿ha sido bien solicitada la PP por el Fiscal teniendo en cuenta la existencia de peligros procesales? ¿Esos peligros procesales son demostrados o sólo enunciados? ¿Cómo actúa frente a esto la Defensa del

\footnotetext{
${ }^{176}$ Un ejemplo de régimen de violencia en nuestra sociedad sería el de una discusión entre dos personas por un choque con sus automóviles que concluye con golpes por parte de ambos. Si bien éste puede ser un supuesto, Boltanski complejiza el régimen de disputa violenta, caracterizándolo como aquel que "abre la posibilidad de tratar a los seres humanos como si fueran cosas. Pero [...] las cosas en la violencia -es decir, también la gente cuando se encuentra en ese estado- no son ya cosas humanas, estabilizadas por su asociación con los hombres, sino seres naturales, fuerzas de la naturaleza" (2000: 110). En este sentido, una pelea entre dos conductores que puede derivar en heridas, incluso en arrestos policiales, para ellos no es simplemente una disputa de dos individuos por dos cosas humanas -sus coches-, sino una pelea entre seres humanos como si fueran cosas.

${ }_{177}$ El régimen del ágape lo desarrollaremos en el cuarto punto de este capítulo.

${ }^{178}$ En este régimen las personas no hacen uso del lenguaje -como sí lo hacen en el régimen de justiciapara cuestionar las equivalencias inscriptas en la estabilidad de las cosas y en la firmeza de las personas cuando presentan lo que es constante en ellas (Boltanski, 2000: 107). En la justeza los objetos del mundo tienen principalmente la función de estabilizar la vida humana. En nuestro caso, tanto los expedientes como las audiencias son ejemplos de aquello que estabiliza el vínculo entre los actores judiciales.
} 
imputado? ¿Qué prioriza el JG para resolver el pedido de la PP? Estos interrogantes permiten ver cómo en torno a la PP suele darse una confrontación por la supuesta necesidad o arbitrariedad que constituye su dictado, y cómo esta confrontación se resuelve a partir de las justificaciones y las críticas que los actores judiciales lleven adelante para ponerse de acuerdo. O sea, lo que sucede aquí es que los actores judiciales buscan resolver sus controversias argumentando y activando los principios de equivalencia.

A partir de los modelos de argumentación propuestos en los capítulos preliminares sobre los expedientes y las audiencias, lo que intentamos fue explicitar el sentido de justicia -las implicancias metafísicas- de los planteos y justificaciones que estos actores utilizan en el plano judicial, es decir, criterios que van más allá de la situación concreta y poseen un nivel más alto de generalidad ${ }^{179}$. Esto surgió de comparar los enunciados observados tanto en los expedientes como en las audiencias con los modelos que construimos en el "laboratorio", modelos que son el "producto de un trabajo de elaboración realizado a partir de los argumentos planteados por los actores y de las situaciones en las que se desarrollaron" (Boltanski, 2000: 59). Lo dicho nos permitió examinar el problema de la PP desde una perspectiva propia, ya que donde muchos pueden ver sólo recurrencia de los argumentos y tendencia a la repetición dentro de los expedientes y las audiencias, nosotros vimos categorías relacionadas con la justicia, la crítica y la justificación ${ }^{180}$.

Por lo tanto, a lo que le prestamos atención es a la manera como los actores judiciales llevan adelante sus capacidades interpretativas frente a lo que sucede cuando alguien formula una demanda de PP. Para realizar esta observación evitamos juzgar

\footnotetext{
${ }^{179}$ Boltanski sostiene que "en el centro [del] modelo de competencia figura, por lo tanto, lo que podemos denominar capacidad metafisica. Dotamos a las personas humanas de una capacidad metafísica y consideramos que esa capacidad es esencial para comprender la posibilidad de un lazo social. En efecto, para converger hacia un acuerdo las personas deben hacer referencia a algo que no son personas y que las trasciende. Es esta referencia común lo que llamamos principio de equivalencia. Cuando el acuerdo es difícil de establecer, para realizarlo las personas deben aclarar sus posiciones de justicia, adecuarse a un imperativo de justificación y, para justificar, deben sustraerse de la situación inmediata y alcanzar un nivel más alto de generalidad. Así, se orientan hacia la búsqueda de una posición apoyada en un principio generalmente válido, es decir, en un principio con pretensiones de validez universal" (2000: 72).

${ }^{180}$ Es importante aclarar que "[...] la justicia, la crítica y la justificación no han sido tratados por Boltanski de forma independiente, sino como un trío de temas inseparable, dado que todo reclamo de justicia (o lo que es igual, toda denuncia de una injusticia) comporta en sí mismo(a) — así sea de manera implícita - una crítica a un orden establecido. Asimismo, es muy corriente —o al menos posible - que en el mundo social las operaciones críticas se vean acompañadas de operaciones de justificación, puesto que la justificación es la manera como un actor puede responder o prevenir la crítica de otro. Ahora, tanto en el ejercicio de la crítica como en el ejercicio de la justificación las personas expresan valores morales (valores de justicia) que tienen importancia para ellas. Esto quiere decir que es posible tomar la crítica y la justificación como dos facetas distintas, pero vinculadas a la justicia" (Guerrero y Ramírez, 2011: 43).
} 
desde un punto de vista externo y superior el grado de validez de las justificaciones y de las críticas expresadas por los actores que intervienen en el pedido de esta medida cautelar. Más en concreto, analizamos el grado de validez que los actores judiciales le otorgan a las distintas interpretaciones que entran en juego y que se enfrentan cuando surge un caso en el que está presente la PP. Y apelando a ese grado de validez que le otorgan los mismos actores judiciales es que tuvimos la posibilidad de especificar las competencias que dichos actores desarrollan y crear modelos argumentativos por medio de los cuales esclarecer cómo justifican el uso del encierro preventivo (Guerrero y Ramírez, 2011).

\subsection{Los modelos y el sentido de la normalidad en los expedientes}

Es conveniente recuperar ahora el trabajo hecho en el capítulo sobre el uso de la $\mathrm{PP}$ en los expedientes y reafirmar que los argumentos de los actores judiciales tienen importancia para analizar este uso, que no son un simple reflejo. Dicho de otra forma, podemos asumir que los tres primeros modelos de argumentación satisfacen las condiciones que se consideran exigibles para la aplicación de la PP en el ámbito judicial. Si aceptamos que la normalidad es una precondición de admisibilidad para que una demanda de PP sea concedida por el JG, debemos considerar a los argumentos construidos en base a la ley, en base a un acuerdo tácito, y en base a un acuerdo en disidencia como normales más allá de sus diferentes contenidos. Vale aclarar que la normalidad a la que hacemos referencia es, en realidad, el sentido ordinario de la normalidad que los actores judiciales son capaces de poner en práctica en su trabajo cotidiano respecto de la PP. A continuación, caracterizaremos este sentido ordinario de la normalidad presente en los expedientes.

En el modelo realizado en base a la ley, la normalidad de la que hablamos se manifiesta cuando la PP es solicitada por el Fiscal y concedida por el JG respecto a uno -o dos- de los riesgos procesales que requiere el CPP.

En el segundo modelo hecho en base a un acuerdo tácito, el sentido de la normalidad se observa cuando la medida cautelar es pedida y otorgada, sin que haya sido necesario mencionar en las justificaciones ni el peligro de fuga ni el entorpecimiento en la investigación. 
En el tercer modelo, el sentido ordinario de la normalidad se distingue cuando Fiscal y JG consideran que la PP debe ser utilizada más allá de ambos discrepen en sus argumentos.

El último modelo de argumentación, el que se apuntala en base a la confianza perdida, es puesto fuera de la normalidad en tanto precondición para conceder una demanda de PP por el JG.

Según los expedientes examinados, la normalidad está sustentada en dos condiciones. Primero, que el Fiscal demuestre frente al JG la existencia del delito, y segundo, que el imputado haya participado presumiblemente en este último. Como consecuencia, lo que acabamos de expresar permite ver que la cuestión de la normalidad y del sentido de la normalidad tiene un vínculo directo con la cuestión de la justicia y del sentido de la justicia en estos casos.

Estos modelos de expedientes hacen posible evidenciar los distintos grados de condicionamiento que los operadores jurídicos enfrentaron en las situaciones en las que se hallaron para hacer que las solicitudes -en el caso de los Fiscales- y las aceptaciones en el caso de los JG- resultaran justificables. Pero insistimos en que los grados de condicionamiento están vinculados con las situaciones, y no con la interiorización de la exterioridad judicial o institucional. Y en definitiva es por esto que podemos explorar al encierro preventivo como una competencia que desarrollan los operadores jurídicos al producir justificaciones y argumentos, escepticismos y acuerdos activos.

\subsection{Los modelos y el sentido de la normalidad en las audiencias}

En el caso de las audiencias, la configuración de los argumentos es diferente ya que como lo hemos planteado en su momento, los actores judiciales que deciden sobre la PP durante la IPP interactúan en simultáneo, desplegando frente a frente sus competencias. Las críticas y las justificaciones que llevan adelante respecto de aquello que consideran justo o injusto son planteadas en un mismo ámbito, lo que supone un cambio en los marcos de significación de la PP. Como consideración general, las audiencias muestran ventajas sobre los expedientes a la hora de disputar la viabilidad o no de la medida cautelar durante la IPP. La razón fundamental está dada por la presencia del Defensor, que puede objetar las justificaciones de la Fiscalía previo a que el JG conceda la PP. Esta posibilidad en los expedientes no existe. Sin embargo, desde el punto de vista de la normalidad como precondición de aceptación frente a una 
solicitud de PP, volvemos a encontrar modelos en los que el JG considera justa dicha solicitud, y son los que se realizan en base a la velocidad del proceso, en base a las personas, y en base a los delitos. Como lo hicimos con los expedientes, describiremos este sentido ordinario de la normalidad existente en las audiencias.

El primero de estos modelos muestra que a la hora de justificar el encierro preventivo, los Fiscales y JG apelan al vocabulario en base a la velocidad con el que el proceso de flagrancia se impulsó, considerándolo ambos actores suficientemente válido o normal como criterio para solicitar y conceder la PP.

El segundo modelo en base a las personas, con cierta afinidad respecto del positivismo criminológico, expresa el sentido de la normalidad como precondición de admisibilidad de la PP al poner como principal argumento a los imputados. Es decir, se invocan los peligros procesales partiendo del comportamiento previo -al hecho que se ventilando- de la persona a la que está siendo investigada.

Y en el tercero, con resabios de la Escuela Clásica de derecho penal, los argumentos en las audiencias se sustentan en la correspondencia que los actores judiciales observan entre la gravedad de la conducta ilícita realizada y la aplicación del encierro preventivo. O lo que es lo mismo, el sentido ordinario de la normalidad que los actores judiciales ponen aquí en práctica se apoya en la proporcionalidad entre la conducta ilícita y la aplicación de la PP.

El modelo que en las audiencias es ubicado por fuera de la normalidad es el que se sostiene en base a la policía sospechada, puesto que esta fuerza de seguridad incita desconfianza para la Defensa y el JG. O dicho de otro modo, cuando la Defensa logra persuadir al JG de que la policía se ha desempeñado capciosamente en una causa, más posibilidades existirán para que la PP no se otorgue.

Como primera conclusión de este punto podemos decir que los modelos de argumentación que presentamos en los capítulos IV y $\mathrm{V}$ de la tesis permiten ver que el sentido ordinario de la normalidad entre los actores judiciales está presente en seis de los ocho modelos, si bien se trata de un sentido de la normalidad que se manifiesta de distintas formas, tanto en los expedientes como en las audiencias.

En segundo lugar, vimos que al solicitar al JG que la PP se conceda (Fiscalía) o se deniegue (Defensa), lo que llevan adelante los actores judiciales intervinientes es un reclamo de justicia por lo que cada uno de ellos considera apropiado. Y formulan, en 
simultáneo, una crítica implícita a la decisión del JG en caso de ser contraria a su demanda, dado que es el JG quien homologa la normalidad o anormalidad como precondición de admisibilidad de la PP según el caso. Las operaciones críticas implícitas que acabamos de señalar van acompañadas de operaciones de justificación, puesto que la justificación es la manera como un actor judicial puede responder o prevenir la crítica de otro.

Por último, tanto en el ejercicio de la crítica como en el ejercicio de la justificación, los actores judiciales expresan valores morales de justicia sobre la necesidad o innecesidad de la PP, valores que tienen importancia para ellos. Con esto queremos decir que es posible tomar a la crítica y a la justificación como dos facetas distintas que se vinculan al sentido de justicia y normalidad que atraviesa la cuestión del encierro preventivo.

\section{2- Delito, violencia y justicia}

A partir de lo que señalamos en el apartado anterior, ¿qué estamos en condiciones de decir sobre las formas en que los actores judiciales argumentan acerca de la PP en la práctica? ¿Realizan operaciones críticas al respecto? ¿Qué sentido de justicia, en tanto sentido ordinario de la normalidad, ponen en acción? En definitiva, ¿podemos llegar a comprender las justificaciones de los actores judiciales sobre la PP señalando las exigencias que han debido tener presentes en la situación en que se encontraban?

Para responder estas preguntas y complementar lo que expresamos acerca de los expedientes y las audiencias es necesario mencionar un elemento por lo general soslayado en los documentos e investigaciones sobre la PP, y que resulta importante para entender las justificaciones que utilizan los actores judiciales. Se trata del hecho de que esta medida cautelar gira en torno a la investigación de un delito, es decir, a una acción que se aparta del orden aceptado normalmente como legítimo ${ }^{181}$, que sale de un régimen de justicia y se ubica dentro de un régimen de violencia. Alguien que está imputado por la comisión de un delito es alguien acusado de llevar adelante una disputa por fuera de las equivalencias aceptadas como justas en un orden reconocido como

\footnotetext{
${ }^{181}$ Un orden aceptado como legítimo, que esté por encima de los criterios personales, es lo que Boltanski denomina principio de equivalencia Según este autor, "para converger hacia un acuerdo las personas deben hacer referencia a algo que no son personas y que las trasciende. Es esta referencia común lo que llamamos principio de equivalencia" (2000: 72).
} 
legítimo $^{182}$. Basta recordar a Matza (2014: 230), cuando caracterizaba al crimen consensual como aquel comportamiento evidentemente incorrecto y dañino cuya represión no ameritaba mayores objeciones en la sociedad, para comprender que también en el ámbito judicial los delitos son percibidos como el incumplimiento de ciertas normas, incumplimiento que debe tener sus consecuencias.

"El castigo para mi es importante, como retribución. Y como disuasión. Hay que hacer hincapié en las oportunidades que tuvo [el imputado], y que lo que hizo está mal, y que eso tiene consecuencias. Si estás a prueba, debés entender que estas a prueba, y no tiene que ver con la clase social sino con el respeto a las normas" (Fiscal de Instrucción del Departamento Judicial de La Plata).

Tal como lo sugiere esta Fiscal, la PP viene a restablecer cautelarmente un equilibrio que fue alterado por la comisión de un delito, por la generación de un daño concreto inadmisible. No es nuestra intención polemizar aquí sobre el tipo de criminalidad que se investiga en general, ni advertir sobre la selectividad en la persecución de la misma. Esto último tampoco significa que alberguemos una mirada ingenua respecto de las desigualdades en las que tiene lugar el control de determinado tipo de delitos por parte del Estado, desigualdades que este control contribuye generalmente a profundizar y reproducir ${ }^{183}$. Sin embargo, lo que nos parece necesario subrayar es que las denuncias sobre esta selectividad y estas desigualdades son procedentes pero no suficientes para comprender la utilización de la PP dentro del PJ. En este sentido, es importante señalar que a partir de la IPP estos actores buscan, cada uno según su función, introducir al delito dentro de un régimen de justicia activando equivalencias que la infracción ha quebrantado. Esta vuelta al régimen de justicia es necesaria puesto que para investigar un delito y eventualmente utilizar la PP, dichos actores deben justificar sus planteos desde un orden aceptado como legítimo. O sea que

\footnotetext{
${ }^{182}$ En el régimen de la violencia existe disputa, pero mientras que en régimen de la justicia las personas buscan resolver dichas disputas argumentando sobre los principios de equivalencia, en la violencia se rechazan o niegan las equivalencias: "En este régimen las personas mismas ya no se conocen más que como fuerzas opuestas y desconocidas a prueba unas de otras y, como hemos afirmado, el principio de su lucha no difiere en nada de la relación que podrían mantener con una cosa. Pero en este régimen en que las cosas ya no están sujetas por la equivalencia y por eso mismo ya no están obligadas a respetar las convenciones preestablecidas ni a satisfacer las expectativas puestas en ellas, la gente pierde toda influencia sobre ellas" (2000: 110).

${ }^{183}$ Las relaciones entre desigualdad y delito deben ser analizadas desde diferentes perspectivas, tales como la pérdida de bienestar que genera en las personas las altas tasas de ilícitos, las relaciones que existen entre las probabilidades de las personas de ser víctimas de determinados delitos y su pertenencia a determinados sectores sociales, y la correlación general entre desigualdad y delito (Kessler, 2014).
} 
"la disputa pasa de la violencia a la justicia cuando cada uno reconoce la equivalencia general y reconoce que el otro la reconoce y cuando ese otro reconoce que también él la reconoce, y así sucesivamente" (Boltanski, 2000: 132).

En definitiva, la solicitud de PP que realiza un Fiscal durante la investigación de un delito contra la propiedad, por ejemplo, no puede sustentarse sólo en fórmulas preestablecidas o redundantes. Lo mismo pasa con la concesión o denegación que lleve adelante un JG, o la objeción efectuada por la Defensa. Es decir, existe por parte de los actores judiciales la necesidad de brindar justificaciones en cada situación, y estas justificaciones - pese a que pueden tener una serie de referencias comunes, tal como lo permiten ver los modelos de argumentación- no son necesariamente habladurías. De este modo, la exigencia de justificaciones pone condiciones y límites para el uso de la PP. Si bien no siempre estas condiciones y estos límites son rigurosos, sí contribuyen a regular el ejercicio de una violencia que es la del encarcelamiento de una persona jurídicamente inocente.

\subsection{La prisión preventiva como consecuencia}

Junto con lo que acabamos de mencionar sobre la importancia del delito para la utilización de la PP, debemos rescatar algo que ya hemos sugerido en esta tesis y que tiene que ver con la importancia de la división judicial del trabajo. En la mayoría de los casos, los operadores jurídicos muestran diferentes competencias que se vinculan con la tarea específica que cumplen durante la IPP a partir de una situación concreta. Esto contribuye a expresar diferentes sentidos de justicia así como diferentes justificaciones y operaciones críticas, todas cuestiones que pueden variar en función de si controlan la legalidad de las actividades que se llevan a cabo para investigar un delito, si dirigen dicha investigación o si defienden al imputado.

Si bien lo que acabamos de expresar puede parecer evidente resulta un avance respecto a ciertos abordajes y estudios que se han hecho sobre la PP, en los cuales se plantea el problema sin diferenciar con claridad esta cuestión aparentemente obvia. Un ejemplo de estos abordajes es la perspectiva presentada en el primer capítulo de la tesis que trabaja al encierro preventivo desde las ciencias sociales. En términos generales, para esta perspectiva es posible, y en algunos casos suficiente, afirmar que la PP se trata del encierro de personas jurídicamente inocentes, definiendo por adelantado y en lugar de los actores judiciales cómo se produce y para qué sirve. En otras palabras, deciden investigar a la PP como si fuera un todo homogéneo dejando de lado que para 
comprender su uso hay que abordarla como una práctica, como un acuerdo activo, pero no como un fenómeno de significado único. Por consiguiente, para nuestro análisis sobre este problema es crucial no definirla anticipadamente, ya que el destino de la PP está en manos de quienes pueden decidir utilizarla o no utilizarla y quienes pueden impedir o favorecer que se utilice. En síntesis, que las cualidades de la PP son una consecuencia, y no la causa, de lo que hacen los actores judiciales con ella (Latour, 1992).

Según las expresiones recogidas, buena parte de los actores judiciales acuerdan con este planteo y vinculan tanto el sentido de justicia como las críticas que utilizan para la puesta en marcha de la PP con la función que desempeñan en la IPP. Al no ser vista del mismo modo por JG, Fiscales y Defensa, la PP tampoco genera los mismos requerimientos ni articula las mismas relaciones. Se trata de un enfoque "institucionalista" de la PP, en el sentido de que las presiones que surgen a partir de las diferentes situaciones se apoyan fundamentalmente en el papel que la institución judicial les asigna que cumplan. Así lo plantea este actor judicial:

"Aún con la mejor de las intenciones, lo que se pregunta del lado de la fiscalía y lo que se pregunta del lado de la defensa es absolutamente distinto. Parten de premisas absolutamente distintas. El problema del juez es que debería ser equidistante de ambas posiciones, y ya ahí entra a jugar la ideología que tiene el juez, su visión del proceso penal. Y a mí me parece que en esto tiene mucha influencia cuál ha sido la trayectoria judicial de ese juez. En general, el 90\% de los jueces provienen del lado de la fiscalía. Fijate qué diferente ve el proceso el juez que vino de la profesión, o de la defensa. A mí me parece que vos no podés ser juez si no estuviste en los dos lados, pero sé que es difícil en la práctica. Es muy difícil sacarle una absolución al juez, porque cree que sólo se hace justicia si hay una condena”. (Defensor Oficial del Departamento Judicial de La Plata).

Tomando las palabras de este Defensor, el recorrido de los actores judiciales organiza los parámetros que ellos mismos utilizan para evaluar la medida cautelar. Sin embargo, no debe verse como una contradicción con nuestra propuesta el hecho de que las posiciones en la IPP sean relevantes para la percepción de los actores sobre la PP. 
Según esta última, lo más importante no son los roles ${ }^{184}$ sino los regímenes de acción que los actores judiciales despliegan a partir de las situaciones por las que atraviesan,

Sus competencias consisten en referirse a principios generales de justicia y adaptar su comportamiento a esos principios, pero esos principios no son roles incorporados, sino formas de acuerdos entre las personas. En particular, una persona debe cambiar de programa de acción según las situaciones en las que se encuentra (Eymard-Duvernay, 2001: 59).

En definitiva, el lugar que ocupan los actores judiciales no deja de ser un elemento significativo para analizar los regímenes de acción que despliegan, si bien es relevante a partir de las diferentes situaciones por las que atraviesan.

Frente a esta perspectiva "institucionalista", existen otros actores que sugieren en sus testimonios que la actitud frente a la PP no tiene que ver con la división judicial del trabajo, o al menos no prioritariamente, sino con convicciones previas a los cargos que invisten. Acá la diferencia no sería entre JG, Fiscales y Defensores, sino entre posturas críticas, moderadas y conservadoras frente a la aplicación de la PP en particular, y frente a la selectividad del control del delito en general. Por lo tanto, es un enfoque más "ideológico" que "institucional" puesto que las percepciones se configuran incluso al margen de la función o el cargo, sea antes o después de ingresar al PJ.

"Para mí [lo que piensan] lo traen, en mi experiencia creo que es así. Los que yo conozco que han cambiado de función que eran compañeros míos, y que ahora son Jueces de Garantías, no cambiaron. Pensaban de una manera en la Defensa y ahora piensan igual. En todo caso lo que hace la rutina del Poder Judicial es acentuar lo que uno ya traía. Y en La Plata, los que son Jueces de Garantías eran antes Jueces Correccionales, por lo que tendrán que pasar años para que vengan nuevos" (Defensor Oficial del Departamento Judicial de La Plata).

Lo que cobra protagonismo aquí es la cosmovisión del actor judicial sobre el papel del derecho penal y de los factores que intervienen en el fenómeno del delito. Desde luego que esta diferenciación es más difusa que la de la división judicial del trabajo, porque carece de respaldo por parte de la organización judicial. Además, es

\footnotetext{
${ }^{184}$ Tal como lo sostiene François Eymard-Duvernay, "en la sociología que atribuye un rol a las personas, estas actúan bajo el efecto de un programa incorporado. El rol es un programa que regulariza el comportamiento de una persona y permite a los otros anticipar su comportamiento" (2001: 58-9). En este sentido, nosotros no hacemos mayor hincapié en los programas incorporados de las personas.
} 
producto de categorías que surgen de aquello que los actores judiciales expresan a la hora de referirse a sus colegas en general o para aludir a un colega en particular, pero no para presentarse a sí mismos. Ningún actor judicial en las entrevistas se identifica con el rótulo de conservador, moderado o crítico ${ }^{185}$. Lo que sí puede suceder es que alguno de estos actores se percate de estar siendo definido de una $u$ otra forma por sus colegas. Tal es el siguiente caso:

"[...] cuando voy a algunos juzgados me dicen: ¡vos sos la gorila! Yo creo que a veces aplicar la ley es duro e implica posicionarse. Hay otros grupos más laxos.

ENTREVISTADOR: Si vos sos gorila, ellos ¿cómo se consideran?

Ah, el famoso garantista. Y yo no estoy de acuerdo con esos rótulos, para nada [...]. El fiscal debe buscar objetivamente la verdad, o lo más cercano a la verdad. Yo muchas veces, si no hay pruebas suficientes pido la libertad. Entonces lo que me da bronca es que te digan esto o aquello y no se fijen cómo actuás" (Fiscal de Instrucción del Departamento Judicial de Quilmes).

Considerando las críticas que recibe por su comportamiento, podemos sugerir dos cuestiones sobre las justificaciones que ofrece esta Fiscal: en primer lugar, que se apoya en la objetividad o neutralidad frente a los hechos y frente a la utilización del derecho. Segundo, que sus justificaciones pueden interpretarse como un medio de defensa o adaptación a los problemas manifiestos o encubiertos que le ha creado el rótulo que le aplicaron ${ }^{186}$.

En consecuencia, podemos decir que a partir de las situaciones y los casos concretos, las formas de argumentación y justificación sobre la PP durante la IPP pueden tener tres niveles de análisis. En primer lugar, si se realiza en expedientes o en audiencias, dado que cuando el proceso se lleva adelante por medio del expediente, la Defensa recién conoce sobre el pedido de la PP hecho por el Fiscal cuando el JG ya

\footnotetext{
${ }^{185}$ Hemos notado en algunos actores judiciales que podríamos considerar críticos la intención de dejar en claro que son conscientes de la selectividad en la persecución del delito, y la relación de esta última con desigualdades estructurales más amplias. Incluso esta intención puede tener que ver con el afán de diferenciarse de otros actores judiciales menos "conscientes". Sin embargo, y esto es lo que resulta importante, en ninguna circunstancia eligieron rotularse ellos mismos como "críticos".

${ }^{186}$ Edwin Lemert (1973) definía a la desviación secundaria afirmando que se trataba de la utilización del comportamiento desviado como un medio de defensa, ataque o adaptación a los problemas abiertos y encubiertos que le ha creado a un individuo la reacción social a su comportamiento previo. Si bien no se trata de un caso típico de desviación secundaria y asunción de identidad tal como lo planteaba Lemert, hay elementos afines que permiten ver a las explicaciones de algunos actores judiciales como reacciones a la etiqueta que le han impuesto.
} 
concedió o denegó la medida cautelar. Es por esto que las audiencias facilitan que las justificaciones y operaciones críticas se desplieguen en simultáneo, dada la presencia de los tres actores judiciales implicados.

El segundo nivel de análisis es el que surge cuando se analiza la PP a partir del lugar que ocupan los operadores jurídicos en la división judicial del trabajo. Según los testimonios, las exigencias propias de la función aparecen fuertemente marcadas en el modo en que los actores justifican o critican el uso de la PP. Así las cosas, existirá mayor condicionamiento para que los Fiscales la soliciten, los Defensores la objeten, y los JG la concedan. Sin embargo, y éste es el tercer nivel, también aparece como relevante la ideología que tengan -y conserven- estos actores judiciales, incluso antes de trabajar en el PJ. Esta ideología sirve para diferenciar tanto el papel que le otorgan al encarcelamiento preventivo como el modo en el que los actores justifican las decisiones que toman teniendo en cuenta las críticas de sus colegas.

Retomando las preguntas iniciales de este apartado podemos concluir, en primer lugar, que lo más importante respecto al sentido de la justicia sobre la PP parece estar en la función judicial que tienen dentro de la división del trabajo junto con la ideología, no influyendo el hecho de que la IPP se desarrolle en expedientes o en audiencias. Y es para destacar que la división judicial del trabajo con la ideología pueden asumir diferentes entrecruzamientos dependiendo de las situaciones.

En segundo lugar, si bien los actores realizan las operaciones críticas tanto en los expedientes como en las audiencias parece que es en estas últimas donde dichas operaciones críticas, junto a las justificaciones que las acompañan, tienen mayor posibilidad de desplegarse, más allá de que esto no sea necesariamente ventajoso o perjudicial respecto a la utilización de la PP.

En definitiva, logramos comprender que las variables que pueden tener en cuenta los actores judiciales a la hora de realizar sus justificaciones pueden provenir de tres cuestiones distintas: la del instrumento que se utilice, la de la función que se desempeñe, la de la ideología que se detente. Estas tres cuestiones están en condiciones de repercutir, insistimos, a partir de la situación en la que se encuentren los actores judiciales y no como parte de un sistema inscripto de estructuras mentales estructuradas y estructurantes. 


\section{3- La expectativa, una pena}

El siguiente paso para seguir analizando la PP como competencia es profundizar sobre algo que había quedado planteado en el cuarto capítulo de esta tesis, cuando afirmamos que no hay tiempo en el que el encierro preventivo no pueda justificarse. Esto significa que el pronóstico que sustenta el encierro preventivo consigue validarse en el presente a partir del arraigo del imputado, en el pasado a partir de su reincidencia, y en el futuro a partir de la PEE estipulada para el delito investigado.

Sobre la PEE en concreto vale recordar que según el CPP se trata de "la pena que se espera como resultado del procedimiento", la cual puede considerarse como un indicador del peligro de fuga ${ }^{187}$. Sin embargo, en la práctica la PEE es esgrimida para habilitar el uso de la medida cautelar cuando la sentencia a dictarse, en caso de ser condenatoria, tuviese que cumplirse efectivamente. En Argentina, las condenas son de efectivo cumplimiento en los casos en que una pena supere los tres años de prisión, o cuando las personas sancionadas posean antecedentes penales. Esto último suele transformarse en razón suficiente para concluir que el imputado intentará evadirse. De allí que la PEE, en su empleo habitual, aglutine tanto la gravedad del delito -de la cual emana la posible pena de efectivo cumplimiento- como la situación legal de la persona que está siendo investigada -puesto que si se trata de alguien con antecedentes, no podría gozar de una condena de ejecución condicional.

Se suele mencionar que la expectativa de pena de cumplimiento efectivo funciona como condición necesaria y aceptable para solicitar y conceder la PP (Gutiérrez, 2013). De este modo parece afianzarse en los hechos una postura sustancialista, según la cual el uso del encierro preventivo es utilizado como un anticipo del castigo futuro que sobrevendrá en caso de una sentencia condenatoria. Complementando esto, observamos que la PEE aparece no sólo en las teorizaciones de los dogmáticos del derecho y en los documentos de las ONGs, sino también en la práctica concreta. Hemos comprobado que al justificar la necesidad de la medida cautelar en los expedientes y las audiencias, los actores judiciales lo hacen en función de la pena que le cabría al imputado por el delito que se investiga. Algunos ejemplos presentados en los capítulos IV y V son:

\footnotetext{
${ }^{187}$ El Art. 148 del CPP de la PBA afirma que "[...] para merituar sobre el peligro de fuga se tendrán en cuenta especialmente las siguientes circunstancias: [...] 2. La pena que se espera como resultado del procedimiento [...]". La PEE es uno de los indicadores que pueden utilizarse para pronosticar el peligro de fuga que vuelva justificable la aplicación de la PP.
} 
- "Se trata de un delito de índole no excarcelable, teniendo en cuenta la pena en expectativa" (ARGUMENTO DE LA FISCALÍA en expediente),

- "Siendo que la pena en expectativa que se espera en caso de que sean condenados sería de cumplimiento efectivo, esto me hace presuponer los peligros de fuga que prevé el Art. 148 del CPP” (ARGUMENTO DE LA FISCALÍA en audiencia),

- “[...] ello dado la pena en expectativa prevista para el delito endilgado, y la posible fuga, circunstancia que torna viable la medida de coerción peticionada" (ARGUMENTO DEL JG en expediente),

- “[...] ello teniendo en cuenta la pena en expectativa que se espera como resultado del proceso, como así también la circunstancia de registrar una condena anterior, datos objetivos previstos en el art. 148 del CPP para merituar el peligro de fuga y que permite sostener la procedencia del encarcelamiento preventivo" (ARGUMENTO DEL JG en expediente).

A partir de lo dicho, la cuestión que nos interesa profundizar es la siguiente: cómo la PEE llega a tener ese lugar preponderante en el acuerdo activo que desemboca en el uso de la PP (Becker, 2009: 85). En primer lugar, es importante dejar en claro que en su trabajo cotidiano los actores judiciales no precisan preguntarse por el principio de equivalencia que valida el argumento de la PEE con el que justifican el uso de la PP. Si bien el empleo de esta medida cautelar debe entenderse como una situación que requiere determinada justificación que se base en algún principio de equivalencia, en el despliegue habitual de sus competencias los actores no se remontan hasta los fundamentos en los que se respalda la PEE como indicador del peligro de fuga (Boltanski, 2000: 60). De hecho, tanto los actores judiciales objetores de la PEE como aquellos que no lo son, señalan a este indicador como un elemento habitual en la institución judicial.

Como resultado de lo anterior, la PEE no es sólo un elemento para justificar o criticar la justicia o injusticia por el uso de la PP, sino que además es el elemento que aparece con más frecuencia en todos los planos de la PP que hemos trabajado para esta tesis. Lo que estamos sugiriendo es que la PEE resulta un elemento importante alrededor del cual los actores estabilizan la PP, la vuelven una rutina (Latour, 2008: 348).

En términos generales, los Defensores son aquellos que evidencian las mayores impugnaciones, así como las más sonadas resignaciones sobre la circulación de la PEE. 
Reconocen que es un tipo de justificación plenamente admitida cuya desactivación los excede, a raíz de que la habitualidad de este indicador proviene de la negligencia de los Fiscales y JG para dar otro tipo de respuesta al problema. Así lo expresan:

"El criterio que utilizan los Fiscales y los Jueces de Garantía acá en La Plata te diría que es casi exclusivamente la pena en expectativa. Es decir, en el caso de una pena en expectativa que en el caso hipotético de que fuera condenado la pena resultara de efectivo cumplimiento, siempre se pide la PP, y en general siempre la conceden. Esto quiere decir que para los delitos que no admiten la condena condicional como para los delitos que sí la admiten pero que por tener antecedentes no sería posible la condena condicional, los Fiscales la piden y los Jueces de Garantía suelen hacer lugar a esos pedidos.

ENTREVISTADOR: ¿Qué análisis hacés de eso?

Que es una desvirtuación de la función de la prisión preventiva con las que tenemos que luchar desde la Defensa con las armas que tenemos. Uno a veces hace una evaluación pero conoce el criterio del Jueces de Garantía y sabe que no va a tener éxito, le busca otra vuelta. Por ejemplo en casos de pena de efectivo cumplimiento trabajamos más con el arresto domiciliario que con la excarcelación, porque conocemos los criterios de los Jueces de Garantía y sabemos que en definitiva nosotros tenemos que hacer lo más favorable para nuestros defendidos y no perder el tiempo objetando una prisión preventiva que sabemos va a ser concedida" (Defensor Oficial del Departamento Judicial de La Plata).

"Lo que más me preocupa, aunque sea una pelea quijotesca, es la justificación de la prisión preventiva con criterios sustantivos. Es decir, con argumentos que serían propios de una sentencia de condena: gravedad del hecho, resultado del hecho, extensión del daño causado. Estas son consideraciones que aunque estén en la ley para que se tengan en cuenta respecto de la prisión preventiva, en rigor son propios de una sentencia de condena que lógicamente no está dictada cuando se resuelve la prisión preventiva. Pocas veces se encuentra un peligro procesal real demostrado. Para esto está el otro cliché, que es que como la pena en expectativa permite suponer que la condena será de efectivo cumplimiento, ergo, hay una presunción iure et de iure ${ }^{188}$ de que el imputado se va a escapar, y que el único modo de neutralizar ese riesgo de escaparse, que en realidad es un argumento circular, es con la prisión preventiva. Y digo circular porque es carente de pruebas concretas, sólo discursivo. Y se rechaza cualquier alternativa que

\footnotetext{
${ }^{188}$ Las presunciones iure et de iure son las presunciones que no admiten prueba de que son falsas.
} 
pidas a la prisión preventiva. La práctica te indica que cuando el imputado tiene antecedentes, o cuando está acusado de un delito con una pena grave, no hay manera de evadir la prisión preventiva" (Defensor Oficial del Departamento Judicial de Quilmes).

La "pelea quijotesca" que los Defensores pretenden librar contra la PEE es producto más de sus esperanzas que de las experiencias acumuladas, puesto que generalmente ocurre que la PP se concede automáticamente frente a una eventual pena de efectivo cumplimiento. Lo que dichos actores parecen denunciar aquí es la predicción que la PEE implica sobre el futuro, o más específicamente, el "miedo al futuro" que los Fiscales y JG evidencian al utilizar la PP. Miedo que intentan combatir con una serie de prácticas, tanto jurídicas como judiciales, dirigidas a disminuir la probabilidad de que ciertos eventos dañosos sucedan (Pitch, 2009: 39, 55). Según los Defensores, si se trata de la liberación de un imputado detenido, cualquier nivel de riesgo es inaceptable para Fiscales y JG. Los cálculos parecen claros: el valor de la libertad del preso es inexistente si de su excarcelación puede derivar o una probabilidad para el público de un peligro evitable o que el funcionario responsable del caso corra con algún riesgo en su reputación profesional (Garland, 2005: 311).

El caso de los JG difiere del de los Defensores ya que vinculan la PEE con un pronóstico que consideran obligatorio hacer y a partir del cual resuelven la pertinencia de la PP. Los JG entienden que sus decisiones son el resultado de una técnica objetiva y transparente, decisiones que no son tomadas "en el aire", ya que deben estar sustentadas en las particularidades del hecho como la gravedad del delito, los antecedentes del imputado, etc. Según sus planteos:

\footnotetext{
"Algo que suele estar para solicitar la PP es la entidad de la sanción, y en muy pocos casos, el entorpecimiento probatorio [...]. En realidad, uno fundamenta esto en una predicción. Es lo que se nos exige, hacer pronósticos. Por supuesto que tienen que estar basados en datos que tengan algún tipo de objetividad. Hay características del hecho, la actitud asumida antes o después del delito.

ENTREVISTADOR: ¿Y la pena en expectativa?

Sí, bueno, pero hay que ver porque quizá el delito es excarcelable pero el imputado tiene una condena anterior, y entonces más que la pena en expectativa, es el hecho de que la pena sería de efectivo cumplimiento" (JG del Departamento Judicial de Mar del Plata).
} 
ENTREVISTADOR: ¿Qué tenés en cuenta para conceder la PP?

No es lo único, pero sí es importante la existencia de peligros procesales. Por ejemplo, si tuvo procesos anteriores donde dio nombres falsos. Si violó las condiciones en excarcelaciones anteriores. Si realizó conductas tendientes a molestar testigos. Esto es lo más importante. Tampoco podés olvidar los criterios objetivos como la magnitud de penas en expectativa: esto procesalmente tiene mucha importancia, porque está expresamente en el CPP” (JG del Departamento Judicial de Quilmes).

Los JG siempre mencionan los requisitos del CPP, dejando en claro que hacen lo que deben hacer según la regulación legal sobre la PP. Y lo que deben hacer es pronosticar. Más allá de que los pronósticos no son competencia exclusiva de los JG, se trata de los pronósticos más decisivos a la hora de definir la aceptación o denegación de la PP para el imputado. Sin embargo, la predicción respecto de la PEE como indicador de riesgos procesales está muy lejos de perseguir los objetivos que les atribuye la literatura especializada a otros criterios predictivos como por ejemplo los criterios actuariales (O’Malley et al, 2010). Según Harcourt (2013), lo que está en el corazón de la racionalidad predictiva sobre el control del delito es el deseo de conocer al criminal, de predecir la criminalidad. Por el contrario, con la PEE lo que se hace es renunciar a conocer al imputado, o porque ya se lo conoce demasiado -en los casos de tener antecedentes- o porque no es primordial conocerlo - ya que la gravedad del delito que cometió es suficiente para saber la pena que eventualmente le correspondería.

Por su parte, los Fiscales son los que rescatan el carácter utilitario de la PEE, alegando que de no aplicarse la PP en los casos en que se aplica podría dificultarse el desarrollo del proceso frente a la elusión de los imputados. Ponen en primer lugar la necesidad de que la investigación se lleve adelante para arribar a la sentencia que el hecho amerite. Así lo sostienen:

"La pena en expectativa yo la uso. Es un argumento tramposo, pero se necesita para trabajar cotidianamente" (Fiscal de Instrucción del Departamento Judicial de La Plata).

"En la realidad es determinante la expectativa de pena. Las normas dicen que esta es un indicador de riesgo procesal. Si la pena en expectativa es baja, se trata de evitar. En general son delitos de gente que está en la lona. Y siempre que sean delitos que no engendren violencia física. Cuando hay violencia, entran las víctimas a tenerse en 
cuenta. Si hay amenazas. Hay que buscar que la víctima esté tranquila" (Fiscal de Instrucción del Departamento Judicial de Mar del Plata).

"La pena que sea superior a tres años, siempre va a ser de cumplimiento efectivo sí o sí. Y ¿cómo hacés para que un tipo excarcelado venga después solito a cumplir la pena?, porque a nadie le gusta que lo condenen, sobre todo si sabés que no vas a salir por los próximos años y medio.

ENTREVISTADOR: Y eso incrementaría el peligro de fuga...

Eso incrementaría el peligro de fuga. Por eso muchas veces se utiliza esa prisión preventiva como un adelanto de la pena futura a cumplir que sabés que le vas a imponer" (Fiscal de Instrucción del Departamento Judicial de Quilmes).

Sobre los testimonios que acabamos de exponer resulta relevante subrayar que, si bien implícitamente, aparecen presupuestos célebres que suelen utilizarse para los análisis del riesgo dentro de la justicia penal. Estos presupuestos son los de la responsabilidad individual y la elección racional, que en el caso de la PEE se aplican al presunto delincuente. Se trata de postulados que definen al delincuente como una persona que maximiza su toma de decisión y calcula cuidadosamente las ventajas y desventajas asociadas a sus actividades. La prevención, por lo tanto, está destinada a alterar ese proceso de toma de decisiones para aumentar el riesgo o el esfuerzo implicados por la comisión de un delito y disminuir cualquier recompensa asociada con éste (Crawford, 1998). Esto significa que existe alguna relación entre el razonamiento que acabamos de presentar y lo que los operadores jurídicos valoran de la PEE en tanto indicador para la imposición de la PP. Si bien no identifican explícitamente al imputado con un individuo "abiográfico" o con el "homo economicus" de la economía política clásica, por otro lado no hay demasiada preocupación por saber cuáles son las características individuales de cada uno de ellos. Volvemos a encontrar indiferencia por "el problema del individuo" cuyo delito se está investigando en detrimento del interés por conocerlo como sugiere la hipótesis de Harcourt (2013; O'Malley, 2006, 1999).

Luego de analizar la PEE vemos que hay otras cuestiones que se pueden señalar acerca del indicador más empleado para la utilización de la PP. Los documentos e informes en general afirman que

El principal criterio práctico para dictar la prisión preventiva es la pena en expectativa. Esto quiere decir que la medida cautelar será utilizada cuando la pena asignada para el 
delito que se le imputa a un procesado no parezca permitir su ejecución en suspenso. Este criterio, arraigado de forma estable en la práctica judicial de todos los circuitos judiciales del país, se encuentra avalado explícita o indirectamente en artículos precisos de los ordenamientos procesales que contradicen a los principios generales de los mismos cuerpos normativos y a los principios constitucionales y convencionales. El juego de interpretaciones que se abre en la contradicción normativa permite justificar de formas complejas y confusas la aplicación de la coerción personal en atención a la pena en expectativa" (Gutiérrez, 2013: 57).

Sin embargo, estas aseveraciones no permiten responder el interrogante que planteamos al inicio de este apartado, sobre cómo la PEE tiene un lugar preponderante en el acuerdo activo que desemboca en el uso de la PP. Está claro que no buscamos una respuesta exacta sobre las razones por las que la PEE llega a tener dicho lugar. No obstante, podemos indicar que lo hace mediante diferentes presupuestos que los actores judiciales ponen en juego para justificar la necesidad o arbitrariedad de la PP. En concreto, a través de los múltiples sentidos que dichos actores le atribuyen a la PEE en función de la PP, que como vimos son los de conjurar problemas futuros que podría generar un imputado del que se presupone que frente al costo eventual de una condena efectiva buscará fugarse y eludir la justicia, imputado sobre el cual no hay una preocupación específica por conocerlo individualmente.

\section{4- De la justicia al amor}

Por lo visto hasta aquí, podemos considerar una cuestión importante que el acuerdo entre JG y Fiscal se establece como un estado del cual el JG sale únicamente si la situación lo enfrenta con hechos en los que no se puede confirmar la existencia de un delito, o bien existiendo un delito no haya modo de vincular en su realización al imputado (Boltanski, 2000: 112). Esto último es significativo ya que si bien permite reconocer que existe una tendencia a la utilización de la PP, impide considerarla como producto de disposiciones configuradas por el ya mencionado sistema de estructuras estructuradas y estructurantes. Se trata, entonces, de competencias que despliegan los actores judiciales respecto al uso de la PP, competencias que parecen ubicarse mayoritariamente en el régimen de justicia, incluso aquellas donde la medida cautelar es denegada. Es decir, competencias que se hallan en un régimen orientado hacia la disputa 
entre quienes pugnan por la aplicación o denegación de la medida cautelar a partir de la activación de principios de equivalencia.

Sin embargo, es posible analizar esta medida cautelar a partir de otro régimen de acción, el cual ni se dirige a resolver disputas ni se basa en equivalencias. Un régimen en el que la conmensurabilidad, definida por Matza (2014: 229) como la relación imaginable entre la infracción y la sanción, es alterada. Este cambio de régimen en la modalidad de la acción se observa, en lo fundamental, cuando les solicitamos a los actores judiciales que hagan referencia a algunas anécdotas sobre la PP. Anécdotas que hubieran tenido lugar en IPP tramitadas en expedientes y en audiencias.

\subsection{El amor en las audiencias}

El cambio de régimen de acción al que apuntamos se acerca al régimen del amor (o del ágape) del que habla Boltanski. Según este autor, el régimen del amor está orientado hacia la paz, a diferencia de los regímenes de justicia y de violencia. En este régimen, las personas hacen a un lado las equivalencias, se distancian de ellas, trayéndoles aparejada la dificultad para realizar cálculos. Desde luego, la preferencia de los actores judiciales por la ausencia de cálculos está acompañada de una inclinación por el presente y un menosprecio de los riesgos procesales o sus indicadores. Aunque sólo sea temporalmente, en la paz del ágape los actores se olvidan el objeto de la controversia, los riesgos procesales pesan menos, y también se diluyen las magnitudes de las cuales ellos eran el soporte;

Las disputas en la justicia, nacidas allí donde se vinculan las personas y las cosas, se pierden en el olvido; la gente se conoce como personas sin el sostén de las equivalencias, las cuales se desvanecen junto con los objetos que les servían de soporte (Boltanski, 2000: 109).

Este régimen de amor hay que entenderlo en términos muy específicos respecto al uso de la PP. No se trata de un vínculo amoroso en sentido tradicional entre actores judiciales e imputados, sino de la puesta en práctica de un criterio muy distinto al que recurren habitualmente en el régimen de justicia. En consecuencia,

Los estados de ágape sólo resultan accesibles al análisis a condición de abordarlos mediante un desvío por la justicia. En efecto, la salida de la equivalencia en dirección del ágape puede inscribirse en un discurso por medio de desvíos hacia la justicia y, más precisamente, por la intermediación de relatos metafóricos que despejan un espacio del 
cual la justicia constituye uno de los bordes [...]. Esta propiedad está ligada a las principales características del régimen de amor en ágape: la preferencia por el presente, la preeminencia del don sobre el deseo y el rechazo de la comparación, de la totalización y del cálculo, incluso del cálculo destinado a asegurar la reciprocidad de los intercambios" (Ibíd.: 119).

Visto en conjunto, este régimen sirve para visualizar una modalidad de acción sobre la medida cautelar en la que se suspende la forma tradicional de evaluar a las personas y a los hechos, la cual no se reduce ni a una actitud estratégica inconsciente ${ }^{189}$ ni a una actitud basada en los principios de justicia. Se trata, como lo sugiere un Defensor, de algo "mágico":

"Me acuerdo una que no lo podía creer, era un delito sobre cuestión de género en la que ya se había negado la excarcelación, se había dispuesto la PP, y mágicamente, contra mis indicaciones en las que le decía al imputado que no hablase, él se pone a hablar, y hablar, y llora, y se levanta la remera y dice "a mí también me pegaba", y mostraba unas marcas en la panza. Y cuando me dí cuenta que la Fiscal y la JG lo estaban mirando con compasión, pensé "que siga adelante", y mágicamente, sin que yo pidiera nada, la PP que ya se había otorgado, y la excarcelación que ya se había denegado, fue revocada por contrario imperio. Yo me fui de esa audiencia sin entender jurídicamente qué había pasado.

ENTREVISTADOR: Y después, pensándolo, ¿qué sería?

Y, la verdad, no sé qué sería. Porque una vez que un JG resuelve, salvo que alguna de las partes le pida algo, no puede revocar por contrario imperio lo que resolvió" (Defensor Oficial del Departamento Judicial de La Plata).

Este Defensor no encontró la manera de explicar jurídicamente, es decir, a partir de la regulación legal, aquello que se terminó resolviendo en favor de su defendido. La idea de que la PP acabó por denegarse "mágicamente" lo deja ver con elocuencia. La denegación se observa como un "indulto por compasión” del que, según el Defensor, es mejor beneficiarse antes que ponerlo en cuestión. Las equivalencias, necesarias en el régimen de justicia que vimos en los dos apartados anteriores, quedan silenciadas en la situación que describe el Defensor, ya que no hay disputa entre los actores judiciales. Al

\footnotetext{
${ }^{189}$ Boltanski afirma que "para adoptar una «estrategia» es necesario disponer de un espacio de cálculo, un horizonte de tiempo, medios cognoscibles y fines identificables, por lo que la idea de estrategia inconsciente es difícil de sostener [...]" (2000: 124).
} 
basarse en la persona - del imputado-, esta decisión ya no necesita sustentarse en los parámetros que la normativa jurídica ofrece a los actores para que resuelvan sobre la PP como es el caso de los peligros procesales y sus indicadores. Y es este modo de referirse a las personas lo que además lo diferencia del modelo de argumentación que se realizan en base a las personas en las audiencias. En este modelo, las personas eran utilizadas para ir de un régimen de violencia a otro de justicia, ambos orientados hacia la disputa. El JG del siguiente testimonio permite ver con mayor claridad esta diferencia.

"En un caso de flagrancia, a un chico marginado lo imputan por el delito de robo con arma de fuego que no se había demostrado su aptitud para el disparo. La pena en expectativa es de 3 a 10 años, un delito grave, si se quiere, con cargos suficientes para justificar la preventiva. El hecho, para dar la excarcelación, sólo podía encajar en el Inc. 3 del Art. 169, porque podría ser de ejecución condicional si se lo condenara por el mínimo de 3 años. Pero por el tipo de hecho, difícilmente fueran sólo 3 años, pero hice hincapié no en las circunstancias objetivas del hecho, sino en las circunstancias personales del imputado. Era joven, de clase baja, vivía en un asentamiento, en pareja con una chica de 17 años, y tenía un bebé de un año y medio. Limpiaba vidrios, y lo sigue haciendo, en un semáforo cerca de acá [tribunales]. A todo esto, la Fiscal se oponía a la excarcelación, y dijo que el imputado había dado datos falsos sobre su domicilio, por lo que no se había sujetado al proceso, y no tenía arraigo. Frente a eso, yo tuve la posibilidad de preguntarle al imputado, y debido a la experiencia que uno va acumulando en este trabajo, me había causado buena impresión, estaba su mujer con la bebita. Y el chico explicaba muy razonablemente que vivía en un asentamiento grande, que la inundación se llevó todo. En ese contexto, le otorgué la excarcelación [...]. El chico vino a la audiencia de finalización con el certificado pasado por agua de la dirección donde vivía, lo que confirmada que antes no había mentido, demostrando la intención de sujetarse a proceso. El caso se resolvió en un juicio abreviado, con una pena de 3 años de ejecución condicional, lo que terminó convalidando mi prognosis respecto de la de la Fiscal, que luego aceptó la ejecución condicional. El chico terminó haciendo un curso de electromecánica, con la posibilidad de tener una salida laboral” (JG del Departamento Judicial de La Plata).

En este caso, para no otorgar la medida cautelar solicitada por la Fiscalía, el JG tuvo que enfrentarse a la lógica judicial que, por el tipo de delito y la PEE, obligaría a utilizarla. Se trata de un acto fuera de las equivalencias que el mismo JG sustentó en las circunstancias personales del imputado, es decir, en el hecho de que éste último le 
"había causado buena impresión”, a raíz de lo cual resolvió excarcelarlo. En un régimen de paz como en el que decidió el JG,

Las personas pueden ponerse en presencia recíproca descartando la equivalencia porque apartan también de su mundo la importancia de las cosas. Si nuestro vocabulario alcanzara y dispusiéramos de una gama suficiente de términos para designar a la gente tal como es calificada según diferentes modalidades, de hecho deberíamos reservar el nombre de personas para designar a los seres cuando se encuentran en régimen de ágape. El régimen de paz como ágape realiza a las personas en cuanto tales (Boltanski, 2000: 109).

Para ser más precisos, digamos que los actores judiciales en estos testimonios justifican las denegaciones del encierro preventivo no en la inexistencia del delito o en el irregular accionar policial, como vimos anteriormente en los expedientes y en las audiencias. Se trata de razones no jurídicas, como la compasión o la buena impresión. Esto nos permite llegar a dos conclusiones. En primer lugar, que la posibilidad para que exista la compasión o la buena impresión mencionadas por el Defensor y el JG respectivamente, surge del espacio de las audiencias. Este nuevo ámbito de visibilidad es el que habilita para decidir sobre la utilización o desestimación de la PP, sustentándose en el contacto entre los imputados y los actores judiciales que intervienen en las audiencias. Y como segunda conclusión, que estas razones no jurídicas se observan no sólo en los testimonios que pudimos recoger, sino también en los informes de organismos que han promovido y monitoreado el proceso de flagrancia ${ }^{190}$. El caso más notorio es el informe Reformas procesales en América Latina del CEJA, en el cual se afirma que es la inmediatez entre las partes la que contribuye a disminuir la aplicación de la PP. En dicho informe, un Defensor consultado asegura que

La presencia del imputado en la sala de audiencias e inclusive la de su familia parecen haber cambiado la forma de mirar el caso tanto en fiscales como jueces, asumiendo un mayor grado de responsabilidad respecto de la decisión que toman, que en el sistema escrito se divide con los empleados que proyectan sus decisiones (CEJA, 2008: 251).

\footnotetext{
${ }^{190}$ Véase Sistema Judiciales, 2009; DPLF, 2013; CIDH, 2013.
} 
Aunque este documento no es categórico respecto de la inmediatez ${ }^{191}$, sugiere que el nuevo ámbito de visibilidad generado por las audiencias es una oportunidad para conocer mejor a los imputados. Un JG citado en este trabajo dijo:

He otorgado morigeraciones que por escrito no he dado. En un caso di un cese de la medida de coerción por el delito de portación de arma de fuego que nunca hubiese concedido. Vi a la familia, la condición familiar, que el imputado no tenía antecedentes, tenía un domicilio fijo y me dio una buena impresión. Inclusive el cese fue consentido por el fiscal (Ibíd.) ${ }^{192}$.

Como puede notarse, las expresiones de los actores judiciales en el informe del CEJA reeditan los criterios no jurídicos del ágape que sugirieron los actores que entrevistamos. Asimismo, en este informe los criterios no jurídicos se valoran como una nueva herramienta para contrarrestar el uso de la PP y por ende, se estiman provechosos. Sin embargo, las benignidades adjudicadas a los criterios no jurídicos o a la cercanía con el imputado, así como las bondades de la buena impresión o a la compasión que dicho imputado consiguiese despertar, plantean un interrogante. Y es el de si esa falta de equivalencia típica del ágape no pudiese tomar la dirección contraria en otras situaciones y llevar a que los criterios no jurídicos recrudezcan la selectividad en el control del delito. Como lo planteara Malcom Feeley (2008) en sus Reflexiones sobre los orígenes de la justicia actuarial dentro de EEUU, existen consecuencias no deseadas de cambios plagados de buenos propósitos. Según sus propias palabras, hay fuertes razones para creer que con la intención de lograr mayores libertades previas al juicio lo que se logró justificar fue una dureza creciente en el tratamiento de gente supuestamente peligrosa.

Si bien no pretendemos subestimar los beneficios que la oralidad y la inmediación están en condiciones de generar en el desarrollo de los procesos de flagrancia, resulta arriesgado afirmar que a los actores judiciales les provocará "buena impresión" o "compasión" aquello que beneficie a los imputados. El optimismo que exhiben la mayoría de los informes de las ONGs debe tener en cuenta que los actores judiciales, además de por buenas intenciones, están atravesados por cuestiones como la

${ }^{191}$ En el mismo Informe se formula: "Una cuestión discutible es si la visibilización del imputado provoca una mayor 'humanización' de los operadores. Al respecto, una defensora sostuvo que no veía que generara un cambio y afirmó que 'los jueces y fiscales que eran duros antes, siguen siendo duros ahora'. Sin embargo, señaló que para los imputados "es importante verles las caras"” (Ibíd.: 259).

${ }^{192}$ En el informe también se mencionan las palabras de un Fiscal, según el cual: "Como no lo indagamos, no conocemos al imputado; por eso incide verlo en la audiencia, donde puede causar buena impresión y así acceder a alguna alternativa a la prisión preventiva" (Ibíd.: 251). 
de los saberes específicos de la institución a la que pertenecen. Si bien no estamos presuponiendo la existencia de un sistema de estructuras estructuradas que los actores judiciales han internalizado y aplican en cualquier situación, sí indicamos que estar capacitado y legitimado para enunciar razones no jurídicas ligadas al régimen del ágape depende de marcos de percepción que no son el resultado de situaciones y actividades meramente voluntarias.

\subsection{El amor por escrito}

Respecto al régimen del ágape en los cuales el instrumento utilizado durante la IPP es el expediente, surgen elementos análogos al de las audiencias. En este sentido, vale recordar que la gravedad del delito acostumbra a ser un motivo relevante para el dictado de la PP, y no sólo por la PEE sino también por la sensibilidad que es capaz de afectar. Esto significa que las equivalencias que vulnera un ilícito suelen ser tenidas en cuenta, fundamentalmente si se trata de una agresión contra la integridad sexual. Son estas equivalencias en concreto las que desactivó un JG para excarcelar a un imputado por violación.

\footnotetext{
"No se la dí [la PP] a un violador acusado de violar a la hija de un camarista, funcionaria judicial. Se había dado con un estudiante de ingeniería, del interior, y él decía que no era, pero estaba como shokceado y no aportaba pruebas, y tenía los dos reconocimiento de las víctimas positivos. Quedó preso. Vinieron de su pueblo, el intendente, diputados, senadores, el cura, le doy arresto domiciliario, el chico tenía un control social, político y religioso total. Al tiempo agarran a otro violador idéntico, muy parecido, una de las víctimas rectifica, y en juicio condenaron al otro. Nos salió bien porque apostamos por él en un delito gravísimo, socialmente asqueroso, revocamos la prisión preventiva. Si las derivaciones hubiesen sido otras, a mí me hacían juicio político, y los medios diciendo hay que terminar con el juez, por hijo de puta o coimero" (JG del Departamento Judicial de La Plata).
}

Este testimonio puede interpretarse como producto de un factor de clase, esto es, de que el JG vio alguien afín a él. Se trataba de un estudiante universitario de buen pasar, con un respaldo importante de su localidad. Se trataba de lo que en el PJ suelen 
denominar gente como uno ${ }^{193}$. Sin embargo, no parece que eso sea suficiente para analizar su decisión. Esta última se respalda no sólo en el olvido de los parámetros habituales para el uso de la PP, sino además en el olvido de los cálculos primordiales para su propia carrera judicial. En definitiva, tuvo que anclar su decisión en el presente, y no en el futuro porque "si las derivaciones hubiesen sido otras, a mí me hacían juicio político, y los medios diciendo hay que terminar con el juez, por hijo de puta o coimero".

Este régimen de amor, entonces, se aleja de las equivalencias del mismo modo que se acerca a la arbitrariedad, más allá de las derivaciones que tenga esta última para los imputados. No hay forma de instalarse en el régimen del ágape si no es a partir del olvido de las igualdades existentes en un régimen de disputa como el de la justicia. Por este motivo es que debemos ser cuidadosos con las ventajas de una ampliación del régimen del ágape, porque no es posible calcular sus consecuencias.

Sucede también que las magnitudes con las que operan los actores judiciales para decidir sobre la PP en diferentes casos son a veces incompatibles entre sí. Y tal como lo habíamos sugerido antes, es por esta incompatibilidad que deben tener la capacidad de ignorar los principios sobre los cuales apoyaron sus justificaciones en las otras situaciones donde la PP había sido concedida (Boltanski, 2000). Y es esto último lo que podemos observar en el testimonio siguiente.

\begin{abstract}
"Cuando empecé como Jueza me encontré con que tenía 10.000 expedientes, realmente, y me puse a visitar a los presos, y había gente que no podía estar presa, por el daño que se les estaba causando. Y hubo mucha gente a la que le dí la posibilidad. Es trabajoso, porque eran delitos que a simple vista no eran excarcelables, pero si mirabas el caso..., cómo había sido, pensaba si saco a este hombre, va a ser mejor. Un caso que no me voy a olvidar más: una persona, con profesión, la esposa embarazada, maestra jardinera. No andaba bien económicamente y le ofrecieron hacer algo para salvarse y les salió mal, pero no era alguien que pudiese ser peligroso para el resto, además tenía su casa, vivía ahí. Bueno, puntualmente a este hombre lo recuperé, a este hombre lo salvé de estar en Olmos. Pero bueno, a ese hombre lo vi, sino hubiese sido un expediente más (JG del Departamento Judicial de La Plata).
\end{abstract}

\footnotetext{
${ }^{193}$ En la institución judicial suele utilizarse la expresión gente como uno, o simplemente las siglas $G C U$, para hacer referencia a un sentido de pertenencia entre sus integrantes o entre estos últimos y personas que aún no trabajando en el PJ, podrían ubicarse en la misma escala social. A su vez, los actores judiciales suelen emplear esta expresión en algunos casos con humor, y en otros casos críticamente, impugnando su impronta elitista.
} 
Encontramos aquí nuevas alusiones "de clase" como la profesión o la casa que poseía el imputado. Sin embargo, esto se combina con el hecho de que la JG prioriza a la persona por sobre los principios de equivalencia, junto a un maternalismo por medio del cual "dado que no era alguien peligroso, pude recuperarlo y salvarlo del Olmos". Podría haber sido un expediente más pero mediante el régimen de ágape alcanzó a ser salvado.

A partir de estos cuatro testimonios que acabamos de transcribir y analizar, podemos sugerir algunas conclusiones del paso de la justicia en la disputa al amor en la paz respecto de la PP. En primer término, son primordialmente los JG quienes dan ese paso puesto que, en última instancia, son ellos quienes deciden sobre la pertinencia de las equivalencias en cada caso en particular. Segundo, que no hay otra forma de acercarse al régimen del ágape si no es por medio de los testimonios, porque éste régimen de acción tanto en los expedientes y como en las audiencias necesita ser traducido al lenguaje jurídico de las equivalencias. Luego, por la información que hemos recogido este paso aparentemente aumenta las posibilidades de que la PP sea denegada, aunque no podemos ser categóricos al respecto. Cuarto, que este paso de un régimen a otro tiene un potencial peligroso ya que se aleja tanto de las equivalencias como de las garantías que estas últimas ofrecen. Último, si bien puede llegarse al régimen del ágape en las audiencias y en los expedientes, lo que requiere es que el JG vea al imputado -al menos por los testimonios de los actores judiciales entrevistados-.

\section{5- A modo de cierre}

Con el desarrollo de éste capítulo pudimos observar que surgen acuerdos activos respecto de la PP por el despliegue de las competencias de los actores judiciales a partir de la injerencia de factores judiciales y extrajudiciales. En otras palabras, si bien factores internos como la carrera judicial y el desencantamiento de los operadores jurídicos con el mundo judicial, y externos como las presiones de los medios de comunicación y las autoridades políticas, tienen relevancia en la utilización de la PP, sin embargo los actores judiciales deben ponerse de acuerdo en concreto para dicha utilización. Esto significa que en el ámbito judicial no existe sólo condicionamiento, ilusión, inercia o desencanto, conclusión a la que podríamos haber llegado si sólo hubiésemos considerado al encierro preventivo como una práctica judicial compleja. 
Existen también, lo repetimos, competencias que se ponen en juego y permiten considerar a la PP como un acuerdo activo en el que los actores judiciales durante la IPP participan, más allá de que lo hagan con diferentes posibilidades de éxito en la disputa.

En primer lugar, pudimos ver que cuando Fiscales y Defensores solicitan al JG que la PP se conceda o se deniegue, lo que realizan es un reclamo de justicia por lo que cada uno de ellos considera apropiado. Esto quiere decir que las operaciones críticas van acompañadas de operaciones de justificación, puesto que la justificación es la manera como un actor judicial puede responder o anticipar la crítica de otro. A su vez, lo más importante respecto al sentido de la justicia o de la normalidad sobre la PP parece estar en la función judicial dentro de la división del trabajo junto con la ideología de los actores judiciales.

Sobre las operaciones críticas, los actores las realizan tanto en los expedientes como en las audiencias, si bien parece que en las audiencias estas operaciones tienen mayor posibilidad de ser desplegadas. Asimismo, logramos comprender las justificaciones de los actores judiciales señalando que las exigencias pueden proceder de tres cuestiones distintas: del instrumento que se utilice, de la función que se desempeñe, de la ideología que se detente. Estas tres cuestiones están en condiciones de influir en los actores a partir de la situación en la que se encuentren, y no como producto de un sistema inscripto de estructuras mentales incorporadas.

Acerca de la PEE afirmamos que se trata del indicador más relevante para la utilización de la PP. Sobre cómo la PEE tiene un lugar preponderante en el acuerdo activo que desemboca en el uso de la PP pudimos mostrar que lo hace mediante diferentes presupuestos que los actores judiciales esgrimen para justificar la necesidad o arbitrariedad de la medida cautelar. Con estos presupuestos, los actores buscan conjurar problemas futuros que podría generar un imputado, presumiendo que frente al costo de una condena efectiva el procesado buscará fugarse y eludir la justicia.

Por último, comprobamos que la PP como competencia puede analizarse dentro de un régimen de paz como el del ágape. Utilizando cuatro testimonios sugerimos algunas conclusiones del paso de la justicia (en la disputa) al amor (en la paz) respecto a dicha medida cautelar. En primer término, son los JG quienes dan ese paso puesto que se trata de quienes deciden sobre la pertinencia de las equivalencias para cada caso en particular. Segundo, no hay otra forma de acercarse al régimen del ágape si no es por medio de los testimonios, porque este régimen de acción es traducido al lenguaje jurídico de las equivalencias en los expedientes y las audiencias. Luego, por la 
información que recogimos, este paso de régimen aumenta las posibilidades de que la PP sea denegada. En cuarto lugar, que este movimiento de un régimen a otro entraña un riesgo ya que se aleja tanto de las equivalencias como de las previsiones que estas últimas ofrecen. Por último, si bien este paso puede darse en las audiencias y en los expedientes, requiere que el JG haya visto al imputado. 


\section{CONCLUSIONES}

En esta tesis nos propusimos brindar herramientas para analizar y comprender con mayor precisión el uso de la PP en la PBA durante la IPP. Tal como lo revelan las estadísticas que presentamos en el tercer capítulo, se trata de una medida cautelar por la cual están encarcelados actualmente más de la mitad de las personas en el SPB, habiendo existido períodos en los que el porcentaje de presos preventivos superó el 90\%. Establecida para asegurar los fines del proceso penal, la PP en el área bonaerense es en definitiva una medida recurrente.

Para llevar adelante nuestros propósitos utilizamos y complementamos otros enfoques con los que usualmente se han abordado el problema de la PP. Hicimos referencia a una serie de contribuciones que se refieren a los efectos que genera la utilización de esta medida cautelar en términos negativos, enfatizando a menudo los agravios que el encierro preventivo ocasiona.

La primer perspectiva que presentamos sobre la problemática de la PP fue la del enfoque dogmático, el cual se concentra en dar cuenta de que no pasa aquello que debería pasar según lo demandan las normas jurídicas, sin preocuparse centralmente por comprender por qué pasa lo que pasa respecto a la PP. Este enfoque presupone una coherencia interna del derecho que hay que salvaguardar y considera a la presunción de inocencia del imputado como el sostén del edificio jurídico que la PP debilita. La prioridad aquí es señalar aquello que no se hace como se supone tendría que hacerse sin describir ni explicar por qué se hace lo que se hace y no lo que debería hacerse.

La segunda propuesta que situamos dentro de la "hipótesis represiva" del encarcelamiento cautelar es la de los distintos documentos e informes provenientes de diferentes contextos, los cuales revelan un conjunto de regularidades al analizar el problema del encarcelamiento preventivo. Más allá de sus variaciones en Europa, EE.UU., América Latina, Argentina, y en particular la PBA, se puede hablar de la PP como una medida cautelar poco peculiar. En este sentido, dichos documentos e informes denuncian que el uso indiscriminado la PP es el corolario de decisiones políticas irresponsables $\mathrm{y}$ efectistas con un objetivo electoral predominante, junto a una injerencia cada vez mayor de los medios de comunicación en las decisiones que toman los operadores jurídicos al respecto. Si bien esta segunda perspectiva se encarga de 
llevar adelante un importante trabajo de denuncia y visibilidad de las consecuencias del fenómeno, no tiene como objetivo distinguir el modo en que se configuran las asociaciones a las que da lugar la PP. O lo que es lo mismo, prescinde de explicitar cómo se generan la serie de relaciones que el uso del encierro preventivo produce a diario entre actores judiciales y extrajudiciales.

Por último, mencionamos una tercera perspectiva que pretende estudiar la PP y su incremento en función de procesos más amplios. Esto quiere decir que la medida cautelar es apreciada como un instrumento de dinámicas sociales que se engendran en esferas alejadas de la institución judicial. Tanto quienes perciben a la PP como producto del fortalecimiento de racionalidades actuariales destinadas a la represión del delito o vinculada al ascenso de cierto populismo punitivo, como aquellos que la consideran un instrumento para neutralizar grupos riesgosos que se expanden a raíz de los cambios estructurales en el mercado laboral, terminan por mostrar a la PP y su incremento como un efecto de procesos exteriores al ámbito judicial. En consecuencia, desde este enfoque la PP no es tenida en cuenta en tanto objeto de estudio en sí mismo, sino como un fenómeno que emerge al calor de otros motivos "reales", que son los motivos que le confieren su lugar en tanto herramienta de control.

En conjunto, estas tres perspectivas sobre el encierro preventivo dieron como resultado trabajos que pasan de las teorizaciones que no tienen en cuenta los hechos a la presentación de hechos y datos sin recurrir a algún abordaje teórico, olvidando las asociaciones a las que da lugar la PP, es decir, omitiendo aquello que cotidianamente se produce entre actores judiciales y extrajudiciales a partir de su utilización. A raíz de nuestro interés en definir y evaluar a la PP principalmente por lo que genera, por lo que está en condiciones de articular, decidimos rastrear las tareas y las relaciones que esta medida cautelar motiva, por un lado, entre los mismos actores judiciales, y por el otro, entre los actores judiciales y determinados actores extrajudiciales. Una de las derivaciones más importantes del enfoque que propusimos es admitir que para que el encarcelamiento preventivo exista como existe se vuelve imprescindible que los actores hagan algo con él, que lo utilicen para justificar sus demandas, sus objeciones, sus promesas, sus resoluciones. Insinuamos entonces que la PP no es tanto una sustancia como un movimiento, puesto que sus cualidades son una consecuencia de los acuerdos activos a los que arriban JG, Fiscales y Defensores. En otras palabras, que la PP es el resultado de la acción colectiva dentro y fuera de la institución judicial. 
Teniendo en cuenta lo que acabamos de señalar, organizaremos las conclusiones a partir de la estructura que presentamos al comenzar esta tesis: un plano extrajudicial compuesto por actores que desde afuera de los tribunales aportan elementos al problema de la PP, pues son considerados importantes por los operadores jurídicos. Luego, un plano jurídico a partir del cual revisamos la regulación legal de esta medida cautelar en la PBA junto a las reformas más relevantes que atravesó dicha regulación. En tercer lugar, un plano judicial en el que describimos los modos de argumentación que los actores judiciales utilizan en la práctica, indagando las justificaciones y las críticas que ellos ofrecieron en los expedientes y las audiencias. Cuarto y último, un análisis sobre el uso de la PP que va desde las disposiciones que los actores han adquirido en el PJ hasta las competencias que despliegan en las situaciones concretas, rescatando para esto sus testimonios y prácticas.

\section{El plano extrajudicial de la prisión preventiva}

Si bien a lo largo de la tesis centramos nuestro trabajo en el despliegue judicial de la PP, consideramos indispensable señalar que existen actores extrajudiciales que influyen en esta medida cautelar según criterios e intervenciones distintas. Tal como lo dijimos en el segundo capítulo, el propósito de describir este plano es dejar en claro que si bien la PP se resuelve dentro del ámbito tribunalicio, de ningún modo puede subsumírsela por entero al mismo.

Un ejemplo claro de esto es la policía, que aparece como un factor decisivo para los actores judiciales en general, dado que con su accionar inicia el número más elevado de investigaciones penales. No obstante, surgieron desavenencias al consultarles a estos actores por el desempeño de esta fuerza de seguridad, desavenencias que en parte pueden interpretarse como producto de la división judicial del trabajo.

Los Fiscales han sido quienes presentaron mayor cercanía con la policía: si bien existe una fuerte dependencia de estos actores judiciales respecto del trabajo policial, en el trato diario parece imponerse un vínculo respaldado en la empatía más que uno marcado por el interés.

Por el contrario, los Defensores han sido quienes expresaron un pronunciado escepticismo al respecto. En la mayoría de los testimonios, porque consideraron que la policía fomenta nichos de impunidad adulterando pruebas o versiones falsas sobre determinados hechos. En algunos testimonios más esporádicos, ciertos Defensores 
además sugirieron que dicha fuerza de seguridad está en condiciones de causar crisis sensibles en el ejercicio del Poder Ejecutivo en general y en el área de seguridad en particular.

Finalmente, los JG parecieron basarse en un enfoque más estructural, en el sentido de que la agencia policial debe ser analizada en relación a otros actores y procesos que dirigen su actividad, atendiendo a los vaivenes del poder político respecto al problema de la seguridad pública.

En síntesis, podemos sostener que si bien la utilización de la PP para los imputados por algún delito se decide en el PJ, esta decisión viene precedida en la mayoría de los casos por el trabajo policial. Es este último el que habitualmente da inicio a los procedimientos en los cuales puede llegar a ser aplicado el encierro preventivo. Y según los testimonios que recogimos de los actores judiciales, este desempeño policial es evaluado, principalmente, a partir de las tareas que dichos actores realizan en el proceso.

Los medios de comunicación es otro de los actores extrajudiciales que suelen tener en cuenta los operadores jurídicos a la hora de analizar el uso de la PP, con la particularidad de que aquí el lugar que estos operadores ocupan en la división judicial del trabajo no tiene la relevancia que tenía para el caso de la policía. A partir de los testimonios fue posible plantear tres modelos con los cuales caracterizar la evaluación que hacen Defensores, JG y Fiscales de la prensa.

Al primero de los modelos lo definimos como "prensa hegemónica", en el cual se consideró muy influyentes a los medios de comunicación pasando por alto matices o especificaciones. La prensa fija límites y ejerce presiones hacia dentro del PJ, en concreto respecto a la utilización de la PP.

Otros testimonios fueron agrupados en un modelo centrado en el "voluntarismo judicial", es decir, en la percepción de que los medios de comunicación son un factor a tener en cuenta pero que es posible enfrentar. Este "voluntarismo judicial" muestra a los actores judiciales capacitados para ponerles límites a los medios, y no estos últimos como poseedores de una influencia decisiva.

El tercero de los modelos que propusimos es el que considera a los medios de comunicación como una "astucia" que los mismos operadores jurídicos utilizan para eludir las responsabilidades que debería tener aquel que trabaje en el PJ respecto de la 
PP. La prensa es la excusa ideal para evitar el compromiso necesario que se necesita para oponerse al statu quo sobre el uso de esta medida cautelar.

Una cuestión importante que estos modelos permitieron ver es que la influencia que los actores judiciales le atribuyen a los medios de comunicación es variada, cuestión que permitió debilitar la imagen de una institución judicial avasallada por la prensa, principalmente en torno al uso de la PP. Si bien hay indicios de que los medios de comunicación poseen cada vez más preponderancia, dicho incremento no es señalado como uniforme. En todo caso, dichos medios pueden redefinir ciertos problemas ligados a la PP siempre y cuando existan elementos compartidos de interés entre los actores judiciales y no judiciales.

Las autoridades políticas en la PBA han tenido una relación oscilante con el uso de la PP en particular y con el PJ en general. En un primer momento existió un acuerdo entre los actores judiciales y los representantes políticos sobre la reforma procesal del año 1998 y la limitación que esta reforma implicaba para el uso de la PP. Sin embargo, se trató de un acuerdo coyuntural que permitió advertir la fragilidad que por lo general tienen los consensos respecto a temas de seguridad, en especial la cuestión de las excarcelaciones de imputados. Esta fragilidad pareció ir configurándose por el vínculo urdido entre los representantes políticos y los medios de comunicación debido a que la presión pública que desplegaron dichos representantes la efectuaron principalmente por los medios de comunicación. Y de esto derivó la consolidación de la metáfora de la "puerta giratoria" por medio de la cual se esloganizó el problema de las excarcelaciones. Con esta esloganización los políticos se volvieron capaces de representar el peligro que significa dejar en libertad a las personas imputadas de cometer un delito y los medios de comunicación de poner en escena el riesgo potencial de una justicia tolerante con los infractores.

Tal como lo planteamos en el segundo capítulo de la tesis, el otro paso que reforzó las diferencias entre el ámbito político y el ámbito judicial fue la ejecución de las respectivas políticas criminales. Según manifestaron los operadores jurídicos tanto Gobernadores, Ministros de Seguridad como Legisladores han tenido -y siguen teniendo- criterios irreflexivos e impulsivos para enfrentar el problema de la inseguridad. Las autoridades políticas, sostuvieron los actores judiciales, promulgan medidas altisonantes de dudosa efectividad que evitan reconocer las dificultades que entraña dicho problema. De esta manera los dirigentes dejan de lado las complejidades y 
estrategias a largo plazo que demanda el problema del control del delito, dándole preferencia a las recompensas electorales rápidas. En este sentido, destacamos que para los operadores jurídicos entrevistados la PP es uno de los elementos predilectos de las autoridades políticas provinciales para conseguir ventajas inmediatas en lugar de soluciones duraderas.

Las ONGs han conseguido estructurar a la PP como un problema en la agenda pública. Como pudimos ver con el caso "Verbitsky" y con la ley 14.434, distintas agrupaciones lograron adjudicar responsabilidades en el momento en el que llevaron adelante sus demandas, ubicando al encierro preventivo en el centro de sus denuncias. El uso excesivo de la PP fue señalado como aquel que provoca una situación de sobrepoblación y hacinamiento para un gran número de presos en la PBA. Este perjuicio lo padecían internos de diversas cárceles y comisarías bonaerenses puesto que las condiciones de habitabilidad de unas y otras eran lesivas de sus derechos humanos. Según las ONGs, esa situación podía ser alterada si los tres poderes del Estado provincial se comprometían y trabajaban en conjunto para erradicar la aplicación desmesurada de la PP. Como consecuencia, los ejemplos que mencionamos sirvieron para advertir de qué manera las ONGs asumieron a partir del problema de la PP un protagonismo que les ha facilitado señalar falencias de los tres poderes del Estado en la PBA.

A partir del plano extrajudicial de la PP pretendimos brindar un panorama amplio sobre la medida cautelar en cuestión, ratificando que existen por fuera del ámbito judicial un conjunto de actores que influyen en la estructuración de este problema. Esto quiere decir que si bien el encarcelamiento preventivo se resuelve en el seno de la institución judicial entre el Fiscal, el Defensor y el JG, existen una serie de relaciones que penetran dicha institución y que por esta razón consideramos imprescindible mencionarlas. Aunque no haya consenso sobre cómo condicionan en concreto cada uno de estos actores extrajudiciales el uso de la PP, sabemos que los operadores jurídicos no son pasivos frente a las distintas intervenciones de la policía, los medios de comunicación, las autoridades políticas o determinadas ONGs. 


\section{El plano jurídico de la prisión preventiva}

El plano jurídico fue aquel que nos permitió profundizar en la historia interna de la PP que ya habíamos insinuado al hablar de la dogmática del encierro preventivo. Y justificamos su ubicación en la tesis por el hecho de que resulta ineludible detallar la regulación legal de la PP para comprender su uso en los expedientes y las audiencias, es decir, para poder dar el paso hacia el plano judicial de la medida cautelar.

Los CPP en general, y el CPP de la PBA en particular, formulan presupuestos y requisitos para que en los hechos concretos la PP pueda ser aplicada. Esta regulación nosotros la interpretamos a partir de dos criterios provenientes de los doctrinarios del derecho, criterios que ofrecen cierta afinidad con lo que puede leerse en el CPP de la PBA. El primero de estos enfoques, el "sustancialista", identifica a la PP con la ejecución de una eventual condena por adelantado. En oposición al "sustancialismo", los doctrinarios proponen un enfoque "procesalista" que postula a la PP como un instituto excepcional cuyo objetivo no es castigar al imputado sino desactivar cualquier tipo de riesgo que pueda obstaculizar la consecución del juicio y eventual ejecución de la condena. Al analizar la regulación que el CPP-PBA brinda para aplicar la PP observamos que ambos criterios, teóricamente incompatibles, conviven. En algunos artículos se exalta la libertad del imputado, circunscribiendo la posibilidad del encarcelamiento a determinados presupuestos, y en otras normas se facilita la denegación de la excarcelación ofreciendo numerosos indicadores para ello.

Tanto en un criterio como en el otro, la PP es producto de la facultad que tienen los actores judiciales para pronosticar el comportamiento de los imputados, o lo que es lo mismo, del poder para prever los riesgos procesales que les concede el CPP. Y lo que vimos al respecto es que los pronósticos y las predicciones no se respaldan en datos empíricos o en estudios probabilísticos, sino en razonamientos efectuados en base a aprendizajes locales sobre cómo deben analizarse los riesgos procesales de fuga o entorpecimiento de la investigación. Razonamientos que, según observamos, parecen priorizar indicadores sobre la PP como la PEE o la peligrosidad del imputado y no los Principios constitucionales de Inocencia o Legalidad. Sin embargo, en algunos casos los actores judiciales ofrecieron una mirada crítica al respecto, según la cual no se suelen acreditar en concreto los peligros procesales a partir de los que elaboran los pronósticos. $\mathrm{O}$ incluso que estos diagnósticos no son producto del riesgo de fuga o entorpecimiento 
en la investigación por parte del imputado, sino que son el resultado de componentes "clasistas y fascistas" que atraviesan el PJ. Estas competencias críticas de los actores fueron especialmente activadas cuando evaluaron las oscilaciones en la legislación procesal penal de la PBA a partir de la reforma estructural de la ley 11.922 en 1998.

Tal como los reconstruimos, estos vaivenes comenzaron entre los años 1996 y 1998 con el intento por limitar el uso de la PP, que va desde los debates legislativos sobre el nuevo CPP hasta su puesta en práctica. En 1999 esto parece cambiar, con un momento decisivo que es la sanción de la llamada "ley Ruckauf", y que se mantiene hasta 2005 con el paquete de "reformas Blumberg". A partir del año 2006, junto al "fallo Verbitsky" y la sanción de la ley 13.449, las excarcelaciones y medidas alternativas a la PP tuvieron un renovado alcance en la redacción de las normas procesales bonaerenses. Esta tendencia se estancó cuando se limitaron las morigeraciones u opciones al encierro cautelar a principios de 2009 agravado por el intento de consagrar delitos no excarcelables a comienzos de 2013. Lo que pudimos observar a partir de las cifras sobre presos preventivos a los largo de estos cuatro períodos es que no existe una relación directa entre retórica política, tasas de encarcelamiento y utilización de la PP. Si bien los indicadores disponibles no han sido suficientes para analizar concluyentemente los factores que estructuran la relación entre cambios legislativos y la aplicación de la PP, sí permitieron ver, por ejemplo, que reformas como la "ley Ruckauf" considerada contra-reformistas no provocó un mayor porcentaje de presos preventivos en los lugares de encierro en la PBA. O que fallos progresistas como el del caso "Verbitsky", no logró disminuir dicho porcentaje -más allá de haber podido favorecer la caída en el número de personas encarceladas-. En este sentido, muchos eventos destacados en los informes y documentos de las ONGs tienen efectos menos evidentes de los que suelen atribuirle.

Por su parte, los actores judiciales perciben a estas reformas procesales de manera diversa, en especial cuando las relacionan con el uso del encierro preventivo. Si bien es posible notar que los cambios en la regulación procesal de la PP y las excarcelaciones tienen un lugar significativo en el análisis de estos actores, en algunos casos es considerado como un factor que posee cierta autonomía para generar un mayor uso de la PP. En otros casos, las reformas procesales aparecen como un indicador de las formas contradictorias con las que las autoridades estatales y sus diversas agencias han respondido al dilema del delito y la PP. Respuestas que, según los actores judiciales, han eludido la complejidad de este dilema buscando resultados ventajosos a corto plazo. 
En definitiva, en el plano jurídico vimos que el CPP está atravesado por los dos criterios propuestos por la doctrina para entender la regulación de la PP: tanto el sustancialismo como el procesalismo se encuentran presentes. Y que esta regulación legal se sustenta en la posibilidad de anunciar el futuro, es decir, en la facultad que tienen los actores judiciales para predecir el comportamiento ulterior del imputado. Además, en la PBA la legislación sobre la PP ha ido cambiando sucesivamente, lo que trajo aparejado más problemas que soluciones según lo testimonian los mismos actores.

\section{El plano judicial de la prisión preventiva}

Al analizar el uso de la PP en el ámbito judicial buscamos especificar qué ocurre específicamente con la medida cautelar, o lo que es lo mismo, intentamos analizar lo que hacen en la práctica los actores judiciales cuando exponen sus posturas respecto al encierro preventivo. Y para llevar adelante este análisis observamos dichos expedientes y audiencias y los agrupamos en una serie de modelos que nos facilitaron localizar los argumentos por medio de los cuales los JG, Fiscales y Defensores dan sus puntos de vistas. Esta decisión permitió identificar y comparar los principios válidos a los que recurren los operadores jurídicos a la hora de justificar sus posiciones en diferentes disputas en las que la PP estuvo presente. En definitiva, nos acercamos a la serie de relaciones que el pedido de esta medida cautelar instaura junto a las exigencias que este pedido impone, considerando a la PP como resultado de un acuerdo activo a realizar entre estos actores judiciales.

Respecto de los expedientes sostuvimos que contribuyen a organizar el trabajo dentro del ámbito judicial ya que en ellos se describen hechos, jerarquizan explicaciones, evidencian capacidades y delimitan responsabilidades. Además, los expedientes nos permitieron observar bajo qué manifestaciones la medida cautelar es solicitada, aceptada o rechazada, siendo estas manifestaciones las que hicieron posible rastrear el movimiento de la PP en este instrumento dentro del PJ. Para examinar las referidas justificaciones empezamos por el pedido que realizan los Fiscales, ya que la sucesión de argumentos sobre la PP se inicia con su solicitud, y porque además estos fundamentos deberían tener en cuenta las eventuales críticas que pudieran efectuarle tanto la Defensa del imputado como el JG.

Los modelos propuestos permitieron verificar distintos grados de condicionamiento que los operadores jurídicos reflejaron en la situación en que se 
hallaban para lograr que los requerimientos en el caso de los Fiscales, y las aceptaciones o denegaciones en el caso de los JG, sean consideradas admisibles.

El primero es un modelo de argumentación en base a la ley, lo que significa que aquí la PP fue solicitada y concedida respecto a uno o dos de los riesgos procesales que requiere el CPP.

El segundo se llevó adelante en base a un acuerdo tácito, es decir, un modelo en el que la medida cautelar fue pedida y otorgada sin que se mencionen en las justificaciones ni el peligro de fuga ni el entorpecimiento en la investigación.

El tercer modelo se compuso de acuerdos en disidencia, acuerdos en los cuales los argumentos de los Fiscales y de los JG no coincidían, sin embargo la PP es aplicada de todos modos.

El cuarto y último de los modelos fue en el cual el encarcelamiento preventivo no es otorgado, y según los expedientes consultados esto ocurrió cuando el Fiscal no demostró o la existencia del delito o que el imputado haya participado posiblemente en este último.

Para el caso de la circulación de la PP en las audiencias mencionamos que el empleo de estas últimas durante la IPP generó modificaciones en el uso de la PP, dado que los planteos allí se realizan oralmente y en presencia de los otros actores judiciales. Nos pareció importante cómo surgió y se consolidó el proceso de flagrancia a partir del cual se implementaron las audiencias tempranas. En julio de 2005 se lanzó un plan piloto en el DJ de Mar del Plata que fue considerado exitoso por las autoridades y los responsables que lo llevaron adelante, lo que hizo posible que el proceso de flagrancia se estableciera en toda la PBA. Y sobre dicho proceso, señalamos que la evaluación de los operadores jurídicos estuvo guiada, al menos primordialmente, por la función que cumplen en la división judicial del trabajo. Los Defensores han sido quienes ofrecieron las críticas más severas, los JG quienes manifestaron mayor equilibrio entre las ventajas y perjuicios, y los Fiscales quienes se declararon más conformes, recurriendo incluso a un vocabulario consonante al que utilizaron los reformadores para la promoción del proceso de flagrancia.

Tal como lo hicimos con los expedientes, para las audiencias también elaboramos modelos que nos ayudaran a describir mejor la serie de relaciones que instaura el pedido de la PP, junto a las exigencias que este pedido impone. 
Con el modelo caracterizado por argumentos en base a la velocidad mostramos que a la hora de justificar el encierro preventivo, tanto Fiscales como JG apelan al vocabulario con el que el proceso de flagrancia se impulsó, utilizando a la velocidad para solicitar y conceder la PP.

El segundo modelo se configuró en base a las personas y mostró cierta afinidad respecto del positivismo criminológico, ya que puso como principal argumento a los imputados invocando los peligros procesales a partir del comportamiento previo de quienes se está investigando.

En el tercer modelo cuyo eje son los delitos, los argumentos en las audiencias se sustentaron en la correspondencia que los actores judiciales observaron entre la gravedad de la conducta ilícita realizada y la aplicación del encierro preventivo.

En el último de los modelos no se hizo lugar a la aplicación de la PP, dado que la actuación policial despertó desconfianza en la Defensa y el JG. O en otras palabras, la Defensa logró persuadir al JG que la policía empleó algún modo fraudulento de investigar en la causa.

A partir del plano judicial procuramos explorar a la PP como una competencia que desarrollan los JG, Defensores y Fiscales al promover justificaciones y acuerdos activos. Tanto los expedientes como las audiencias fueron agrupados en modelos que permitieron identificar los argumentos que los actores judiciales utilizaban para desplegar la PP a lo largo de la IPP. Estos argumentos decidimos trascribirlos y no traducirlos en función de nuestra interpretación. Con esta decisión no pretendimos minimizar los efectos perjudiciales que la utilización de la PP ocasiona como consecuencia del encarcelamiento de personas jurídicamente inocentes en la PBA. Al ir más allá de las reprobaciones con las que se presenta al encierro preventivo cuando sólo se intenta criticar su uso, lo revalorizamos como una práctica que produce relaciones entre los actores judiciales que intervienen en los expedientes y en las audiencias.

\section{El plano en conjunto de la prisión preventiva}

Al llegar a los dos últimos capítulos de la tesis buscamos complementar los resultados que habíamos conseguido en el plano judicial de la PP con los testimonios de los actores judiciales, utilizando para ello los enfoques propuestos en el marco teórico. En este sentido, articulamos lo que estos actores hacían en los expedientes y las 
audiencias con lo que formularon en las entrevistas en torno al uso de la medida cautelar. Como consecuencia de lo anterior, pudimos presentar un plano en conjunto con el cual describir y analizar más en detalle las relaciones y exigencias que instaura el pedido de la PP. Señalamos además que en una institución como el PJ los actores están en condiciones favorables para hablar acerca de lo que hacen con la PP, identificando y clasificando prácticas y saberes. Y que esto sucede, entre otras cosas, porque la misma institución judicial es la que respalda dichas prácticas y saberes volviéndolos visibles y determinables. En síntesis, advertimos que los operadores jurídicos encuentran relaciones entre elementos importantes que gravitan en el uso de la PP, como por ejemplo los parámetros legales nominados (Principio de Inocencia, peligros procesales) y los factores extralegales emergentes (medios de comunicación, autoridades políticas).

En el primero de estos capítulos, planteamos que la PP es una práctica judicial compleja que hay que estudiar como producto de las relaciones que se desarrollan entre elementos judiciales y extrajudiciales, elementos de los que prescinde la dogmática jurídica debido a que evalúa sólo cuestiones formales de la medida cautelar.

Al respecto, comenzamos por destacar los elementos judiciales que hay que tener en cuenta para comprender el uso de la PP, entre los que señalamos al débil control institucional que existe para limitarla junto a la motivación presente en el PJ para aplicarla. En cualquier caso, se trata de dos variables importantes para esclarecer la “ecuación” de la PP.

Posteriormente hicimos mención al desencantamiento de los actores judiciales que aparece, según algunos de sus testimonios, como consecuencia tanto del declive del prestigio dentro del PJ como por la percepción de cambios considerados ilegítimos en su organización. Estos actores parecen experimentar como indebidos los cambios, los cuales podrían ser evitados si los responsables judiciales y políticos hicieran otra cosa. Si bien estas formulaciones provienen en gran medida de operadores jurídicos que trabajan en el PJ desde antes de la reforma de 1998, lo que consideramos importarte destacar es que el desencantamiento del que hablamos genera menos compromisos respecto a la utilización de la PP. Y esto último porque buscan evitar quedar expuestos dentro de una institución judicial que parece mostrar cada vez menos autonomía.

De los elementos extrajudiciales, tanto los medios de comunicación como los representantes políticos son destacados por los actores judiciales para analizar el desempeño de la justicia penal en general, y el uso de la PP en particular. Estos 
componentes que están por fuera del PJ influyen, además, en la pérdida de autonomía del PJ. Para algunos operadores jurídicos esta mayor influencia es la causa de la erosión de dicha autonomía, a raíz de que fueron los medios de comunicación y los representantes políticos los que la generaron. Para otros operadores, en cambio, sólo después del declive de dicha autonomía del PJ tanto los medios como los políticos estuvieron en condiciones de incrementar su influencia. Y es en este escenario de mayor debilidad de la institución judicial que la PP se brinda como una respuesta disponible, sugerida y avalada por esta misma institución, limitando la posibilidad de recurrir a otras respuestas frente a sucesos similares.

Al pasar de las disposiciones que provocan los elementos judiciales y extrajudiciales en los operadores jurídicos a las competencias que estos últimos despliegan para lograr acuerdos en torno a la PP, logramos mostrar un sentido de lo que dichos operadores consideran como justo e injusto a la hora de solicitar, objetar, conceder o denegar la PP. Y que los factores que limitan o condicionan el comportamiento de los actores judiciales se inscriben en las situaciones en las que dichos actores desempeñan sus competencias, y no como determinaciones que estos actores han interiorizado de una vez y para siempre. Como consecuencia de lo dicho, los criterios que utilizan los JG, los Fiscales y los Defensores para sopesar la necesidad de la PP no surgen, fundamentalmente, de un sistema de disposiciones incorporadas y transferibles, sino de los diferentes contextos en los que se ponen en acción las escalas que guían las decisiones sobre el uso de la PP.

Las escalas a las que nos referimos forman parte de un orden general que los actores judiciales no consideran arbitrario dado que descansa en la presencia de principios a partir de los cuales ellos logran acuerdos en cada caso. Esto significa que frente a toda solicitud, existen principios comunes que les posibilitan dirimirla dentro de un régimen de justicia, régimen en el cual las soluciones se logran por medio de la argumentación.

Lo que pudimos confirmar tomando en cuenta lo que acabamos de decir es que son los indicadores de riesgos procesales como por ejemplo la PEE, la violencia que entrañe el delito o la reincidencia, los que configuran el orden de las escalas que están presentes en las situaciones y que apoyan las decisiones sobre el uso o no de la PP.

Señalamos también que los acuerdos activos acerca de la PP suelen ser más frecuentes entre Fiscales y JG, es decir, entre quien investiga y quien controla la investigación, postergando el papel que puede ejercitar la Defensa. 
A partir de algunos testimonios confirmamos una cuestión que ya habíamos advertido en uno de los modelos de argumentación en los expedientes: que la PP se solicita y se concede sólo en los casos, según esos mismos testimonios, en que están presentes los requisitos estipulados en el CPP.

Conjuntamente, y matizando la afirmación del párrafo anterior, notamos que no pocas veces los operadores confunden los riesgos procesales, únicos que pueden justificar según el CPP la aplicación de la PP, con los indicadores de esos riesgos. Es decir, asimilan el peligro de fuga o el entorpecimiento en la investigación con los elementos que podrían servir como indicadores para pronosticar alguno de esos riesgos, como es el caso de la PEE, los antecedentes del imputado, su falta de arraigo, etc.

Ahora bien, en el último capítulo de la tesis sostuvimos que los elementos judiciales y extrajudiciales sobre los que trabajamos a lo largo de la tesis contribuyen a configurar las situaciones en las que se llega a un acuerdo activo por el uso o la denegación de la PP. O lo que es lo mismo, si bien existen factores internos como la carrera judicial y el desencantamiento de los operadores jurídicos, y externos como los medios de comunicación y las autoridades políticas, no obstante los actores judiciales debieron ponerse de acuerdo en concreto para resolver sobre la medida cautelar en cuestión. Esto quiere decir que en el ámbito judicial no existe sólo condicionamiento, ilusión, inercia o desencanto, conclusión a la que podríamos haber arribado si hubiésemos considerado al encierro preventivo únicamente como una práctica judicial compleja.

Una de las posibilidades para observar las competencias de los actores judiciales ha sido cuando Fiscales y Defensores solicitan al JG que la PP se conceda o se deniegue, momento en el cual realizan un reclamo de justicia por lo que cada uno de ellos considera apropiado. Y algo tan importante, o más tal vez, respecto a este reclamo de justicia sobre la PP lo encontramos en la relación que tiene con la función judicial dentro de la división del trabajo junto con la ideología de los actores judiciales. De acuerdo con esto, podemos decir que en términos generales Defensores, Fiscales y JG valoran de manera diferente al encierro preventivo, valoración que a su vez está atravesada por las convicciones -no necesariamente jurídicas- que estos actores detentan sobre la función que la PP tiene como herramienta.

Recordemos también que estas valoraciones forjadas por la función judicial y la ideología de los operadores jurídicos se actualizan como consecuencia de la 
investigación de un delito, es decir, de un hecho que se aparta del orden aceptado normalmente como legítimo. Más allá de la selectividad en el control del delito, es necesario tener en cuenta que con el uso de la PP se trata de recomponer un equilibrio perturbado por la comisión de un delito, por la producción de un daño concreto inaceptable.

Acerca de las operaciones críticas que realizan los actores judiciales, más allá de que las realicen tanto en las audiencias como en los expedientes, tienen mayor posibilidad de ser efectuadas en las audiencias por la presencia simultánea de estos actores en un mismo espacio, lo que facilita el intercambio fluido de argumentos.

Por lo tanto, estamos en condiciones de sugerir que las orientaciones que inciden en los actores judiciales pueden proceder de tres cuestiones distintas: de la función que desempeñen, de la ideología que detenten, del instrumento que utilicen. Se trata de tres factores que son capaces de influir en los actores a partir de la situación en la que se encuentren.

Con respecto a la PEE demostramos que es el indicador más significativo para justificar la necesidad de la PP. En relación a la manera en que la PEE adquiere un lugar preponderante en el acuerdo activo que desemboca en el uso de la PP pudimos señalar que lo hace mediante diferentes presupuestos que los actores judiciales esgrimen para argumentar la necesidad o arbitrariedad de la medida cautelar. Con estos presupuestos, los actores buscan evitar problemas ulteriores que podría ocasionar un imputado, pronosticando que frente al costo de una condena efectiva este imputado buscará escaparse y eludir la justicia.

Posteriormente, vimos que la PP como competencia puede analizarse no sólo desde un régimen orientado a la disputa como es el caso de la justicia, sino también dentro de lo que Boltanski define como un régimen de paz como el del ágape. Este último sirve para visualizar una modalidad de acción sobre la medida cautelar en la que se interrumpe la forma habitual de apreciar a las personas y a los hechos, modalidad que no se limita ni a una actitud especulativa ni a una actitud sustentada en los principios de justicia compartidos.

A partir de una serie de testimonios propusimos cuatro puntos sobre el paso de la justicia (en la disputa) al amor (en la paz) respecto a dicha medida cautelar. El primero tiene que ver con que los JG son quienes dan ese paso puesto que se trata de aquellos 
que deciden sobre la pertinencia o desactivación de las equivalencias para cada caso en particular. Segundo, no advertimos otra forma de acercarnos al régimen del ágape que no sea por medio de los testimonios, porque este régimen de acción en los expedientes y las audiencias es traducido al lenguaje jurídico de las equivalencias. En tercer lugar, este paso de régimen aumenta las posibilidades de que la PP sea denegada, al menos por lo que nosotros pudimos recoger. Cuarto, que el desplazamiento de un régimen de justicia a uno de amor tiene un potencial peligroso ya que deja de lado las equivalencias junto con las garantías que estas últimas brindan. Último, este paso puede darse tanto en las audiencias como en los expedientes, siendo imprescindible que el JG haya visto al imputado.

Al inicio de esta investigación nos trazamos como objetivos identificar los actores judiciales y extrajudiciales que hayan participado en la configuración de la PP como un problema público a partir de la sanción del nuevo CPP-PBA. Luego, caracterizar la medida cautelar desde un punto de vista jurídico abarcando tanto los cambios legislativos que se dieron desde la ley 11.922 respecto de la PP como los efectos que esto pudo haber provocado en los porcentajes de presos preventivos. Además, indagar los argumentos que los actores judiciales ofrecieron en los expedientes y en las audiencias para justificar su posición respecto a la PP. Por último, recuperar los testimonios que los actores judiciales brindaron sobre la PP y analizarlos a partir del marco teórico elegido. Ahora podemos decir que la tarea la realizamos explorando los distintos planos que componen el problema de la PP, junto al modo en que estos planos se articulan en la práctica. 


\section{BIBLIOGRAFÍA}

ADC. (2011). La prisión preventiva en la Argentina, ¿cuánta información tenemos?, disponible en http://www.adc.org.ar/sw_seccion.php?id_categoria=8

ADC. (2012). Prevenir no es curar, EMEPE, Bs. As.

ADC. (2012b). Uso abusivo de la prisión preventiva en las Américas, Informe presentado en el $146^{\circ}$ período de sesiones de la Comisión Interamericana de Derechos Humanos

Anitua, G. (2006). Historias de los pensamientos criminológicos, Del Puerto, Bs. As. Arzadún, D. (2005). "Las instituciones policiales en la Argentina", en Tiempos inclementes, UNLa., Bs. As.

Arslanian, C. (2008). Un cambio posible, Edhasa, Bs. As.

Baradaran, S. y McIntyre, F. (2012). Predicting Violence, Texas Law Review.

Baratta, A. y Silbernagl, M. (1985). La legislación de emergencia y el pensamiento jurídico garantista en el proceso penal, en Doctrina Penal N³2, Depalma, Bs. As.

Baratta, A. (2004). Criminología crítica y crítica del derecho penal, Siglo XXI, Bs. As.

Baratta, A. (2004b). Criminología y sistema penal, B de F, Bs. As.

Barrera, L. (2007). Del "Campo" a la "Red": una mirada a la Corte Suprema Argentina desde una epistemología de estudios de Ciencia y Tecnología, disponible en http://seminariounlpam.blogspot.com.ar

Barrera, L. (2008). La circulación de expedientes y las formas de los expertos legales: agencia y sujeto en la Corte Suprema argentina, disponible en http://www.palermo.edu

Barrera, L. (2011). Más allá de los fines del derecho: expedientes, burocracia y conocimiento legal, disponible en http://www.flacso.org.ec

Barrera, L. (2011). La corte suprema en escena, Siglo XXI, Bs. As.

Beccaria, C. (1993). Del delito y de las penas, Heliasta, Bs. As.

Becker, H. (2005). ¿De qué lado estamos?, en Delito y Sociedad, No 21, Buenos Aires

Becker, H. (2009). Outsiders, Siglo XXI, Bs. As.

Becker, H. (2009b). Trucos del oficio, Siglo XXI, Bs. As.

Bentham, J. (2008). Los Principios de la Moral y la Legislación, Claridad, Bs. As.

Bergalli, R. (2002). Presentación a El nuevo paradigma criminológico de la exclusión social, Barcelona, I/XVIII 
Bergalli, R. (2003). Sistema penal y problemas sociales, Tirant lo blanch, Valencia.

Bergalli, R. (2004). Presentación a Pena y estructura social, Temis, Bogotá.

Beirne, P. (2002). Hacia una ciencia del homo criminalis. De los delitos y de las penas de Cesare Beccaria, en Nueva Doctrina Penal, Buenos Aires, pp. 3-49

Binder, A. (2009). El control de la criminalidad en una sociedad democrática. Ideas para una discusión conceptual, en G. Kessler (comp.), Seguridad y ciudadanía, Edhasa, Bs. As.

Blumer, H. (1971). Social problems as collective behavior, en Social Problems, ${ }^{\circ} 18$

Blumer, H. (1982). El interaccionismo simbólico: perspectiva y método, Hora, Barcelona.

Boltanski, L. (2000). El amor y la justicia como competencias, Amorrortu, Bs. As.

Boltanski, L. (2005). Usos débiles y fuertes del habitus, en Pierre Encrevé et RoseMarie Lagrave, Trabajar con Pierre Bourdieu, Universidad Externado de Colombia, Bogotá, pp. 167-176.

Boltanski, L. y Chiapello, È. (2002). El nuevo espíritu del capitalismo, Akal, Madrid.

Bourdieu, P. (1972). Esquisse d'une théorie de la pratique, Droz, Genève, p. 162-164

Bourdieu, P. (1990). Sociología y cultura, Grijalbo, México.

Bourdieu, P. (1991). Los juristas, guardianes de la hipocresía colectiva en http://www.historiayderecho.com.ar/constitucional/bourdieu1.pdf

Bourdieu, P. (2001). Poder, derecho y clase social, Desclée, Bilbao.

Bourdieu, P. (2007). El sentido práctico, Siglo XXI, Bs. As., 2007

Bourdieu, P. y Boltanski, L. (2009). La producción de la ideología dominante, Nueva Visión, Bs. As.

Bourdieu, P. y Wacquant, L. (2005) Una invitación a la sociología reflexiva, Siglo XXI, Bs. As.

Bovino, A. (1998). Problemas del derecho procesal penal contemporáneo, Del puerto, Bs. As.

Bovino, A. (2005). Contra la inocencia, disponible en www.derechopenalonline.com.ar Cabrera, S. (2005). Pena y prisión preventiva, Urbe et ius, Año I.

Cafferata Nores, J. (1992). Medidas de coerción en el nuevo Código Procesal Penal de la Nación, Depalma, Bs. As.

Caimari, L. (2004). Apenas un delincuente, Siglo XXI, Bs. As.

Calzado, M. (2006). Elementos para el análisis del tratamiento mediático del caso Blumberg, consultado el 10 de noviembre de 2012 en www.flacso.org.ar 
Camou, A. y Moreno, J. (2005). Crisis, reforma y contrarreforma..., en Tiempos inclementes, UNLa., Bs. As.

Carranza, E. y otros. (1982). El "preso sin condena” en América Latina y el Caribe, en “Doctrina Penal”, Ed. Depalma, Bs. As.

Carranza, E. (1999). Estado actual de la prisión preventiva en América Latina y su comparación con los países de Europa, Revista de la Asociación de Ciencias Penales, N 16, San José, p. 81-88

Carranza, E. (2001). Justicia penal y sobrepoblación penitenciaria, Siglo XXI, México. Carrasco Solís, J. (2009). Servicios de evaluación de riesgos y supervisión: mecanismos para el manejo de las medidas cautelares, CEJA, Santiago de Chile.

Castel, R. (2006). La inseguridad social, Manantial, Bs. As.

Cefai, D. (2014). Investigar los problemas públicos: con y más allá de Joseph Gusfield, en J. Gusfield, La cultura de los problemas públicos, Siglo XXI, Bs. As.

CEJA. (2008). Reformas procesales en América Latina: resultados del proyecto de seguimiento $V$ etapa, disponible en http://www.cejamericas.org/portal/index.php/es/biblioteca/bibliotecavirtual/cat_view/43-documentos/63-experiencias-de-innovacion?start=5

CEJA. (2009). Prisión preventiva y reforma procesal en América Latina (Volumen I), CEJA, Santiago.

CEJA. (2011). Prisión preventiva y reforma procesal en América Latina (Volumen II), CEJA, Santiago.

CELS. (1998). La inseguridad policial, Eudeba, Bs. As.

CELS. (2004). Politicas de seguridad ciudadana y justicia penal, Siglo XXI, Bs. As.

CELS. (2005). Colapso del sistema carcelario, Siglo XXI, Bs. As.

CELS. (2007). Derechos humanos en la Argentina: informe 2007, Siglo XXI, Bs. As.

CELS. (20010). El uso de la información estadística y la forma de definir el problema de la prisión preventiva, disponible en http://www.cels.org.ar, 2010

CELS. (2010b). Derechos humanos en la Argentina: informe 2010, Siglo XXI, Bs. As.

CELS. (2011). Derechos humanos en la Argentina: informe 2011, Siglo XXI, Bs. As.

Cerruti, P. (2009). "Víctimas y movilización política en la Argentina contemporánea", ponencia presentada en XXVIII Congreso Internacional de la Asociación de Estudios Latinoamericanos, Río de Janeiro, 11 al 14 de junio de 2009.

CIDH. (2013). Informe sobre el uso de la prisión preventiva en las Américas, consultado el 10 de abril de 2013 en http://www.oas.org/es/cidh/ppl/informes/pdfs/InformePP-2013-es.pdf 
CIPPEC. (2011). ¿Qué criterios están en juego a la hora de aplicar la prisión preventiva en la provincia de Buenos Aires?, Documento de Trabajo No 74, Bs. As.

Ciocchini, P. (2010). La Gestión Del Tiempo En La Justicia Penal De La Provincia De Buenos Aires, XI Congreso de Sociología Jurídica, U.B.A.

Ciocchini, P. (2013). Tiempo de justicia, Tesis Doctiral, Onate

Commission de suivi de la détention provisoire. (2007). RAPPORT 2006, Février.

Corcuff, P. (2005). Lo colectivo en el desafio de lo singular: partiendo del habitus, en

B. Lahire, El trabajo sociológico de Pierre Bourdieu: deudas y críticas, Siglo XXI, Bs. As.

Corcuff, P. (2008). Figuras de la individualidad, en Revista Cultura y representaciones sociales $\mathrm{N}^{\circ}$ 4, México, págs. 9-41

Corcuff, P. (2010). Los procesos de individualización en las ciencias sociales, en Revista Cultura y representaciones sociales $\mathrm{N}^{\circ}$ 8, México, págs. 7-33

Corcuff, P. (2013). Las nuevas sociologías, Siglo XXI, Bs. As.

Crawford, A. (1998). Crime Prevention and Community Safety: Politics, Policies and Practices, Longman, Harlow.

Chateauraynaud, F. (2005). La coacción argumentativa. Las formas de coacción en los marcos deliberativos y las potencialidades de expresión política, GSPR-EHESS, Revista Europea de Ciencias Sociales.

Christie, N. (1993). La industria del control del delito, Del Puerto, Bs. As.

Christie, N. (2004). Una sensata cantidad de delitos, Del Puerto, Bs. As.

Dammert, L. (2005). Reforma policial y participación militar en el combate a la delincuencia en Revista Fuerzas Armadas y Sociedad, Año 19, № 1, pp. 133-152

Dammert, L. (2008). Seguridad Privada ¿respuesta a las necesidades de seguridad pública en conglomerados urbanos?, OEA.

Dammert, L. (2009). Politicas públicas de Seguridad Ciudadana: Innovaciones y desafios, en G. Kessler (comp.), Seguridad y ciudadanía, Edhasa, Bs. As.

Daroqui, A. y Guemureman, S. (2008). Administración punitiva de la exclusión, IX Congreso Nacional de Sociología Jurídica.

Da Rocha, J. y De Luca, J. (2011). La prisión preventiva como anticipo de pena en América Latina, Ad-Hoc, Bs. As.

De Giorgi, A. (2006). El gobierno de la excedencia, Traficantes de sueños, Madrid.

Demirović, A. (2008). Crítica y verdad, recuperado de http://eipcp.net/transversal/0808/demirovic/es 
Díaz, E. (1965). Sociología jurídica y concepción normativa del derecho, Revista de Estudios Políticos Nro 143.

Dodier, N. (1993). Les appuis conventionnels de l'action, Réseaux, Pág. 63-86

Downes D. y Rock, P. (2010). Sociología de la desviación, Gedisa, México.

DPLF. (2013). Independencia judicial insuficiente, prisión preventiva deformada, DPLF, Washington.

Duce, M. y Riego, C. (2010). Prisión preventiva y nueva justicia penal en Chile, CEJA, Santiago de Chile.

Dünkel F. y Vagg J. (eds.) (1994).Waiting for Trial: International Perspectives on the Use of PreTrial Detention and the Rights and Living Conditions of Prisoners Waiting for Trial, Instituto Max Planck, Friburgo.

Durkheim, E. (1982). Las reglas del método sociológico, Hyspamerica, Madrid.

Durkheim, E. (1999). Dos leyes de la evolución penal, en Revista Delito y Sociedad, $\mathrm{N}^{\circ} 13$, pp. 71-90.

Durkheim, E. (2004). La división del trabajo social, Libertador, Bs. As.

Dutil C. y Ragendorfer, R. (1997). La bonaerense, Planeta, Bs. As.

Elías, N. (1998). La civilización de los padres y otros ensayos, Norma, México.

Estévez, E. (2010). La reforma de inteligencia en el contexto de la reforma policial en la provincia de Buenos Aires, disponible en http://www.portalseguridad.org.

Eymard-Duvernay, F. (1994). Economía de las convenciones, Asociación Trabajo y Sociedad, Bs. As.

Feeley, M. y Simon, J. (1995). La nueva penología, en Delito y Sociedad. Revista de Ciencias Sociales. $N^{\circ}$ 6/7. Bs. As.

Feeley, M. (2007). The process is the punishment, Rusell Sage Foundation, New York Feeley, M. (2008). Reflexiones sobre los orígenes de la justicia actuarial, en Delito y Sociedad N²6, pp. 19-36

Ferrajoli, L. (1989). Derecho y razón, Trotta, Madrid

Ferri, E. (1907). Sociología Criminal Tomo I, Madrid, Editorial de Góngora

Ferri, E. (1907b). Sociología Criminal Tomo II, Madrid, Editorial de Góngora

Foucault, M. (1992). Microfísica del poder, La Piqueta, Madrid

Foucault, M. (2002). Historia de la sexualidad, Siglo XXI, Bs. As.

Foucault, M. (2003). Vigilar y castigar, Siglo XXI, Bs. As.

Foucault, M. (2004). Seguridad, territorio, población, FCE, Bs. As.

Foucault, M. (2007). El nacimiento de la biopolítica, FCE, Bs. As. 
Frederic, S. (2009). Comentario a La dinámica de delito-policía en los procesos de reforma policial en G. Kessler (comp.), Seguridad y ciudadanía, Edhasa, Bs. As.

Fucito, F. (2001). ¿Podrá cambiar la Justicia en la Argentina?, FCE, Bs. As.

Ganon, G. (2006). ¿La macdonalización del sistema de justicia criminal? Nuevo orden o nuevo derecho en la globalidad de la sociedad excluyente, Revista Pensamiento Penal, edición 60.

García Inda, A. (1997). Las violencia de las formas jurídicas, Cedecs, Barcelona

Garfinkel, H. (1996). Estudios en etnometodología, Anthropos, Madrid

Garland, D. (2001). The culture of control, University of Chicago Press.

Garland, D. (2005). La cultura del control, Gedisa, Barcelona.

Garland, D. (2006). Castigo y sociedad moderna, Siglo XXI, México.

Garland, D. (2006b). Las contradicciones de la sociedad punitiva, en Delito y Sociedad. $\mathrm{N}^{0}$ 22. Bs. As.

Garland, D. (2007). Crimen y castigo en la modernidad tardía, Siglo del Hombre, Bogotá.

Garland, D. (2010). Los conceptos de cultura en la sociología del castigo, en Delito y Sociedad. No 30 , Bs. As.

Garland, D. (2013). Una institución peculiar, Didot, Bs. As.

Garland, D. y Sparks, R. (2000). Criminology, social theory and the challenge of our times en Criminology and Social Theory, Oxford University Press, New York.

Garófalo, R. (1912). La criminología, Daniel Jorro, Madrid.

Giddens, A. (1987). El La constitución de la sociedad, Amorrortu, Bs.As.

Godoy, J. (1990). La lógica de la escritura y la organización de la sociedad. Alianza

Editorial, Madrid.

Gómez Urso, J. y Paolini, R. (2008), La oralidad en la investigación penal preparatoria, Di Plácido Editor, Bs. As.

González, G. (2005). Las Reformas Policiales en la Argentina: Hablando de las Estatuas de Naipaul, en David Bayley y Lucia Dammert (eds): Seguridad y reformas policiales en las Americas, Siglo XXI, Mexico, 58-79.

Guber, R. (2005). El salvaje metropolitano, Paidós, Bs. As.

Guerrero, J. C. y Ramírez, H. (2011). La justicia, la crítica y la justificación. Un análisis desde la perspectiva de la sociología pragmática, Revista colombiana de sociología, Bogotá.

Gusfield, J. (2014). La cultura de los problemas públicos, Siglo XXI, Bs. As. 
Gutiérrez, M. (2008). Populismo y actuarialismo en Argentina, V Jornadas de Sociología de la UNLP, La Plata.

Gutiérrez, M. (2010). La dimensión jurídica de las prácticas educativas en contextos de encierro, Ministerio de Educación, Bs. As.

Gutiérrez, M. (2013). Informe Argentina en Independencia judicial insuficiente, prisión preventiva deformada, DPLF, Washington.

Gutiérrez, M. y Álvarez, V. (2009). La construcción de la trama politica del Poder Judicial, Jornadas Preparatorias del Congreso Alas.

Haggerty, K. (2004). Displaced expertise: three constraints on the policy relevance of criminological thought, Theoretical Criminology 8, p. 211-231.

Hall, S. (2010). Sin garantías, Envión Editores, Popayán.

Harcourt, B. (2011). The Illusion of Free Markets, Harvard University Press.

Harcourt, B. (2012). Punitive Preventive Justice A Critique, in Andrew Ashworth and Lucia Zedner, eds., PREVENTIVE JUSTICE, Oxford University Press.; University of Chicago Institute for Law \& Economics Olin Research Paper No. 599; U of Chicago, Public Law Working Paper No. 386

Harcourt, B. (2013). Política criminal y gestión de riesgos. Genealogía y crítica, Ad Hoc, Bs. As.

Hazan, L. (2009). La introducción de audiencias preliminares como variable para la humanización del proceso penal, CEJA, Santiago de Chile.

Hegel, G. W. (1937). Filosofia del derecho, Claridad, Bs. As.

Hobbes, T. (1994). Leviatan. FCE, México.

INECIP-CEJA. (2006). Informe evaluativo del plan piloto para la profundización del sistema acusatorio en Mar del Plata, Revista Sistemas Judiciales (CEJA), Bs. As.

INECIP. (2012). El estado de la prisión preventiva en la Argentina, Servicop, Bs. As.

International Human Rights Program. (2011). Presumed innocent, behind bars, Univerity of Toronto, Toronto.

Iud, A. (2009). El impacto de la oralidad en la reducción del uso de la prisión preventiva, Revista de Derecho Procesal Penal, Bs. As.

Iud, A y Hazan, L. (2008). Informe de Evaluación del Proceso de Fortalecimiento del Sistema Acusatorio en la Provincia de Buenos Aires - Plan de Flagrancia, en Reformas procesales en América Latina: resultados del proyecto de seguimiento $V$ etapa, disponible en http://www.cejamericas.org/portal/index.php/es/biblioteca/biblioteca-virtual/cat_view/43-documentos/63experiencias-de-innovacion?start $=5$ 
Kaminky, G. (2005). Tiempos inclementes, UNLa, Lanús.

Kessler, G. (2004). Sociología del delito amateur, Paidós, Bs. As.

Kessler, G. (2007). "Miedo al crimen. Representaciones colectivas, comportamientos individuales y acciones públicas" en En los márgenes de la ley. Inseguridad y violencia en el Cono Sur (Alejandro Isla, Comp.), Paidos, Bs.As.

Kessler, G. (2009). El sentimiento de inseguridad, Siglo XXI, Bs. As.

Kessler, G. (2009b). (comp.), Seguridad y ciudadanía, Edhasa, Bs. As.

Kessler, G. (2014). Controversias sobre la desigualdad, FCE, Bs. As.

Kreplak, E. (2007). Prisión preventiva como regla de funcionamiento del sistema punitivo. La excepción como regla y la clandestinidad del derecho, I Congreso Federal de Justicia Penal (U.B.A.).

Kunz A.y Cardinaux, N. (2004). Investigar en derecho, Dpto. de publicaciones (UBA), Bs. As.

Lahire, B. (2004). Socializaciones y disposiciones heterogéneas, Propuesta Educativa, Bs. As.

Lahire, B. (2005). El trabajo sociológico de Pierre Bourdieu: deudas y críticas, Siglo XXI, Bs. As.

Lahire, B. (2005b). Campo, fuera de campo, contracampo en B. Lahire, El trabajo sociológico de Pierre Bourdieu: deudas y críticas, Siglo XXI, Bs. As.

Lahire, B. (2006). El espíritu sociológico, Manantial, Bs. As.

Langer, M. (2009). Revolución en el proceso penal latinoamericano: difusión de ideas legales desde la periferia, por Revista de Derecho Procesal Penal, Año 2009, número extraordinario: El proceso penal adversarial - Tomo II, Ed. Rubinzal Culzoni. Larrauri, E. (2001). La herencia de la criminología crítica, Siglo XXI, Bs. As.

Larrauri, E. y Cid Moliné, J. (2001). Teorías criminológicas, Bosch, Barcelona.

Latour, B. (1992). Ciencia en acción, Labor, Barcelona.

Latour, B. (2007). Nunca fuimos modernos, Siglo XXI, Bs. As.

Latour, B. (2008). Reensamblar lo social, Manantial, Bs. As.

Latour, B. (2010). The making of Law, Polity Press, Cambridge.

Lea, J. (1993). Criminology and Postmodernism en The New Criminology Revisited de Paul Walton and Jock Young (1998), Macmillan, London.

Lea, J. (2006). Delito y modernidad. Nuevas argumentaciones en la Criminología realista de izquierda, Coyacán, México.

Lea, J. y Young, J. (2008). ¿Qué hacer con la ley y el orden?, Del puerto, Bs. As. 
Lemert, E. (1967). Estructura social, control social y desviación, en M. Clinard, Anomia y Conducta Desviada, Paidos, Bs. As., pp.64-100

Lemert, E. (1973). Desviación primaria y secundaria, en AAVV, Estigmatización y Conducta Desviada, Universidad de Zulia, Maracaibo, pp. 97-104

Lemieux, C. (2005). ¿Una crítica sin razón? El abordaje bourdieusiano a los medios y sus límites, en B. Lahire, El trabajo sociológico de Pierre Bourdieu: deudas y críticas, Siglo XXI, Bs. As.

Lemieux, C. (2012). Después de Bourdieu: La sociología pragmática francesa, Conferencia realizada en la UNSAM, Bs. As.

R. Levene (H.) (1993), Manual de Derecho Procesal Penal - Tomo I-, Depalma, Bs. As. R. Levene (H.) (1993b), Manual de Derecho Procesal Penal - Tomo II-, Depalma, Bs. As.

Lombroso, C. (1887). Los criminales, Centro Editorial Presa, Barcelona.

Lombroso, C. (1902). El delito: Sus causas y remedios, Ed. Victoriano Suárez, Madrid.

Lorenc Valcarce, F. (2005). Orden, derechos y delitos, consultado el 5 de abril de 2009 en http://www.saap.org.ar

Lorenc Valcarce, F. (2005b). La sociología de los problemas públicos, Revista Nómadas Nro. 12, Universidad Complutense.

Lorenc Valcarce, F. (2012). Delito, medios y política, Revista del Programa de Investigaciones sobre Conflicto Social, Bs. As.

Llobet Rodríguez, J. (1997) La prisión preventiva, San José, Ed. UCI

Magalhaes Gomes, A. (1995). Presunción de inocencia y prisión preventiva, Ed. Conosur, Santiago.

Maier, J. (1989). Derecho Procesal Penal argentino 1a, Hammurabi, Bs. As.

Maier, J. (1989b). Derecho Procesal Penal argentino 1b, Hammurabi, Bs. As.

Marí, E. (1983) La problemática del castigo, Hachette, Bs. As.

Marradi, A., Archenti, N., y Piovani, J. (2007). Metodología de las ciencias sociales, Emecé, Bs. As.

Martínez, J. (2002). Las burocracias penales y su violencia naturalizada, en Violencias, delitos y justicias, Manantial, Bs. As., p. 259-274

Martínez, J. (2004). Expedientes, CEJA, Santiago de Chile.

Mathiesen, T. (2003). Juicio a la prisión, Ediar, Bs. As.

Mathieu, L. (2011). Marcos y ciudades: del orden del discurso a la acción en situación, en Cultura y representaciones sociales $N^{0} 11$, México, págs. 33-58 
Matthews, R. (2009). El mito de la punitividad, en Delito y Sociedad № 28. Bs. As.

Matza, D. (2014). Delincuencia y deriva, Siglo XXI, Bs. As.

Melossi, D. (1992). El estado del control social, Siglo XXI, México.

Melossi, D. (2006). Teoría social y cambios en las representaciones del delito en Reconstruyendo las criminologías críticas, AD-HOC, Bs. As..

Melossi, D. (2012). Delito, pena y control social, AD-HOC, Bs. As.

Morris, N. (1992) Incapacitation within Limits, en Principled Sentencing, Ed. Northeastern University Press, Boston.

Nardacchione, G. (2011). El conocimiento científico y el saber práctico en la sociología pragmática francesa, Apuntes de investigación del CECYP, Bs. As.

ObEP, (2007). Estado, justicia y ciudadanía, Ministerio de Justicia, Bs. As.

O'Malley, P. (1999). Volatile and contradictory punishment en Theoretical Criminology, Sage, London, p. 175-196

O’Malley, P. (2006). Riesgo, neoliberalismo y justicia penal, Ad-Hoc, Bs. As.

O'Malley, P. (2010). Crime and risk, Sage, London.

Open Society Justice. (2009). ¿Cuánto cuesta la prisión sin condena?, MLK, Monterrey.

Open Society Justice. (2009b). Los mitos de la prisión preventiva en México, MLK, Monterrey.

Open Society (2008). Justice Initiatives A publication of the Open Society, Spring.

Open Society (2014). Presumption of Guilt: The Global Overuse of Pretrial Detention, Open Society Foundations.

Palmieri, G., Perelman M. y García Méndez, E. (2008). “Incidencia de los Organismos de Derechos Humanos en la agenda de seguridad en la Argentina”, en Estado, democracia y seguridad ciudadana (comp.), PNUD, Bs. As.

Palmieri, G. y Wagmaister, F. (2009). La dinámica de delito-policía en los procesos de reforma policial en G. Kessler (comp.), Seguridad y ciudadanía, Edhasa, Bs. As.

Pastor, D. (1993). El encarcelamiento preventivo, en AA.VV., El nuevo Código procesal penal de la Nación. Análisis crítico, Depalma, Bs. As.

Pavarini, M. (2003). Control y dominación, Siglo XXI, Bs. As.

Pavarini, M. (2006). Un arte abyecto, AD-HOC, Bs. As.

Pavarini, M. (2009). Castigar al enemigo, FLACSO, Quito.

Pereyra, S. (2010). Crtique de la politique, expertice et transparense, Tesis Doctoral Pereyra, S. (2013). Política y transparencia, Siglo XXI, Bs. As. 
Piñero, V. (2007). Oficina de Gestión de Audiencias en el Plan piloto para el fortalecimiento del sistema, Revista Sistemas Judiciales (CEJA), Bs. As.

Pitch, T. (1996). ¿Qué es el control social?, en Delito y Sociedad. Revista de Ciencias Sociales. $\mathrm{N}^{\mathrm{o}} 8$. Bs. As.

Pitch, T. (2009). La sociedad de la prevención, AD-HOC, Bs. As.

Pratt, J. (2006). Castigo y civilización, Gedisa, Barcelona.

Pratt, J. (2006b). Lecturas contemporáneas de sociología del castigo. Castigos Ostentosos y Emotivos, en Delito y Sociedad. № 22. Bs. As.

Pratt, J. (2007). Penal Populism, Routledge, London.

Renoldi, B. (2008). Narcotráfico y justicia en Argentina: la autoridad de lo escrito en el juicio, Antropofagia, Bs. As.

Riquert, M. (2008). Oralidad y proceso de flagrancia, Disertación brindada en el marco de las "Jornadas Nacionales 10 años de vigencia del sistema acusatorio en la Provincia de Buenos Aires".

Rivera Beiras, I. (2008). La cuestión carcelaria. Historia, Epistemología, Derecho y Política penitenciaria, Del Puerto, Bs. As.

Rodríguez, E. (2012). Circuitos carcelarios: el encarcelamiento masivo-selectivo, preventivo y rotativo en la Argentina, Revista Question, Nro. 36.

Rusche, G. y Kirchheimer, O. (2004). Pena y estructura social, Temis, Bogotá.

Saín, M. (1998). Democracia, Seguridad Pública y Policía, CELS, Bs. As.

Saín, M. (2002). Seguridad, democracia y reforma del sistema policial en la Argentina, FCE, México

Saín, M. (2008). El Leviatán azul, Siglo XXI, Bs. As.

Saín, M. (2009). Comentario a Políticas públicas de Seguridad Ciudadana: Innovaciones y desafios en G. Kessler (comp.), Seguridad y ciudadanía, Edhasa, Bs. As.,

Sarrabayrouse, M. J. (2004). La justicia penal y los universos coexistentes, en Burocracias y violencia, Antropofagia, Bs. As., p. 203-238

Sautu, R. (2003). Todo es teoría, Lumiére, Bs. As.

Servicio Penitenciario Escocés. (2000). Punishment First Verdict Later: A Review of Conditions for Remand Prisoners in Scotland at the End of the 20th Century, Edimburgo, disponible en: www.scotland.gov.uk/hmip/docs/pfvl-00.asp

Simon, J. (2006). Gobernando a través del delito, en Delito y Sociedad. № 22. Bs. As. 
Simon, J. (2010). How Should We Punish Murder?, 94 Marq. L. Rev., disponible en: http://scholarship.law.berkeley.edu/facpubs/1721 , p. 1241-1312

Simon, J. (2011). Gobernar a través del delito, Gedisa, Barcelona.

Sistemas Judiciales. (2009). Prisión preventiva, CEJA, Santiago.

Sousa Santos, B. (2009). Sociología Jurídica crítica, Trotta, Madrid.

Sozzo, M. (2005). Policía, violencia y democracia, UNL, Santa Fe.

Sozzo, M. (2007). Populismo punitivo, proyecto normalizador y 'prisión depósito' en Argentina, en Nueva Doctrina Penal N², Del Puerto, Bs. As., pp. 527-578

Sozzo, M. (2009). Comentario a Politicas públicas de Seguridad Ciudadana: Innovaciones y desafios en G. Kessler (comp.), Seguridad y ciudadanía, Edhasa, Bs. As.

Spector M. y Kitsuse, J. (1977). Constructing social problems, New York, Aldine.

Tapia, J. (2012). La introducción de audiencias orales en la etapa de investigación, Pensamiento Penal, Viedma.

Taylor, I., Walton P. y Young, J. (2001). La nueva criminología, Amorrortu, Bs. As.

Tedesco, I. (2004). El castigo como una compleja institución social: el pensamiento de David Garland, en Mitologías y Discursos sobre el Castigo, Anthropos, Barcelona, pp. 231-249

Tiscornia, S. (2008). Activismo de los derechos humanos y burocracias estatales, Del Puerto, Bs. As.

Van Den Dooren, S. (2008). La "pena" (medida) propia del estado de control de los peligrosos. Un ensayo sobre la función política de la prisión preventiva, recuperado de www.derechopenalonline.com

Vasilachis, I. (1992) Métodos Cualitativos I. Los problemas teórico-epistemológicos, Buenos Aires, Centro Editor de América Latina

Vaughan, D. (1999) The dark side of organizations, Annual Review of Sociology, p. 271-305

Vaughan, D. (2007) Criminología y sociología de las organizaciones, Delito y Sociedad $\mathrm{N}^{\circ} 24$, p. $7-25$

Vilker, S. (2006), Truculencia. La prensa policial entre el terrorismo de Estado y la inseguridad, Bs. As., UBA-Prometeo

Villadiego Burbano, C. (2010). Estrategias para racionalizar el uso de la prisión preventiva en América Latina, CEJA, disponible en http://www.cejamericas.org 
Vitale G. y García G. (2011). Abolicionismo de la prisión sin condena, Bs. As., Del Puerto

Von Hirsch, A. (1992). Incapacitation, en AA.VV. Principled Sentencing, Ed. Northeastern University Press, Boston.

Von Hirsch, A. (1998). Censurar y castigar, Trotta, Madrid.

Wacquant, L. (2004). Las cárceles de la miseria, Manantial, Bs. As.

Wacquant, L. (2010). Castigar a los pobres, Gedisa, Barcelona.

Weber, M. (2002). Economía y sociedad, FCE, México.

Williams, R. (2009). Marxismo y literatura, Las Cuarenta, Bs. As.

Wuggenig, U. (2008). Crítica paradójica, (Raúl Sánchez Cedillo, trad.) Recuperado de http://eipcp.net/transversal/0808/wuggenig/es

Young, J. (2003). La sociedad excluyente, Marcial Pons, Madrid.

Young, J. (2011). El pánico moral, Delito y Sociedad, Bs. As. - Santa Fe.

Young, J. (2012). El vértigo de la modernidad tardía, Didot, Bs. As.

Zaffaroni, E. (2006). El enemigo en el derecho penal, Ediar, Bs. As.

Zaffaroni, E. (2011). La cuestión criminal, Página 12, Bs. As.

Zaffaroni, E. (2012). La cuestión criminal, Planeta, Bs. As.

Zamalea, D. (2007). La Reforma Procesal Penal en Ecuador en Prisión preventiva y reforma procesal en América Latina, CEJA

Zimring, F. (1996). Populism, Democratic Government, and the Decline of Expert Authority: Some Reflections on Three Strikes in California, Pacific Law Journal, 28, p. $243-256$.

Zimring, F. (2010). The scale of imprisonment in the United States, Northwestern University, p. 1225-1246

Zimring, F. (2012). The city that became safe, Oxford University Press.

Zimring, F., Fagan, J. y Johnson, D. (2009). Executions, deterrence and homicide: a tale of two cities en Columbia Law School, Public Law \& Legal Theory.

Zino Torrazza, J. (2003). El análisis de las instituciones y organizaciones del sistema penal: una propuesta metodológica. en R. Bergalli (Ed.), Sistema penal y problemas sociales (pp. 209-242), Tirant Lo Blanch, Valencia 